INEL BNCT Research Program Annual Report 1993
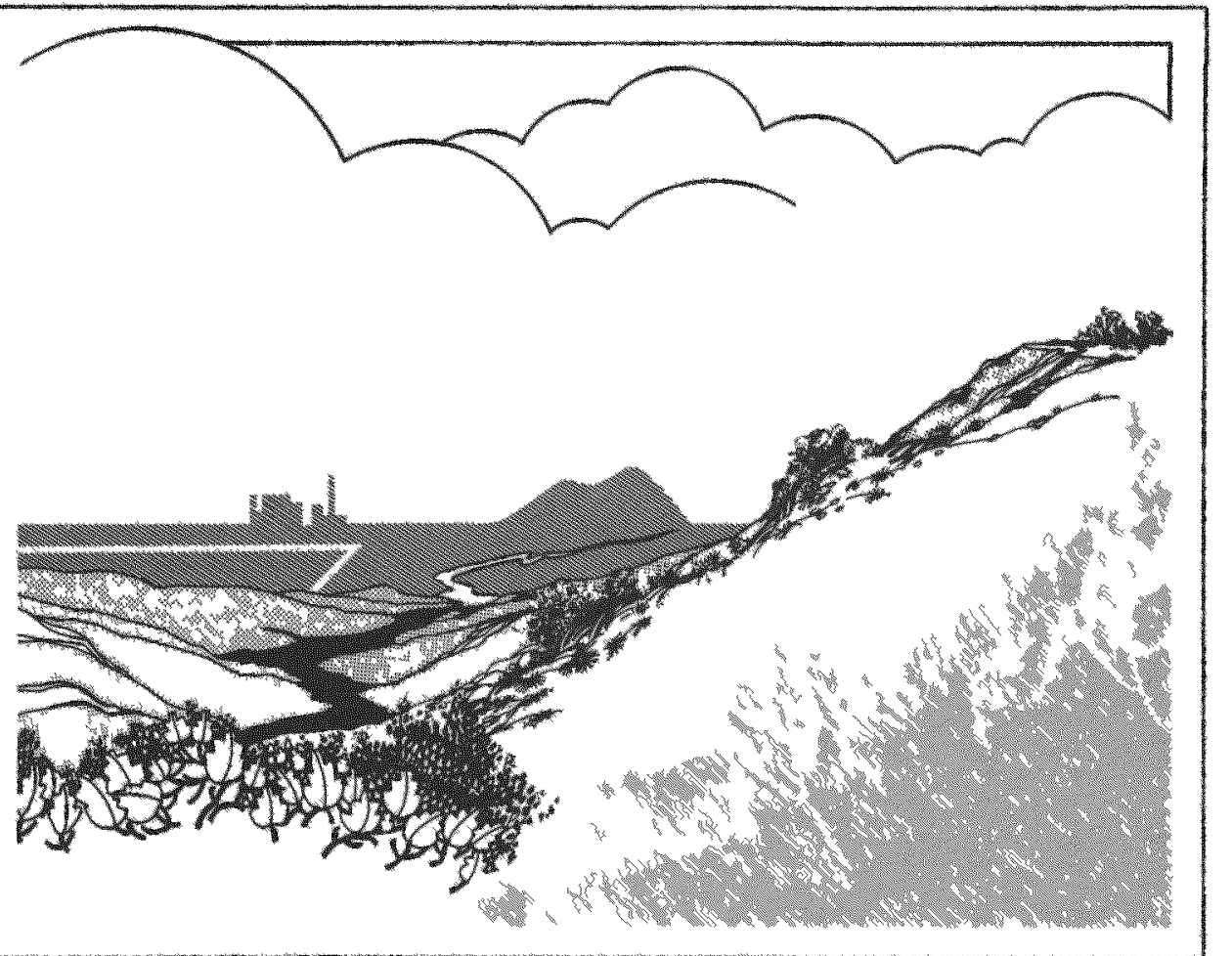

\section{Idaho National \\ Idaho National}

3. Managed by the U S Department of Energy

\section{Edited by}

J. R. Venhuizen

QSECRTHECEIVED Work performed under

DOE Contract NO DE ACO7 761007570 .

OSTI 
This document contains new concepts or the author(s) interpretation of new calculations and/or measurements; accordingly, EG\& G Idaho, Inc. is required by the United States Government to include the following disclaimer:

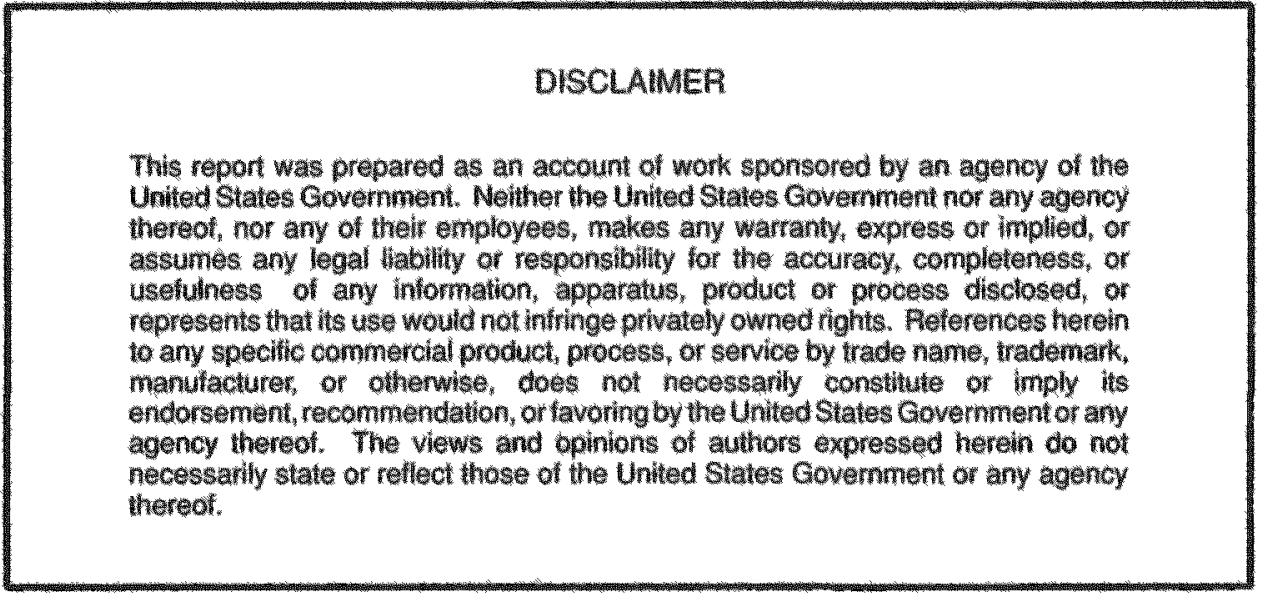


EGG-2738

\title{
INEL BNCT Research Program Annual Report 1993
}

\author{
Edited by
}

J. R. Venhuizen

Published August 1994

\section{Idaho National Engineering Laboratory EG\& G Idaho, Inc. Idaho Falls, Idaho 83415}

Prepared for the

U.S. Department of Energy Office of Energy Research Under DOE Idaho Operations Office Contract DE-AC07-76ID01570 



\section{DISCLAIMER}

This report was prepared as an account of work sponsored by an agency of the United States Government. Neither the United States Government nor any agency thereof, nor any of their employees, make any warranty, express or implied, or assumes any legal liability or responsibility for the accuracy, completeness, or usefulness of any information, apparatus, product, or process disclosed, or represents that its use would not infringe privately owned rights. Reference herein to any specific commercial product, process, or service by trade name, trademark, manufacturer, or otherwise does not necessarily constitute or imply its endorsement, recommendation, or favoring by the United States Government or any agency thereof. The views and opinions of authors expressed herein do not necessarily state or reflect those of the United States Government or any agency thereof. 



\section{DISCLAIMER}

Portions of this document may be illegible in electronic image products. Images are produced from the best available original document. 


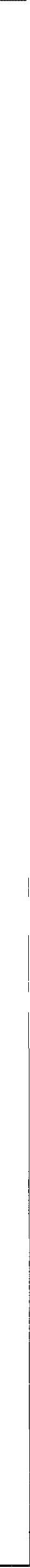




\begin{abstract}
This report is a summary of the progress and research produced for the Idaho National Engineering Laboratory Boron Neutron Capture Therapy Research Program for calendar year 1993. Contributions from all the principal investigators are included. covering chemistry (pituitary tumor studies, boron drug development including liposomes, lipoproteins, and carboranylalanine derivatives), pharmacology (murine screenings, toxicity testing, boron drug analysis), physics (radiation dosimetry software, neutron beam and filter design, neutron beam measurement dosimetry), and radiation biology (tissue and efficacy studies of small and large animal models). Information on the potential toxicity of borocaptate sodium and boronophenylalanine is presented. Results of 21 spontaneous-tumor-bearing dogs that have been treated with boron neutron capture therapy at the Brookhaven National Laboratory are updated. Boron-containing drug purity verification is discussed in some detail. Advances in magnetic resonance imaging of boron in vivo are discussed. Several boron-carrying drugs exhibiting good tumor uptake are described. Significant progress in the potential of treating pituitary tumors is presented. Measurement of the epithermal-neutron flux of the Petten (The Netherlands) High Flux Reactor beam (HFB11B), and comparison to predictions are shown.
\end{abstract}





\section{CONTENTS}

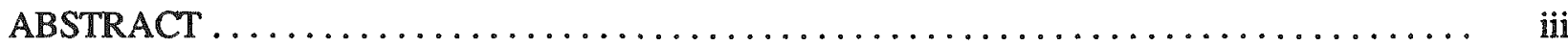

ACRONYMS AND ABBREVIATIONS $\ldots \ldots \ldots \ldots \ldots \ldots \ldots \ldots \ldots \ldots \ldots \ldots \ldots \ldots$

INTRODUCTION $\ldots \ldots \ldots \ldots \ldots \ldots \ldots \ldots \ldots \ldots \ldots \ldots \ldots \ldots \ldots \ldots \ldots \ldots \ldots \ldots \ldots$

Drug Development $\ldots \ldots \ldots \ldots \ldots \ldots \ldots \ldots \ldots \ldots \ldots \ldots \ldots \ldots \ldots \ldots \ldots \ldots$

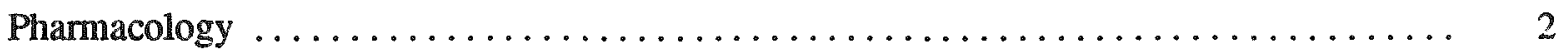

Radiation Biology $\ldots \ldots \ldots \ldots \ldots \ldots \ldots \ldots \ldots \ldots \ldots \ldots \ldots \ldots \ldots \ldots \ldots \ldots \ldots \ldots . \ldots \ldots$

Computational Dosimetry $\ldots \ldots \ldots \ldots \ldots \ldots \ldots \ldots \ldots \ldots \ldots \ldots \ldots \ldots$

Neutron Source Design $\ldots \ldots \ldots \ldots \ldots \ldots \ldots \ldots \ldots \ldots \ldots \ldots \ldots \ldots \ldots \ldots$

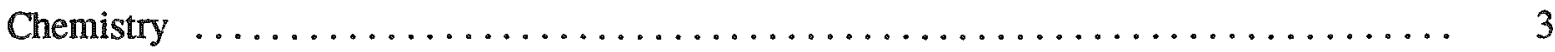

Measurement Dosimetry $\ldots \ldots \ldots \ldots \ldots \ldots \ldots \ldots \ldots \ldots \ldots \ldots \ldots \ldots \ldots$

Program Integration $\ldots \ldots \ldots \ldots \ldots \ldots \ldots \ldots \ldots \ldots \ldots \ldots \ldots \ldots \ldots$

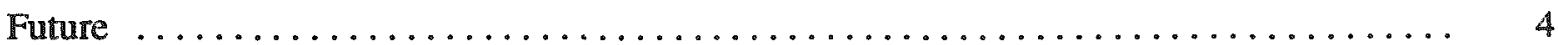

LOW-DENSITY LIPOPROTEIN DEVELOPMENT AND EVALUATION,

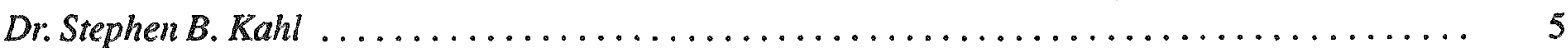

BORONATED LIPOSOME DEVELOPMENT AND EVALUATION,

Dr. M. Frederick Hawthorne .............................

PITUITARY TUMOR EVALUATION, Dr. Barry Albertson, Dr. Steve Binney . . . . . . . . . . 24

BORON LOCALIZATION SCREENING, Dr: Catherine A. Elstad ............. 36

PHARMACOLOGY AND TOXICOLOGY OF BSH, Dr: Tom LaHann ............ 46

TREATMENT PROTOCOL DEVELOPMENT, Dr. Carol Schwartz, Dr. Patrick Gavin ....... 55

PHYSIOLOGICAL RESPONSE EVALUATION AND INTERDICTION, Dr. Philip Rubin . . . . . 62

METHODOLOGY FOR QUANTITATING BORONATED DRUG PHARMACOKINETICS

VIA BORON-11 MAGNETIC RESONANCE IMAGING, Dr. Martin Schweizer . . . . . . . . . . 69

RADIATION TRANSPORT IN TISSUE BY MONTE CARLO, Flovd Wheeler . . . . . . . . . 78

BNCT RADIATION TREATMENT PLANNING ENVIRONMENT, D. E. Wessol,

F. J. Wheeler, R. S. Babcock ................................ 8

A COMPACT ACCELERATOR-BASED EPITHERMAL PHOTONEUTRON SOURCE

FOR BORON NEUTRON CAPTURE THERAPY, Dr. Daid W. Nigg, Dr. Woo Y. Yoon,

Dr: Yale D. Harker, James L. Jones . . . . . . . . . . . . . . . . . . . . . . . . .

PURITY AND QUALITY DETERMINATIONS OF BOROCAPTATE SODIUM,

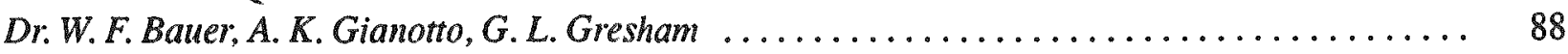

MEASUREMENT DOSIMETRY, Dr. Y. D. Harker, C. R. Amaro, Dr. P. D. Randolph . . . . . . . 104

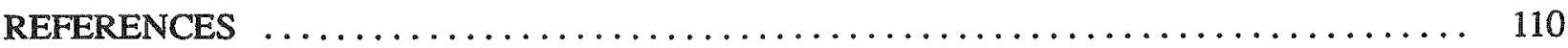




\section{FIGURES}

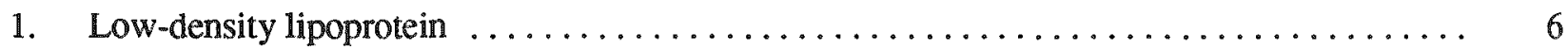

2. Diagram of a unilamar vesicle $\ldots \ldots \ldots \ldots \ldots \ldots \ldots \ldots \ldots \ldots \ldots \ldots \ldots \ldots \ldots \ldots$

3. X-ray crystal structure of $\left[\mathrm{ae}-\mathrm{B}_{20} \mathrm{H}_{17} \mathrm{NH}_{3}\right]^{3-} \ldots \ldots \ldots \ldots \ldots \ldots \ldots \ldots \ldots \ldots \ldots \ldots$

4. Degradation of $\left.\left.\mathrm{K}\left[\text { nido-7-[( } \mathrm{CH}_{2}\right)_{15} \mathrm{CH}_{3}\right]-7,8-\mathrm{CzB}_{9} \mathrm{H}_{11}\right] \ldots \ldots \ldots \ldots \ldots \ldots \ldots \ldots$

5. Proposed synthetic route for the production of a species that would possess a

nido-carborane head group rather than a phosphate head group $\ldots \ldots \ldots \ldots \ldots \ldots \ldots$

6. Proposed synthetic route for the production of a species that would possess

closo-carboranes at the termini of the lipophilic chains $\ldots \ldots \ldots \ldots \ldots \ldots \ldots$

7. Time course biodistribution of boron in BALB/c mice $\ldots \ldots \ldots \ldots \ldots \ldots \ldots \ldots \ldots$

8. The amino acid sequence of $\mathrm{OCRH}$ is shown with the conjugated carboranyl cage

$\left({ }^{10} \mathrm{~B}_{10}\right)$ attached.

9. The amino acid sequence of human GHRH is shown with the conjugated

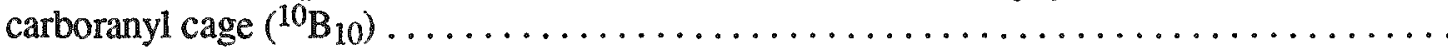

10. cAMP response of ATT-20 cells to $\mathrm{OCRH}$, carboranyl-oCRH, or carboranyl cage alone

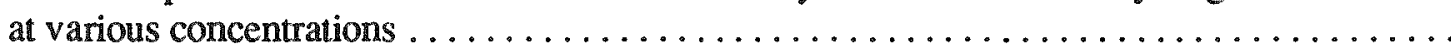

11. Cyclic AMP response: Cultured rat pituitary cells $\left(10^{6}\right)$ were stimulated with increasing doses $\left(10^{-9}\right.$ to $\left.3 \times 10^{-7} \mathrm{M}\right)$ of GHRH, GHRH-40-Lys ${ }^{41}$, or carboranyl GHRH peptide

$\left({ }^{10} \mathrm{~B}_{10}-\mathrm{GHRH}\right)$, and cAMP was assayed by the stat package (RIA) in the culture media ....

12. Growth hormone response: The response of rat pituitary cell growth hormone production and release to the three peptides (described in Figure 4a) was similar, reaching maximal values at approximately $10^{-10} \mathrm{M}$ (unpublished data from Chen, Merriam, and Loriaux) ....

13. AtT-20 cells incubated for 5 and 10 minutes with ${ }^{10} \mathrm{~B}_{10^{-}} \mathrm{OCRH}$ carboranyl cage conjugate had significantly fewer cell colonies surviving 14 days postirradiation than cells

incubated with oCRH plus unconjugated carboranyl cage $\ldots \ldots \ldots \ldots \ldots \ldots \ldots$

14. AtT-20 cell colony survival fraction (control was $10^{-6} \mathrm{M}$ oCRH alone) $\ldots \ldots \ldots \ldots . \ldots$.

15. Effect of phenylalanine ammonia-1yase (PAL) on tissue levels of boron . . . . . . . . ... 39

16. Boron levels in tumors excised from control mice and mice pretreated with

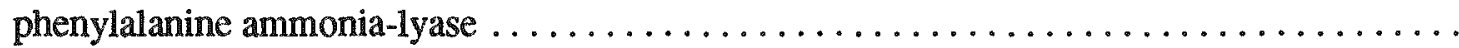

17. Boron biodistribution in mice bearing Lewis lung carcinoma after intravenous injection of $200 \mu \mathrm{l}$ of the indicated liposomal-encapsulated boron compound $\ldots \ldots \ldots \ldots \ldots \ldots$

18. Boron biodistribution in mice bearing Lewis lung carcinoma after intravenous injection of $200 \mu \mathrm{l}$ of free, unencapsulated boron compound 
19. In vitro cytotoxicity of the indicated liposomal-encapsulated boron compound on growth

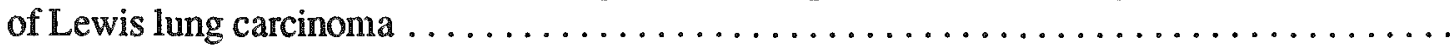

20. In vitro cytotoxicity of the indicated liposomal-encapsulated boron compound on growth

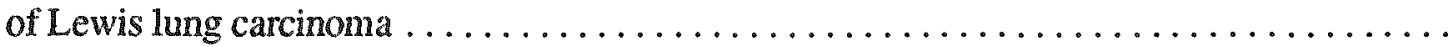

21. In vitro uptake of boron by B 16-BL6 murine melanona, RG2 rat glioma, U87MG human glioma. Lewis lung murine carcinoma. and normal murine mammary fibroblasts exposed

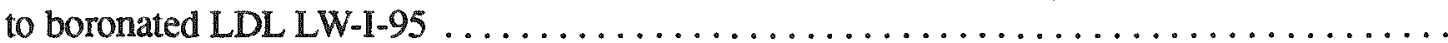

22. In vitro uptake of boron by B16-BL6 murine melanoma, RG2 rat glioma, U87MG human glioma, Lewis lung murine carcinoma, and normal murine mammary fibroblasts exposed

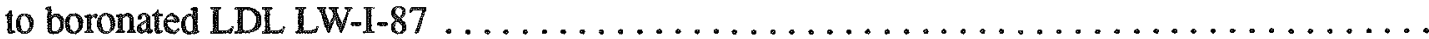

23. Effect of ethinyl estradiol pretreatment on in vitro uptake of boron by B16-BL6 murine melanoma exposed to boronated LDL LW-I-87

24. Effect of ethinyl estradiol pretreatment on in vitro uptake of boron by normal murine

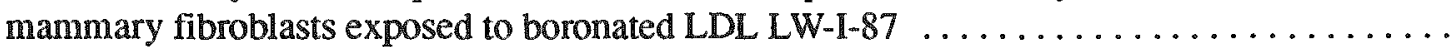

25. MRI showing radiation-induced, subclinical changes in the brain of a dog treated with $\mathrm{BNCT}$

26. Changes in blood boron levels over time in intracranial tumors, blood. and normal brain

27. Histologic section of a dog brain showing radiation-induced changes following BNCT ... 58

28. Coronal section of a normal brain in the area of tumor implantation $\ldots \ldots \ldots \ldots$

28b. Coronal brain sections, 14 days postimplantation, showing tumor growth $\ldots \ldots \ldots$

28c. Coronal brain sections, 1 year post BNCT treatment $\ldots \ldots \ldots \ldots \ldots \ldots \ldots \ldots \ldots \ldots$

28d. Coronal brain sections, 1 year post $x$-irradiation treatment $\ldots \ldots \ldots \ldots \ldots \ldots \ldots$

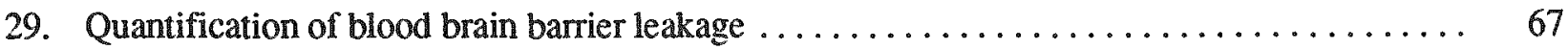

30. Relative vascular density postirradiation $\ldots \ldots \ldots \ldots \ldots \ldots \ldots \ldots \ldots \ldots \ldots \ldots \ldots \ldots \ldots$

31. Cerebral atrophy, measured in both hemispheres $\ldots \ldots \ldots \ldots \ldots \ldots \ldots \ldots \ldots$

32. Axial proton (left) and boron-11 (right) images for dog bearing ring-enhancing lesion in left paretal lobe

33. Proton MRI (left) and two boron-11 images for Boo, bearing a 9-day gliosarcoma in left temporal lobe.

34. Placement of BSH-BSA phantoms and references within RF coil

35. Comparison of $\mathrm{BSH}$ in $4 \% \mathrm{BSA}$ for different temperatures 
36. Intensity measurements compared with the actual boron concentrations determined by ICP-AES. . . . . . . . . . . . . . . . . . . . . . . . . . . . . . . .

37. Boron-11 longitudinal relaxation rates $\left(\mathrm{R}_{1}\right)$ for $\mathrm{BSH}$ (200 ppm boron) nuclei with increases in BSA concentration

38. Coronal fast spin echo proton MR images of an 18-day $9 \mathrm{~L}$ gliosarcoma in the frontal lobe of a Fischer 344 rat

39. Coronal proton (right) and boron-11 images of a Fischer 344 rat infused with $200 \mathrm{ppm}$ boron (as BSH)

40. Conceptual accelerator-based epithermal photoneutron source for BNCT $\ldots \ldots \ldots \ldots .86$

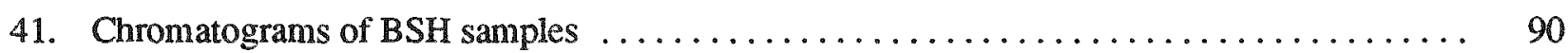

42. HPLC showing major contamination of $\mathrm{CC}$ with $\mathrm{B}_{12} \mathrm{H}_{12}{ }^{2-} \ldots \ldots \ldots \ldots \ldots \ldots \ldots \ldots \ldots$

43. ${ }^{1} \mathrm{H}$ decoupled ${ }^{10} \mathrm{~B}$ NMR spectra for ${ }^{10} \mathrm{BSH}(\mathrm{HH})$ and ${ }^{10} \mathrm{BSH}$ with significant ${ }^{10}{ }_{\mathrm{B}_{12} \mathrm{H}_{12}{ }^{2-}(\mathrm{CC}) \ldots \ldots \ldots \ldots \ldots \ldots \ldots \ldots \ldots \ldots \ldots \ldots \ldots \ldots \ldots \ldots \ldots \ldots \ldots \ldots \ldots} 92$

44. Infrared spectra of $\mathrm{BSH}$ samples obtained from $\mathrm{KBr}$ pellets $\ldots \ldots \ldots \ldots \ldots \ldots \ldots . . \ldots . \ldots . \ldots$

45. Representative chromatograms of BNCT 202 and $620 \ldots \ldots \ldots \ldots \ldots \ldots \ldots \ldots$

46. Representative chromatograms of BNCT 646 and the $\mathrm{BSS}^{4-}$ and $\mathrm{BSSO}^{4-}$ retention time

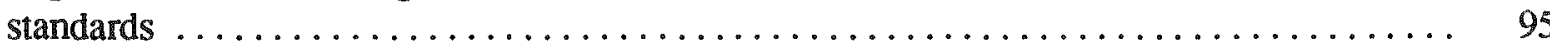

47. Infrared spectra of BNCT 620,646, and 313 in $\mathrm{KBr}$ pellets $\ldots \ldots \ldots \ldots \ldots \ldots \ldots . \ldots 6$

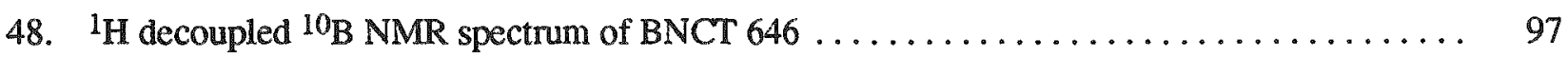

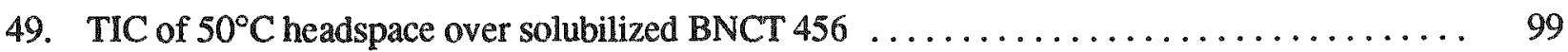

50. Selected ion chromatograms of the $50^{\circ} \mathrm{C}$ headspace over solubilized BNCT 456 at

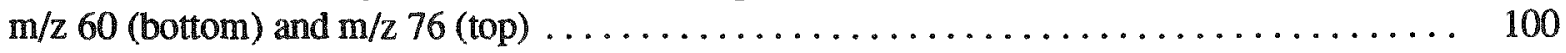

51. TIC of $50^{\circ} \mathrm{C}$ headspace over BSH powder from BNCT $170 \ldots \ldots \ldots \ldots \ldots \ldots . \ldots 2$

52. Selected ion chromatograms of the $50^{\circ} \mathrm{C}$ headspace over dry BNCT 170 at $\mathrm{m} / \mathrm{z} 60$

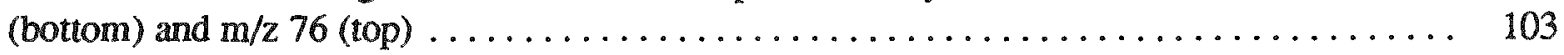

53. Neutron angular distribution from a thick lithium target $\ldots \ldots \ldots \ldots \ldots \ldots \ldots \ldots . . \ldots \ldots$

54. Neutron spectra from a thin lithium target for neutron angles of 0 and 60 degrees relative

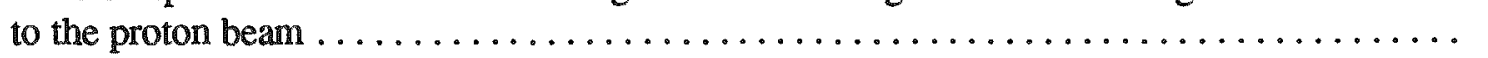

\section{TABLES}

1. In vivo $\mathrm{LDL}$ exposure in mice $\mathrm{B} 16 \mathrm{BL} 6$ melanoma. $\mathrm{LDL}=800 \mu \mathrm{g} \mathrm{B} / \mathrm{kg} \ldots \ldots \ldots \ldots \ldots$

2. In vivo exposure in mice $\mathrm{B} 16 \mathrm{BL} 6$ melanoma, $\mathrm{LDL}=4,800 \mu \mathrm{g} \mathrm{B} / \mathrm{kg} \ldots \ldots \ldots \ldots \ldots$.

3. In vitro $\mathrm{LDL}$ exposure, $\mathrm{LDL}=1.12 \mu \mathrm{g} \mathrm{B} / \mathrm{mL} \ldots \ldots \ldots \ldots \ldots \ldots \ldots \ldots \ldots \ldots \ldots \ldots$ 


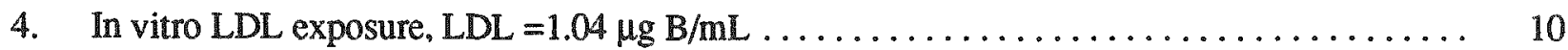

5. In vitro $\mathrm{LDL}$ exposure, $\mathrm{LDL}=2.08 \mu \mathrm{g} \mathrm{B} / \mathrm{mL} \ldots \ldots \ldots \ldots \ldots \ldots \ldots \ldots$

6. In vitro $\mathrm{LDL}$ exposure, pretreatment with $17 \alpha$-ethynylestradiol, $\mathrm{LDL}=1.04 \mu \mathrm{g} \mathrm{B} / \mathrm{mL} \ldots \ldots \quad 10$

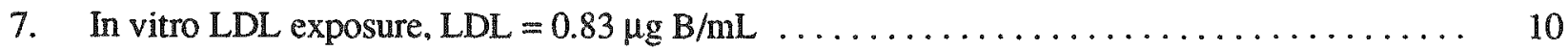

8. In vitro $\mathrm{LDL}$ exposure, $\mathrm{LDL}=3.0 \mu \mathrm{g} B / \mathrm{mL} \ldots \ldots \ldots \ldots \ldots \ldots \ldots \ldots \ldots \ldots \ldots \ldots \ldots \ldots \ldots \ldots$

9. $\mathrm{Mn}-\mathrm{BOPP}$ in vivo experiment with $\mathrm{RG}-2$ glioma $\ldots \ldots \ldots \ldots \ldots \ldots \ldots \ldots \ldots \ldots \ldots$

10. Effect of phenylalanine ammonia-lyase (PAL) on in vitro tumor levels of boron $\ldots \ldots \ldots$

11. Effects of phenylalanine ammonia-lyase (PAL) and low medium concentrations of tyrosine and phenylalanine on in vitro tumor levels of boron $\ldots \ldots \ldots \ldots \ldots \ldots$

12. Infusion of $\mathrm{BSH}(550 \mathrm{mg} / \mathrm{kg})$ at different volume rates (dilutions) $\ldots \ldots \ldots \ldots \ldots \ldots$

13. Effect of dose-rate of BSH administration on acute lethality $\ldots \ldots \ldots \ldots \ldots \ldots \ldots$

14. Effect of physiological state on BSH lethality $\ldots \ldots \ldots \ldots \ldots \ldots \ldots \ldots \ldots \ldots \ldots \ldots$

15. Comparison of the lethality of Centronics BSH and Boron Biologicals BSH ........ 53

16. Normal brain tissue tolerance levels for $\mathrm{BNCT} \ldots \ldots \ldots \ldots \ldots \ldots \ldots \ldots \ldots \ldots$

17. INEL BNCT canine tumor treatment study $50 \mathrm{mg}{ }^{10} \mathrm{~B} / \mathrm{kg}$ body weight

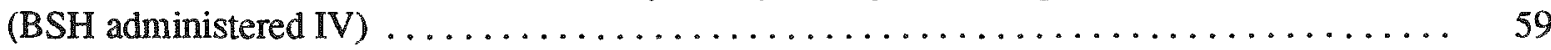

18. T1 values for gliosarcoma and normal canine brain $\ldots \ldots \ldots \ldots \ldots \ldots \ldots \ldots$

19. Effect of ' $F$ ' Mode $n$ t $M C$ peak dose calculation $\ldots \ldots \ldots \ldots \ldots \ldots \ldots \ldots$

20. Calculated results for BMRR Lucite cylinder measurements . . . . . . . . . . . 80

21. Typical results of HPLC analyses for BSS and BSSO contamination of BSH salts $\ldots . \ldots .90$

22. Mole ratios determined from elemental analyses by ICP-AES $\ldots \ldots \ldots \ldots \ldots \ldots$

23. ICP-AES elemental analysis results for BNCT $620, \mathrm{BNCT} 646$, and representative

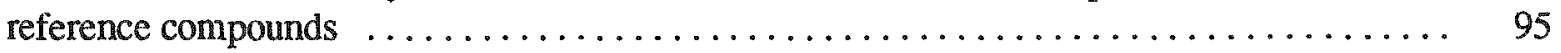

24. CHN analysis of BSH samples BNCT 620,646 , and $313 \ldots \ldots \ldots \ldots \ldots$

25. Instrumentation and experimental parameters used for determining volatile compounds over BSH $\ldots \ldots \ldots \ldots \ldots \ldots \ldots \ldots \ldots \ldots \ldots \ldots \ldots \ldots \ldots$

26. HFR/BMRR comparison: free beam $\ldots \ldots \ldots \ldots \ldots \ldots \ldots \ldots \ldots \ldots \ldots \ldots \ldots \ldots \ldots \ldots$

27. HFR/BMRR comparison: free beam fast dose per unit epithermal fluence . . . . . . . . 107

28. HFR/BMRR comparison cylindrical Lucite phantom $\ldots \ldots \ldots \ldots \ldots \ldots \ldots$

29. Summary of dose tolerance Labrador dog irradiations Fiscal Year $1993 \ldots \ldots \ldots \ldots \ldots$ 



\section{ACRONYMS AND ABBREVIATIONS}

\begin{tabular}{|c|c|}
\hline ae & apical-equatorial \\
\hline$a^{2}$ & apical-apical \\
\hline ACTH & adrencorticotropic hormone \\
\hline AES & atomic emission spectroscopy \\
\hline AND & acute neurologic deterioration \\
\hline BBB & blood-brain barrier \\
\hline BMRR & $\begin{array}{l}\text { Brookhaven Medical Research } \\
\text { Reactor }\end{array}$ \\
\hline $\mathrm{BNCT}$ & boron neutron capture therapy \\
\hline BNCT-Rtpe & $\begin{array}{l}\text { BNCT radiation treatment } \\
\text { planning environment }\end{array}$ \\
\hline BNL & Brookhaven National Laboratories \\
\hline BOPP & water-soluble boronated porphyrin \\
\hline BPA & boronophenylalanine \\
\hline BSA & bovine serum albumin \\
\hline BSH & $\begin{array}{l}\text { borocaptate sodium } \\
\left(\mathrm{Na}_{2} \mathrm{~B}_{12} \mathrm{H}_{11} \mathrm{SH}\right)\end{array}$ \\
\hline BSS & dimer of BSH \\
\hline BSSO & oxidized dimer of BSH \\
\hline cAMP & cyclic adenosine monophosphate \\
\hline $\mathrm{CHN}$ & carbon, hydrogen, nitrogen \\
\hline CNS & central nervous system \\
\hline $\mathrm{CRH}$ & corticotropin releasing hormone \\
\hline $\mathrm{CT}$ & computed tomography \\
\hline CVM & College of Veterinary Medicine \\
\hline DHPE & $\begin{array}{l}\text { dihexadecyl } \\
\text { phosphatidylethanolamine }\end{array}$ \\
\hline D-MEM & $\begin{array}{l}\text { Dulbecco's modified eagle's } \\
\text { medium }\end{array}$ \\
\hline
\end{tabular}

\begin{tabular}{|c|c|}
\hline DOE & Department of Energy \\
\hline DSPC & disterylphosphatidyl choline \\
\hline DSPE & disterylphophatidyl ethanolamine \\
\hline $\mathrm{ECC}$ & elaidyl carborane carboxylate \\
\hline EDTA & ethylenediaminetetraacetic acid \\
\hline EEDA & $\begin{array}{l}\text { Extemal Edge Detection } \\
\text { Algorithm }\end{array}$ \\
\hline EKG & electrocartiogram \\
\hline FBS & Fetal bovine serum \\
\hline FDA & Food and Drug Administration \\
\hline FERRET & Least Squares Data Fitting Code \\
\hline FFOE & free form object editor \\
\hline FOV & field of view \\
\hline FTIR & Fourier transform infrared \\
\hline GC/TMS & $\begin{array}{l}\text { gas chromatograph/ion trap mass } \\
\text { spectrometer }\end{array}$ \\
\hline GC/MS & $\begin{array}{l}\text { gas chromatograph/mass } \\
\text { spectrometer }\end{array}$ \\
\hline GDV & gastric dilatation volvulus \\
\hline GH & growth hormone \\
\hline GHRH & $\begin{array}{l}\text { growth hormone releasing } \\
\text { hormone }\end{array}$ \\
\hline HFR & high-flux reactor \\
\hline HPLC & $\begin{array}{l}\text { high-pressure liquid } \\
\text { chromatography }\end{array}$ \\
\hline HRP & horseradish peroxidase \\
\hline HSA & human serum albunin \\
\hline i.v. & intervenous \\
\hline i.p. & intraperineal \\
\hline ICP-AES & $\begin{array}{l}\text { inductively coupled plasma-atomic } \\
\text { emission spectroscopy }\end{array}$ \\
\hline
\end{tabular}


ICP-MS inductively coupled plasma-mass spectroscopy

$\mathbb{I G F}_{1}$ insulin-like growth factor

IND investigational new drug

INEL Idaho National Engineering Laboratory

$\mathbb{R}$ infrared

ISU Idaho State University

ITMS ion trap mass spectrometer

LDL low-density lipoprotein

LET linear energy transfer

MCNP Monte Carlo Neutron and Photon Transport Code

MRI magnetic resonance imaging

MSU Montana State University

MTT 3-[4,5-dimethylthiazole-2-y1]

-2,5-diphenyltetrazolium bromide; thiazolyl blue

NCAR National Center of Atmospheric Research

ND not detected

NDA new device exemption

NMR nuclear magnetic resonance

oCRH ovine corticotropin releasing hormone

OHSU Oregon Health Science University

OSU Oregon State University

PAL phenylalanine ammonia-lyase

PBS phosphate-buffered saline
PEG polyethylene glycol

pen-strep penicillin/streptomycin

PI principal investigator

PND progressive neurologic deterioration

PNS peripheral nervous system

RBE relative biological effectiveness

REDA Radial Edge Detection Algorithm

RFQ radio frequency quadrupole

RIA stat package

ROI region of interest

RsOI regions of interest

rtt_MC Radiation Transport in Tissue by Monte Carlo

SEM standard error of mean

SNR signal-to-noise

SPET single photon emission tomography

SUNY State University of New York

TBAS tetrabutyl ammonium sulfate

TIC total ion current

UCLA University of California-Los Angeles

UCSF University of California-San

Francisco

$\mathrm{U}$ of $\mathrm{R} \quad$ University of Rochester

$U$ of $U$ University of Utah

urt Utah Raster Toolkit

WSU Washington State University 


\section{INEL BNCT Research Program Annual Report 1993}

\section{INTRODUCTION}

The Idaho National Engineering Laboratory (INEL) Boron Neutron Capture Therapy (BNCT) Research Program completed its sixth year as a Department of Energy (DOE)-funded program, with a continuing increase in interest from the medical community. The goal of the INEL Program remains: To provide the scientific and technological basis for using $\mathrm{BNCT}$ in the treatment of human malignant brain tumors, bringing the therapy to human clinical trials. This year, increasing interest has been shown in BNCT from the medical community by participation in the planning meeting in Seattle. This publication, along with its companion volume of 1993 published papers, summarizes the INEL Program research accomplished this past year. Analytical chemistry, computational and measurement physics, treatment planning and Program integration remain the strong parts of the INEL contribution, while the university programs continue to contribute developments in new boroncontaining drugs, drug evaluation, and radiation biology used for treatment protocol development.

This annual report reviews the 1993 status of 13 components of the INEL BNCT Research Program, and the experimental results and developments of the past year.

\section{Drug Development}

Significant progress toward the application of boronated low-density lipoproteins (LDLs) for site-selective boron drug delivery has been made during the past year. A series of in vivo mouse studies using the B16 BL6 murine melanoma clearly demonstrated the pitfalls of using rodents to evaluate the biodistribution of boronated LDL, while multiple in vitro studies in five cell lines demonstrated the abilities of cancerous cells to bind and internalize boronated LDL in a dosedependent fashion. A Finnish study of nine human patients with malignant gliomas evaluated the tumor accumulation of radioactively labeled LDL. This study demonstrates for the first time, in vivo, in humans, that LDLs have significant potential as carriers of boron for BNCT. During the past year, biodistribution studies of the boronated metalloporphyrin Mn-BOPP were carried out in rats bearing the $R$ G-2 glioma. Results suggest that this compound has significant potential for diagnosis and therapy of malignant glioma. The results of these studies are presented.

The boronated liposome development and evaluation effort consists of two separate tasks. The first is the development of new boron compounds and the synthesis of known boron species with BNCT potential. These compounds are then encapsulated within liposomes for the second task: biodistribution testing in tumorbearing animals, which examines the potential for the liposomes and their contents to concentrate boron in cancerous tissues. Excellent results have now been achieved with boron compounds equipped with the ability to chemically react with intracellular components, thereby anchoring the boron within tumor cells. Developments this year in boronated liposome research have been centered upon the following topics: (a) continued development and scale-up of the most successful candidate boron species, (b) synthesis of new boron-containing compounds expected to exhibit the most favorable features of efficacious boron species, (c) the biological testing of these compounds, incorporated in liposomes, in expedient preliminary screening experiments using mice and rats to determine tumor uptake and retention of boron, and (d) intracellular distribution and mechanistic studies with liposomes labeled with fluorescent markers. Research during the past year was concentrated upon the production of boron-rich species based upon the 20-boron $\left[\mathrm{B}_{20} \mathrm{H}_{18}\right]^{2-}$ ion, chosen for its high boron content, ease of preparation, stability, and rich derivative chemistry related to its propensity to react with 
nucleophiles and to undergo redox reactions. Although the biodistributions of all the compounds examined during the past year have not been included, compounds producing exciting results, both as potential therapeutic agents and as mechanistic information, are presented.

BNCT has also shown promise in treating pituitary tumors and other endocrine-associated malignancies via endocrine cell receptor specificity and internalization after hormone binding. Results are consistent with BNCT cell destruction being mediated through the AtT-20 cell corticotropin releasing hormone receptor. Data from this year's research suggest that (a) hypothalamic releasing hormones can be synthesized and conjugated to a ${ }^{10} \mathrm{~B}_{10}$-cage in a manner that preserves the biologic activity of the polypeptide hormone component in specific targeted pituitary cells, (b) incubation of AtT-20 cells with ${ }^{10} \mathrm{~B}_{10}$-ovine corticotropin releasing hormone for as little as 5 minutes, followed by neutron irradiation, makes the cell susceptible to neutron capture and cell death. Moreover, it appears that this effect is mediated via the corticotropinreleasing hormone receptor, providing evidence that pituitary and other tumor cells can be targeted via specific membrane receptors and killed with ${ }^{10} \mathrm{~B}_{10}$ hormone conjugates.

Twenty-three screening assays utilizing both tumor and normal cells were completed during 1993. Tumor systems which are typically not responsive to conventional means of cancer therapy but are possible candidates for $\mathrm{BNCT}$, were targeted and included: B16-BL6 murine melanoma, RG2 rat glioma, U87MG human glioma, and Lewis lung murine carcinoma. The P1798 murine lymphosarcoma was dropped from studies after histopathological results indicated that this tumor does not remain localized but infiltrates normal organs and tissues, particularly liver, spleen, and regional lymph nodes. To evaluate the preferential loading of boron into tumor tissue relative to normal tissues, all assays have examined levels of boron in normal tissues as well as the tumors. Research has shown that selected boronated compounds do accumulate both in vitro and in vivo in tumor cells. Several of these compounds accumulate to therapeutic levels for BNCT or to levels comparable to, or higher than, those previously reported in the scientific literature.

\section{Pharmacology}

The type and amount of preclinical safety information required to bring a boron-containing drug to human clinical trials depends upon the proposed clinical studies, the intended route of administration, the proposed dose schedule, and the history of past clinical use of the drug or structural derivatives. The two boron delivery drugs for $\mathrm{BNCT}$ that currently are under consideration for clinical use are borocaptate sodium (BSH) and boronophenylalanine (BPA) as the fructose complex. Efforts of the INEL Program are currently focused on $\mathrm{BSH}$. The clinical evaluation of BSH within the U.S. may require additional animal testing to better characterize the risk associated with BSH administration. Initial clinical evaluations are likely to employ BSH doses similar to those used in Japan and Europe, i.e., BSH doses no greater than $100 \mathrm{mg} / \mathrm{kg}$ (approximately equivalent to $50 \mathrm{mg}^{10} \mathrm{~B} / \mathrm{kg}$ ). Because theoretical calculations indicate that the efficacy of BNCT is dramatically enhanced by increasing tumor levels of boron, higher dose BSH studies can also be anticipated. Thus, two separate toxicity issues have been identified: (a) which battery of toxicity tests is necessary to determine the probable safety of clinical administration of $\mathrm{BSH}$ at a maximal dose of $100 \mathrm{mg} \mathrm{B} / \mathrm{kg}$ (or $200 \mathrm{mg} \mathrm{BSH} / \mathrm{kg}$ ), and (b) which battery of toxicity tests is necessary to determine the maximum clinical dose of BSH that seems to be acceptable for administration to humans. In developing the research program, attention has been directed at addressing the toxicity concerns likely to be of interest to regulatory authorities. Data are summarized and grouped according to their relevance to specific issues.

\section{Radiation Biology}

Safety of BNCT is measured by the tolerance of normal brain tissue to the boron neutron cap- 
ture reaction. These normal tissue tolerance studies are performed in canine subjects using varying peak physical doses. Response to the treatment is monitored through serial neurological exams, computed tomography and magnetic resonance scans, and through postmortem histological exams. During the past year, normal brain tissue tolerance endpoints for epithermal irradiation alone and for single and fractionated (two fractions) BNCT schedules for BSH have been defined. Studies were also performed to determine normal tissue tolerance to BNCT in a large animal model using BPA-fructose as the boron delivery agent. A sublethal contrast-enhancing lesion in the cerebral cortex was chosen as the endpoint for normal tissue tolerance studies. This contrast enhancing lesion has been shown histologically to be consistent with radiation-induced cerebral necrosis. Given the BSH distribution in the normal brain, brain necrosis is logically due to endothelial damage, which has been supported by histologic analysis of affected brains. Data are presented to support this hypothesis.

BNCT, with BSH, in dogs with spontaneously occurring brain tumors began in 1989 and continues to be an integral part of the INEL Program. Nine more dogs were screened for presence of a mass in the brain during the past year, and three were chosen for treatment. This brings the total number of dogs with brain tumors treated on the project to 23 . Information on all 23 dogs is presented.

Direct measurement of the extent of vascular damage following BNCT has also been undertaken using the rat model. Comparison of the damage from photon irradiation with $\mathrm{BNCT}$ irradiation on brain parenchyma and vasculature is presented. Radiation effects on the blood-brain barrier such as demyelination, gliosis, and necrosis for photons and BNCT are presented.

Methods for quantitating boron-containing drugs in vivo using magnetic resonance imaging techniques in the canine model continue to show promise. Improvements in the resolution are presented along with actual images. Plans for imaging boron drugs in rat-tumor models are discussed.

\section{Computational Dosimetry}

Developing radiation transport in tissue by Monte Carlo software module continued. A new version is ready for beta testing by interested collaborators. This version contains several new features and is partially integrated with the planning environment software. The radiationtransport software has been tested by comparison with analytic solutions, with results from other radiation transport software, and with measurements made in the Brookhaven Medical Research Reactor (BMRR) epithermal-neutron beam.

Several new features have been developed for the BNCT radiation treatment planning environment during Fiscal Year 1993. The new acronym, BNCT_Rtpe, was adopted to more accurately reflect its purpose. Features discussed include image plane dose contours, voxel editor, automated control point selection algorithm an other miscellaneous features. Beta test versions of the software are available for use by research institutions.

\section{Neutron Source Design}

BNCT research in the U.S. and Europe has been focused on the use of an epithermal-neutron beam to generate the necessary thermal neutron field in deep-seated treatment volumes. Epithermal-neutron beams can be generated by nuclear reactors and by accelerator-based neutron sources. Researchers have developed a concept for an alternate approach to the realization of a clinically useful accelerator-based source of epithermal neutrons for BNCT via a two-stage photoneutron production process. A conceptual design for a device to produce epithermal photoneutrons is discussed.

\section{Chemistry}

Methods to determine the purity and quality of drugs to be used in BNCT are discussed in some detail, with the determination of the purity and quality of BSH used as an example. A variety of analytical chemical analysis techniques are discussed, and results are presented for several different lots of BSH. 


\section{Measurement Dosimetry}

Measurement of neutron beams remains an area of great interest, both for real-time as well as integrated measurements. Real-time measurements using fission chambers are discussed. Preliminary measurements of neutron flux from an accelerator-generated source, and additional measurements of the Petten High Flux Reactor (HFR) and the BMRR epithermal-neutron beams, are presented.

\section{Program Integration}

Integration of the INEL Program remains a high priority of the Program Office. With the required diversity of the Program spanning such areas as neutron physics, chemistry, radiation biology with both internal and external university (via subcontracts) projects, timely and effective information and guidance is key to the effective use of our resources. This year two planning meetings were held to bring the researchers together and bring common problems into focus, that focus being eventual human clinical trials. The INEL Program, also known as the National Center for BNCT Measurement and Development, acts as a national resource for the DOE Office of Health and Environmental Research.

\section{Future}

The technology of BNCT is now ready for human clinical trials in the U.S. (Japan has been doing a form of BNCT for 20 years, with several U.S. patients as part of their trial). Several nuclear reactors at both national laboratories and universities have been identified as possible treatment sites. Two drugs are currently available for the first clinical studies. The treatment planning software is in beta test at several major medical universities. Several options are being investigated as nonreactor neutron sources. It is expected that early success of the initial clinical trials will immediately raise the interest in the application of BNCT methodologies for treatment of several other types of difficult cancers. 


\section{LOW-DENSITY LIPOPROTEIN DEVELOPMENT AND EVALUATION}

\section{Dr. Stephen B. Kahl, Principal Investigator (PI), Department of Pharmaceutical Chemistry, University of California, San Francisco (UCSF)}

Significant progress toward the application of boronated LDL for site selective boron drug delivery has been made during the past year by researchers at UCSF in collaboration with researchers at Washington State University (WSU), the INEL, and the University of Helsinki in Helsinki, Finland. A series of in vivo mouse studies using the B16 BL6 murine melanoma clearly demonstrate the pitfalls of using rodents to evaluate the biodistribution of boronated LDL, while multiple in vitro studies in five cell lines demonstrated the abilities of cancerous cells to bind and internalize boronated $\mathrm{LDL}$ in a dose-dependent fashion. In collaboration with our Finnish colleagues, nine human patients with malignant gliomas were evaluated for the accumulation of autologous ${ }^{99} \mathrm{~m}$ Tc-LDL-labeled low-density lipoprotein. The uptake of $99 \mathrm{~m} \mathrm{Tc}-\mathrm{LDL}$ in gliomas was compared with that of $99 \mathrm{~m}$ Tc-labeled human serum albumin (HSA) using brain single photon emission tomography (SPET). This study is the first of its kind and demonstrates for the first time in vivo in humans that low-density lipoproteins have significant potential as carriers of boron for BNCT. During the past year, biodistribution studies of the boronated metalloporphyrin Mn-BOPP were carried out in rats bearing the $\mathrm{RG}-2$ glioma. Results suggest that this compound has significant potential for diagnosis and therapy of malignant glioma.

\section{LDL Development-Background}

One of the major differences between cancer cells and normal cells is the rate of metabolism of low-density lipoproteins. LDL is the principal cholesterol transport protein in human plasma and is found in an average concentration range of $150-250 \mathrm{mg} / \mathrm{dL}$ in normal adults in the United States. The term low-density lipoprotein is actually misleading; the term refers to a range of spherical particles of 17-25 nanometer diameter and having a density between 1.019 and $1.063 \mathrm{~g} / \mathrm{mL}$. A schematic cartoon of the organization of the LDL particle is shown in Figure 1. Each particle contains a nonpolar core, composed chiefly of long chain fatty acid esters of cholesterol, and a polar coat consisting of phospholipid, unesterified cholesterol and a single copy of a protein known as apoprotein B-100. Seventy-five percent of the total cholesterol in LDL is in the cholesterol ester core, while the remaining $25 \%$ is not esterified and is found embedded in the phospholipid coat. It is estimated that an average of 1,500-2,000 molecules of cholesterol ester are present in each particle core, and the particles are roughly one-half cholesterol ester by weight. The apo B-100 surface protein is large, about 550,000 molecular weight, and is probably wound around throughout the surface of the particle. It provides approximately $20 \%$ of the total mass of the particle. This protein is recognized by specific, high-affinity receptors clustered in regions of the target cell plasma membranes known as clathrin coated pits. After LDL binds to these receptors, the particle-receptor complex is brought into the cell by endocytosis. The bound $\mathrm{LDL}$ is transported to the intracellular lysosomes, where the $\mathrm{LDL}$ is broken down. The receptor is usually recycled to the cell surface to pick up more cholesterol. This recycling process is believed to occur some 250 times during the 20-hour half-life of the receptor. In the lysosome, the particle is exposed to a multitude of enzymes, which degrade the LDL protein to amino acids and hydrolyze the esters to free cholesterol for storage and use by the cell. Approximately $45 \%$ of the plasma LDL pool in normal humans is catabolized daily. Of this, about two-thirds enters cells through this receptor-mediated pathway; the remaining onethird is catabolized by nonspecific pathways involving various kinds of macrophage or "scavenger cells."

Cells require cholesterol chiefly for the construction of new membrane. Both normal and cancerous cells obtain about $90 \%$ of their cholesterol requirements by importation, as 


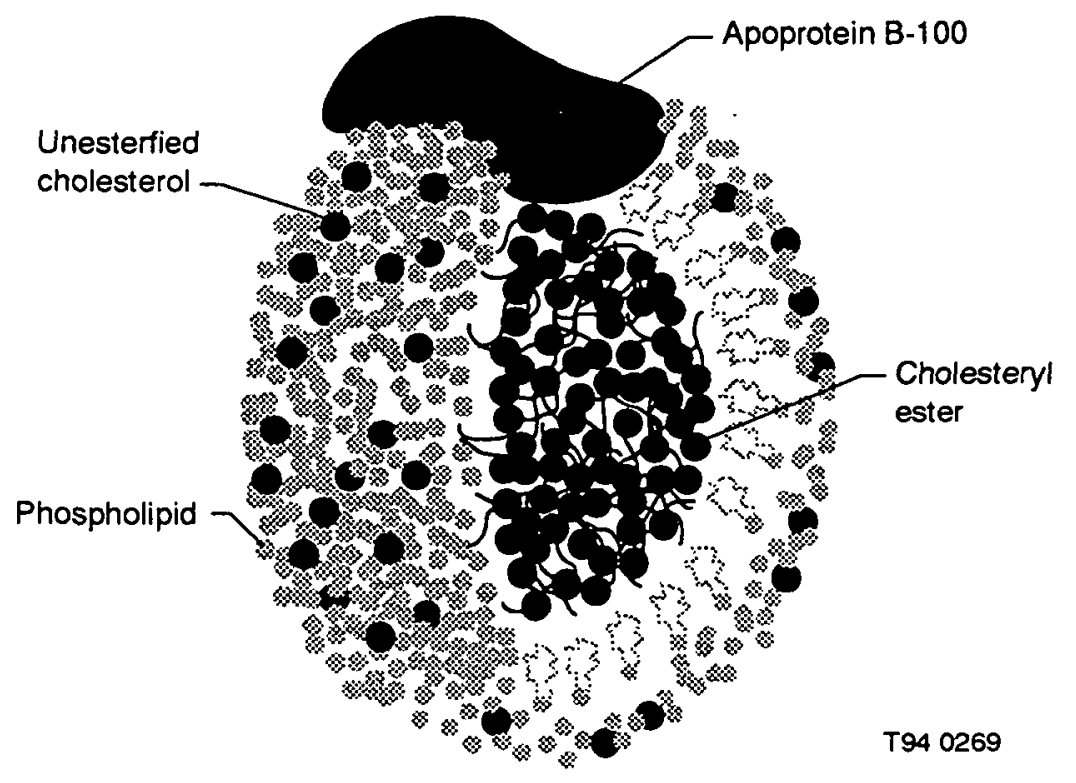

Figure 1. Low-density lipoprotein.

described above. However, rapidly proliferating cells such as cancer cells require increased amounts of cholesterol over surrounding normal cells. A logical consequence of this is that cancer cells have high $L D L$ requirements and higher $L D L$ receptor activity than normal cells. A number of research groups have reported experimental cholesterol flux measurements in various types of cancers consistent with this hypothesis. In some cases, this differential rate in cholesterol flux is 20 times higher in cancer cells than in normal fibroblasts. LDL receptor activity in gliomas has been found to be significantly elevated, making LDL an ideal drug delivery agent for treatment of gliomas, since the LDL particle is much too large to pass the normal blood-brain barrier (BBB).

Low-density lipoproteins possess several potential advantages as drug delivery vehicles. They are "natural" body components and as such are able to survive in tissue or plasma for significant periods. The small particle size allows diffusion from the vascular to the extravascular compartments of the body. Intracellular uptake via receptormediated endocytosis permits the contents of LDL particles to enter the interior of cells, an important factor when considering drug delivery vehicles for BNCT, since the boron fission reaction is much more effective in cell killing than if the boron is located extracellularly. The oily core of LDL provides a favorable domain for lipophilic drugs and prodrugs. Researchers at UCSF and elsewhere have demonstrated that the LDL core components can be partly or even totally replaced with lipophilic drugs. And, finally, receptor-mediated LDL uptake is significantly enhanced in certain pathophysiologic states, providing the potential to selectively administer boronated LDL to such cells.

In principle, then, if the cholesterol ester core of LDL can be replaced by a similarly hydrophobic boron compound, the receptor-mediated uptake of boronated LDL could provide a "Trojan horse"like mechanism for the selective delivery of boron to tumor cells. This is a stealth-type effect, since, in principle, the reconstituted boron-loaded LDL should appear to the body and behave as normal LDL.

The UCSF group has previously pioneered and developed a method by which the cholesterol esters can be stripped from human LDL and replaced by a series of long chain unsaturated fatty alcohol esters of 1,2-carborane carboxylic acid. The carborane is a polyhedral molecule consisting of 10 boron atoms and two carbons with each of the 12 atoms linked to a single hydrogen atom. Its closed cage "ball-like" nature renders it more or 
less inert and nontoxic. Of the several dozen esters evaluated, it was found that the elaidyl ester could be reconstituted to the highest degree. Indeed. calculations based on the boron content of the resultant boronated $\mathrm{LDL}$ showed that an average 2.000-3,000 molecules of the ester could be placed in the LDL core. Using cell culture techniques and the BMRR beam, it was shown that the reconstituted $\mathrm{LDL}$ apparently entered cultured cancer cells via the normal receptor-mediated process and that the boron internalized by this process provided very potent sensitization to the beam of thermal neutrons. When sufficient cells were cultured in the presence of boronated LDL to enable independent measurement of their boron content, an average intracellular boron content of $-240 \mathrm{ppm}$ was determined. This concentration is far higher than that from any other known boron delivery system and is an order of magnitude greater than that needed for therapy.

\section{LDL Development-In Vivo Studies}

Five biodistribution studies were carried out during the past year using the B16BL6 murine melanoma. Mice bearing the tumor on the dorsal hip were given human LDL boronated with elaidyl carborane carboxylate (ECC). Single tail vein bolus injections of LDL in phosphate buffered saline (PBS) were used for administration of the drug complex. Six mice were sacrificed at each of several (up to six) time points, and samples of blood, tumor, and brain were obtained. Boron analyses were carried out using inductively coupled plasma-atomic emission spectroscopy (ICP-AES) at the INEL.

Results of two of these experiments are presented in Tables 1 and 2, and are representative of the other three biodistribution experiments. Table 1 shows the resultant mean tissue boron content \pm standard error of mean (SEM) for an administered boron dose equivalent to $800 \mu \mathrm{g}$ $\mathrm{B} / \mathrm{kg}$. Given the very low boron dose, the absolute tumor boron levels are quite respectable, especially at the early points. By way of comparison. administration of the UCSF's best boronated porphyrin, BOPP, at a dose of $30 \mathrm{mg} \mathrm{B/kg}$ or about 30 times higher than in the present study, results in maximal tumor boron content of about $65 \mu \mathrm{g} / \mathrm{g}$ or roughly only an order of magnitude greater than that observed here. Moreover, the blood boron levels show a decay pattern similar to that previously observed in rats with a $t_{1 / 2}$ of approximately $4-6$ hours.

Little or no boron was found in the brains of these animals, confirming the hypothesis that $\mathrm{LDL}$ particles are far too large to pass across the intact BBB. Disappointingly, however, no selectivity of LDL for tumor over blood was observed and at no time was the tumor-to-blood ratio greater than unity.

Table 2 shows results from a similar study in which liver and spleen boron concentrations were measured in addition to tumor, blood, and brain. Administered boron dose in this study was equivalent to $4,800 \mu \mathrm{g} \mathrm{B} / \mathrm{kg}$. These results are qualitatively similar to the previous study and are representative of the other studies. In this case, tumor boron levels are lower than in the previous study despite the higher administered boron dose. A similar lack of selectivity for tumor over blood is again observed. Liver and spleen boron levels are quite large considering the dose and suggest that boronated $\mathrm{LDL}$ is being actively removed by the reticuloendothelial system. This may be the result of changes in the LDL particle induced by the stripping/reconstitution process which had not been observed in the in vitro experiments carried out at BMRR. A full analysis of this problem awaits electrophoretic studies next year.

Data obtained with the B16BL6 in vivo uptake studies raised the question of whether this tumor and animal combination were an appropriate model for biodistribution studies of boronated LDL. Although it is well-documented that rat and mouse liver LDL receptors can recognize human $\mathrm{LDL}$, rodents do not use $\mathrm{LDL}$ as their primary source of exogenous cellular cholesterol. Thus, although the liver and spleen boron levels suggest at least potential recognition of the LDL by the mouse receptors, the receptor-mediated uptake in the B16BL6 tumor is insufficient to give 
Table 1. In vivo $\mathrm{LDL}$ exposure in mice $\mathrm{B} 16 \mathrm{BL} 6$ melanoma, $\mathrm{LDL}=800 \mu \mathrm{g} \mathrm{B} / \mathrm{kg}$.

Tissue boron concentration

$(\mu \mathrm{g} / \mathrm{g})$

\begin{tabular}{lcccccc} 
& $6 \mathrm{hr}$ & $12 \mathrm{hr}$ & $18 \mathrm{hr}$ & $24 \mathrm{hr}$ & $48 \mathrm{hr}$ & $72 \mathrm{hr}$ \\
\hline Tumor & $6.1 \pm 2.7$ & $4.6 \pm 1.4$ & $3.6 \pm 0.9$ & $2.3 \pm 0.5$ & $1.1 \pm 0.3$ & $0.8 \pm 0.2$ \\
Blood & $7.2 \pm 0.9$ & $5.7 \pm 0.4$ & $4.2 \pm 0.6$ & $3.4 \pm 0.4$ & $1.1 \pm 0.3$ & $0.6 \pm 0.1$ \\
Brain & $0.6 \pm 0.2$ & $0.5 \pm 0.1$ & $0.6 \pm 0.1$ & $0.5 \pm 0.1$ & $0.5 \pm 0.1$ & $0.6 \pm 0.2$ \\
\hline
\end{tabular}

Table 2. In vivo exposure in mice B16 BL6 melanoma, $\mathrm{LDL}=4.800 \mu \mathrm{g} \mathrm{B} / \mathrm{kg}$.

\begin{tabular}{lrccccc}
\hline & $6 \mathrm{hr}$ & $12 \mathrm{hr}$ & $18 \mathrm{hr}$ & $24 \mathrm{hr}$ & $48 \mathrm{hr}$ & $72 \mathrm{hr}$ \\
\hline Blood & $5.6 \pm 0.5$ & $4.6 \pm 1.6$ & $2.7 \pm 0.5$ & $2.4 \pm 0.3$ & $0.8 \pm 0.1$ & $0.8 \pm 0.1$ \\
Tumor & $3.6 \pm 0.5$ & $2.7 \pm 1.0$ & $2.1 \pm 0.7$ & $2.1 \pm 0.4$ & $1.1 \pm 0.3$ & $0.6 \pm 0.1$ \\
Liver & $11.1 \pm 1.1$ & $6.0 \pm 2.2$ & $4.9 \pm 1.7$ & $4.4 \pm 0.5$ & $2.5 \pm 0.7$ & $1.9 \pm 0.4$ \\
Spleen & $8.6 \pm 1.8$ & $4.9 \pm 1.9$ & $4.4 \pm 1.5$ & $3.6 \pm 1.0$ & $2.6 \pm 0.4$ & $1.3 \pm 0.5$ \\
\hline
\end{tabular}

selectivity. An altemative explanation is that this tumor does not over-express the LDL receptor in contrast to most of the other tumor lines where this activity has been measured.

\section{LDL Development-In Vitro Studies}

To answer the appropriate model question. a series of in vitro studies were carried out using murine carcinoma (Lewis lung), murine melanoma (B16BL6), and normal fibroblast cell lines. The latter are expected to have "normal" or basal levels of $\mathrm{LDL}$ receptors and thus serve as controls for the experiments. In each case, cells were incubated with boronated LDL containing $\mathrm{ECC}$ for 6,12 , or 24 hours. Boron concentration of the incubation medium was $1.12 \mu \mathrm{g} \mathrm{B} / \mathrm{mL}$ for the data obtained in the first experiment. results of which are presented in Table 3. Cells were spun down to separate them from supernatant incubation medium. Both cell pellet and supernatant were analyzed for boron at the INEL using ICP-AES. Each entry in Table 3 represents the average of three cultures $\pm S E M$.

Several conclusions are immediately apparent. The melanoma and carcinoma behave identically toward the boronated LDL, suggesting that both cell lines do over-express the LDL receptor as compared to murine fibroblasts. (The 24-hour fibroblast point has a large relative SEM caused by one major outlyer.) Noteworthy is the increasing boron content over time in both transformed cell lines. Linear uptake versus time for boronated LDL has previously been observed by us for $\mathrm{CHO}$ and $\mathrm{V}-79$ cells, and is believed to be related to the nearly complete replacement of cholesterol ester with carborane ester. In the natural LDL, internalized cholesterol ester from the LDL core acts as a negative feedback signal to suppress receptor-mediated uptake, but with boronated LDL the signal is missing and receptor-mediated uptake is linear with time. Also noteworthy is the total boron content of both cell lines at 24 hours. Given the very small administered boron dose, a 24-hour value of $\sim 20 \mathrm{ppm}$ boron is very substantial. By comparison. when $\mathrm{CHO}$ cells were incubated at a boron concentration of $23 \mu \mathrm{g} / \mathrm{mL}$ and then measured for boron by the prompt gamma technique, a cell pellet content of $240 \mathrm{ppm}$ boron was found. The present values are proportionally $30 \%$ greater, which are not unreasonable values considering that we have previously demonstrated that in vitro uptake is more efficient at lower incubation concentrations. In all but one case, the 
Table 3. In vitro $\mathrm{LDL}$ exposure, $\mathrm{LDL}=1.12 \mu \mathrm{g} \mathrm{B} / \mathrm{mL}$.

\begin{tabular}{lccc}
\hline & \multicolumn{3}{c}{ Cell pellet boron concentration } \\
& \multicolumn{3}{c}{$(\mu \mathrm{g} / \mathrm{g})$} \\
\cline { 2 - 4 } & $5.0 \pm 0.5$ & $12 \mathrm{hr}$ & $24 \mathrm{hr}$ \\
\hline Murine melanoma & $10.9 \pm 0.7$ & $19.2 \pm .57$ \\
Murine carcinoma & $4.8 \pm 0.6$ & $12.8 \pm 1.4$ & $22.0 \pm 2.0$ \\
Murine fibroblast & $1.2 \pm 0.3$ & $1.5 \pm 0.3$ & $5.1 \pm 3.2$ \\
& \multicolumn{3}{c}{ Supernatant boron concentration } \\
& $0.9 \pm 0.1$ & $1.0 \pm 0.2$ & $0.8 \pm 0.0$ \\
Murine melanoma & $0.9 \pm 0.1$ & $1.3 \pm 0.7$ & $0.9 \pm 0.2$ \\
Murine carcinoma & $0.9 \pm 0.1$ & $1.0 \pm 0.3$ & $1.6 \pm 0.5$ \\
Murine fibroblast & &
\end{tabular}

supernatant boron concentration is within experimental error of starting incubation value.

To confirm the results of this initial study and to broaden its scope to cells of model gliomas, a series of similar experiments were carried out using the three original cell lines and two more. These were the U87-MG human glioma line and the RG-2 rat glioma line. Table 4 presents data from the first of these experiments with an incubation boron concentration of $1.04 \mu \mathrm{g} \mathrm{B} / \mathrm{mL}$.

Murine cell results are basically similar to those from Table 3, where a slightly higher concentration of boronated $\mathrm{LDL}$ was used $(1.12 \mu \mathrm{g} \mathrm{B} / \mathrm{mL})$. Results of the supernatant analysis are not shown for sake of simplicity, but in all but two cases (melanoma and carinoma@6 hours) the supernatant values are between 0.8 and $1.1 \mathrm{ppm}$ boron. This is what one would expect using an incubation concentration of $1.04 \mathrm{ppm}$. The increase over time of all of the cell lines except fibroblast is also similar to what was found in the earlier murine studies. The substantial uptake in rat glioma cells over time is noteworthy as is the poorer uptake in the human glioma line.

Table 5 illustrates the effect of doubling the dose of boronated LDL. In general, the increased boron dose results in increased cell pellet boron concentration, although the effect is clearly not linear. In terms of boron uptake per unit dose, most cancerous cell lines took up boron less efficiently at the higher dose. Fibroblasts are the apparent exception, but the boron uptake in these essentially control cells is not significantly different at the two doses with the possible exception of the 24-hour high-dose point. Taken together, these two series clearly demonstrate that the B 16 BL6 murine melanoma cell line has not lost its over-expression of the LDL receptor. We conclude that the disappointingly low in vivo murine tumor data are the result of differences in lipoprotein biochemistry and that the normal mouse is not an adequate or representative model of in vivo tumor uptake.

Data in Table 6 were obtained at the same boron dose as those in Table 3, but the cells were pretreated with $17 \alpha$-ethynylestradiol, the active estrogen in the oral contraceptive. This drug has been reported to reduce serum LDL concentrations in women with type II hyperlipoproteinemia as a result of up-regulating the $\mathrm{LDL}$ receptor activity.

Comparison of Tables 4 and 6 suggest that the murine melanoma cells may be somewhat responsive to pretreatment with this drug; the glioma lines clearly are not.

While the results of the foregoing experiments present a nice, neat picture, other data suggest that there is yet more complexity. Table 7 presents the data from a lower LDL boron dose $(0.83 \mu \mathrm{g}$ 
Table 4. In vitro $\mathrm{LDL}$ exposure, $\mathrm{LDL}=1.04 \mu \mathrm{g} \mathrm{B} / \mathrm{mL}$.

\begin{tabular}{lrrr} 
& \multicolumn{3}{c}{$\begin{array}{c}\text { Cell pellet boron concentration } \\
(\mu \mathrm{g} \mathrm{B} / \mathrm{g})\end{array}$} \\
\cline { 2 - 4 } & \multicolumn{1}{c}{$6 \mathrm{hr}$} & $12 \mathrm{hr}$ & $24 \mathrm{hr}$ \\
\hline Murine melanoma (B16 BL6) & $5.8 \pm 0.8$ & $14.0 \pm 0.2$ & $29.8 \pm 3.0$ \\
Murine carcinoma (Lewis lung) & $5.9 \pm 0.1$ & $8.7 \pm 0.9$ & $14.0 \pm 0.7$ \\
Murine fibroblast & $1.4 \pm 0.3$ & $2.0 \pm 0.3$ & $2.3 \pm 0.2$ \\
Rat glioma (RG-2) & $14.0 \pm 2.0$ & $20.5 \pm 2.7$ & $22.8 \pm 2.4$ \\
Human glioma (U87 MG) & $1.2 \pm 0.1$ & $3.9 \pm 0.2$ & $5.5 \pm 0.4$ \\
\hline
\end{tabular}

Table 5. In vitro $\mathrm{LDL}$ exposure, $\mathrm{LDL}=2.08 \mu \mathrm{g} \mathrm{B} / \mathrm{mL}$.

\begin{tabular}{lccc}
\hline & \multicolumn{3}{c}{$\begin{array}{c}\text { Cell pellet boron concentration } \\
(\mu \mathrm{g} \mathrm{B} / \mathrm{g})\end{array}$} \\
\cline { 2 - 4 } & \multicolumn{1}{c}{$6 \mathrm{hr}$} & $12 \mathrm{hr}$ & $24 \mathrm{hr}$ \\
\hline Murine melanoma & $12.9 \pm 1.0$ & $22.1 \pm 3.2$ & $50.6 \pm 3.6$ \\
Murine carcinoma & $9.1 \pm 1.8$ & $10.3 \pm 0.6$ & $17.5 \pm 0.6$ \\
Murine fibroblast & $1.7 \pm 0.4$ & $1.9 \pm 0.5$ & $3.8 \pm 0.1$ \\
Rat glioma & $13.6 \pm 2.6$ & $14.7 \pm 1.7$ & $28.7 \pm 1.3$ \\
Human glioma & $2.3 \pm 0.3$ & $5.1 \pm 0.6$ & $13.6 \pm 2.4$ \\
\hline
\end{tabular}

Table 6. In vitro $\mathrm{LDL}$ exposure, pretreatment with $17 \alpha$-ethynylestradiol, $\mathrm{LDL}=1.04 \mu \mathrm{g} \mathrm{B} / \mathrm{mL}$.

\begin{tabular}{lrr}
\hline & \multicolumn{2}{c}{$\begin{array}{c}\text { Cell pellet boron concentration } \\
(\mu \mathrm{g} \mathrm{B} / \mathrm{g})\end{array}$} \\
\cline { 2 - 3 } & \multicolumn{1}{c}{$12 \mathrm{hr}$} & $24 \mathrm{hr}$ \\
\hline Murine melanoma & $24.4 \pm 2.0$ & $34.7 \pm 3.3$ \\
Murine fibroblast & $1.8 \pm 0.1$ & $2.3 \pm 0.6$ \\
Rat glioma & $9.4 \pm 0.5$ & $12.6 \pm 0.6$ \\
Human glioma & $2.5 \pm 0.5$ & $3.9 \pm 0.3$ \\
\hline
\end{tabular}

Table 7. In vitro $\mathrm{LDL}$ exposure, $\mathrm{LDL}=0.83 \mu \mathrm{g} \mathrm{B} / \mathrm{mL}$.

\begin{tabular}{lccc}
\hline & \multicolumn{3}{c}{$\begin{array}{c}\text { Cell pellet boron concentration } \\
(\mu \mathrm{g} \mathrm{B} / \mathrm{g})\end{array}$} \\
\cline { 2 - 4 } & \multicolumn{4}{c}{$6 \mathrm{hr}$} & $12 \mathrm{hr}$ & $24 \mathrm{hr}$ \\
\hline Murine melanoma & $9.0 \pm 0.4$ & $20.6 \pm 0.5$ & $35.6 \pm 3.6$ \\
Murine carcinoma & $7.7 \pm 0.5$ & $11.8 \pm 0.3$ & $15.1 \pm 0.8$ \\
Murine fibroblast & $3.0 \pm 0.6$ & $7.3 \pm 0.6$ & $19.3 \pm 3.5$ \\
Rat glioma & $10.1 \pm 1.5$ & $16.0 \pm 1.1$ & $20.9 \pm 0.6$ \\
Human glioma & $7.0 \pm 1.2$ & $16.0 \pm 1.1$ & $35.9 \pm 2.7$ \\
\hline
\end{tabular}


$\mathrm{B} / \mathrm{mL}$ ). Comparison with Table 4 reveals that in almost every case, the lower dose is associated with higher absolute boron uptake. Particularly noteworthy in this regard are the human glioma data. These U87 MG cells had been found in our other experiments to be rather poor scavengers of boron, whilst in the present case they are among the best.

Similarly, Table 8 represents a higher $\mathrm{LDL}$ boron dose. Taken by itself, it is a noteworthy set of data in that such a relatively low dose of boron $(3 \mu \mathrm{g} / \mathrm{mL})$ can result in such exceptionally high amounts of cellular boron. At the present time, we are unable to provide encompassing rationale to explain data in Tables 4 through 8 . However, several conclusions from these studies are clear: (1) the normal mouse is not the proper test animal, (2) very high cellular boron content can be achieved in vitro with very low doses of boron, and (3) various cancerous cell lines differ significantly in their receptor-mediated behavior toward boronated LDL.

\section{LDL Development-Human Studies}

One of the more significant and exciting developments in the LDL program occurred during the past year as our collaborators in Finland completed the first study of the accumulation of radioactively labeled LDL in brain tumor patients. Prior to this study, the presence of $L D L$ receptors in surgical brain tumor specimens had been demonstrated, but the Finnish study represents the first in vivo demonstration of the potential for LDL as a carrier of boron for BNCT treatment. Only a brief description of the protocol and results will be presented here, as a manuscript detailing the results has been submitted and is under review.

Accumulation of autologous $99 \mathrm{~m}$ Tc-labeled LDL was observed in four patients with primary (untreated) gliomas and five patients with recurrent malignant gliomas. The uptake of $99 \mathrm{mTC}-\mathrm{LDL}$ in tumors was compared with that of $99 \mathrm{~m}$ Tc-labeled HSA injected intravenously 3-7 days before administration of labeled LDL. Doses (expressed as $\mathrm{mg}$ protein) were $2-3 \mathrm{mg}$ of $99 \mathrm{~m} \mathrm{Tc}-\mathrm{LDL}$ and $60-150 \mathrm{mg}$ of ${ }^{99 \mathrm{~m}} \mathrm{Tc}-\mathrm{HSA}$. Brain SPET was performed 2 hours and 20 hours after the injection of radiolabeled protein. Blood samples were collected at $0,10,20$, and 40 minutes and at 1,2,3, $4,7-9,10-12,18-21$, and $22-25$ hours after

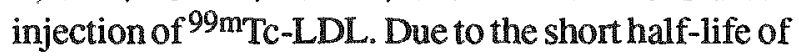
the radiolabel, no samples were taken beyond 24 hours.

The disappearance curve of $99 \mathrm{mTc}-\mathrm{LDL}$ in blood was monoexponential during the first 24 hours with a mean half-life of $18.5 \pm 4.2$ hour. Similar behavior has been noted previously with radioiodinated LDL, but the disappearance rate of $99 \mathrm{mTc}-\mathrm{LDL}$ was higher than that of radioiodinated LDL. The plasma half-life of ${ }^{99 \mathrm{~m}} \mathrm{Tc}-\mathrm{LDL}$ observed in this study compares well with the 15-hour value found by Leitha. ${ }^{1}$

SPET images showed that both ${ }^{99} \mathrm{~m}$ TC-LDL and $99 \mathrm{~m}$ Tc-HSA accumulated in the tumor area defined by computed tomography ( $\mathrm{CT}$ ) scans, but the distribution of radioactivity in the images was not

Table 8. In vitro $\mathrm{LDL}$ exposure, $\mathrm{LDL}=3.0 \mu \mathrm{g} B / \mathrm{mL}$.

\begin{tabular}{lrcc}
\hline & \multicolumn{3}{c}{$\begin{array}{c}\text { Cell pellet boron concentration } \\
(\mu \mathrm{g} \mathrm{B} / \mathrm{g})\end{array}$} \\
\cline { 2 - 4 } & \multicolumn{4}{c}{$6 \mathrm{hr}$} & $12 \mathrm{hr}$ & $24 \mathrm{hr}$ \\
\hline Murine melanoma & $16.8 \pm 1.6$ & $40.2 \pm 2.6$ & $64.6 \pm 3.6$ \\
Murine carcinoma & $17.7 \pm 0.3$ & $43.9 \pm 2.1$ & $99.9 \pm 3.4$ \\
Murine fibroblast & $9.9 \pm 3.3$ & $16.0 \pm 2.3$ & $34.4 \pm 6.7$ \\
Rat glioma & $17.1 \pm 1.5$ & $24.3 \pm 1.3$ & $35.4 \pm 2.7$ \\
Human glioma & $22.3 \pm 2.2$ & $47.1 \pm 4.2$ & $67.0 \pm 8.6$ \\
\hline
\end{tabular}


identical for the two tracers. This suggests different mechanisms of uptake and/or retention of radioactivity. In all cases, the uptake in tumor correlated well with areas delineated as tumor in the CT scans, but there were some differences between untreated and recurrent tumors. The mean LDL tumor-to-brain uptake ratio, as determined from transverse SPET slices at 20 hours postinjection. was 1.5 in primary and 2.2 in recurrent gliomas. The corresponding values for HSA were 1.6 and 3.4 . The greater LDL uptake in recurrent tumors may reflect their more highly vascularized state and more aggressive growth as reflected by higher LDL receptor activity. The higher tumor/brain ratio for HSA may be related to its size relative to $\mathrm{LDL}$. At a molecular weight of $66 \mathrm{kD}$, HSA probably has a higher diffusion rate through the disrupted bloodbrain barrier than LDL, which has a molecular weight of about $3,000 \mathrm{kD}$. The observation that brain/blood ratios were constant indicates that $99 \mathrm{~m} \mathrm{Tc}-\mathrm{LDL}$ does not cross the intact blood-brain barrier. The present study does not disclose whether the mechanism of ${ }^{99} \mathrm{~m}$ Tc-LDL uptake in malignant gliomas is receptor-mediated or nonspecific, but it does indicate that LDL has potential as a carrier for boron for BNCT treatment of this disease. Studies are currently under way to reconstitute autologous LDL with ECC, label with ${ }^{99 \mathrm{~m}} \mathrm{Tc}$, and evaluate the biodistribution by both SPET and boron analysis of tumor, blood, and normal tissue.

\section{Boronated Porphyrin Studies}

In collaboration with Dr. Pat Gavin at WSU, a study has been initiated to examine the biodistribution and magnetic resonance imaging
(MRI) contrast enhancing properties of a boronated metalloporphyrin Mn-BOPP. A recently published initial study of the contrast-enhancing ability of this compound in the $9 \mathrm{~L}$ gliosarcoma rat brain tumor suggested its potential for diagnosing and treating brain tumors. ${ }^{2}$ Tumor-bearing rats were treated at a dose of porphyrin $30 \mathrm{mg} / \mathrm{kg}$ and imaged at $5 \mathrm{~min}$, $24,48,72$, and 92 hours postadministration. Maximal contrast enhancement $(60 \%)$ was obtained at 24 hours and was sustained at $>50 \%$ for the full 92-hour period, indicating that the pharmacokinetics of this compound may be similar to that of the parent apometalloporphyrin BOPP. The purpose of the study was two-fold: (1) to measure the organ content of boron in tumor, normal brain, blood, and skin, and (2) to determine whether the degree of contrast enhancement over 24 hours was related to the tumor boron and manganese content.

The protocol in the present study was to administer Mn-BOPP at a dose of $30 \mathrm{mg} / \mathrm{kg}$ to three groups of seven tumor-bearing rats, each by a single intervenous (i.v.) bolus injection. One group was sacrificed at 2 hours without imaging. The second group was imaged en masse at 2 hours and 8 hours and then sacrificed. The third group was imaged at 2, 8, and 24 hours followed by sacrifice. No acute toxicity was observed in any of the animals over the period of the experiment. Boron and manganese analyses were performed by ICP-AES at the INEL.

Table 9 presents the boron analytical data resulting from this experiment. It is readily apparent that even at this rather low boron dose

Table 9. Mn-BOPP in vivo experiment with RG-2 glioma.

Tissue boron concentration

$(\mu \mathrm{g} \mathrm{B} / \mathrm{g})$

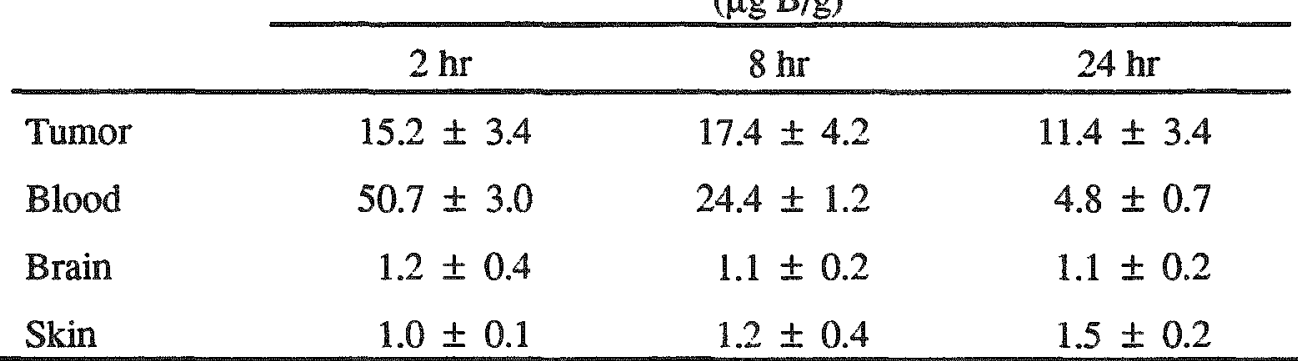


$(8.5 \mathrm{mg} / \mathrm{kg}$ ) there is substantial tumor boron. As with $B O P P$, the blood levels fall rapidly and reach $-10 \%$ of the 2 -hour value at 24 hours after injection. It appears, however, that the time of maximal tumor boron content is different from that found with BOPP. With BOPP, this time is -24 hours, whereas the present results suggest that maximal tumor uptake for Mn-BOPP is reached between 8 and 24 hours.

As with BOPP, Mn-BOPP does not appear to cross the intact $\mathrm{BBB}$, nor is it taken up in the skin to any appreciable degree. The tumor/normal brain ratios at all times exceed 10:1, and the actual ratios are probably significantly higher given that the normal brain values are at the lower detection limit for boron on samples of this size (average sample $\sim 70 \mathrm{mg}$ ). The tumor/blood ratio rises from $\sim 0.3$ to exceed unity at or near 8 hours and continues to rise to $\sim 2-3$ at 24 hours. Analysis for manganese (data not shown) on samples containing sufficient boron so as to make $\mathrm{B} / \mathrm{Mn}$ ratios meaningful (i.e., early blood and tumor values) suggest that the $\mathrm{Mn}$ and $\mathrm{B}$ remain associated. These values average $\sim 35: 1$, which is in reasonable agreement with the actual value of $40: 1$.

Analysis of the MRI images has not yet been completed. but it appears that there is a definite relationship between the boron content of the tumor and the degree of contrast enhancement. 


\section{BORONATED LIPOSOME DEVELOPMENT AND EVALUATION}

\section{Dr. M. Frederick Hawthorne, Pl, University of California, Los Angeles (UCLA), Department of Chemistry and Biochemistry}

The boronated liposome development and evaluation effort consists of two separate tasks. The first is the development of new boron compounds and the synthesis of known boron species with BNCT potential. These compounds are then encapsulated within liposomes for the second task: biodistribution testing in tumor-bearing mice, which examines the potential for liposomes and their contents to concentrate boron in cancerous tissues.

The team at UCLA (Drs. Kenneth Shelly and Debra Feakes) under the direction of Dr. Hawthorne continues to develop new boron chemistry to produce a variety of boron agents with BNCT potential. These researchers also produce the boron-containing liposomes for biological screening experiments that demonstrate the efficacy of boron localization in tumor-bearing mice. The primary liposome biodistribution experiments and the physical characterization of liposomes are performed under the direction of Dr. Gary Fujii at Vestar, Inc. (a private firm specializing in the pharmaceutical applications of liposomes), San Dimas, CA, with the assistance of Teresa Krisch, A.H.T. Further murine experiments with liposomes are performed at WSU by Dr. Catherine Elstad (Lewis lung carcinoma in mice) and Dr. Patrick Gavin (RG2 intracranial glioma in rats). Additional liposome characterization and fluorescence studies are performed at the State University of New York (SUNY) at Buffalo by Dr. Robert Straubinger.

\section{Background}

One of the more pressing problems in BNCT has been developing effective strategies for selective localization of boron within tumor tissue. Primary difficulties to overcome are specific delivery of therapeutic quantities of boron to the tumor, while avoiding normal tissues, and the potential toxicity of the boron agent delivered. Liposomes have been studied extensively as drug delivery systems. and as such they present a novel approach for solving these problems as well as presenting a new and innovative method for delivering boron for BNCT.

Liposomes (small unilamellar vesicles) are microscopic spheroidal structures composed of a phospholipid bilayer membrane enclosing an aqueous core (Figure 2). The utility of liposomes as drug delivery systems arises from their ability to

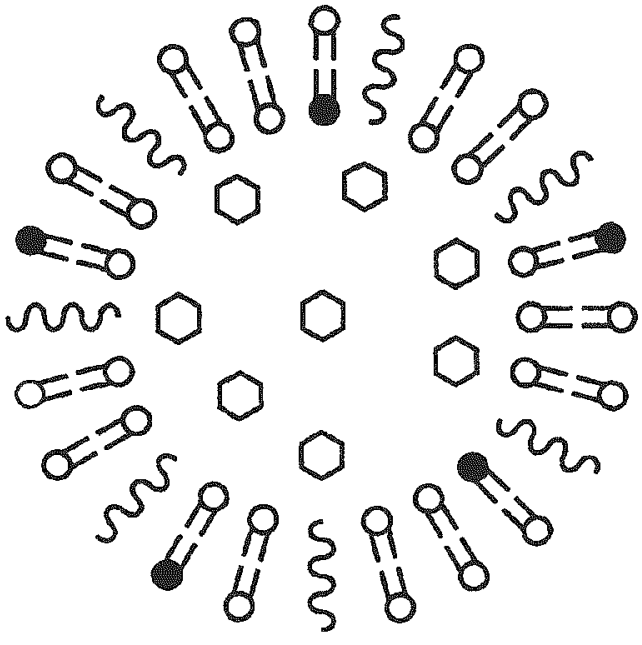

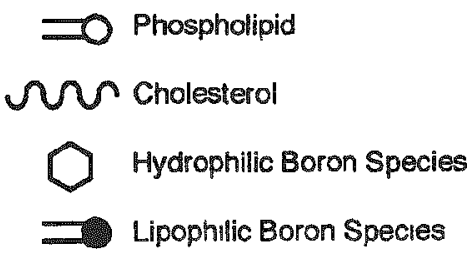

T94 0258

Figure 2. Diagram of a unilamar vesicle. 
encapsulate aqueous solutions of water-soluble compounds in the aqueous core or to accommodate hydrophobic compounds within the lipid membrane. The liposomal delivery of drugs, when successful, has several attractive consequences. Sequestering the effector species in vesicles can provide it with an extended circulation lifetime, thereby increasing its opportunity to be taken up by tissue. The liposome also offers protection for the occluded species from attack by normal physiological agents in vivo and reduces potential toxicity effects (the liposome constituents themselves are nontoxic). Liposomes have been demonstrated to deliver their contents directly to the interior of cells, where their therapeutic utility is maximized. Since both tumor cell-selective delivery and cell entry are provided by the liposome, the encapsulated species need not have a natural affinity for the targeted tumor cells. thus making this method amenable to a wide variety of effector molecules.

Researchers at UCLA, assisted by Vestar, Inc. have identified liposomes of a specific size and composition suitable for delivering therapeutic quantities of boron to tumors. The results of initial studies of this type (1988-1991) demonstrated that liposomes are a viable boron delivery system for BNCT. ${ }^{1}$

Liposomes were shown to be capable of encapsulating polyhedral borane anions, as their soluble sodium salts. in the high concentration required to deliver a sufficient quantity of boron in a reasonable dose volume. These high concentrations, while much greater than those normally employed in liposomes, were encapsulated in stable liposomes, which demonstrated only negligible leakage over a period of months. The extended circulation lifetime and tumor selectivity provided by the liposomes permitted use of relatively small injected doses of boron to produce significant boron concentrations in tumors. The relatively simple polyhedral borane anions initially studied normally exhibit brief circulation lifetimes and no tumor selectivity as free species. These same agents were selectively delivered to tumors in mice after encapsulation in liposome carriers. Perhaps the most significant finding of this early work was the importance of intracellular chemical reactivity of the delivered boron species. Although simple, inert, nonspecific boron species, such as $\mathrm{Na}_{2} \mathrm{~B}_{10} \mathrm{H}_{10}$, were selectively delivered by the liposome to tumor cells, they were rapidly excreted, since they presented no innate chemical reactions that could be used to bind them to the tumor cell interior. Excellent results have now been achieved with boron compounds equipped with the ability to chemically react with intracellular components, thereby anchoring the boron within tumor cells.

Recent developments in boronated liposome research have been centered upon the following topics: (a) continued development and scale-up of the most successful candidate boron species. (b) synthesis of new boron-containing compounds expected to exhibit the most favorable features of efficacious boron species, (c) biological testing of these compounds, incorporated in liposomes, in expedient preliminary screening experiments using mice and rats to determine tumor delivery and retention of boron, and (d) intracellular distribution and mechanistic studies with liposomes labeled with fluorescent markers.

\section{Compound Development}

Research during the past year centered on producing boron-rich species based upon the 20-boron $\left[\mathrm{B}_{20} \mathrm{H}_{18}\right]^{2-}$ ion, first synthesized in Hawthorne's laboratory 30 years ago. ${ }^{2}$ This ion was chosen for its high boron content, ease of preparation, stability, and rich derivative chemistry related to its propensity to react with nucleophiles and to undergo redox reactions.

Nucleophilic attack of $\left[\mathrm{B}_{20} \mathrm{H}_{18}\right]^{2-}$ by the amide anion. $\left[\mathrm{NH}_{2}\right]^{-}$, produces an apical-equatorial (ae) species, $\left[a e-\mathrm{B}_{20} \mathrm{H}_{17} \mathrm{NH}_{3}\right]^{3-}$, which has demonstrated one of the most promising murine biodistributions thus far observed. These strikingly favorable biodistribution results have been attributed to a facile intracellular oxidation of $\left[\text { ae }-\mathrm{B}_{20} \mathrm{H}_{17} \mathrm{NH}_{3}\right]^{3-}$ to the reactive $\left[\mathrm{B}_{20} \mathrm{H}_{17} \mathrm{NH}_{3}\right]^{-}$. The oxidized product is, in turn. capable of reaction with nucleophilic intracellular moieties, thus providing a means of retaining the compound within the tumor cell. A thorough investigation of 
the structural characteristics, stability, and an increased scale of preparation of the reduced species was initiated in 1993.

A single crystal of $\left[\mathrm{Me}_{4} \mathrm{~N}\right]_{3}\left[\right.$ ae $\left.-\mathrm{B}_{20} \mathrm{H}_{17} \mathrm{NH}_{3}\right]$ was grown from an aqueous solution by slow evaporation of the solvent. The crystal was characterized by $x$-ray crystallography, and the structure of the anion is shown in Figure 3. Although disorder in the crystal structure prevented a completely satisfactory refinement, the gross connectivity of the compound was clearly determined. The only unusual characteristic in the $\left[\text { ae }-\mathrm{B}_{20} \mathrm{H}_{17} \mathrm{NH}_{3}\right]^{3-}$ anion was the nonlinearity of the angle formed by the $\mathrm{B}(10)-\mathrm{B}(1)-\mathrm{B}\left(2^{\prime}\right)$ array $\left(169.1^{\circ}\right)$. Initially, it was believed that this nonlinearity may be related to the extreme ease of oxidation of the $\left[a e-\mathrm{B}_{20} \mathrm{H}_{17} \mathrm{NH}_{3}\right]^{3-}$ species in comparison to similar 20-boron atom compounds. However, a recent $x$-ray crystal structure of the structurally analogous $\mathbb{K}_{4}\left[a e-\mathrm{B}_{20} \mathrm{H}_{17} \mathrm{OH}\right]$, the only other 20-boron, apical-equatorial linked species that has been structurally investigated, also demonstrates a nonlinearity of the angle formed by the $\mathrm{B}(10)-\mathrm{B}(1)-\mathrm{B}\left(2^{\circ}\right)$ array. ${ }^{3}$ However, this species does not exhibit superior performance in biodistribution studies nor is it at all exceptional in its redox properties.
Conversion of the $\left[a e-\mathrm{B}_{20} \mathrm{H}_{17} \mathrm{NH}_{3}\right]^{3-}$ isomer to the thermodynamically more stable apical-apical $\left(a^{2)}\right.$ isomer, $\left[a^{2}-\mathrm{B}_{20} \mathrm{H}_{17} \mathrm{NH}_{3}\right]^{3-}$, occurs to some small extent during liposome formation and also over prolonged storage in aqueous solution at room temperature. Therefore, the isolation and biological characterization of the $\left[a^{2}-\mathrm{B}_{20} \mathrm{H}_{17} \mathrm{NH}_{3}\right]^{3-}$ species were critical. The nonaqueous protonation of [ae- $\left.\mathrm{B}_{20} \mathrm{H}_{17} \mathrm{NH}_{3}\right]^{3-}$ in $\mathrm{CH}_{3} \mathrm{CN}$ and subsequent neutralization with aqueous $\mathrm{NaOH}$ yields the desired $a^{2}$ isomer of $\left[\mathrm{B}_{20} \mathrm{H}_{17} \mathrm{NH}_{3}\right]^{3-}$. The structure of this species has been unambiguously confirmed by ${ }^{11 \mathrm{~B}}$ nuclear magnetic resonance (NMR). The rearrangement is believed to proceed through a protonated species, $\left[\mathrm{B}_{20} \mathrm{H}_{18} \mathrm{NH}_{3}\right]^{2-}$, analogous to the reported $\left[\mathrm{B}_{20} \mathrm{H}_{19}\right]^{3 .}$ of, as yet, unknown structure.

The synthesis of the $\left[a e-\mathrm{B}_{20} \mathrm{H}_{17} \mathrm{NH}_{3}\right]^{3-}$ species has been increased in scale and the compound has been cleanly prepared in the laboratory in a quantity sufficient for the production of liposomes on a scale suitable for human therapy. However, the synthetic procedure employed utilizes liquid ammonia and may not be suitable for routine preparations carried out on a large scale. To alleviate this preparative difficulty, derivatives of $\left[a e-\mathrm{B}_{20} \mathrm{H}_{17} \mathrm{NH}_{3}\right]^{3-}$ are being prepared that do not require use of liquid ammonia, such as the propylammonio derivative. $\left[a e-\mathrm{B}_{20} \mathrm{H}_{17} \mathrm{NH}_{2} \mathrm{CH}_{2} \mathrm{CH}_{2} \mathrm{CH}_{3}\right]^{3}$. The propyl amine

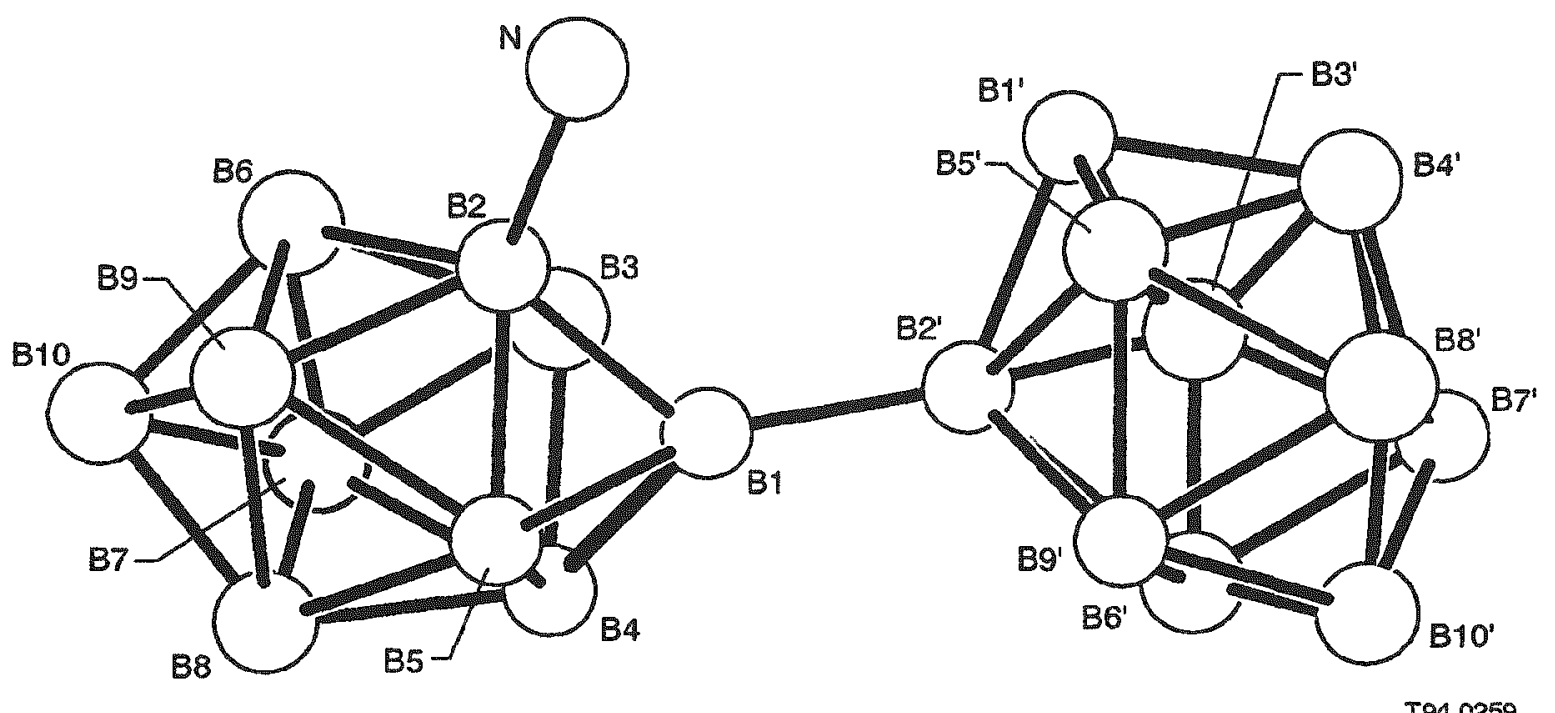

Figure 3. X-ray crystal structure of $\left[\mathrm{ae}-\mathrm{B}_{20} \mathrm{H}_{17} \mathrm{NH}_{3}\right]^{3-}$. 
compound has been prepared, spectroscopically characterized, encapsulated in unilamellar liposomes, and studied in vivo. The biodistribution boron analyses are pending. The oxidation potential of the propylammonio derivative is similar to that of the ammonio derivative.

A dedicated investigation of the chemistry of the isomers of $\left[\mathrm{B}_{20} \mathrm{H}_{18}\right]^{4-}$ has been initiated. The carbonylation of $\left[a^{2}-\mathrm{B}_{20} \mathrm{H}_{18}\right]^{4-}$ to form a series of 20 -boron atom compounds analogous to $\left[\mathrm{B}_{10} \mathrm{H}_{9} \mathrm{CO}\right]^{-}$was studied briefly, but efforts were thwarted by the existence of isomeric products. Further investigation of this chemistry has resulted in the differentiation of two different isomers of $\left[\mathrm{B}_{20} \mathrm{H}_{17} \mathrm{CO}\right]^{3-}$. The $a^{2}$ isomer has been purified and converted to the isocyanate derivative, $\left[\mathrm{B}_{20} \mathrm{H}_{17} \mathrm{NCO}^{4-}\right.$. Attempts to encapsulate the isocyanate derivative have been unsuccessful to date.

A water-soluble, neutral carborane derivative has been reported recently by Nemoto et al. ${ }^{4}$ This compound, closo-1- $\mathrm{CH}_{2} \mathrm{OCH}\left[\mathrm{CH}_{2} \mathrm{OCH}\right.$ $\left.\left(\mathrm{CH}_{2} \mathrm{OH}\right)_{2}\right]_{2}-1,2-\mathrm{C}_{2} \mathrm{~B}_{10} \mathrm{H}_{11}$, was prepared in our laboratory for encapsulation within liposomes for future biodistribution studies. Such a species has two potential advantages for liposomal delivery to tumors. Since it is uncharged and has no counterions, it may be encapsulated at much higher concentrations of boron without exceeding the osmotic stress limits of the liposome, thus provid- ing an increase in the administered dose. Further, although the in vivo behavior of small neutral carboranes has not been studied extensively, the disguised lipophilicity of the compound suggests that it may exhibit attractive intracellular retention characteristics.

Compounds discussed thus far have been water-soluble compounds encapsulated as hyperosmotic solutions in the aqueous core of the liposomes. Addition of relatively small amounts of boron to the lipid constituents of the liposomal membrane should increase the overall boron concentration delivered by the liposomes dramatically, provided suitable compounds can be obtained. The closo-1,2- $\mathrm{C}_{2} \mathrm{~B}_{10} \mathrm{H}_{12}$ cage is among the most versatile boron building-blocks known. It has a rich derivative chemistry based upon the functionalization of the carbon atoms of the cage structure. Certain of these substituted carborane derivatives are quite lipophilic. Additionally, they can be converted to the corresponding anionic nido structure characterized by a polar anionic head group and increased hydrophilicity (Figure 4). Substitution of the carborane with a long hydrophobic side chain, followed by conversion to the anionic nido derivative. should provide a structure that will embed itself within the lipid constituents of the liposomal membrane without significantly diminishing stability of the resulting liposome bilayer. The hydrophobic side chain of the carborane derivative should be similar in
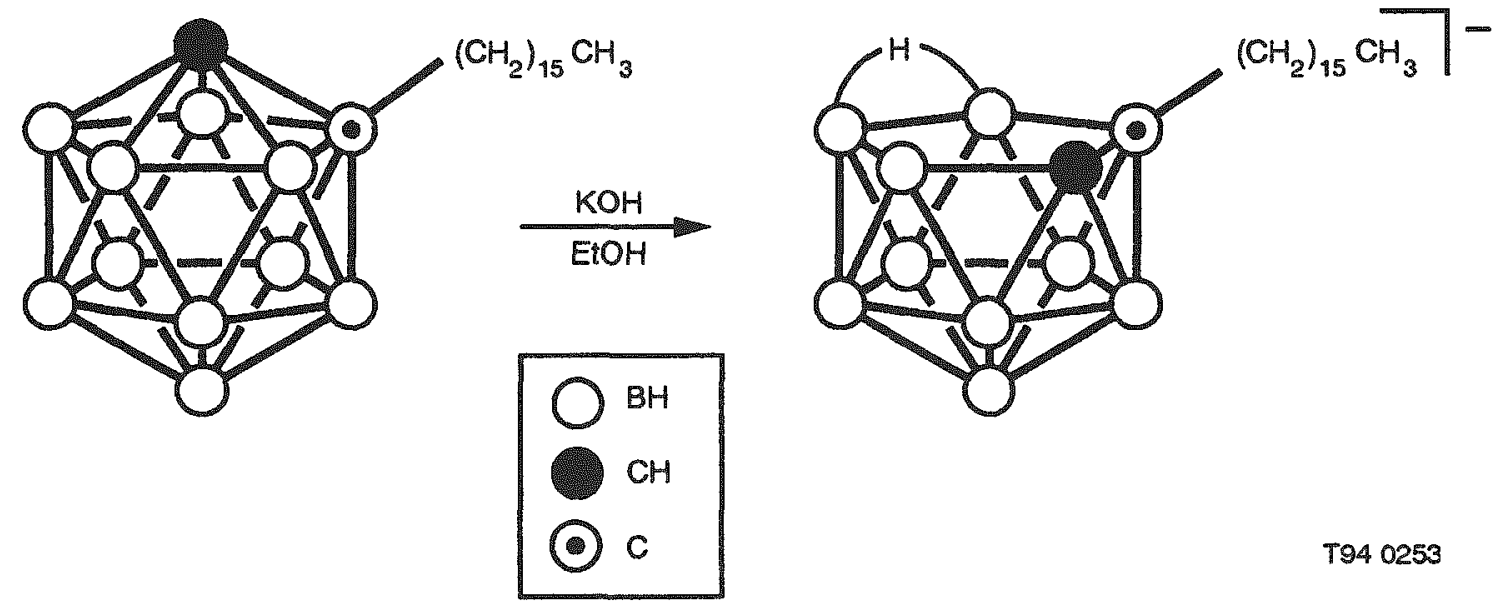

Figure 4. Degradation of $\left.\left.\mathrm{K}\left[\text { nido-7-[( } \mathrm{CH}_{2}\right)_{15} \mathrm{CH}_{3}\right]-7,8-\mathrm{C}_{2} \mathrm{~B}_{9} \mathrm{H}_{11}\right]$. 
length to that of the phospholipid employed in the liposomal membrane.

A suitable compound, $\mathrm{K}$ [nido-7-[( $\left.\left.\mathrm{CH}_{2}\right)_{15} \mathrm{CH}_{3}\right]$ $\left.-7,8-\mathrm{C}_{2} \mathrm{~B}_{9} \mathrm{H}_{11}\right]$. was initially prepared in 1992 , and preparative optimization was successfully achieved in 1993. The compound is derived from a closo-carborane precursor substituted at one carbon vertex by a 16 -carbon alkyl chain. The closo-carborane cage is degraded to form the product characterized by a hydrophilic head group, the anionic nido-carborane moiety. Initial in vivo investigations have proved promising. Ultimately, the goal was to combine an efficacious encapsulated hydrophilic boron species and a suitable embedded hydrophobic boron species within the same liposome. Such a combination alleviates the limited ability of a liposome to encapsulate ever greater concentrations of boron in the aqueous core. This goal has been accomplished in the past year. Two biodistributions have been obtained that utilize liposomes encapsulating water-soluble species in the aqueous core and hydrophobic boron species in the bilayer of the liposome. The first liposome preparation contained encapsulated $\mathrm{Na}_{3}\left[\mathrm{~B}_{20} \mathrm{H}_{19}\right]$ and membraneembedded $\mathrm{K}$ [nido-7-[( $\left.\left.\left.\mathrm{CH}_{2}\right)_{15} \mathrm{CH}_{3}\right]-7,8-\mathrm{C}_{2} \mathrm{~B}_{9} \mathrm{H}_{11}\right]$. The second liposome preparation contained encapsulated $\mathrm{Na}_{3}\left[\right.$ ae $\left.-\mathrm{B}_{20} \mathrm{H}_{17} \mathrm{NH}_{3}\right]$ and membraneembedded $\mathrm{K}$ [nido-7-[( $\left.\left.\left.\mathrm{CH}_{2}\right)_{15} \mathrm{CH}_{3}\right]-7,8-\mathrm{C}_{2} \mathrm{~B}_{9} \mathrm{H}_{11}\right]$. Both of these liposomes yielded tumor boron values well within the therapeutically desired levels in biodistribution studies.

Presumably, the more a boron compound mimics the phospholipid [disterylphosphatidyl choline (DSPC)] utilized in membrane construction, the more stable will be the liposomes formed with this boron species present in the membrane. Therefore, one of the goals of this past year was to prepare a boron species containing two hydrophobic carbon chains. The first species prepared, $\left.\left.\mathrm{K}\left[\text { nido-5,6-[( } \mathrm{CH}_{2}\right)_{17} \mathrm{CH}_{3}\right]_{2}-7,8-\mathrm{C}_{2} \mathrm{~B}_{9} \mathrm{H}_{10}\right]$, is characterized by a hydrophilic head group. the nido-carborane, substituted with two 18-carbon hydrophobic tails anchored to boron vertices. The resulting liposomes were studied in vivo and proved to have very low serum stability as suggested by the very low blood boron values observed at the 6-hour time point.

A double-tailed cobalt bis-dicarbollide species. $\mathrm{Na}\left[\mathrm{Co}\left(\eta^{5}-7-\left[\left(\mathrm{CH}_{2}\right)_{15} \mathrm{CH}_{3}\right]-7,8-\mathrm{C}_{2} \mathrm{~B}_{9} \mathrm{H}_{10}\right)_{2}\right]$, was also synthesized. Attempts to incorporate this lipophilic compound into the bilayer of liposomes containing hypertonic buffer resulted in liposomes too unstable to study in vivo.

Two other species have been proposed (Scheme 1 and Scheme 2, Figures 5 and 6), which possess the desired characteristics. ${ }^{5}$ In Scheme 1 , a synthetic route has been proposed that would produce a species characterized by an anionic nido-carborane head group rather than the phosphate head group in DSPC. The species proposed in Scheme 2 retains the same structural features as DSPC, but two closo-carborane cages are added to the terminis of the lipophilic chains. Syntheses of these species are currently in progress.

\section{Liposome Encapsulation and Biodistribution Results}

Since January 1993, a total of 22 screenings have been performed utilizing seven compounds and four tumor lines. Screenings with EMT6 murine adenocarcinoma were performed at Vestar, Inc., while researchers in the laboratory of Dr. Catherine Elstad at WSU performed screenings with Lewis lung carcinoma. Researchers in the laboratory of Dr. Patrick Gavin at WSU performed screenings in rats bearing intracranial $R G 2$ glioma tumors. Mechanistic studies utilizing liposomes labeled with fluorescent species have been performed using rats bearing intracranial $9 \mathrm{~L}$ tumors in the laboratories of Dr. Robert Straubinger of the SUNY at Buffalo. The Lewis lung tumor line proved to be unsatisfactory in the delineation of suitable boron compounds, because no significant liposomal uptake was observed. All compounds screened since the inception of this project in 1988 have been evaluated in the EMT6 murine adenocarcinoma tumor line, and all biodistributions included in this section, with the exception of the single rat biodistribution experiment, will be from that tumor line grown in $\mathrm{BALB} / \mathrm{c}$ mice. 


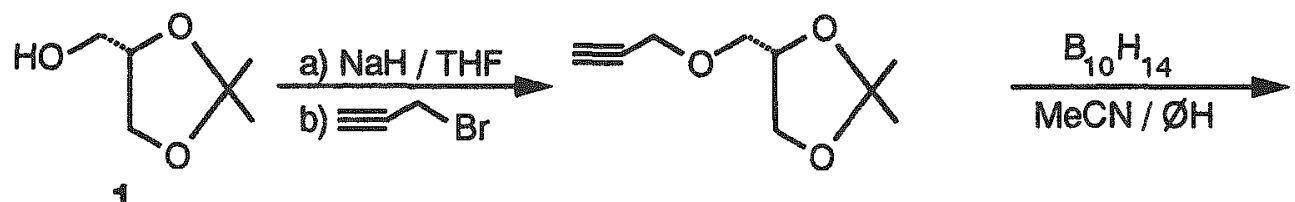

1
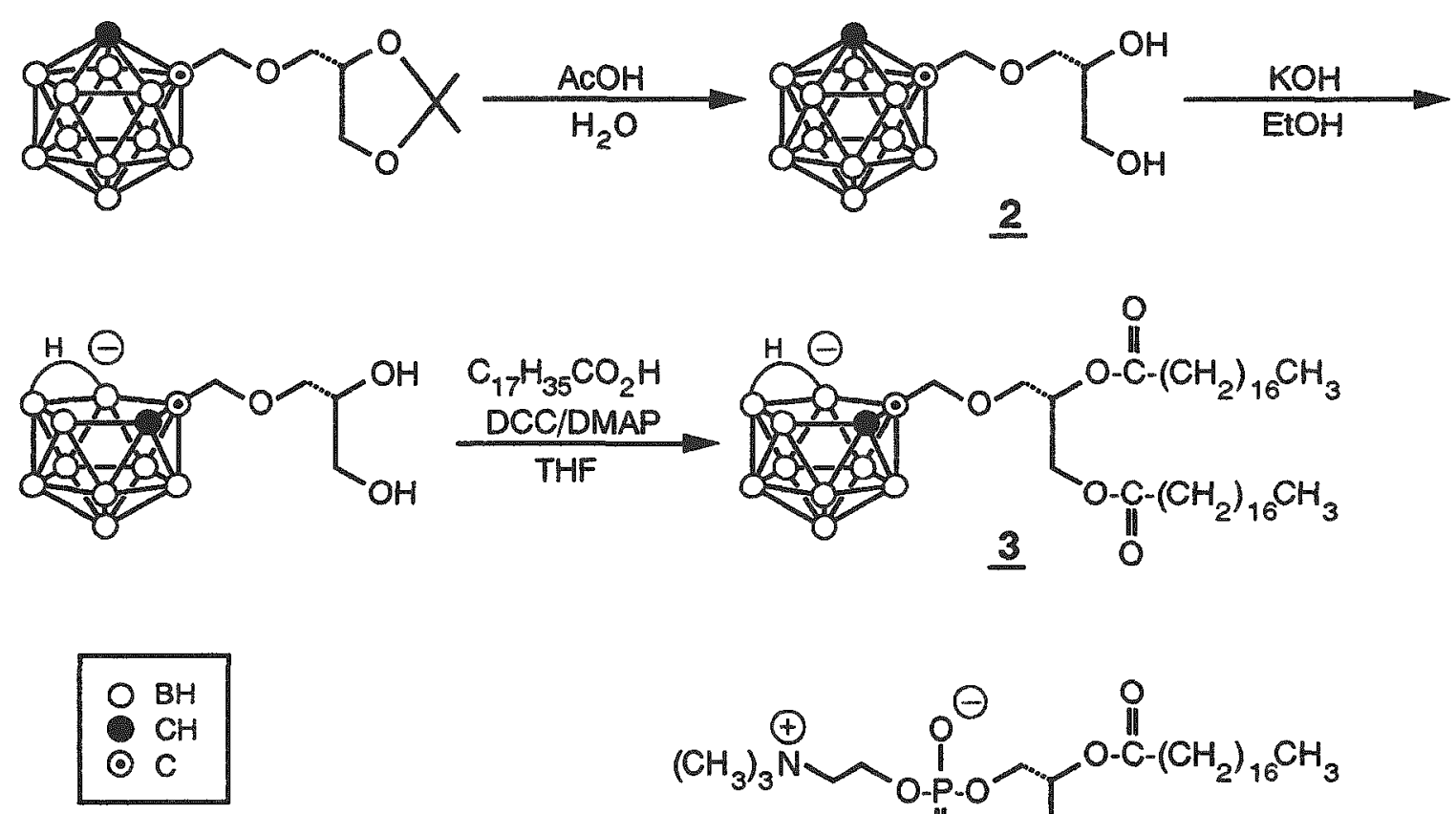

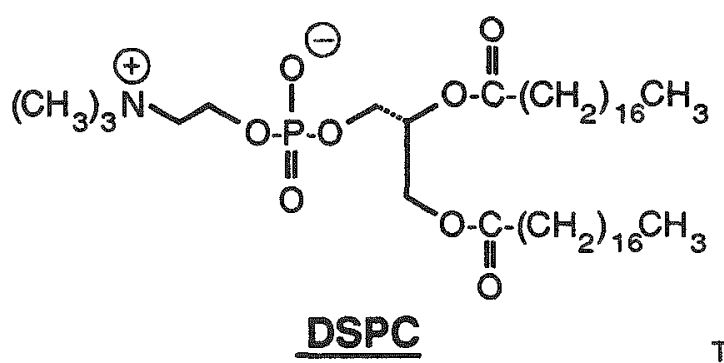

Figure 5. Proposed synthetic route for the production of a species that would possess a nido-carborane head group rather than a phosphate head group.

The biodistribution of unencapsulated $\mathrm{Na}_{3}\left[\mathrm{ae}-\mathrm{B}_{20} \mathrm{H}_{17} \mathrm{NH}_{3}\right]$ (Figure 7a) was obtained to establish the advantage of liposomal delivery. Although the liver, spleen, and blood curves are similar to other unencapsulated borane salts, such as $\mathrm{Na} 2\left[i-\mathrm{B}_{20} \mathrm{H}_{18}\right]$, the tumor values clearly indicate some degree of selective tumor binding. The initial tumor boron concentration of $7.7 \mu \mathrm{g} \mathrm{B} / \mathrm{g}$ tumor is maintained over a period of approximately 30 hours before decreasing to $4.4 \mu \mathrm{g} \mathrm{B} / \mathrm{g}$ tumor. A tumor-to-blood boron ratio of 9.4 was obtained at 16 hours. In comparison, the $\left[i-\mathrm{B}_{20} \mathrm{H}_{18}\right]^{2-}$ species, which also displays promising biodistribution results when encapsulated in liposomes, does not achieve tumor boron concentrations of greater than
$2.0 \mu \mathrm{g} \mathrm{B} / \mathrm{g}$ tumor when not encapsulated in liposomes and demonstrates a tumor-to-blood ratio of only 1.0 at 24 hours. Plans to administer unencapsulated $\mathrm{Na}_{3}\left[\right.$ ae $\left.-\mathrm{B}_{20} \mathrm{H}_{17} \mathrm{NH}_{3}\right]$ by slow injection into rats are in progress. This experiment should delineate whether the liposomes are acting as delivery or slow release systems.

Biodistribution of the thermodynamically stable $\mathrm{Na} \mathrm{a}_{3}\left[a^{2}-\mathrm{B}_{20} \mathrm{H}_{17} \mathrm{NH}_{3}\right]$ was a critical result, since small amounts of the $a^{2}$ isomer have been present in some of the previous ae-isomer liposomal preparations. When the injected dose is taken into account, the basic features of the biodistribution (Figure $7 \mathrm{~b}$ ) of the encapsulated $a^{2}$ isomer of 

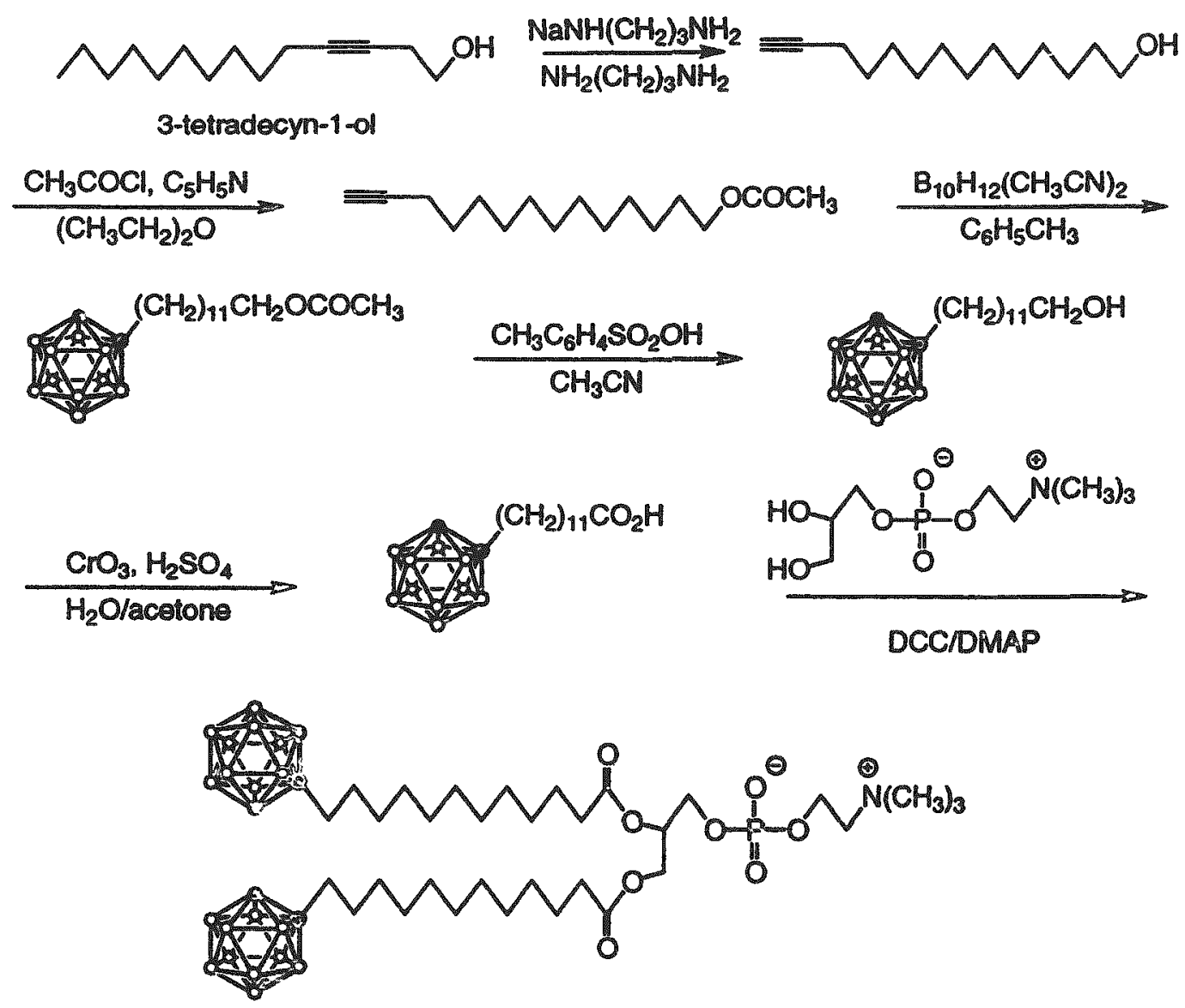

Figure 6. Proposed synthetic route for the production of a species that would possess closo-carboranes at the termini of the lipophilic chains.

$\left[\mathrm{B}_{20} \mathrm{H}_{17} \mathrm{NH}_{3}\right]^{3-}$ are not significantly different from that of the corresponding ae isomer. The tumor boron concentrations observed in the $a^{2}$ isomer biodistribution experiment do not decrease significantly after reaching a plateau at 16 hours. Therapeutic values of boron are maintained in the tumor while the boron concentrations of other tissues decrease with time.

The circulation lifetime of liposomes can be increased by appending polyethylene glycol (PEG) moieties to the bilayer. The PEG groups coat the surface of the liposome, preventing opsonins from adhering to the liposome and thus labeling the liposome as a foreign particle. This disguise mechanism inhibits the clearance of circulating PEG-labeled liposomes by fixed macrophages of the liver and spleen. Introduction of the PEGdisterylphophatidyl ethanolamine (DSPE) coating to the liposomes $\left[\text { ae- } \mathrm{B}_{20} \mathrm{H}_{17} \mathrm{NH}_{3}\right]^{3 *}$ increased their circulation lifetime (Figure 7c), as shown by the relatively high blood boron concentration retained at 48 hours $(19.3 \mu \mathrm{g} \mathrm{B} / \mathrm{g}$ blood). The increased in vivo lifetime of these liposomes enables the tumor to accrete boron throughout the entire 48 -hour experiment, resulting in a final tumor boron concentration of $46.7 \mu \mathrm{g} \mathrm{B} / \mathrm{g}$ tumor. The relatively high 48-hour blood boron concentration reduces the tumor-to-blood boron ratio to a value of 2.4. However, extending the duration of the biodistribution experiment may raise the tumorto-blood boron ratio while maintaining a therapeutic tumor boron level.

One goal of preparing both hydrophilic and lipophilic boron compounds is the simultaneous dual incorporation of these species into liposomes. The hydrophilic boron compounds are encapsulated into the aqueous core of the 

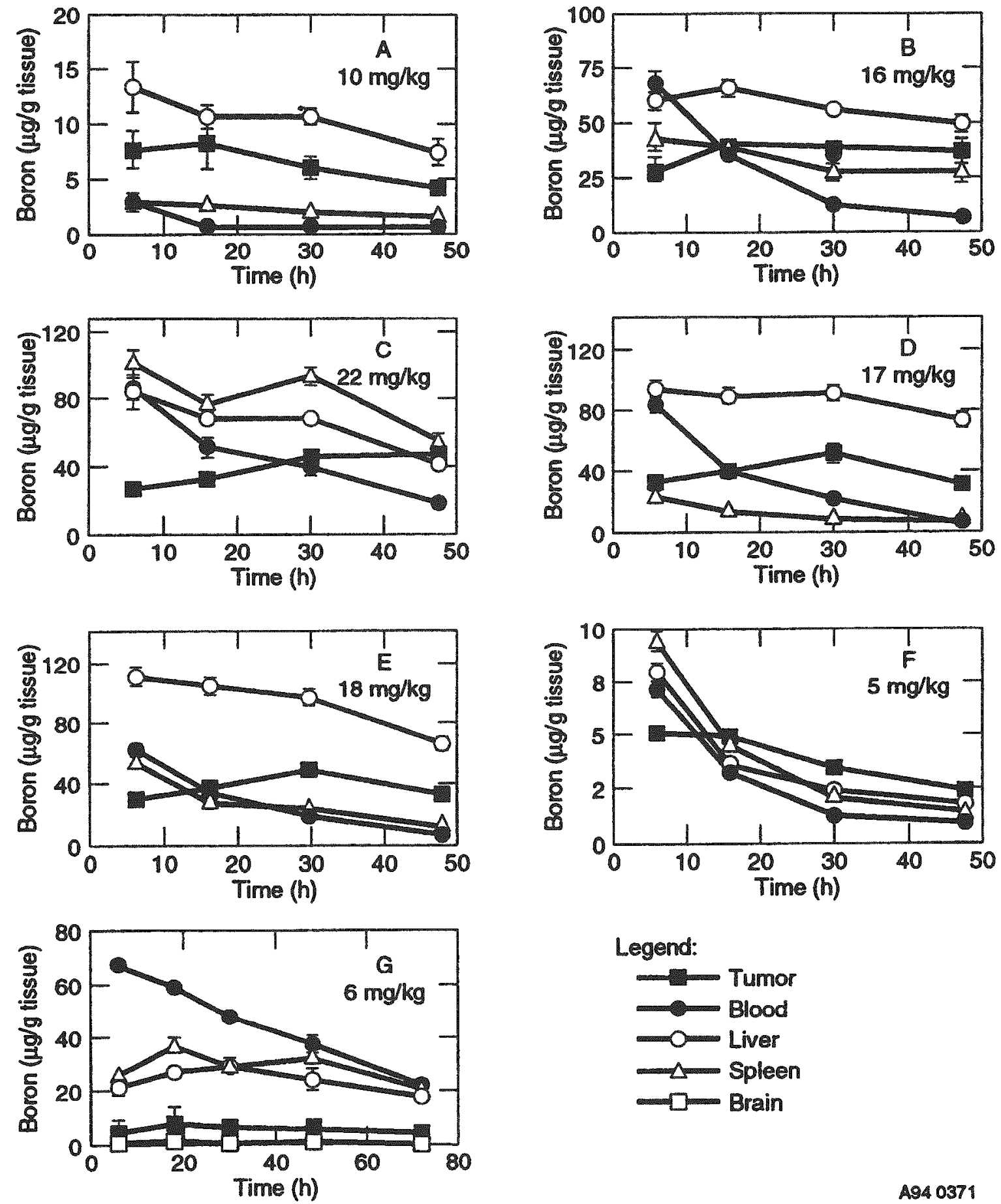

Legend:

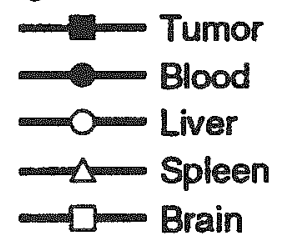

Figure 7. Time course biodistribution of boron in BALB/C mice. Injected doses expressed as milligrams boron per $\mathrm{kg}$ body weight. 
liposomes while the lipophilic boron compounds are embedded into the bilayer of the liposomal membrane. The dual incorporation enables a larger injected dose of boron to be administered. Two experiments were performed during 1993 that incorporated both hydrophilic and lipophilic boron compounds into the same liposomes.

Liposomes encapsulating $\mathrm{Na}_{3} \mathrm{~B}_{20} \mathrm{H}_{19}$ and embedding $\mathrm{K}$ [nido-7-[( $\left.\left.\left.\mathrm{CH}_{2}\right)_{15} \mathrm{CH}_{3}\right]-7,8-\mathrm{C}_{2} \mathrm{~B}_{9} \mathrm{H}_{11}\right]$ in the bilayer were prepared by sonicating a lipid mixture containing 15 mole \% $\mathrm{K}[$ nido-7[( $\left.\left.\left.\mathrm{CH}_{2}\right)_{15} \mathrm{CH}_{3}\right]-7,8-\mathrm{C}_{2} \mathrm{~B}_{9} \mathrm{H}_{11}\right]$. The biodistribution of the liposome suspension is shown in Figure 7d. The initial tumor boron concentration $(32 \mu \mathrm{g} \mathrm{B} / \mathrm{g}$ tumor) increases to a maximum of $50.6 \mu \mathrm{g} \mathrm{B} / \mathrm{g}$ tumor at 30 hours. After 30 hours, the tumor boron concentration decreases, resulting in a final tumor boron concentration of $31.0 \mu \mathrm{g} \mathrm{B} / \mathrm{g}$ tumor and a tumor-to-blood boron ratio of 5.7. Although the liver boron concentrations maintain an average of $86.2 \mu \mathrm{g} \mathrm{B} / \mathrm{g}$ liver over the 48 -hour experiment, the spleen boron concentration is $23.9 \mu \mathrm{g} \mathrm{B} / \mathrm{g}$ spleen at 6 hours and drops rapidly, resulting in a 48 -hour spleen boron concentration of $6.6 \mu \mathrm{g} \mathrm{B} / \mathrm{g}$ spleen. The embedment of $\mathrm{K}$ [nido-7-[( $\left.\left.\mathrm{CH}_{2}\right)_{15} \mathrm{CH}_{3}\right]$ $\left.-7,8-\mathrm{C}_{2} \mathrm{~B}_{9} \mathrm{H}_{11}\right]$ in the bilayer significantly enhanced the in vivo characteristics of the liposomes encapsulating $\left[\mathrm{B}_{20} \mathrm{H}_{19}\right]^{3-}$.

Liposomes encapsulating $\mathrm{Na} 3\left[\right.$ ae $\left.-\mathrm{B}_{20} \mathrm{H}_{17} \mathrm{NH}_{3}\right]$ and embedding $\mathrm{K}$ [nido-7-[( $\left.\left.\mathrm{CH}_{2}\right)_{15} \mathrm{CH}_{3}\right]$ $\left.-7,8-\mathrm{C}_{2} \mathrm{~B}_{9} \mathrm{H}_{11}\right]$ were prepared by sonicating a lipid mixture containing 23 mole $\% \mathrm{~K}$ [nido-7, 8- $\left.\mathrm{C}_{2} \mathrm{Bg}_{9} \mathrm{H}_{11}\left(\mathrm{CH}_{2}\right)_{15} \mathrm{CH}_{3}\right]$. The biodistribution of the liposome suspension is shown in Figure 7e. The 6-hour tumor boron concentration $(26.8 \mu \mathrm{g} \mathrm{B} / \mathrm{g}$ tumor) increases to a value of $47.6 \mu \mathrm{g} \mathrm{B} / \mathrm{g}$ tumor at 30 hours. The final tumor boron concentration is $31.6 \mu \mathrm{g} \mathrm{B} / \mathrm{g}$ tumor, yielding a tumor-to-blood boron ratio of 6 . Although the spleen boron concentrations decrease rapidly, the liver maintains a relatively high boron concentration throughout the time course experiment. Addition of $\mathrm{K}$ [nido-7-[( $\left.\left.\left.\mathrm{CH}_{2}\right)_{15} \mathrm{CH}_{3}\right]-7,8-\mathrm{C}_{2} \mathrm{~B}_{9} \mathrm{H}_{11}\right]$ to the bilayer does not enhance the biodistribution characteristics of the liposomes containing encapsulated $\mathrm{Na}_{3}\left[\right.$ ae $\left.-\mathrm{B}_{20} \mathrm{H}_{17} \mathrm{NH}_{3}\right]$ to a significant extent. However, the ultimate goal of increasing the injected dose of boron has been achieved.

The biodistribution of free $\mathrm{K}$ [nido-7$\left.\left[\left(\mathrm{CH}_{2}\right)_{15} \mathrm{CH}_{3}\right]-7,8-\mathrm{C}_{2} \mathrm{~B}_{9} \mathrm{H}_{11}\right]$ is shown in Figure $7 \mathrm{f}$. No significant accumulation of boron was observed in any of the tissues studied.

The first complete biodistribution has been completed on rats bearing an intracranial RG2 glioma tumor. The biodistribution of encapsulated $\mathrm{Na}_{3}\left[\right.$ ae $\left.-\mathrm{B}_{20} \mathrm{H}_{17} \mathrm{NH}_{3}\right]$ is shown in Figure $7 \mathrm{~g}$. The 6 -hour tumor boron concentration $(4.9 \mu \mathrm{g} \mathrm{B} / \mathrm{g}$ tumor) increased to a maximum of $8.4 \mu \mathrm{g} \mathrm{B} / \mathrm{g}$ tumor at 20 hours. After 20 hours, the concentration decreased. resulting in a 72-hour tumor boron concentration of $4.8 \mu \mathrm{g} \mathrm{B} / \mathrm{g}$ tumor, and a 72-hour tumor-to-blood boron ratio is 0.2 . Essentially no boron accumulated in the normal brain, and the tumor-to-normal brain boron ratio exceeded 8. Unlike any other biodistribution obtained to date, the blood boron values were exceedingly high at the end of the biodistribution experiment $(22.0 \mu \mathrm{g} \mathrm{B} / \mathrm{g}$ blood), indicating an extremely stable liposome formulation. At this time, it is unknown whether the stability of the liposomes is due to a difference in the physiology of a rat as compared to a mouse or whether the stability is due to the large-scale method of preparation. The remaining liposomes from these experiments have been retrieved and studied in vivo using the EMT6 tumor line in BALB/c mice. Boron analyses are pending.

Although liposomes of the size and composition utilized in these experiments have been shown to deliver their contents to the interior of tumor cells, only recently has this observation been confirmed for the hyperosmotic, boron-containing liposomes. Liposomes were prepared that encapsulated $\mathrm{Na}_{3}\left[a^{2}-\mathrm{B}_{20} \mathrm{H}_{17} \mathrm{NH}_{3}\right]$ and that were doubly-labeled with fluorescent markers [rhodamine-dihexadecyl phosphatidylethanolamine (DHPE) and fluorescein dextran]. The rhodamine-DHPE, which exhibits a red fluorescence, was embedded in the bilayer of the liposome, and the fluorescein dextran, which exhibits a green fluorescence, was coencapsulated with the boron-containing species in the aqueous core of the liposome. In vitro experiments clearly indicated the presence of 
liposomes evenly distributed in the cytoplasm of the tumor cells. The corresponding in vivo experiment has been completed and results are pending.

In another experiment, hypertonic buffer was coencapsulated with fluorescein dextran and the two lipophilic species, $\mathrm{K}$ [nido-7-[( $\left.\left.\mathrm{CH}_{2}\right)_{15} \mathrm{CH}_{3}\right]$ $\left.-7,8-\mathrm{C}_{2} \mathrm{~B}_{9} \mathrm{H}_{11}\right]$ and rhodamine-DHPE, were embedded in the bilayer of the liposomes. In vitro experiments clearly indicated the presence of liposomes in the cytoplasm of the tumor cells. The corresponding in vivo experiments have been completed and results are pending.

Liposomes containing both boron-containing species, $\mathrm{Na}_{3}\left[a^{2}-\mathrm{B}_{20} \mathrm{H}_{17} \mathrm{NH}_{3}\right]$ and $\mathrm{K}\left[\right.$ nido-7-[( $\left(\mathrm{CH}_{2}\right)$ $\left.{ }_{15} \mathrm{CH}_{3}\right]-7,8-\mathrm{C}_{2} \mathrm{~B}_{9} \mathrm{H}_{11}$ ], as well as both fluorescent markers, rhodamine-DHPE and fluorescein dextran, have been prepared and in vitro and in vivo experiments utilizing this liposome preparation are in progress.

\section{Conclusion}

Although biodistributions of all the compounds examined in the past year have not been included, compounds producing exciting results, both as potential therapeutic agents and as mechanistic information, have been presented. Syntheses of our most promising water-soluble compound, $\mathrm{Na}_{3}\left[a e-\mathrm{B}_{20} \mathrm{H}_{17} \mathrm{NH}_{3}\right]$, and our most promising lipophilic compound, $\mathrm{K}$ [nido-7-[( $\left.\left.\mathrm{CH}_{2}\right)_{15} \mathrm{CH}_{3}\right]$ $\left.-7.8-\mathrm{C}_{2} \mathrm{~B}_{9} \mathrm{H}_{11}\right]$, have been increased in both scale and yield. Additionally, the thermodynamically stable isomer, $\mathrm{Na}_{3}\left[a^{2}-\mathrm{B}_{20} \mathrm{H}_{17} \mathrm{NH}_{3}\right]$, has been isolated and studied in vivo. Biodistribution data have been obtained that substantiate the desired ability to increase the injected boron dose by preparing stable liposomes containing both hydrophilic and lipophilic boron compounds. Successful scale-up of the $\mathrm{Na}$ [ae- $\left.\mathrm{B}_{20} \mathrm{H}_{17} \mathrm{NH}_{3}\right]$ liposome preparation, sufficient for the first rat biodistribution study, has been achieved. The first tangible evidence of intracellular uptake of hypertonic, boron-containing liposomes for application in the BNCT of cancer has been obtained. 


\section{PITUITARY TUMOR EVALUATION}

Dr. Barry Albertson, PI, Oregon Health Sciences University (OHSU), Division of Endocrinology, Diabetes, and Clinical Nutrition, Department of Medicine; Dr. Steve Binney, PI, Oregon State University (OSU), Department of Nuclear Engineering

\section{Background}

Pituitary tumors make up about $15 \%$ of all brain tumors. ${ }^{8}$ The clinical presentation of these tumors is diverse. The morbidity and mortality can be high, especially for somatotroph tumors producing excess growth hormone and acromegaly. Current treatment modalities include conventional $x$-irradiation and/or neurosurgery. Neither approach is uniformly successful and both are relatively nonspecific. ${ }^{9}$ While conventional radiation is used to treat a wide variety of intracranial tumors, including (in the past) pituitary tumors, global radiation effects are not uncommon, manifested in often poorly categorized but clinically documented and recognized changes in the patient's affect or overall personality. Neurosurgery has become the treatment of choice for both adrencorticotropic hormone (ACTH) and growth hormone (GH) secreting pituitary tumors. Success rates are often in the $80-90 \%$ range for ACTH secreting tumors, based on good surgical skills and tumor localization studies. However, patients with GH secreting tumors of the pituitary frequently must be subjected to more than one neurosurgical procedure, ultimately with the complete removal of the pituitary gland and the prospect of multiple hormone replacement for the remainder of their lives.

Several experimental radiation approaches are currently being investigated, e.g.. the gamma knife and proton beam irradiation. While these modalities have demonstrable efficacies in some intracranial tumors, successful and effective application depends on the tumor being large enough to localize with conventional imaging techniques CT and MRI or sufficiently small or located away from other radiation-sensitive areas (optic chiasm, etc.) so that nonspecific or scattered radiation effects do not cause structural or functional damage. ${ }^{9}$

A new interventional strategy, BNCT, has shown great promise in treating brain and other cancers ${ }^{10}$ and may have even greater potential in treating tumors of the pituitary gland and other endocrineassociated or mediated-malignancies.

BNCT combines use of a stable ${ }^{10} \mathrm{~B}$ atom and a source of thermal neutrons. The thermal neutrons cause little damage to tissue compared with other conventional forms of radiation. However, the ${ }^{10} \mathrm{~B}(\mathrm{n}, \alpha)^{7} \mathrm{Li}$ reaction produces a ${ }^{7} \mathrm{Li}$ nucleus and an $\alpha$-particle, with a total energy of almost $3 \mathrm{MeV}$. Because these particles have a path length of about $10 \mu \mathrm{m}$ (slightly less than the diameter of an average cell), and because it takes only a few of these events within a cell to potentially destroy it, BNCT represents an excellent method of killing cancer cells without compromising adjacent normal tissues.

Several features of pituitary tumors make them ideal candidates for demonstrating BNCT efficacy for endocrine-mediated tumors: (1) these tumors are localized in the pituitary gland and rarely metastasize; (2) the tumors are usually small, rarely larger than $2 \mathrm{~cm}$ in diameter: (3) the tumors are outside the blood-brain barrier, facilitating vascular access; and (4) these tumor cells contain membrane receptors that bind and internalize specific hypothalamic polypeptide-releasing hormones. Thus, hypothalamic-releasing hormones theoretically become "magic bullets" for targeting neutron capture in pituitary cell adenomas. By exploiting these features of pituitary cells, BNCT could be an effective therapeutic modality to kill specific pituitary tumor cells.

\section{Historical Overview}

Use of BNCT for treating brain tumors dates back approximately 40 years to the work of Dr. William Sweet and his colleagues in Boston. ${ }^{11}$ These investigators chose one of the most malignant and therapeutically refractory tumors, 
glioblastoma multiforme, to begin testing BNCT therapy. Although their results were less than dramatic, they paved the way for other investigators to initiate both basic and clinical studies.

Sulfhydryl-containing boron anions have been synthesized over the past several years and tested in transplantable ependymoblastoma cell lines ${ }^{12}$ and gliomas ${ }^{13}$ in rodent models. These compounds gave improved ratios of boron in the tumor tissue when compared to blood levels. Because of this advance, sodium salts of these sulfhydryl compounds (BSH) have been produced and used in clinical studies. In the early 1970s, Hatanaka and Sano in Japan treated patients with glioblastoma multiformes with $\mathrm{BSH}^{14}$ and other related boron compounds in combination with surgery and conventional radiation. Since these earliest clinical series, more than 200 patients have been treated. of these, several have shown remarkable long-term survival, thus sparking more interest in this form of therapy. ${ }^{15}$

Major obstacles to the clinical application of BNCT in human tumor therapy are targeting ${ }^{10} \mathrm{~B}$ only into the tumor tissue while sparing adjacent normal cells, and getting sufficient numbers of ${ }^{10_{B}}$ atoms on or inside the targeted tumor or cancer cells so that, with an adequate neutron source, the probability of a tumor cell kill approaches unity.

One particular type of endocrine tumor, pituitary adenoma, offers an excellent opportunity to employ BNCT because of the uniqueness and specificity of its membrane-releasing hormone receptors. Specific collections of neurons located in the hypothalamus produce and secrete releasing hormones which, when transported to the pituitary gland by the hypothalamic-pituitary portal system, stimulate the release of a single specific trophic hormone (produced by a specific type of pituitary cell). The pituitary cells that make these trophic homones occasionally become neoplastic. In this state, over-production of the hormone can lead to serious clinical consequences and death. Unique to these neoplastic pituitary cells is the fact that they retain their ability to respond to hypothalamic releasing hormones, often with a heightened sensitivity. Moreover, the releasing hormones are internalized into the pituitary cells within minutes after initial hormone binding as part of the normal mechanism of membrane receptor recycling.

Thus, endocrine cell receptor specificity and intemalization after hormone binding constitute key elements to postulate that BNCT will be a successful method of treating pituitary tumors or other endocrine-mediated tumors.

\section{Results to Date}

$\mathrm{A}{ }^{10} \mathrm{~B}_{10}$ cage has been synthesized and supplied by Professor M. Frederick Hawthorne, Department of Chemistry and Biochemistry, UCLA, Los Angeles, CA. ${ }^{16}$ The cage contains ten ${ }^{10} \mathrm{~B}$ atoms covalently linked to two carbon atoms within the cage structure and two carbon atoms extending outside the cage. The most distal carbon has been modified as an acetate, making it reactive for peptide conjugation. The conjugation of this cage to the nonbiologically active end of ovine corticotropin releasing hormone (oCRH) is carried out after solid phase synthesis of the 41 amino acid oCRH peptide ${ }^{17}$ and attachment of the cage to the amino terminal serine residue of oCRH using a modified carbodiimide procedure (Figure 8). A similar construct has been synthesized with human growth hormone releasing hormone (GHRH) as shown in Figure 9. Here the ${ }^{10} \mathrm{~B}_{10}$ carboranyl cage has been conjugated to the carboxyl terminal amino acid, since the biological activity of GHRH resides in the amino terminal end of the molecule.

The AtT-20 rat pituitary corticotroph tumor cell line. established in 1953 by Furth et al., ${ }^{18}$ responds to $\mathrm{OCRH}$ in a dose-dependent fashion over time with the production of the intracellular second messenger cyclic adenosine monophosphate (cAMP). The ${ }^{10} \mathrm{~B}_{10}$-oCRH conjugate has been shown to retain corticotropin releasing hormone (CRH) biological activity, evaluated by its ability to stimulate the production of intracellular levels of cAMP when compared to equimolar concentrations of pure oCRH in in vitro experiments using AtT-20 cells (Figure 10). 


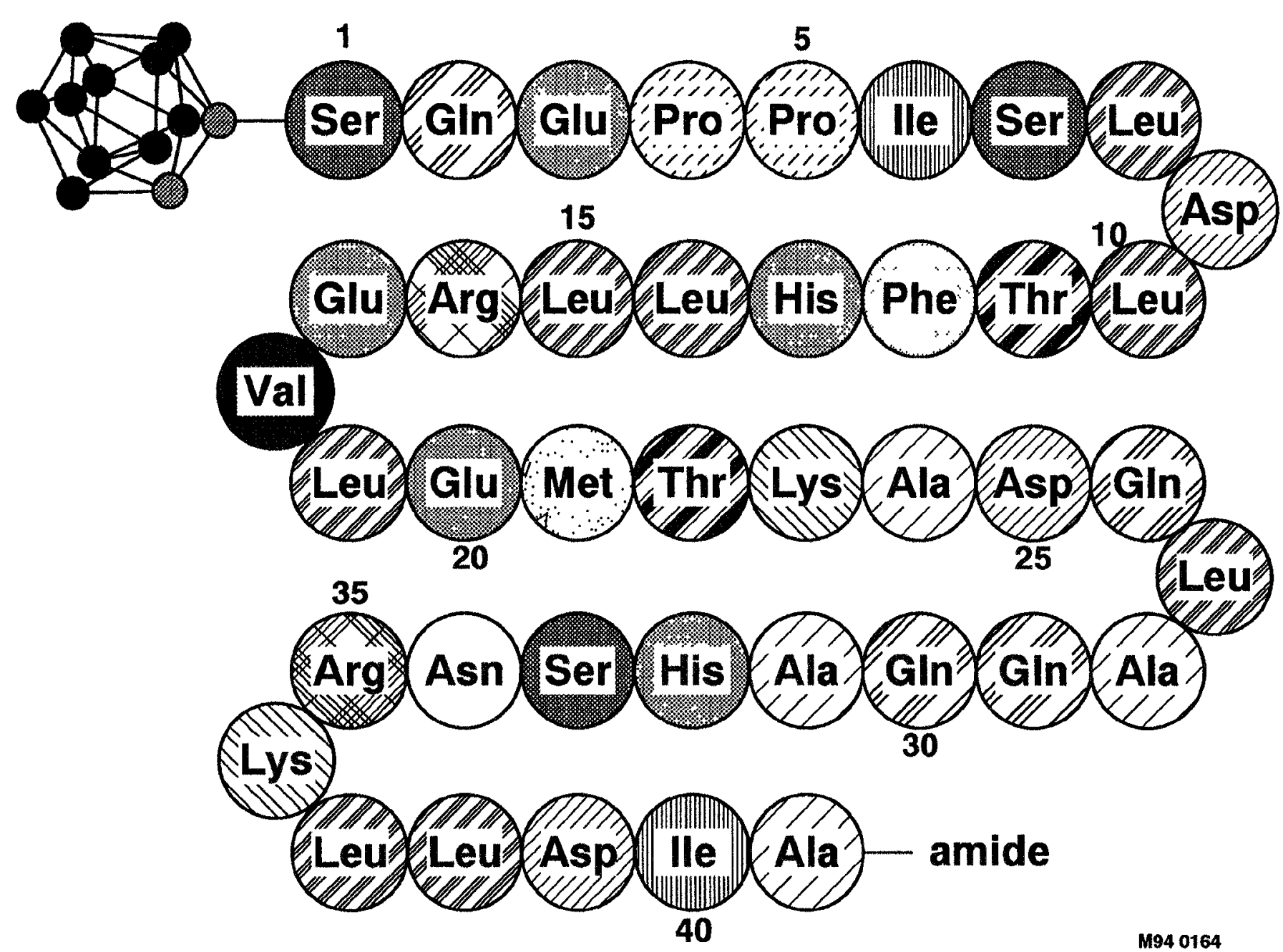

Figure 8. The amino acid sequence of oCRH is shown with the conjugated carboranyl cage $\left({ }^{10} \mathrm{~B}_{10}\right)$ attached. Carboranyl cage ${ }^{10} \mathrm{~B}$ atoms are shown as shaded circles; carbon atoms are shown as black circles. oCRH has been used in preliminary studies at OHSU because of its longer in vitro and in vivo biological half-life when compared to human CRH. (Synthesis and purification of the oCRH-carboranyl conjugate was initially carried out by Dr. Harry Chen, The National Institutes of Health, Bethesda, Maryland; the complex for these studies will be produced by Dr. Craig R. Miles, Macromolecular Resources, Colorado State University, Fort Collins, CO). 

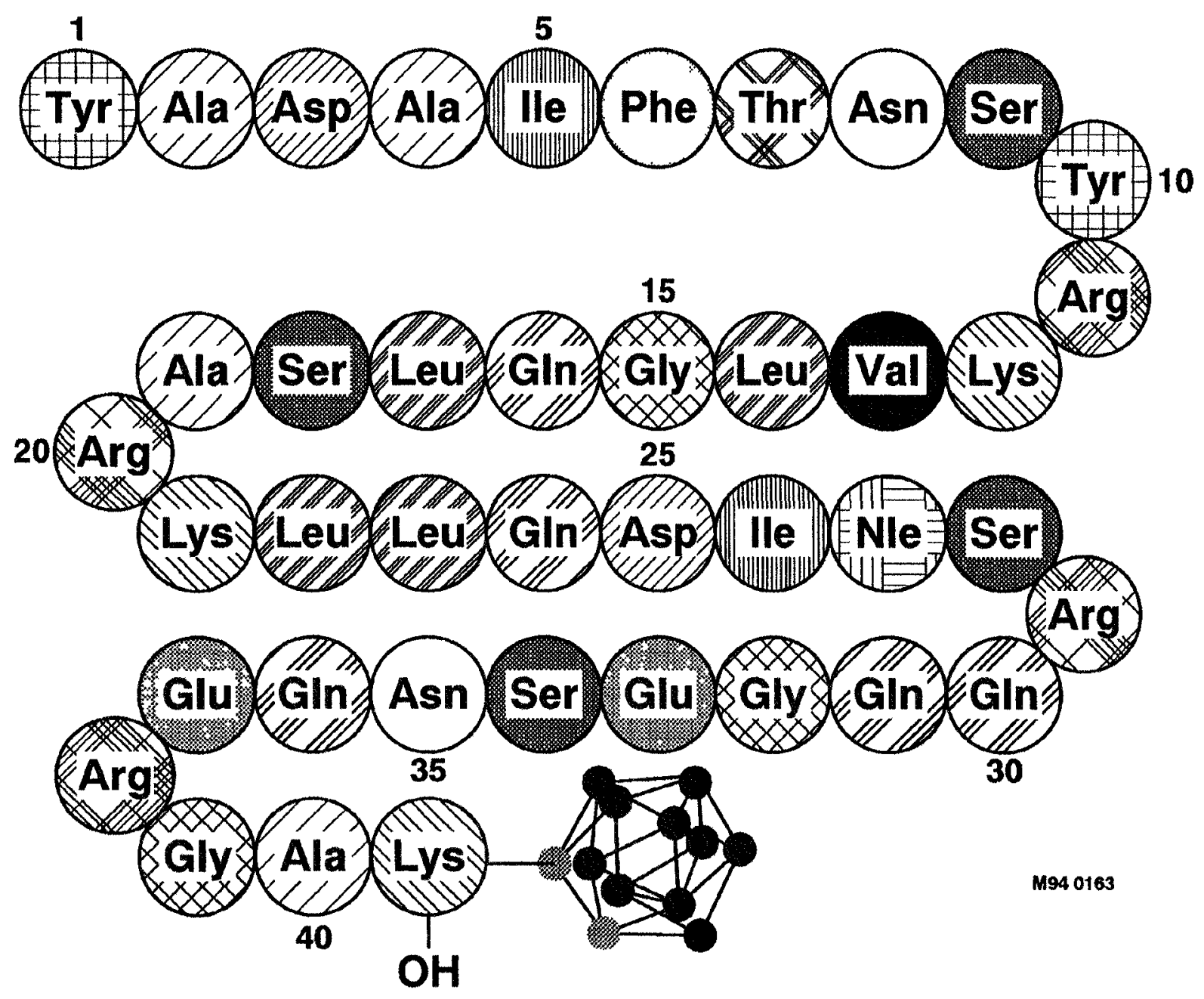

Figure 9. The amino acid sequence of human GHRH is shown with the conjugated carboranyl cage $\left({ }^{10} \mathrm{~B}_{10}\right)$. GHRH is synthesized with a Lys residue at the number 41 position, to which the ${ }^{10} \mathrm{~B}_{10}$ cage is conjugated, thus preserving the biological activity of GHRH which resides at the other end of the molecule. (Synthesis and purification of the ${ }^{10} \mathrm{~B}_{10}$-GHRH conjugate was initially carried out by Dr. Harry Chen, The National Institutes of Health, Bethesda, Maryland; the complex for these studies will be produced by Dr. Craig R. Miles, Macromolecular Resources, Colorado State University, Fort Collins, CO). 


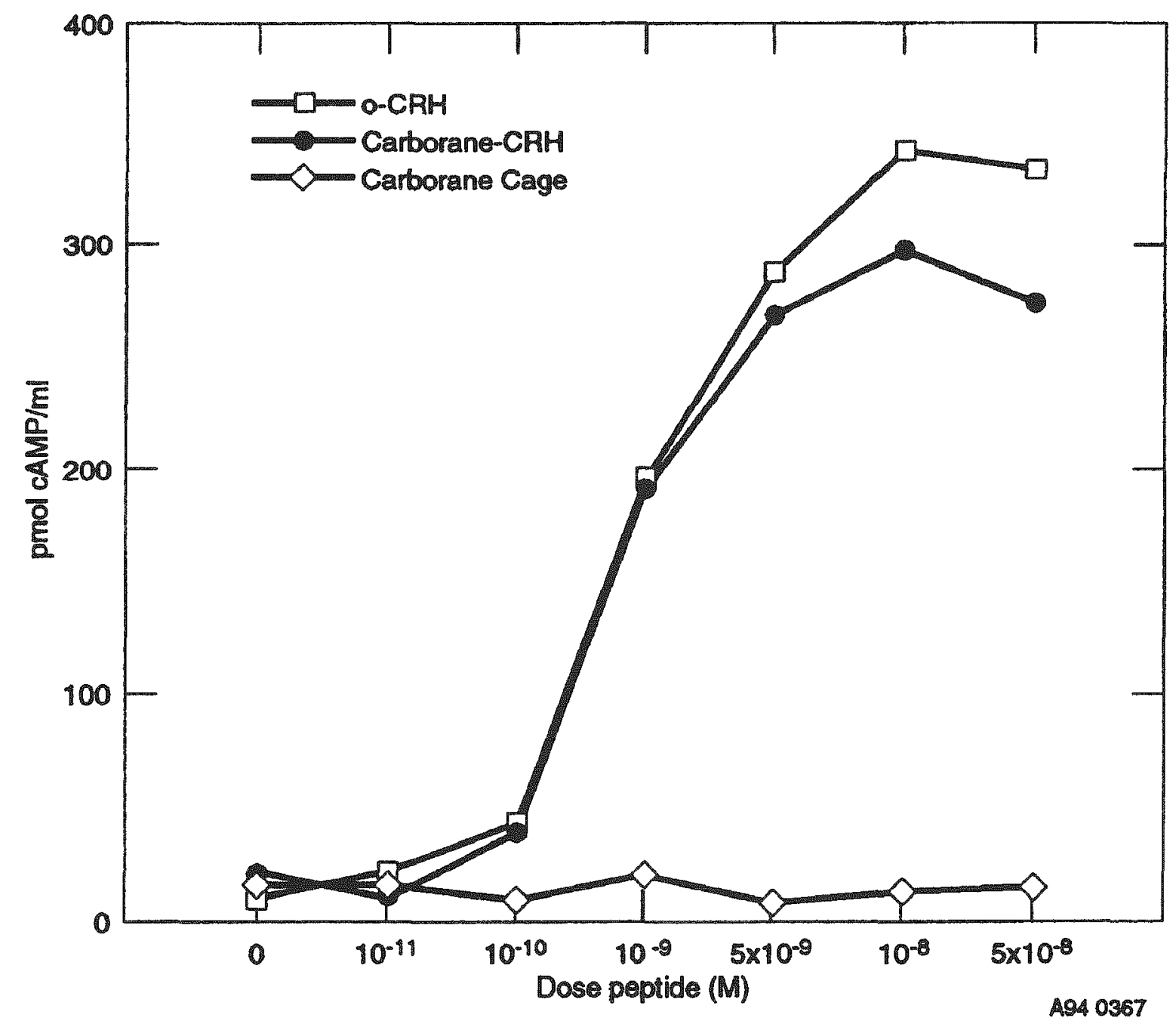

Figure 10. CAMP response of AtT-20 cells to oCRH, carboranyl-oCRH, or carboranyl cage alone at various concentrations. Dose of peptide, carboranyl-oCRH, or cage alone ranges from $10^{-11}$ to $5 \times 10^{-8} \mathrm{M}$. Picomoles of cAMP produced by 500,000 AtT-20 cells cultured in 12 eight-well dishes are shown on the $\mathrm{Y}$ axis.

The $\mathrm{GH}_{4} \mathrm{C}_{1}$ rat pituitary somatotroph tumor cell line. a subclone of the $\mathrm{GH}_{3}$ cell established by Tashjian et al., 19,20 responds to GHRH in a dosedependent fashion over time with the production of cAMP, GH, and prolactin. The ${ }^{10} \mathrm{~B}_{10}-\mathrm{GHRH}$ conjugate has been shown to retain GHRH biological activity, evaluated by its ability to stimulate the production of CAMP and GH when compared to equimolar concentrations of pure human GHRH in in vitro experiments using normal rat pituitary cells (Figures 11 and 12).

\section{Cell Culture Conditions}

AtT-20 cells are grown and maintained in Dulbecco's modified Eagle's medium (D-MEM, Gibco Labs. Grand Island, NY) with antibiotics added [penicillin/streptomycin (pen-strep)] and $10 \%$ fetal bovine serum (FBS, Gibco Labs). $\mathrm{GH}_{4} \mathrm{C}_{1}$ cells are grown in Ham's F-10 medium. Both cell types are washed with sterile Dulbecco's phosphate-buffered saline (PBS, Gibco Labs) and harvested from T-150 culture flasks (Corning Labs, 


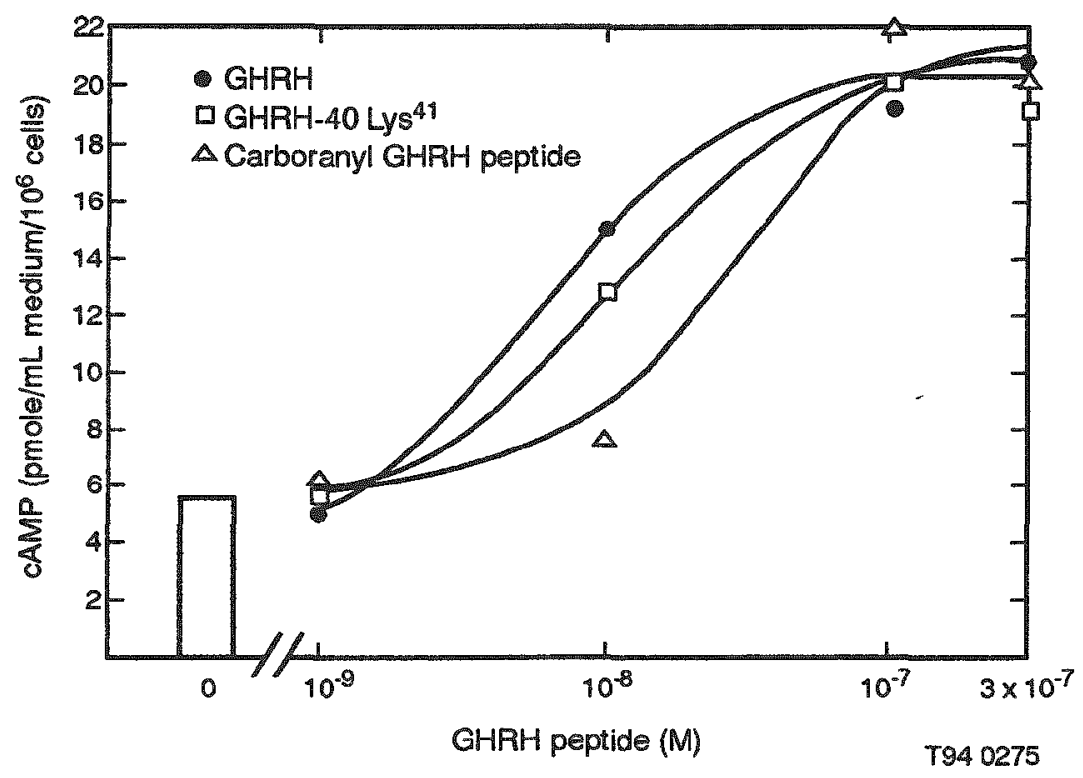

Figure 11. Cyclic AMP response: Cultured rat pituitary cells $\left(10^{6}\right)$ were stimulated with increasing doses $\left(10^{-9}\right.$ to $\left.3 \times 10^{-7} \mathrm{M}\right)$ of GHRH, GHRH-40-Lys ${ }^{41}$, or carboranyl GHRH peptide $\left({ }^{10} \mathrm{~B}_{10}-\mathrm{GHRH}\right)$, and CAMP was assayed by the stat package (RIA) in the culture media. The CAMP response to increasing doses of all three peptides was approximately a three- to four-fold increase over baseline and similar for all three peptides (unpublished data from Chen, Merriam, and Loriaux).

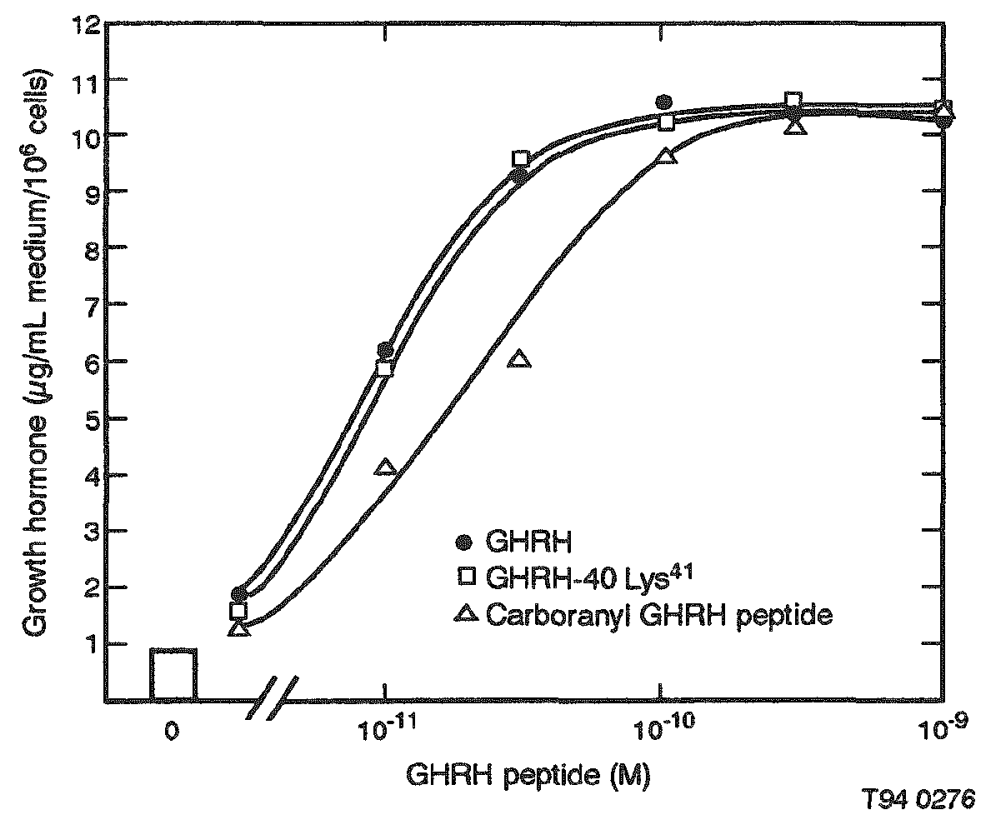

Figure 12. Growth hormone response: The response of rat pituitary cell growth hormone production and release to the three peptides (described in Figure 4a) was similar, reaching maximal values at approximately $10^{-10} \mathrm{M}$ (unpublished data from Chen, Merriam, and Loriaux). 
Corning, NY) using ethylenediaminetetraacetic acid (EDTA) (0.53 mM, i.e., Versene, 1:5000, Gibco Labs).

\section{BNCT Effect on AtT-20 Cells In Vitro}

AtT-20 cells were incubated with oCRH $\left(10^{-6} \mathrm{M}\right)$ or ${ }^{10} \mathrm{~B}_{10^{-}} \mathrm{OCRH}$ conjugate $\left(10^{-6} \mathrm{M}\right)$ for 10 minutes and 5 minutes at $37^{\circ} \mathrm{C}$, washed with sterile phosphate-buffered saline, and irradiated for 3 minutes at $1 \mathrm{MW}$. Incubation times were based on published data suggesting that a very short time interval was needed for binding, activating, and internalizing the CRH-receptor complex. ${ }^{21-23}$ The irradiated cells were appropriately diluted and plated on $100-\mathrm{mm}$ culture dishes. After 14 days, the dishes were washed, fixed with $20 \%$ formaldehyde, stained with Geimsa, and viable colonies counted. Results of this experiment are shown in Figure 13. AtT-20 cell colony numbers were significantly reduced when the cells were incubated with ${ }^{10} \mathrm{~B}_{10}$-OCRH and subjected to neutron irradiation versus incubation with unconjugated $\mathrm{OCRH}$.
To provide evidence that the observed AtT-20 cell killing by BNCT is CRH receptor mediated, cells were incubated for 10 minutes in the presence of $10^{-6} \mathrm{M}$ oCRH, $10^{-6} \mathrm{M}^{10} \mathrm{~B}_{10}$-carboranyl oCRH, or $10^{-6} \mathrm{M}{ }^{10} \mathrm{~B}_{10^{-}} \mathrm{OCRH}$ plus excess oCRH $\left(2 \times 10^{-5} \mathrm{M}\right)$, washed, irradiated for $3 \mathrm{MW}$-min, and cultured for colony counting. The results are shown in Figure 14. AtT-20 cell colonies were significantly lower (i.e., greater cell killing) when cells were incubated with ${ }^{10} \mathrm{~B}_{10}$-oCRH compared with unconjugated oCRH. However, this difference was eliminated (i.e., AtT-20 cell death was significantly reduced) when cells were incubated with ${ }^{10} \mathrm{~B}_{10}-\mathrm{OCRH}$, plus excess oCRH. These results are consistent with BNCT cell destruction being mediated through the AtT-20 cell $\mathrm{CRH}$ receptor. ${ }^{24}$

In summary, these data suggest that:

1. Hypothalamic releasing hormones can be synthesized and conjugated to a ${ }^{10} \mathrm{~B}_{10}$-cage in a manner that preserves the biologic activity of the polypeptide hormone component in specific targeted pituitary cells.

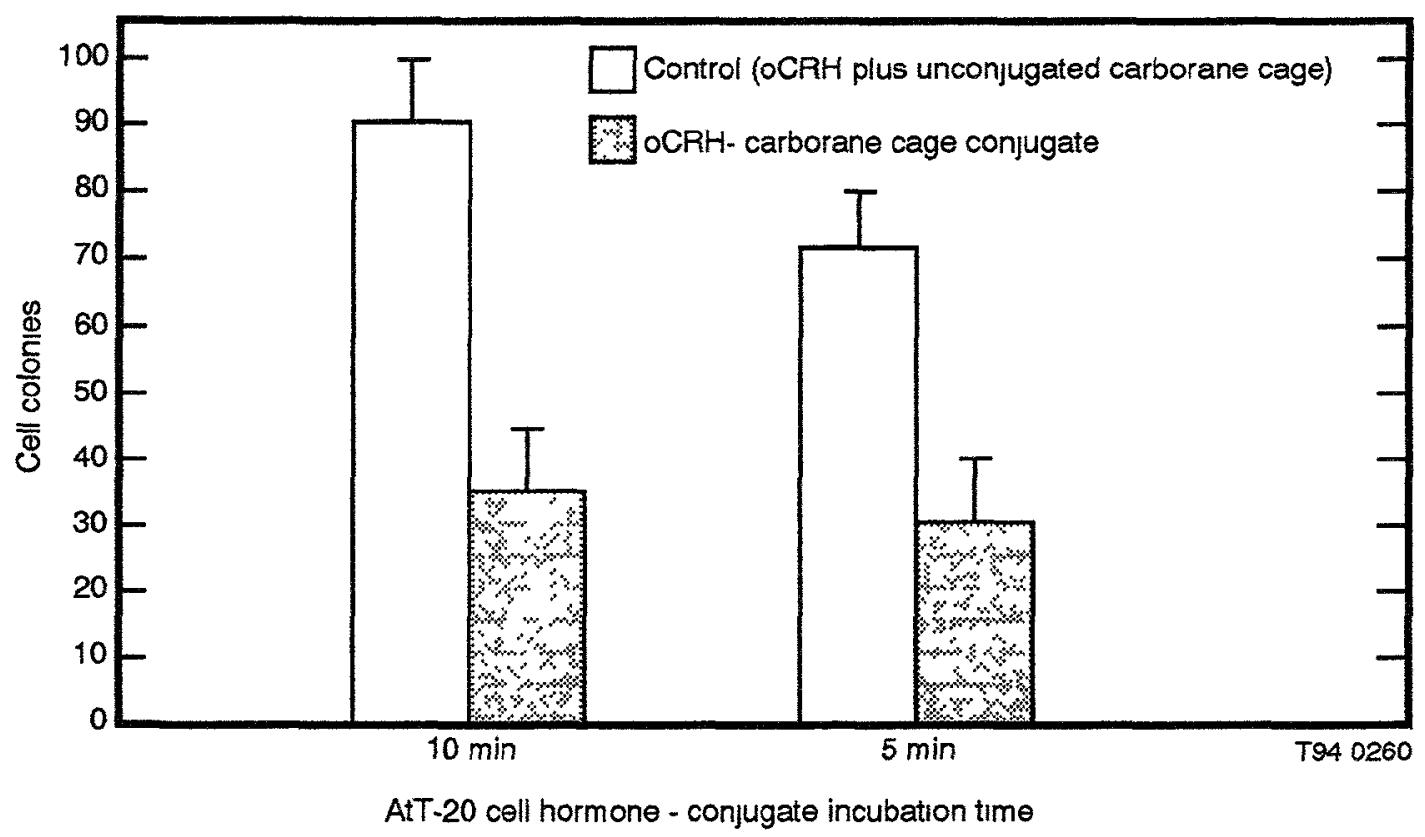

Figure 13. AtT-20 cells incubated for 5 and 10 minutes with ${ }^{10} \mathrm{~B}_{10}$-oCRH carboranyl cage conjugate had significantly fewer cell colonies surviving 14 days postirradiation than cells incubated with oCRH plus unconjugated carboranyl cage. Bars are the mean \pm 1 SD of triplicate culture dishes. Means are statistically different $(p<0.001)$. 


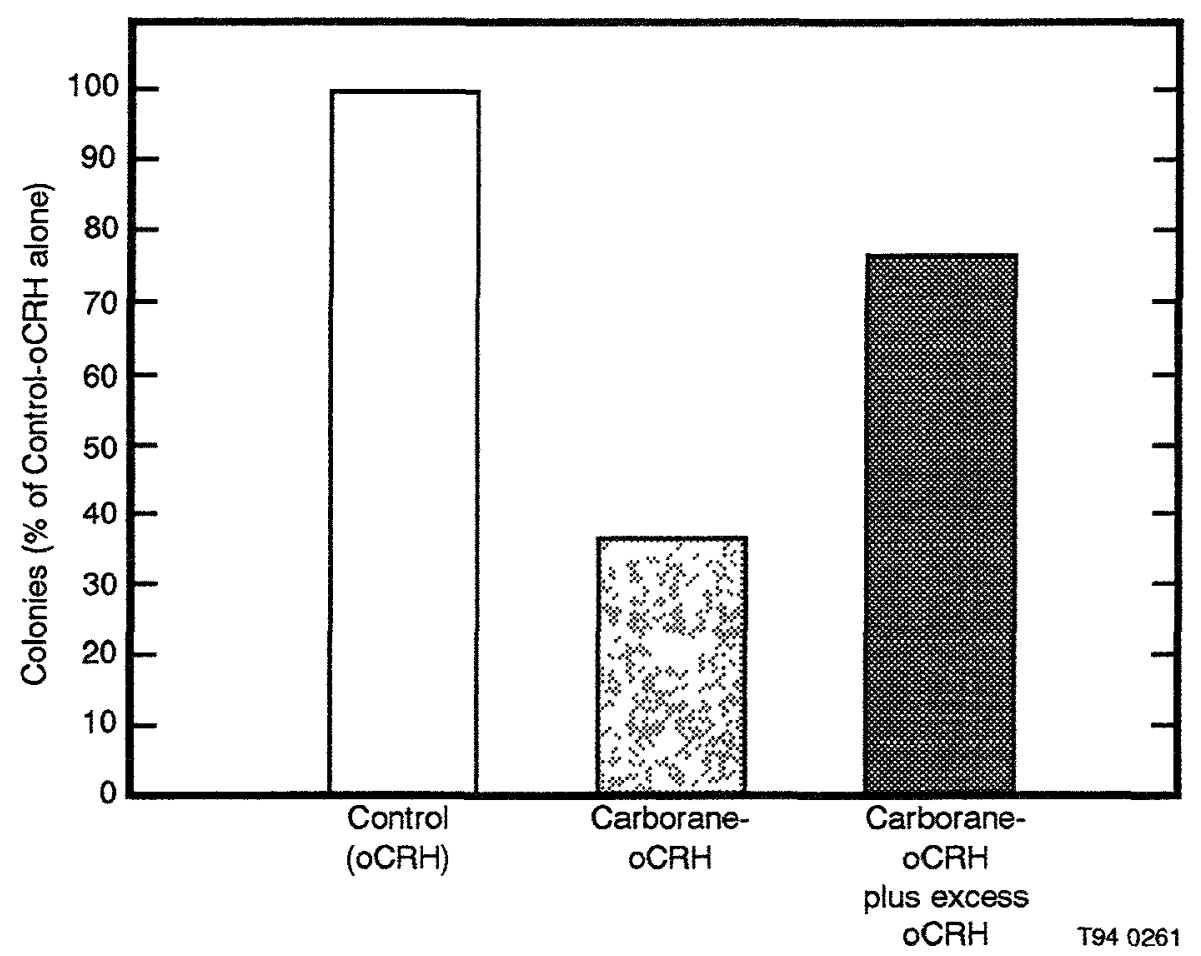

Figure 14. AtT-20 cell colony survival fraction (control was $10^{-6} \mathrm{M}$ oCRH alone). Cells incubated with $10^{-6} \mathrm{M}^{10} \mathrm{~B}_{10}$-oCRH for 10 minutes had significantly fewer cell colonies surviving 14 days postirradiation than control cells. However, this difference was reversed to statistical insignificance $(p<0.001)$ with the addition of excess $O C R H$ to the incubation media, suggesting that AtT-20 cell killing via neutron capture was mediated through entry of carboranyl cage-oCRH conjugate into the cell via the CRH receptor.

2. Incubation of AtT-20 cells with ${ }^{10} \mathrm{~B}_{10}-\mathrm{OCRH}$ for as little as 5 minutes, followed by neutron irradiation, makes the cell susceptible to neutron capture and cell death. Moreover, it appears that this effect is mediated via the $\mathrm{CRH}$ receptor, providing evidence that pituitary and other tumor cells can be targeted via specific membrane receptors and killed with ${ }^{10} \mathrm{~B}_{10}$ hormone conjugates.

3. BNCT may be an effective treatment modality for other endocrine-mediated or hormonally regulated cancers, and peptide hormones or other carriers (e.g., antibodies generated against specific cancer cell membrane receptors) can be conjugated with ${ }^{10} B_{10}$ to produce effective vehicles for targeting tumor or cancer cells.

\section{Future Specific Aims}

The goal of our future research is to assess in vivo tumor levels and tissue distribution of ${ }^{10} \mathrm{~B}$ delivered by the boronylated ovine corticotrophic releasing hormone $\left({ }^{10} \mathrm{~B}_{10}\right.$-oCRH) and boronylated growth hormone releasing hormone $\left({ }^{10} \mathrm{~B}_{10}-\mathrm{GHRH}\right)$ in a tumor-bearing nude mouse. Results from this effort will provide information on the potential efficacy of in vivo BNCT experiments using releasing hormones to carry ${ }^{10} \mathrm{~B}$ into pituitary and other endocrine-mediated tumor cells. To achieve these objectives, two specific aims have been defined:

1. Design and Execute In Vivo Experiments Using ${ }^{10} \mathbf{B}_{10}$-0 $\mathrm{CRH}$ in an AtT-20 Pituitary Tumor Cell-Bearing Nude Mouse to Assess Tumor-to-Blood and Other Tissue ${ }^{10} B$ 
Ratios. Nude, male mice (nu/nu) will have $1 \times 10^{7}$ AtT-20 cells implanted subcutaneously over the scapula. Cells will be allowed to grow for 3-4 weeks, i.e., until the tumor volume is approximately $0.5 \mathrm{~cm}^{3}$. $10 \mathrm{~B}_{10}$-oCRH will be injected into the femoral vein as a single acute bolus of $50 \mu \mathrm{g}$ per mouse. This dose is approximately 1,000-fold greater than the concentrations used in humans for pituitary-adrenal evaluations. These doses are needed to ensure adequate tumor levels for ${ }^{10} \mathrm{~B}$ analysis. Animals will be sacrificed at specified times $(0,5 \mathrm{~min}, 15 \mathrm{~min}, 30 \mathrm{~min}, 1 \mathrm{hr}, 6 \mathrm{hr}, 12 \mathrm{hr}$, and $24 \mathrm{hr}$ ) after injection. Selected tissues (tumor, blood, liver, spleen, kidney, pituitary, brain, and testis) will be harvested for ${ }^{10} \mathrm{~B}$ analysis. Completion of this task will establish the tumor-to-blood and tumorto-normal tissue ${ }^{10} \mathrm{~B}$ levels in a model in vivo system using ${ }^{10} \mathrm{~B}_{10-0} \mathrm{CRH}$ as the boron delivery vehicle and will assist in determining if BNCT is a justifiable approach for treating pituitary corticotroph tumors.

2. Design and Execute Parallel In Vivo Experiments Using ${ }^{10} \mathrm{~B}_{10}-\mathrm{GHRH}$ in a $\mathrm{GH}_{4} \mathrm{C}_{1}$ Pituitary Tumor Cell-Bearing Nude Mouse to Assess Tumor-to-Blood and Other Tissue ${ }^{10} \mathrm{~B}$ Ratios. The experimental design will be identical to Specific Aim A1. Completion of this task will establish tumor-to-blood and normal tissue $10 \mathrm{~B}$ ratios in a model in vivo system using ${ }^{10} \mathrm{~B}_{10}-\mathrm{GHRH}$ as the boron delivery vehicle and will assist in determining if $\mathrm{BNCT}$ is a justifiable approach for treating pituitary somatotroph tumors.

\section{Future Experimental Design and Methods}

The effectiveness of using hypothalamicreleasing hormones as vehicles for carrying ${ }^{10} \mathrm{~B}$ into pituitary tumor cells will be evaluated in vivo in nude mice carrying implanted pituitary tumor cells (either AtT-20 or $\mathrm{GH}_{4} \mathrm{C}_{1}$ ). After the tumor bed has grown to approximately a $0.5 \mathrm{~cm}^{3}$ volume. the mice will be injected with either ${ }^{10} \mathrm{~B}_{10}-\mathrm{OCRH}$ or ${ }^{10} \mathrm{~B}_{10}$-GHRH (50 $\mu \mathrm{g}$ per animal as a bolus in approximately $20 \mu \mathrm{L}$ ) via femoral vein injection and sacrificed later at specified times for tumor and other tissue collection (blood, liver, spleen, kidney, pituitary, brain, and testis). These tissues will be subjected to acid digestion and assayed for ${ }^{10} \mathrm{~B}$ (and ${ }^{11} \mathrm{~B}$ ) by inductively coupled plasma-mass spectroscopy (ICP-MS). Results of these experiments will provide boron tissue distributions and tumor-to-blood (and to other tissue) ratios, and will fumish indispensable data related to pituitary turnor cell ${ }^{10} \mathrm{~B}_{10}$-releasing hormone uptake and tissue levels for evaluating the potential efficacy of treating pituitary tumors and other endocrinemediated and hormonally dependent malignancies with BNCT.

\section{Specific Aim 1}

In Vivo Experiments Using ${ }^{10} \mathrm{~B}_{10^{-0}} \mathrm{CRH}$ in an AtT-20 Pituitary Tumor Cell-Bearing Nude Mouse to Assess Tumor-to-Blood and Other Tissue ${ }^{10} \mathrm{~B}$ Ratios.

Synthesis of ${ }^{10} \mathrm{~B}_{10}$-carboranyl cage has been carried out by Professor M. Frederick Hawthorne. Department of Chemistry and Biochemistry, UCLA, and is available from Dr. Albertson's laboratory at OHSU. This cage will be modified to a thiol-glycine derivative by Dr. Craig R. Miles, Macromolecular Resources, Colorado State University, Fort Collins, CO, thus making conjugation (i.e., condensation) to the releasing homone peptides simpler and more efficient. The 41 amino acid releasing hormones (oCRH and GHRH; see Figures 8 and 9) will be synthesized on a solid phase matrix using standard peptide synthesis techniques. The peptides will be modified with the addition of a bromine moiety at the distal end of the terminal amino acid for conjugation to the carboranyl cage thiol analog. Purification will be carried out on high-pressure liquid chromatography (HPLC). It is anticipated that the yield from these syntheses will be several milligrams, sufficient for the in vivo nude mouse studies.

Assessment of the biological activities of these preparations will be made as described in the preliminary sections by the stimulation of 
intracellular cAMP in AtT-20 cells (or $\mathrm{GH}_{4} \mathrm{C}_{1}$ cells for ${ }^{10} \mathrm{~B}_{10}-\mathrm{GHRH}$ ) in culture. These cells are currently available from the American Type Culture Collection, Rockville, MD. Dr. Albertson currently has cAMP radioimmunoassay in his laboratory, with a sensitivity of $10 \mathrm{pg} / \mathrm{mL}$; intraassay $\mathrm{cv}$ is approximately $8 \%$, interassay $\mathrm{cv}$ is approximately $12 \%$.

When AtT-20 and $\mathrm{GH}_{4} \mathrm{C}_{1}$ cells are near confluence $(80-90 \%)$, they are dislodged using EDTA (Versene, Gibco, Inc., Long Island, NY), transferred to $50 \mathrm{ml}$ sterile conical tubes, and centrifuged at $800 \mathrm{rpm}$ for 10 minutes. The cells are then resuspended in cold sterile normal $(0.9 \%)$ saline and counted. Cells are then diluted with sterile saline so that approximately $10^{7}$ cells are in $100 \mu \mathrm{L}$.

Male nude mice (nu/nu, 35 g, 10 wk old, Bantin and Kingman, Fremont, CA) will be housed in the nude mouse facility at OHSU. AtT-20 cells will be injected subcutaneously above one scapula $\left(10^{7}\right.$ cells in $100 \mu \mathrm{L}$ tunneled under the skin with a 27 ga needle). The tumor cells will be allowed to grow in situ for approximately $3-4$ weeks, i.e., the time needed for the implant tumor volume to reach approximately $0.5 \mathrm{~cm}^{3}$. These exact conditions (numbers of cells to be injected and the time needed for an adequate tumor bed to grow) will be established in a series of test animals prior to ${ }^{10} \mathrm{~B}$ injection experiments.

When nude mouse/tumor cell growth times are established, groups of three mice will receive $50 \mu \mathrm{g}$ ${ }_{10} \mathrm{~B}_{10}$-oCRH as a single acute bolus, i.v. injection via the femoral vein (Isofluorane gas: $5 \%$ induction, with $2 \%$ maintenance for the femoral vein cut-down, injection, and wound suturing), and sacrificed $\left(\mathrm{CO}_{2}\right.$ inhalation) at $5 \mathrm{~min}, 15 \mathrm{~min}$, $30 \mathrm{~min}, 1 \mathrm{hr}, 6 \mathrm{hr}, 12 \mathrm{hr}$, and $24 \mathrm{hr}$ after the injection. A zero time (zero dose) group of three mice will be used as controls, i.e., animals will receive tumor cell implants and an acute i.v. injection of saline vehicle only, but no ${ }^{10} \mathrm{~B}$ compound. Tumor, blood, kidney, spleen, liver, pituitary, brain and testis will be collected. These tissues will be placed in clean (boron free) polypropylene vials, labeled, and prepared for boron analysis by ICP-MS.
The dose of ${ }^{10} \mathrm{~B}_{10}-\mathrm{oCRH}(50 \mu \mathrm{g} /$ animal) corresponds to supraphysiologic doses when compared to the standard CRH test given to patients for evaluation of pituitary function $(100 \mu \mathrm{g} / \mathrm{kg})$, but will provide blood levels of approximately $20 \mathrm{ppm}{ }^{10} \mathrm{~B}_{10}-\mathrm{oCRH}$, easily measured by ICP-MS.

Tissue and/or cell associated ${ }^{10} \mathrm{~B}$ (and ${ }^{11} \mathrm{~B}$ ) levels will be measured using a PlasmaQuad ICP-MS ${ }^{25-27}$ system (V.G. Elemental, Winsford, Cheshire, UK). The sensitivity of the OSU ICP-MS system is currently $0.1 \mathrm{ppb}{ }^{10} \mathrm{~B}$, using extensive sample blanking and prerun cleaning. Tissue samples are acid digested in doubly distilled concentrated nitric acid (GFS Chemicals, Powell, $\mathrm{OH}$ ) and microwaved on the high setting ( $600 \mathrm{~W}$ ) for 30 seconds in $23 \mathrm{~mL}$ Parr Acid Digestion Bombs (Model \#4781, Parr Instrument Co., Moline, IL).

Anticipated Problems: If the above hypothesis is correct, cells with $\mathrm{CRH}$ receptors will be intemally "saturated" with ${ }^{10} \mathrm{~B}_{10}-\mathrm{OCRH}$ and killed by BNCT. This includes the normal, nontumor corticotrophs in the pituitary, and possibly other cells with CRH receptors. There are other tissues that have been demonstrated to have $\mathrm{CRH}$ receptors. Several areas of the normal brain have been shown to have $\mathrm{CRH}$ receptors; however, because these cells and receptors lie in central nervous system (CNS) structures and across the blood-brain barrier, they will not be accessible to the boron compound. The gonads have been shown to have CRH receptors; however, their distance from the neutron beam (at least in humans) would make this tissue a poor target for BNCT; hence, it is expected that few, if any, gonadal cells would be jeopardized. The placenta also has $\mathrm{CRH}$ receptors; however, the likelihood of a pregnant patient being approved for BNCT is extremely low.

Since theoretically all the pituitary receptor positive cells could be killed by BNCT, treated Cushing's disease patients would need glucocorticoid replacement for the rest of their lives. a situation quite common in medicine. With oral replacement doses of glucocorticoids, Cushing's patients live normal, active, healthy lives with only one complication, namely, in times 
of severe stress, when the body compensates by producing extra glucocorticoids from the adrenal, an increased oral dose is necessary. This is no problem, except if the patient is unable to do so for some reason. However, these individuals wear Medical Alert ID bracelets to alert medical personnel that they are taking replacement glucocorticoids.

There are no data providing a comparison of the binding capacity (number of receptor sites and/or turnover of these receptors) in pituitary tumors or normal pituitary corticotrophs. It is suspected that since pituitary tumors arise as a clone from a "normal" pituitary corticotroph, the number of receptors per cell would be approximately the same as the normal pituicytes. A concern for the administration of any compound i.v. is potential untoward or toxic effects. Doses of oCRH that have been found to cause transient hypotension and flushing have been described by Orth et al. ${ }^{28}$ to be approximately $30 \mu \mathrm{g} / \mathrm{kg}$. In this work, a dose of CRH that is about 30 times this amount will be used, warranting close monitoring of the mice after the injections for signs of transient low blood pressure (inability to walk or move, unconsciousness, etc.). If animals show these symptoms, they will be given sterile, normal saline i.v. Test mice will be administered $50 \mu \mathrm{g} \mathrm{CRH}$ in pilot experiments to determine if these effects emerge.

For normal humans given an acute bolus injection of $100 \mu \mathrm{g} \mathrm{CRH}$ (about $1-1.5 \mu \mathrm{g} / \mathrm{kg}$, or about $1 / 30$ or so of the proposed doses to the mice), at any time of the day or night, i.e., in the presence of the hypothalamus making and secreting its own endogenous $\mathrm{CRH}$, the pituitary responds by producing excessive amounts of ACTH and, more distally, adrenal cortisol, suggesting that there are plenty of "spare" receptors available for occupancy.

The proposed nude mouse model is not a true "pituitary tumor" model, and, as such, the hypothalami of these animals may produce sufficient endogenous $\mathrm{CRH}$ to lower ${ }^{10} \mathrm{~B}_{10}$-oCRH uptake by the implanted tumor. This effect can be eliminated by giving the equivalent of an ovemight dexamethasone suppression test to the animal. This procedure involves approximately $1-2 \mu \mathrm{g}$ of dexamethasone per mouse by intraperineal (i.p.) injection at $10 \mathrm{p} . \mathrm{m}$. on the evening before the morning administration. This should provide optimal CRH pituitary and other (tumor implant) receptors for the boron compound administered i.v. at 8-9 a.m.

\section{Specific Aim 2}

In Vivo Experiments Using ${ }^{10} \mathrm{~B}_{10}-\mathrm{GHRH}$ in a $\mathrm{GH}_{4} \mathrm{C}_{1}$ Pituitary Tumor Cell-Bearing Nude Mouse to Assess Tumor-to-Blood and Other Tissue ${ }^{10} \mathrm{~B}$ Ratios.

$\mathrm{GH}_{4} \mathrm{C}_{1}$ pituitary tumor cells will be implanted into nude mice, as described above for AtT-20 cells, and allowed to grow into a $0.5 \mathrm{~cm}^{3}$ tumor bed volume. ${ }^{10} \mathrm{~B}_{10}-\mathrm{GHRH}$ will be injected as a single acute i.v. bolus of $50 \mu \mathrm{g}$ per animal. As stated above, three mice will be used for each time group and sacrificed with $\mathrm{CO}_{2}$ inhalation at times identical to those described in Specific Aim 1. Tissues, tumor, and blood will be harvested from each animal for boron analysis.

Anticipated Problems: Like the oCRH carboranyl conjugate, ${ }^{10} \mathrm{~B}_{10}$-GHRH will be given at a dose that exceeds the usual amount given to humans for pituitary evaluations. However, complications similar to those observed for $O C R H$ do not appear to be evident with GHRH at the doses to be injected. Similar dynamics to $\mathrm{CRH}$ are observed with acute injections of GHRH and GH. In patients with Cushing's disease or acromegaly, endogenous hypothalamic CRH and GHRH are turned off by the negative feedback regulatory mechanisms from excess cortisol (in Cushing's) and $\mathrm{GH}$ and/or insulin-like growth factor $\left(\mathrm{IGF}_{1}\right)$ in acromegalics. However, in the proposed mouse mode, the hypothalamus can be "artificially blocked" from producing CRH by giving dexamethasone, as described above. Similarly in the mouse model, there are data to suggest that giving specific protein or amino acids, e.g., histamine or histidine, acutely suppresses GHRH and GH release. Thus, a pre-i.v. injection with one or both of these substances could lower endogenous GHRH and make the target somatotroph cells "better" targets from a receptor occupancy viewpoint. Functional GHRH receptors 
have only been shown in the pituitary. There are some unpublished data suggesting that the testis may have GHRH receptors, but this site is a long way from the head in humans. Similarly to oCRH. hypothalamic GHRH release will be insignificant relative to the dose of GHRH-carboranyl conjugate to be administered and will not confound pituitary cell ${ }^{10} \mathrm{~B}_{10}$-GHRH binding and internalization.

For GHRH, replacement of $\mathrm{GH}$ in subjects without $\mathrm{GH}$ production by pituitary somatotrophs is not carried out for two reasons: (1) In adults, $\mathrm{GH}$ deficiency is not associated with any medical complications or untoward effects. Hence, adults with growth hormone deficiency usually due to panhypopituitarism or hypophysectomy do not receive GH as a replacement. In children, GH replacement is needed so that they continue to grow and reach their potential adult height and stature. (2) Replacement of GH in adults is very expensive, costing between $\$ 10,000$ and $\$ 12,000$ per year (currently, insurance companies do not cover these costs for adults).

\section{Mathematical and Statistical Analysis}

Microcomputer statistical software programs employed will be the INSTAT and CRUNCH packages. INSTAT will be used for simple comparisons, CRUNCH for more sophisticated multivariate analyses. Group comparisons will be handled in the following way: The distribution characteristics of each experimental group will be examined by calculating the descriptive statistics, mean, and standard deviation. This will be followed by an examination of the data for symmetry of distribution and skew. Parametric tests will be applied when justified. Comparisons between groups will be made with the two-tailed standard $t$ test. Nonparametric tests will be employed when necessary. These comparisons between groups will be made with Mann-Whitney or Wilcoxan tests. Multiple comparisons will be made using one-way analysis of variance for data with normal distributions. For continuous data with a nongaussian distribution, the Kruskal-Wallis test will be employed from the CRUNCH package. CAMP RIA data will be analyzed with a Quattro Pro RIA statistical package. All of the necessary software, described above, is currently in the Division of Endocrinology, Diabetes, and Clinical Nutrition, Department of Medicine, OHSU. A full-time statistician is on that faculty. 


\section{BORON LOCALIZATION SCREENING}

\section{Dr. Catherine A. Elstad, Principal Investigator, College of Pharmacy, WSU}

\section{Introduction}

A crucial requirement for effective BNCT of cancer is the selective localization of high concentrations of boron in tumor tissue relative to adjacent normal tissue. Because normal tissues are included within the activating neutron field during therapy, optimal BNCT efficacy requires higher boron accumulation in the tumor than in the surrounding normal host tissues. In addition, preferential intracellular loading of boron into tumor cells is essential because of the short range of the fission fragments produced by BNCT. Researchers in the College of Pharmacy at WSU have developed in vivo and in vitro assays to evaluate boron pharmacokinetics and distribution in normal cells and tumor cells after exposure to selected boron-delivery compounds. Goals of this research are two-fold: (1) to develop and utilize standardized in vitro and in vivo assays to quantify boron uptake by both tumor cells and normal cells and (2) to investigate mechanisms to enhance preferential uptake of boron by tumor cells and, thus, optimize BNCT. Screening of boron compounds for use in BNCT will help determine which boron compounds will have potential for greatest impact on the treatment of human cancer. In addition, identification of alterable factors enhancing boron uptake could significantly impact BNCT.

\section{Methods}

\section{Tumor and Normal Cell Lines}

Twenty-three screening assays utilizing both tumor and normal cells were completed during 1993. Those tumor systems typically not responsive to conventional means of cancer therapy, but possible candidates for BNCT, were targeted and included: B16-BL6 murine melanoma, RG2 rat glioma, U87MG human glioma, and Lewis lung murine carcinoma. The P1798 murine lymphosarcoma was dropped from
Studies after histopathological results indicated that this tumor does not remain localized but infiltrates normal organs and tissues, particularly liver, spleen, and regional lymph nodes. Use of rodent tumors (tumors derived from mice or rats) facilitates large-scale, rapid, and cost-effective experiments that may have important consequences for large animal research and for potential human clinical trials. Investigations using the highly invasive and highly metastatic B 16-BL6 murine (mouse-derived) melanoma will significantly contribute to evaluating $\mathrm{BNCT}$ for human malignant melanoma and deep-seated metastatic melanoma lesions. The incidence of melanoma is rapidly increasing and the prognosis for survival is poor due to the refractory nature of the tumor to conventional cancer therapies, emphasizing urgent need for investigating the effectiveness of BNCT for treating this cancer. Rat RG2 and human U87MG glioma tumors are used to model the potential effectiveness of BNCT for treating deep-seated brain tumors, especially invasive brain tumors inoperable and resistant to other treatment modalities. In addition, data from in vitro assays using U87MG human glioma will provide valuable preliminary data to complement future in vivo studies using nude or immunocompromised mice and to guide possible human clinical evaluations. Assays using Lewis lung murine carcinoma may indicate the potential of BNCT for treating lung cancer.

To evaluate the preferential loading of boron into tumor tissue relative to normal tissues, all assays have examined levels of boron in normal tissues. For in vitro assays, murine mammary fibroblasts have served as control, normal cells in experiments. Another normal cell line has recently been isolated and identified at the Deparment of Veterinary Microbiology and Pathology, WSU. This cell line was enzymatically isolated from bovine brain and determined by immunohistological techniques to be normal brain astrocytes. These normal astrocytes may be more appropriate controls for experiments using the $\mathrm{RG} 2$ rat glioma or U87MG human glioma. 


\section{Boron Compounds and Delivery Vehicles}

Boron compounds and delivery vehicles screened in assays are those that theoretically demonstrate the greatest potential for BNCT. BPA is one such compound. BPA was originally synthesized as a melanin precursor and phenylalanine amino acid analog. BPA is used as a screening reference in melanoma investigations, since phenylalanine is required by melanoma cells as a precursor for both protein synthesis and melanin production. In addition, BPA has been extensively studied and characterized in clinical trials in Japan and in pharmacokinetic trials in the United States and Australia. Liposome and LDL boron delivery mechanisms have also been evaluated and provided by other INEL/BNCT researchers. Both liposomes and LDLs are selectively targeted to tumors, as reported in the scientific literature. ${ }^{29-41}$ For example, the preferential delivery to tumors of several conventional chemotherapeutic drugs, such as adriamycin or doxorubicin, is enhanced after liposomal encapsulation of the chemotherapeutic drug compared to free or unencapsulated drug.

\section{In Vitro Screening and Cytotoxicity Assays}

Ten in vitro screening assays have been conducted during 1993. For typical in vitro screening assays, boron compounds are added to confluent cultures of tumor and normal cells. Cultures are subsequently harvested in triplicate 6 , 12 , and 24 hours later and analyzed for boron content by inductively coupled plasma-atomic emission spectroscopy (ICP-AES). Selected compounds were also tested in vitro for cytotoxicity against normal cells and tumor cells. The hypothesis is that compounds that are cytotoxic to normal cells in vitro may also be cytotoxic to normal tissues in vivo, with subsequent detrimental effects to the host that could negate any beneficial effects of BNCT. For in vitro cytotoxicity assays, cell cultures were exposed to increasing concentrations of boron compounds. After incubation with the compound. cell viability and numbers were monitored by one of two standard tissue culture methods: (1) trypan blue exclusion, or
(2) MTT-dye reduction, during which living cells convert tetrazolium into a blue formazan product measured spectrophotometrically at $570 \mathrm{~nm} . M T T$ is an acronym for the chemical compound 3-[4,5-dimethylthiazole-2-yl]-2,5-diphenyltetrazolium bromide; thiazolyl blue. These in vitro cytotoxicity assays have indicated that most compounds used in subsequent in vitro and in vivo screening assays were not cytotoxic. For selected boronated LDL compounds, attempts to enhance boron uptake by tumor cells have been made by pretreating cell cultures with ethinyl estradiol to upregulate cell-surface LDL receptors.

\section{In Vivo Screening}

Thirteen in vivo screening assays have been conducted. For in vivo assays, boron compounds are currently screened in specific-pathogen-free, female mice. Mice are inoculated subcutaneously into either the dorsal hip (B16-BL6 melanoma) or the scapular region (Lewis lung carcinoma) with 1 million tumor cells. Approximately 1-2 weeks later, unanesthetized tumor-bearing mice are inoculated with $200 \mu \mathrm{L}$ of boron compound into the dilated tail vein. Following injection of boron compound, mice are sacrificed through a 72-hour interval. At each time point. tissues are collected and analyzed for boron content by other INEL/BNCT researchers using ICP-AES. Collected tissues include tumor, blood, liver, spleen, brain, muscle. kidney, and skin. Of particular interest are tumor boron levels and tumor-to-normal tissue boron ratios. Each assay involves 48 animals, 6 animals per time point. For selected compounds, attempts have been made to preferentially enhance boron uptake by the tumor versus adjacent normal host tissues, for example, by short-term phenylalanine and tyrosine deprivation and by multiple injection of the boronated compound.

\section{Results}

Researchers in the College of Phamacy at WSU have repeatedly shown that selected boronated compounds do accumulate both in vitro and in vivo in tumor cells. Several of these compounds accumulate to therapeutic levels for BNCT or to 
levels comparable to, or higher than, those previously reported in the scientific literature.

\section{Boronophenylalanine}

We have previously reported that in vitro uptake of boron by B16-BL6 melanoma cells increases with increasing levels of BPA and that this uptake is dramatically increased by restriction of tyrosine and phenylalanine via medium formulation. Recent data indicate that in vitro BPA uptake can be enhanced by enzymatic depletion of phenylalanine and tyrosine using the enzyme phenylalanine ammonia-lyase (PAL) (Table 10). PAL is an amino acid degrading enzyme that catalyzes the deamination of phenylalanine to cinnamic acid and tyrosine to coumaric acid. Previous experiments have indicated that levels of phenylalanine and tyrosine in culture medium are reduced by PAL and that BPA is not degraded by this enzyme. In addition, in vitro growth of B16-BL6 is normal after exposure to 0.025 units of PAL. Interestingly, when tyrosine and

Table 10. Effect of PAL on in vitro tumor levels of boron. Cultures of B16-BL6 murine melanoma were pretreated with 0.025 units of PAL 1 hour prior to exposure to 0.1 or $1.0 \mathrm{mg}$ of BPA. Triplicate cultures were harvested 6 hours later.

\begin{tabular}{cc}
\hline Treatment & $\begin{array}{c}\text { Tumor levels of boron } \\
(\mu \mathrm{g} \mathrm{B} / \mathrm{g})\end{array}$ \\
\hline $0.1 \mathrm{mg} \mathrm{BPA}$ & \\
$-\mathrm{PAL}$ & $0.582 \pm 0.143$ \\
+PAL & $1.212 \pm 0.357^{\mathrm{a}}$ \\
$1.0 \mathrm{mg} \mathrm{BPA}$ & \\
- PAL & $6.184 \pm 0.323$ \\
+ PAL & $7.526 \pm 0.288^{\mathrm{a}}$
\end{tabular}

a. Significantly different from control $(p<0.05$. Fisher's protected LSD). phenylalanine are restricted by both medium formulation and PAL, the effects of PAL on boron uptake are not evident and may be masked by the dramatic effects of restricting tyrosine and phenylalanine by medium formulation (Table 11).

Previously reported data have indicated that PAL pretreatment enhances in vivo boron uptake by tumor tissue. More recent data support this observation (Figure 15). Mice bearing B16-BL6 melanoma tumors were injected intravenously into the dilated lateral tail vein with $4 \mathrm{mg}$ of BPA dissolved in $0.5 \mathrm{M}$ Tris buffer. Mice were pretreated intravenously with PAL (2.0 units/mouse) 4 hours prior to BPA injection. Tissue and blood samples were collected $3,6,12$, and 24 hours after BPA injection. Blood amino acid analyses indicate that phenylalanine and tyrosine are significantly lower in PAL-treated mice compared to untreated mice. BPA did not

Table 11. Effects of PAL and low medium concentrations of tyrosine and phenylalanine on in vitro tumor levels of boron. B 16-BL6 murine melanoma was cultured to subconfluency in medium containing low levels of tyrosine and phenylalanine ( $4 \mu \mathrm{g} / \mathrm{mL}$ medium each). Cultures were pretreated with 0.025 units of PAL 1 hour prior to exposure to 0.1 or $1.0 \mathrm{mg}$ of BPA. Triplicate cultures were harvested 6 hours later.

\begin{tabular}{lc}
\hline Treatment ${ }^{\mathrm{a}}$ & $\begin{array}{c}\text { Tumor levels of boron } \\
(\mu \mathrm{g} \mathrm{B} / \mathrm{g})\end{array}$ \\
\hline $\begin{array}{c}\text { 0.1 mg BPA } \\
\text { - PAL } \\
\text { +PAL }\end{array}$ & $2.528 \pm 0.289$ \\
$1.0 \mathrm{mg} \mathrm{BPA}$ & $2.231 \pm 0.047$ \\
- PAL & \\
+ PAL & $20.659 \pm 2.939$ \\
\hline & $17.112 \pm 1.758$ \\
a. Treatments within same BPA concentration not \\
significantly different $(\mathrm{p}>0.05$. Fisher's protected \\
LSD).
\end{tabular}




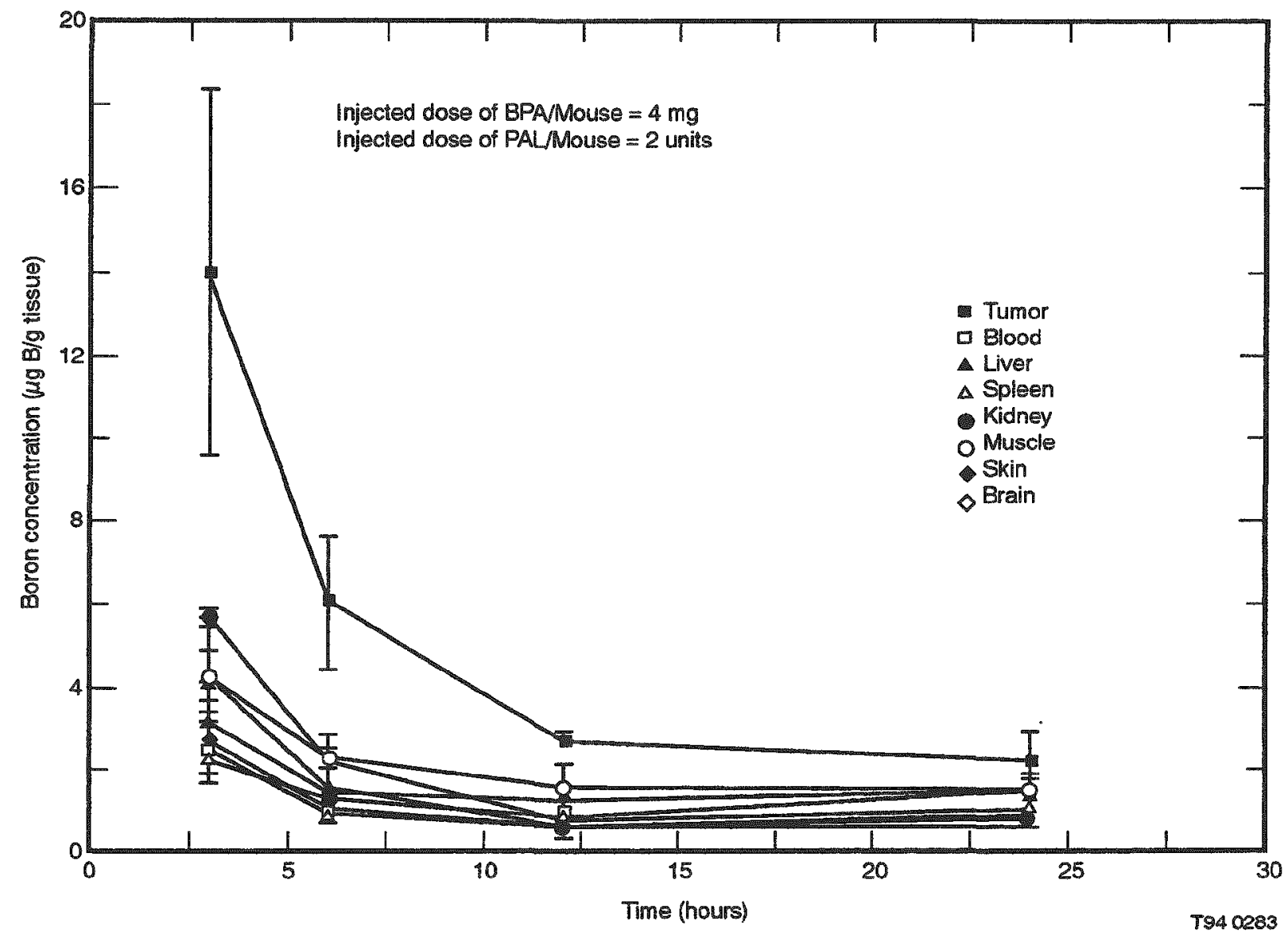

Figure 15. Effect of phenylalanine ammonia-lyase (PAL) on tissue levels of boron. Melanoma-bearing mice were pretreated intravenously with 2.0 units of PAL 4 hours prior to injection with $4 \mathrm{mg} \mathrm{BPA}$ into the dilated lateral tail vein. Groups of mice were sacrificed $3,6,12$, and 24 hours later.

interfere with these amino acid analyses. More importantly, these results indicate that PAL pretreatment does enhance uptake of boron into tumor tissue (Figure 16). These results were presented in a poster session of the 84th Annual Meeting of the American Association for Cancer Research, Orlando, FL, May 19-22, 1993, and the abstract was published in the proceedings of this meeting. ${ }^{42}$ Results from an additional BPA/PAL in vivo experiment are pending.

\section{Liposomal-Encapsulated Boron Compounds}

INEL/BNCT researchers at the UCLA have provided liposomal-encapsulated boron compounds for in vitro and in vivo screening. Boron accumulation in subcutaneous Lewis lung carcinoma tumors has been monitored following intravenous injection of liposomal-encapsulated and free (unencapsulated) boron compounds. Results from an in vivo screening using Lewis lung carcinoma-bearing mice injected intravenously with boronated compounds both encapsulated and embedded in the liposome are represented in Figure 17. Boron levels in the blood are rapidly cleared. Tumor boron levels reach approximately $15 \mu \mathrm{g} / \mathrm{g}$ and plateau at approximately $10 \mu \mathrm{g} \mathrm{B} / \mathrm{g}$. Tumor boron levels in mice receiving two injections of compound (at 0 and 18 hours) average approximately $25 \mu \mathrm{g} / \mathrm{g}$. These initial results indicate that multiple injections may enhance tumor accumulation of boron. Results from in vivo 


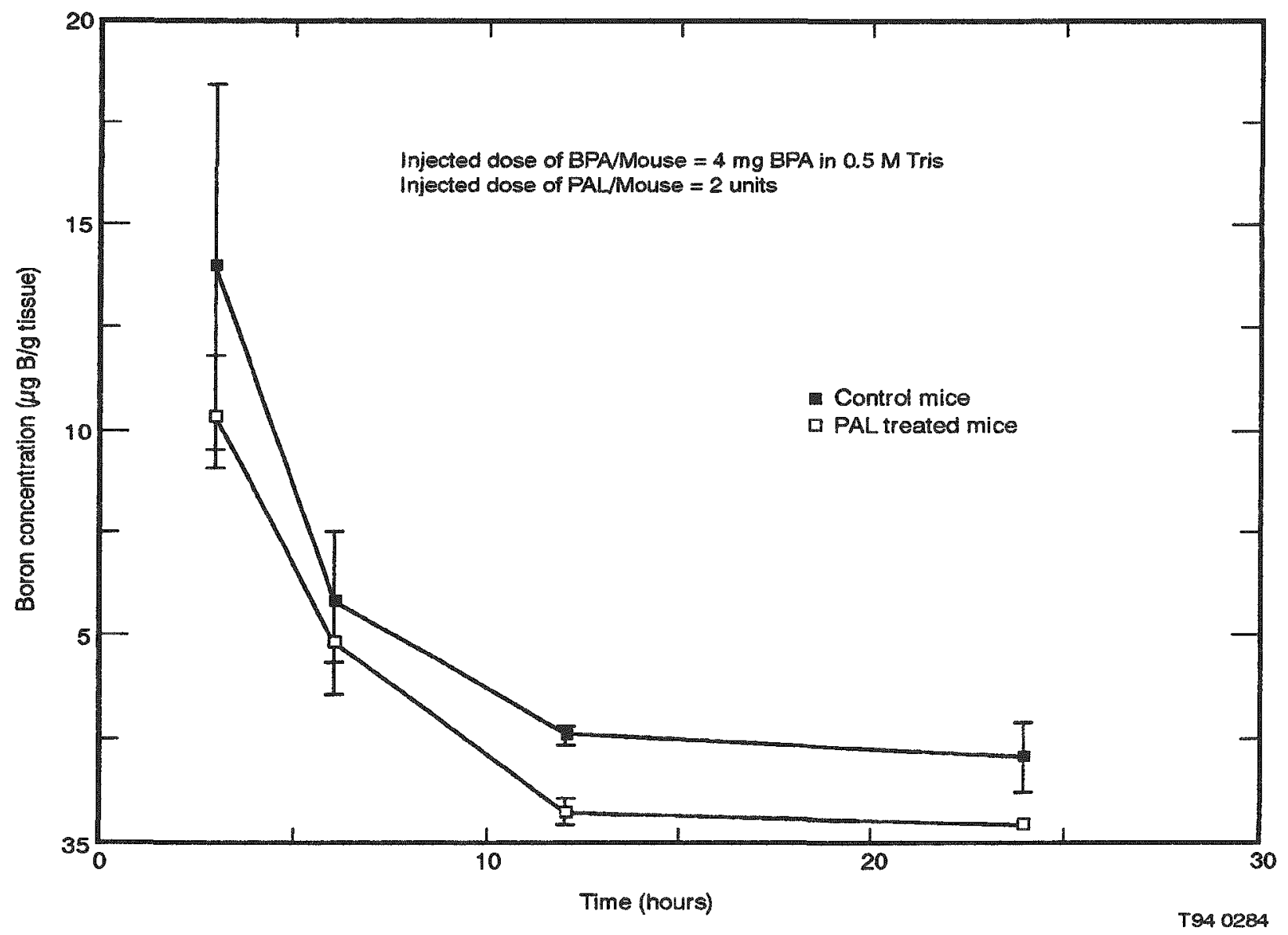

Figure 16. Boron levels in tumors excised from control mice and mice pretreated with phenylalanine ammonia-lyase.

screenings using unencapsulated or free boron compounds demonstrate the effectiveness of liposomes as boron-delivery vehicles. As shown in Figure 18, free boron compound does not accumulate to appreciable levels in tumor tissue. In vitro cytotoxicity assays indicate that although most liposomal encapsulated compounds are nontoxic, as represented in Figure 19, some compounds may express some cytotoxicity (Figure 20).

\section{Boronated Low-Density Lipoproteins}

In vitro LDL delivery of very low doses $(<100 \mu \mathrm{g} \mathrm{B} / \mathrm{g})$ of several boronated compounds has been screened using four tumor cell lines
(B16-BL6 murine melanoma, RG2 rat glioma, U87MG human glioma, Lewis lung murine carcinoma) and one normal cell line (murine mammary fibroblasts). Figures 21 and 22 are representative in vitro screenings using these cell lines and boronated LDLs. These results indicate that LDL delivery of boron is quite effective in vitro and that tumor levels of boron can approach and exceed therapeutic levels of boron. Present efforts are being directed to optimize the experimental protocols for these LDL-boronated compounds and to investigate mechanisms to enhance uptake of these boronated LDL compounds. In particular, use of ethinyl estradiol to upregulate cell surface LDL receptors is being investigated. The hypothesis is that upregulation of 


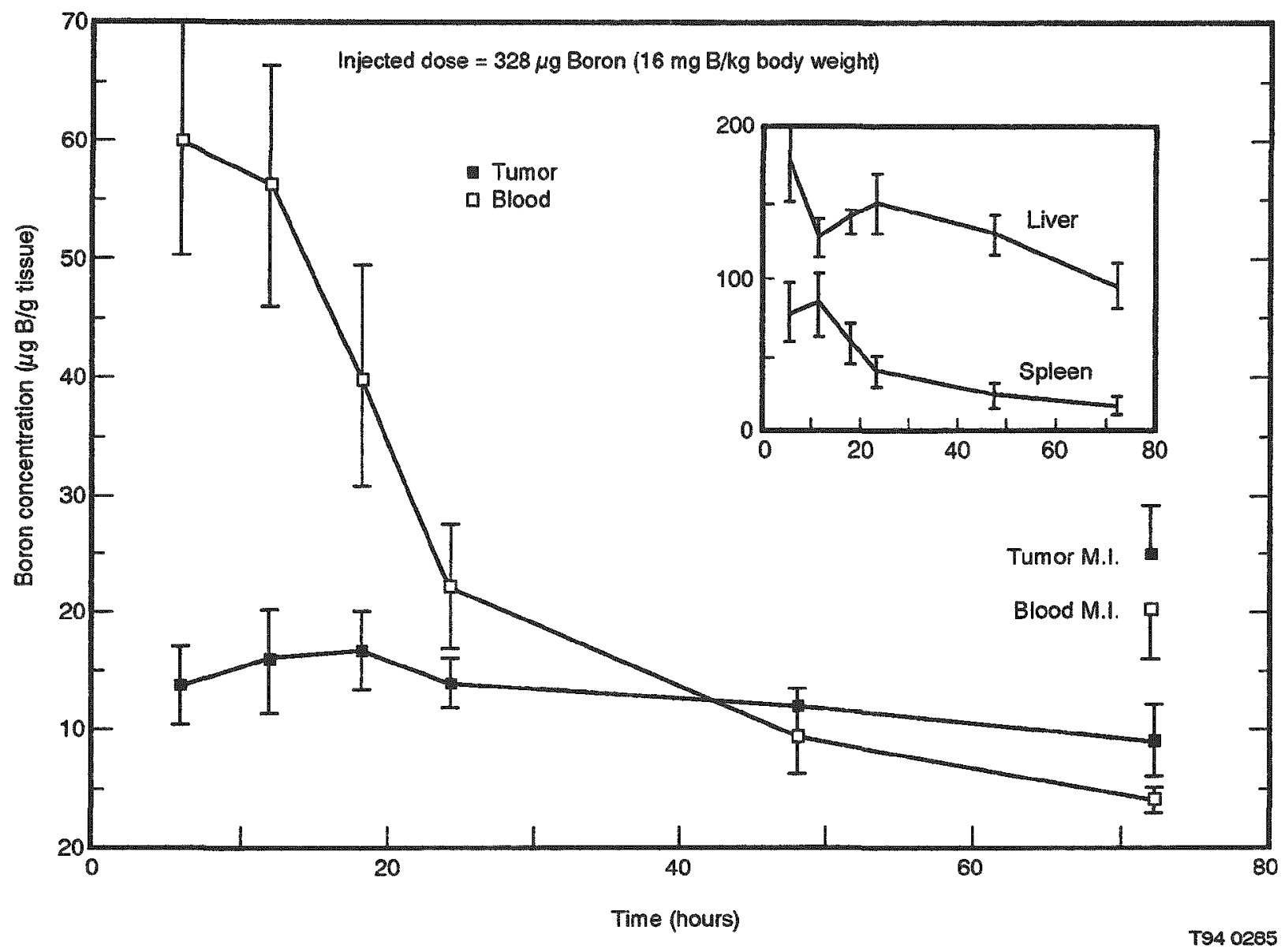

Figure 17. Boron biodistribution in mice bearing Lewis lung carcinoma after intravenous injection of $200 \mu \mathrm{L}$ of the indicated liposomal-encapsulated boron compound. One group of mice received two injections of liposomal-encapsulated compound. For this group, the initial injection was administered at 0 hours followed by a second injection at 18 hours. Tissues for this multiple injection group were collected 72 hours after the initial injection. Tumor and blood boron levels in these mice are indicated as "Tumor M.I." and "Blood M.I." (M.I. = multiple injection).

LDL receptors on the tumor will result in increased uptake of boron by the tumor. Preliminary results indicate that pretreatment of B16-BL6 melanoma with $1 \mathrm{nM}$ ethinyl estradiol does indeed result in increased boron uptake by the tumor cells (Figure 23). Results for RG2 rat and U87MG human gliomas are inconclusive. Little boron is taken up by normal murine fibroblasts in the presence or absence of ethinyl estradiol (Figure 24), indicating that ethinyl estradiol may have no effect on LDL receptors on these cells. This experiment has been repeated twice in greater detail and results are pending. Receptor-binding studies are also being conducted to determine the extent of receptor upregulation by ethinyl estradiol. Results from two in vivo screenings of boronated LDL compounds in mice bearing either B16-BL6 melanoma or Lewis lung carcinoma are pending.

\section{Miscellaneous}

During this reporting period, shipments of B16-BL6 melanoma-bearing mice were sent in June, July, and August to INEL/BNCT researchers at the College of Pharmacy, Idaho State University. (ISU) Another shipment of tumor-bearing mice was sent to ISU the second week in January, 1994. 


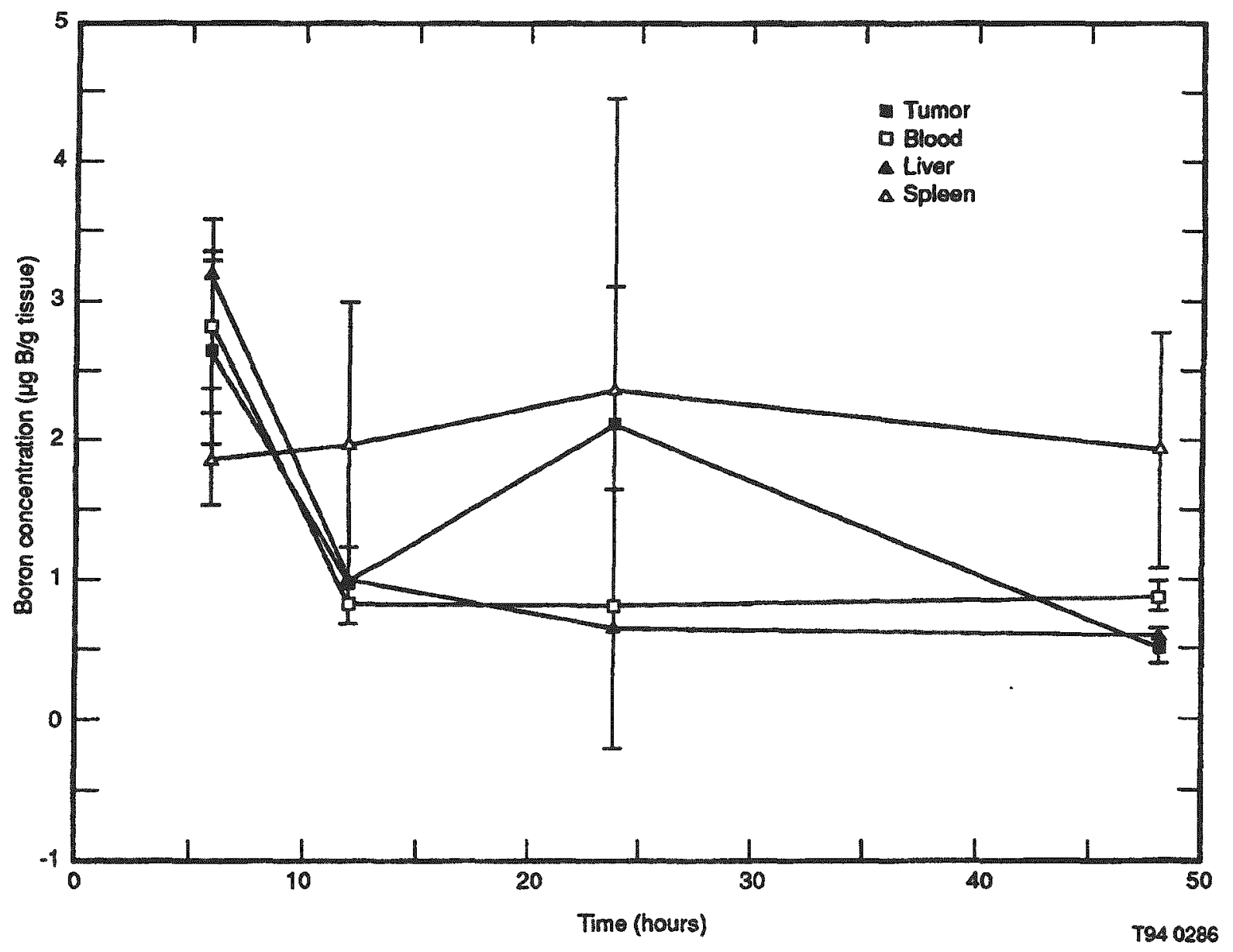

Figure 18. Boron biodistribution in mice bearing Lewis lung carcinoma after intravenous injection of $200 \mu \mathrm{L}$ of free, unencapsulated boron compound.

RG2 rat glioma cultures were also provided to INEL/BNCT researchers at the University of Utah and at the Department of Veterinary Clinical Sciences, WSU.

\section{Conclusion}

In collaboration with other INEL/BNCT researchers, researchers in the College of
Pharmacy at WSU have developed in vitro and in vivo assays that utilize current in vitro technologies and small animals (mice) to determine the effectiveness of boron compounds for BNCT. Efforts are also targeting alterable factors that may enhance selective uptake of boron into tumor cells to optimize BNCT. Identification of these factors. along with the most promising boron compounds, will have a significant impact on therapy of cancer using neutron capture. 


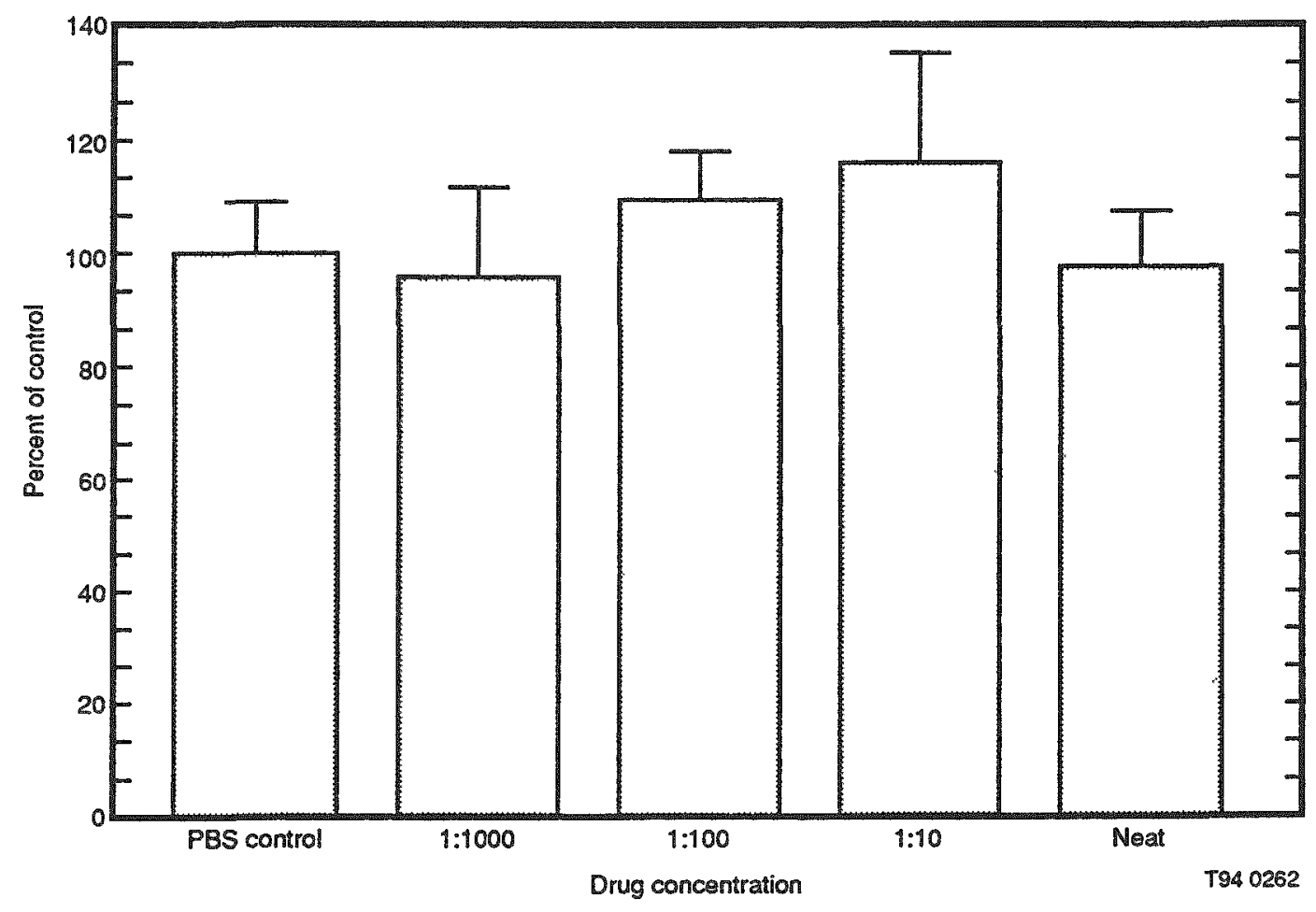

Figure 19. In vitro cytotoxicity of the indicated liposomal-encapsulated boron compound on growth of Lewis lung carcinoma.

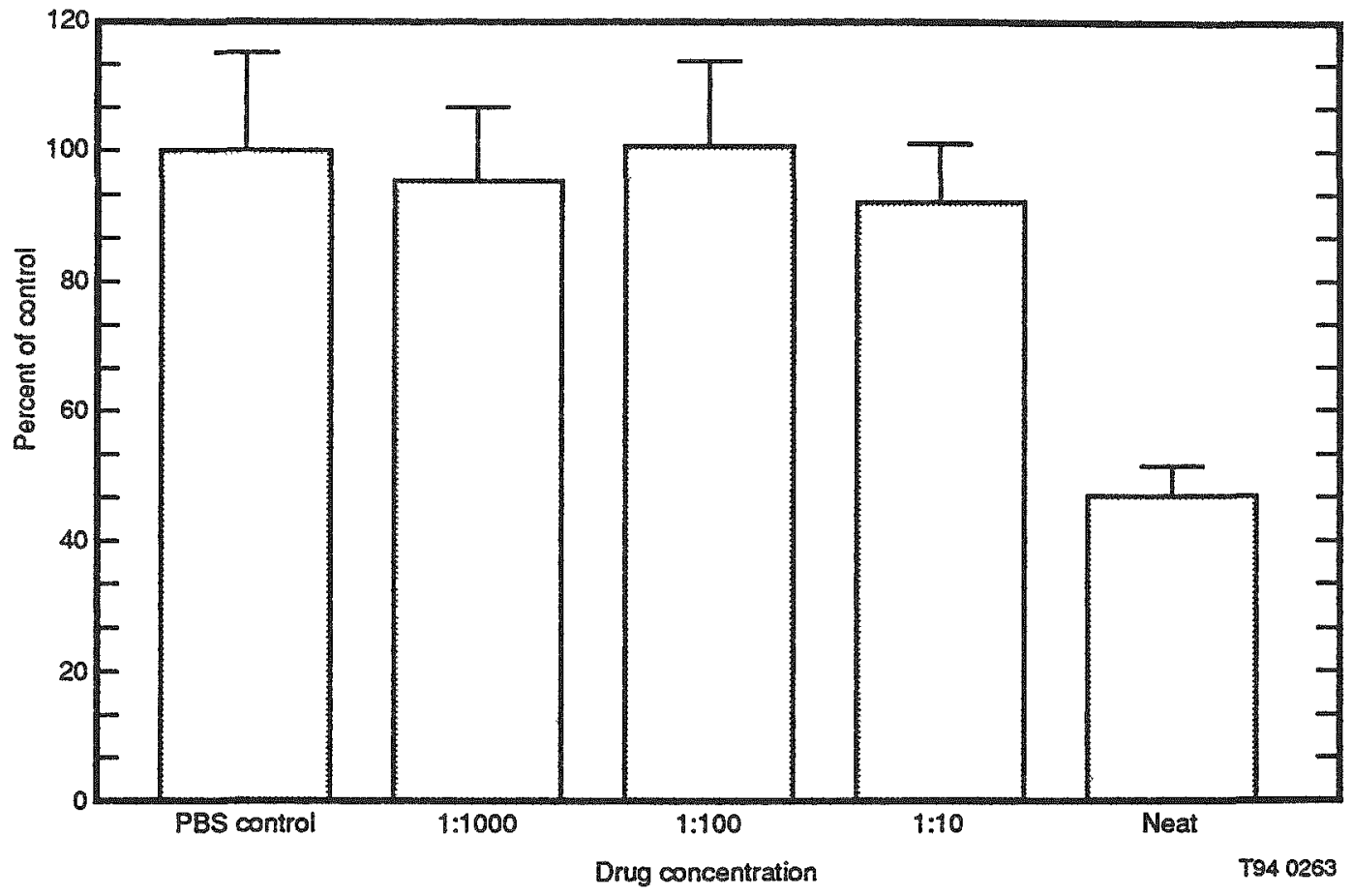

Figure 20. In vitro cytotoxicity of the indicated liposomal-encapsulated boron compound on growth of Lewis lung carcinoma. 


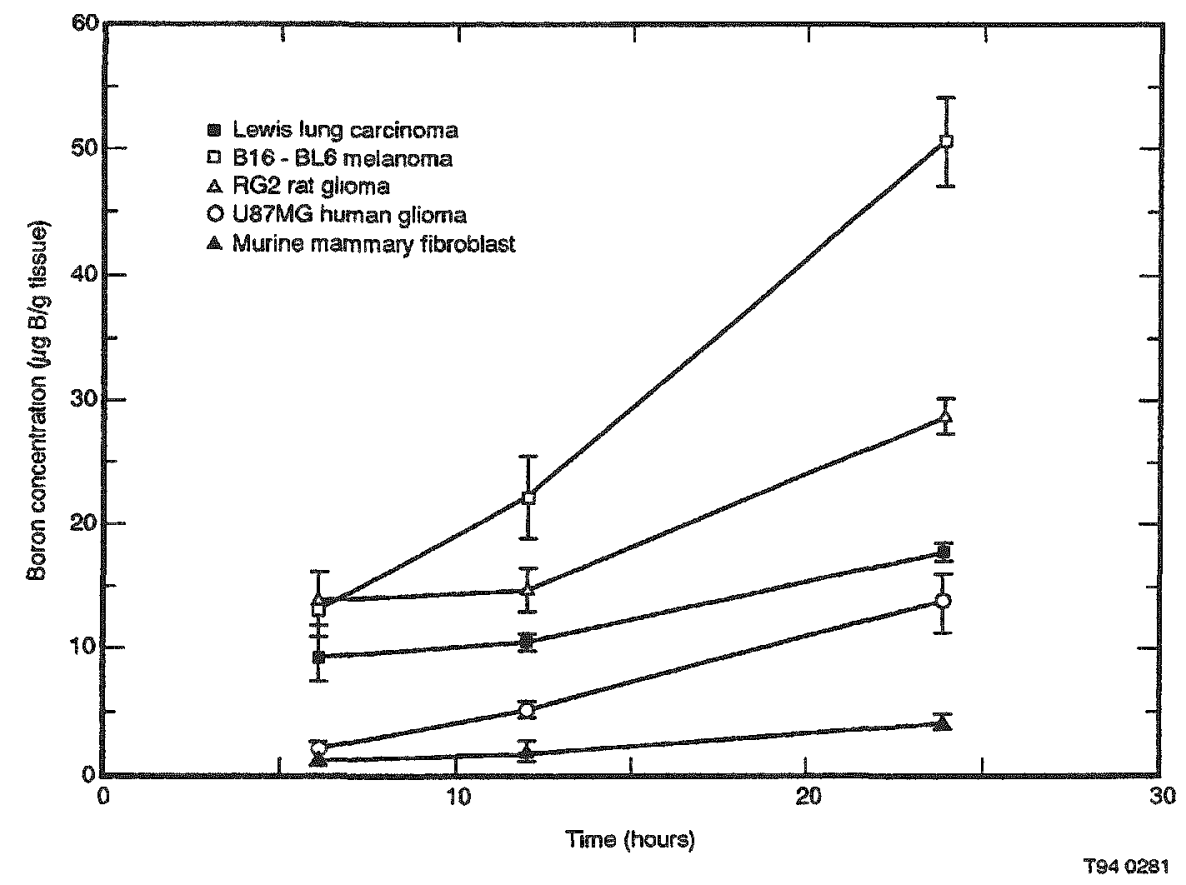

Figure 21. In vitro uptake of boron by B16-BL6 murine melanoma, RG2 rat glioma, U87MG human glioma. Lewis lung murine carcinoma, and normal murine mammary fibroblasts exposed to boronated LDL LW-I-95.

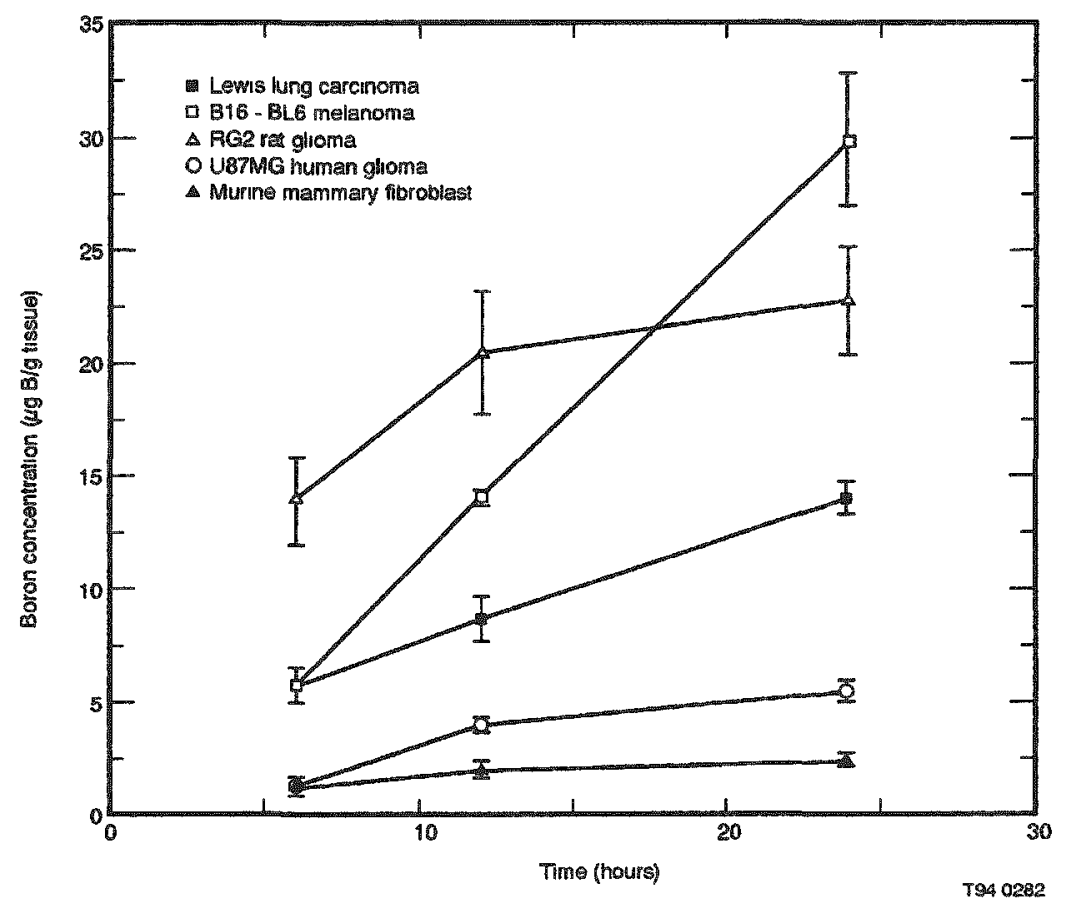

Figure 22. In vitro uptake of boron by B16-BL6 murine melanoma, RG2 rat glioma, U87MG human glioma, Lewis lung murine carcinoma, and normal murine mammary fibroblasts exposed to boronated LDL LW-I-87. 


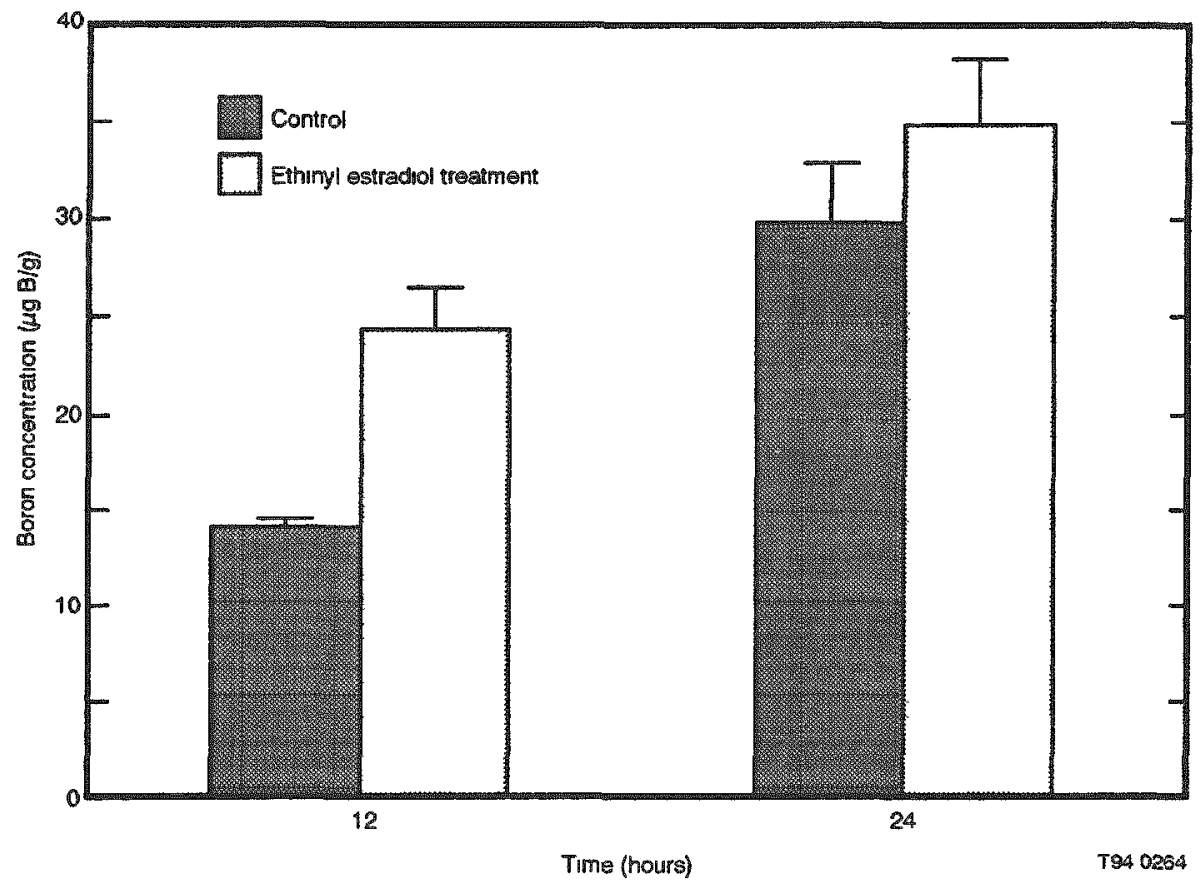

Figure 23. Effect of ethinyl estradiol pretreatment on in vitro uptake of boron by B16-BL6 murine melanoma exposed to boronated LDL LW-I-87. Cell cultures were pretreated with $1 \mathrm{nM}$ ethinyl estradiol 24 hours prior to addition of $200 \mu \mathrm{L}$ of boronated LDL.

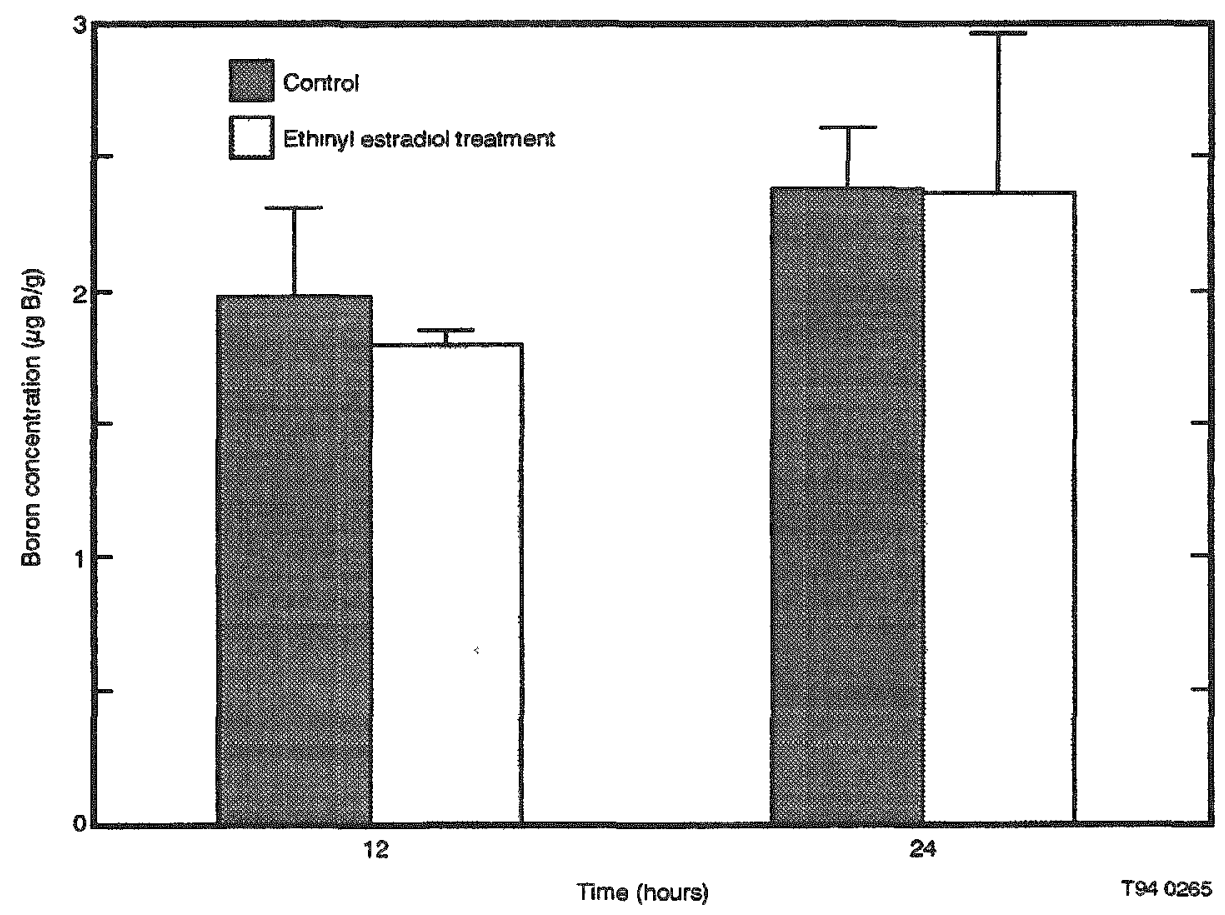

Figure 24. Effect of ethinyl estradiol pretreatment on in vitro uptake of boron by normal murine mammary fibroblasts exposed to boronated LDL LW-1-87. Cell cultures were pretreated with $1 \mathrm{nM}$ ethinyl estradiol 24 hours prior to addition of $200 \mu \mathrm{L}$ of boronated LDL. 


\section{PHARMACOLOGY AND TOXICOLOGY OF BSH}

\section{Dr. Tom LaHann, PI, ISU, College of Pharmacy}

\section{The Approach to Safety Testing}

We begin with the assumption that clinical utilization of $\mathrm{BNCT}$ will necessitate interstate commerce. A new drug or drug-radiation combination (e.g., BSH-mediated BNCT) may not be introduced into interstate commerce without a new device exemption (NDA). The Food and Drug Administration (FDA) approves an NDA for BNCT if the sponsor demonstrates that the drug. radiation, and drug-radiation combination are reasonably safe and that the drug-radiation combination is effective for its intended application. The definition of reasonably safe is influenced by the risk of available alternatives, including risks associated with not undertaking the treatment. With glioblastoma multiforma, the risk associated with not undergoing BNCT is roughly a 97\% chance of dying from the cancer within 3 years. From a regulatory standpoint, the high probability of death in the absence of BNCT means that a moderate risk associated with BNCT should be acceptable, as long as the risk is reasonably well defined. To obtain evidence of safety and efficacy, the sponsor performs studies in animals (preclinical studies) and in humans (clinical studies). Clinical studies are typically performed under an investigational new drug (IND) request. A primary goal of preclinical testing is to aid in assessing if proposed human studies of the drug are likely to be acceptably safe, and the IND request submitted in support of clinical trials must contain sufficient information about the drug to conclude that it is reasonably safe to begin human testing at the proposed dose levels. The type and amount of preclinical safety information required depends upon the proposed clinical studies, the intended route of administration, the proposed dose schedule, and the history of past clinical use of the drug or structural derivatives. The two boron delivery drugs for BNCT currently attracting the most interest are BSH and BPA. Efforts of the U.S. National Center for BNCT Measurement and Development (National Center) are currently focused on BSH. There is a history of human use of BSH in Japan and Europe, but given the toxicity of BSH in animal models, it seems that clinical evaluation of BSH within the U.S. will require additional animal testing to better characterize risks associated with $\mathrm{BSH}$ administration.

Initial clinical evaluations are likely to employ BSH doses similar to those used in Japan and Europe, i.e., BSH doses no greater than $100 \mathrm{mg} / \mathrm{kg}$ (approximately equivalent to $50 \mathrm{mg}$ boron $/ \mathrm{kg}$ ). The Goodman/Ohio State IND request (\#34,687) submitted to the FDA in 1990 and currently on clinical hold, asked permission to dose humans with up to approximately $200 \mathrm{mg} / \mathrm{kg} \mathrm{BSH}$ (boron: $100 \mathrm{mg} / \mathrm{kg}$ ). Because theoretical calculations indicate that the efficacy of BNCT is dramatically enhanced by increasing tumor levels of boron, higher dose BSH studies can also be anticipated. Thus, two separate toxicity issues can be identified:

1. What battery of toxicity tests is necessary to determine the probable safety of clinical administration of BSH at a maximal dose of $100 \mathrm{mg} / \mathrm{kg}$ (or $200 \mathrm{mg} / \mathrm{kg}$ )?

2. What battery of toxicity tests is necessary to determine the maximum acceptable clinical dose of BSH for administration to humans?

\section{Relevant Data}

\section{Clinical Data}

FDA concerns about the animal toxicology profile of BSH will be influenced by the amount and quality of clinical data available. Clinical data on BSH exist; over 200 people in Japan and Europe have received $\mathrm{BSH}$ doses, mostly in the range of $2-120 \mathrm{mgB} / \mathrm{kg}$. By 1989. Japanese neurosurgeon Dr. H. Hatanaka had treated 98 patients with BSH-mediated BNCT. Several more patients received $\mathrm{BSH}$, but not $\mathrm{BNCT}$. However, almost no data relevant to clinical toxicity have been published. With one exception, ${ }^{14}$ publications make little or no mention of any drug-related toxicities associated with clinical BNCT and no 
mention of any BSH-related deaths. The 1973 Hatanaka paper addressed the issue of "complications," but didn't directly address the clinical toxicity of BSH. Over the last 18-24 months, European neurosurgeons have administered BSH clinically, but we have not had access to their toxicity data. The Europeans have reported that BSH doses below $80 \mathrm{mgB} / \mathrm{kg}$ seem to be well tolerated, while some patients exhibit side effects (itch. flushing, pain) in the $80-100 \mathrm{mgB} / \mathrm{kg}$ dose range. Given close ties that National Center-funded researchers have with the European BNCT consortium, it seems likely that access can be gained to the European database. The final point worth noting about clinical studies is that the majority of published clinical studies of $\mathrm{BSH}$ utilize BSH doses less than $120 \mathrm{mgB} / \mathrm{kg}$.

In developing the ISU research program, attention has been directed at addressing the toxicity concerns likely to be of interest to regulatory authorities. ISU data are summarized and grouped below according to their relevance to specific questions.

\section{Physiological Perturbations Associated with BSH Lethality}

Observations Indicative of BSH-Induced Alterations of Cardiovascular Function: In rats administrated $\mathrm{BSH}$ doses of $500 \mathrm{mg} / \mathrm{kg}$ and above, death usually occurred within 6 hours of the i.v. infusion. This rapid onset suggested a druginduced impairment of either the cardiovascular or pulmonary systems and prompted investigations of cardiovascular and pulmonary function. Pulmonary parameters (rate, flow, and tidal volume) were little affected by BSH until just prior to death. Respiratory depression did not appear to be a primary cause of $\mathrm{BSH}$-induced death, since artificial respiration was not an effective antidote. Cardiovascular parameters were rapidly and substantially altered by BSH administration. Specifically, acute i.v. administration of $\mathrm{BSH}$ :

1. Initially elicited a positive inotropic effect on the heart, which likely results in increased oxygen demand. Over time, cardiac contractility decreased, possibly due to a reduction in oxygen supply or as a result of a direct cardiotoxic effect.

2. Caused a massive increase in total peripheral resistance. This likely resulted in a significant redistribution of organ system blood flow. Preliminary studies indicate that both coronary artery blood flow and renal artery blood flow are markedly reduced.

3. Initially increased arterial blood pressure and elicited variable effects on heart rate. In some animals, heart rate increased, while in other animals, little change was noted until significant cardiovascular impairment was evident. The transient elevation in blood pressure was subsequently replaced by hypotension.

4. Elicited electrocardiogram (EKG) changes indicative of cardiac rhythm disturbances. These disturbances often progressed to frank ventricular fibrillation, causing cardiovascular collapse and death. The worsening of the arrhythmias correlated with the decline in cardiac output, and the precipitous fall in cardiac stroke output predictive of eminent death seemed to be immediately preceded by ventricular fibrillation. Rhythm disturbances may reflect cardiac ischemia secondary to coronary artery vasoconstriction, a direct cardiotoxicity, impairment of CNS control mechanisms, elevated blood potassium levels or alterations in cardiac neurotransmitter release or function.

5. Caused a reduction in cardiac output. Reduction in cardiac output seemed to be associated with the cardiac rhythm disturbances. When the cardiac conduction defects disrupted rhythm sufficiently to elicit ventricular fibrillation, cardiac output dropped precipitously, predicting the imminent demise of the animal.

6. May sensitize the myocardium, making it more susceptible to conduction disturbances and increasing the probability of lifethreatening outcomes in the presence of 
elevated sympathetic tone. Evidence for this is strictly indirect and circumstantial.

Thus, ISU researchers conclude that i.v. infusion of high doses ( $>500 \mathrm{mg} / \mathrm{kg}$ ) of BSH to rats causes death secondary to cardiovascular collapse.

Observations Indicative of BSH-Induced Alterations of Renal Function: Intravenous administrations of BSH at doses of $375-500 \mathrm{mg} / \mathrm{kg}$ were often associated with delayed death, the animals not succumbing until $1-4$ days postinfusion. Control experiments demonstrated that delayed death was not a result of the volume loading, osmolarity imbalances, or the rate of fluid administration, nor was it a function of the placement of indwelling catheters or animal husbandry techniques. The delayed time-to-death associated with these doses of $\mathrm{BSH}$ argue against cardiovascular failure or respiratory arrest as a direct cause of death. Observation indicated that within a few hours of BSH infusion, animals are edematous, had low urine output, and at autopsy. displayed enlarged kidneys. Histopathology and clinical chemistry measurements have been consistent with an impairment of renal function. Measured reductions in renal blood flow suggest a shock-like state may be exacerbating any direct, $\mathrm{BSH}$-induced renal damage. Literature reports also are consistent with the concept of BSH-induced renal damage.

BSH-Induced Perturbation of the Function of Other Organ Systems: Except for ISU data, there is little evidence linking BSH administration to functional impairment of organ systems. However, ISU researchers continue to remind our colleagues not to confuse absence of evidence with evidence of absence. Published literature contains reports of changes in hepatic morphology and of clinical chemistry changes predictive of liver damage. ISU clinical chemistry and pathology studies also are consistent with BSH-induced liver damage and suggest possible impairment of hepatic function. As yet, ISU studies are too limited to offer assurances that the observed alterations in liver morphology and clinical chemistry cannot be ascribed to changes in systemic osmolarity. In addition, no evaluation of how BSH affects liver function has yet been undertaken. Literature reports also note that BSH may affect membrane integrity (e.g., erythrocyte agglutination) and respiratory function. ISU research on the toxicity profile of BPA suggests that additional evaluation of BSH effects on pulmonary and reproductive pathology and function may be prudent. Results of recent experiments indicate that i.v. administration of high doses of BPA-fructose formulations to mice elicited histopathological changes that would typically predict reproductive dysfunction and problems with pulmonary blood-gas exchange. If clinically relevant doses of $\mathrm{BSH}$ produce pulmonary histopathological changes similar to those observed for BPA, pulmonary function studies (stress-testing) may be desirable. Literature review of the toxicity profile of other boron compounds (see below) also raises the possibility of BSH effects on neural function.

Histopathology, Hematology, and Clini-
cal Chemisty Alterations Associated with
IV Administration of BSH: Histopathology on tissues harvested 7 days after high dose BSH administration indicated that i.v. administration of BSH solutions can cause renal necrosis. Renal failure secondary to cardiogenic shock was suspected, primarily because of previously observed. BSH-mediated reductions in cardiac output and renal blood flow. However, preliminary attempts to use antishock therapy to ameliorate acute BSH-induced lethality have failed. Preliminary histological studies have also revealed evidence of hepatic damage. Results of clinical chemistry studies predict tissue damage, including damage to renal, hepatic, and possibly cardiac and pulmonary systems. Clinical chemistry results are not inconsistent with a shock-like effect on the kidneys. They also point to a probable increase in vascular permeability and possibly a membrane disruption effect. High blood potassium levels are seen at the same time that significant cardiac arrhythmias occur. BSH is not exerting a significant effect on the current clinical assay systems or on formed elements in vitro. However, work with initial clinical assay systems suggested that either the presence of BSH or the viscosity of rat plasma was exerting a confounding effect on the clinical 
chemistry results. Plasma-to-whole blood boron ratios are on the order of 1.2 , suggesting $\mathrm{BSH}$ binding to the formed elements of rat blood. Hematology studies demonstrate a marked loss of platelets and hemoconcentration after high dose administration of BSH. The hemoconcentration may be secondary to a $\mathrm{BSH}$-mediated increase in vascular permeability.

\section{Literature Reports of Physiological Alterations Associated with BSH Administration: There has been a notable lack of} studies addressing BSH-induced changes in physiological function. ISU researchers have been able to find only eight papers or reports addressing BSH toxicity issues, and most of these focus on identification of a lethal dose, pathology, and clinical chemistry observations. Only two papers address $\mathrm{BSH}$-induced physiological alterations, Fontenelle et al. concluded that BSH administration alters hepatic metabolism. ${ }^{43}$ She reported that BSH potentiated hexobarbital sleep time. enhanced pentobarbital induction of cytochrome $P-450$, and reduced cytochrome b5 content of liver cells. Hayashi et al. (unpublished industrial report) indicated that high dose $\mathrm{BSH}$ administration elicited respiratory arrest, limb paralysis, and agglutination of red blood cells. ${ }^{44}$ Several of the papers report evidence of $\mathrm{BSH}$-induced hepatic and renal damage, although none actually evaluated hepatic or renal function. Several studies reported that predictors of renal and hepatic damage did revert to normal with time, suggesting that any impairment of hepatic or renal function might be reversible.

Review of the Toxicology of Boronhy drides, Borate, and Related BoronContaining Compounds: Although the chemical structures of borates, boronhydrides, BPA, and BSH differ, published literature indicates that there is overlap in the toxicity profiles of these compounds. Comparing published reports of boron compound toxicity with the results of ISU BSH experiments indicates that:

1. BSH and boranes (e.g., pentaborane, decaborane) elicit similar effects on cardiovascular function. Both:
a. Elicit hypertension followed by hypotension

b. Increase total peripheral resistance

c. Initially increase cardiac contractility, then decrease it

d. Elicit cardiac arrhythmias that progress to cardiac asystole

e. Have been reported to elicit clumping of red blood cells, with consequent vessel blockage.

2. BSH and boranes both can cause gross morphologic changes in liver

3. BSH, boranes, and borates can cause renal tubular necrosis and oliguria/anuria

4. Acute lethality of BSH, borates, and boranes is mediated through cardiovascular collapse at high doses. while for lower doses of borates and boranes, renal failure is a causative factor.

Toxicity comparisons with other boron compounds also suggest several potential complications of BSH administration that have not previously been considered:

1. Boranes, borates, and BPA can cause testicular damage.

2. Borates and boranes inhibit pyridoxal dependent enzymes and interfere with the action of riboflavin. This implies that BSH might interfere with glutamate, histamine, dopamine, norepinephrine, and serotonin neurotransmitter systems, since synthesis of these neurotransmitters is pyridoxal dependent.

3. Borates and boranes alter neurotransmitter release, potentiate CNS depressants, elicit cognitive defects, and/or cause residual brain dysfunction. BSH potentiates the CNS depressant effect of hexobarbital, although it is unclear if this reflects an effect on metabolism or a CNS action. 
4. Renal disease, epilepsy, and vitamin B deficiency are reported to enhance borate toxicity, raising the concern that BSH may be more toxic in "sick" people.

To summarize, secondary actions of $\mathrm{BSH}$ that can or may occur at high doses have been identified. The extent to which these effects may occur at clinically relevant doses is currently unknown. Known and potential physiological effects that can be associated with BSH administration include:

1. Alteration of cardiovascular function, mechanism unknown. Alterations include:

\section{a. Vasoconstriction as reflected by an increase in total peripheral resistance}

b. Cardiac abnormalities as reflected by generation of arrhythmias and reduced cardiac output.

2. Possible alteration of renal function, mechanism unknown

3. Possible alteration of hepatic function, mechanism unknown

4. Possible membrane disruption effect

5. Possible effect on CNS and peripheral nervous system (PNS) neurotransmitter systems

6. Possible impaiment of reproductive function

7. Possible alteration of pulmonary function.

\section{BSH Interaction with Other Biological Agents and Clinical Significance}

For many years, it has been recognized that BSH binds tightly to plasma proteins. The high affinity of BSH to plasma proteins raises concern that BSH administration may displace other protein-bound drugs, increase the free (unbound) fraction of these drugs, and so produce clinically significant side effects. Cancer patients frequently receive glucocorticoids, anticonvulsants, sedative-hypnotics, and diuretics, so the effect of BSH on the plasma protein binding of these agents is of concern. Few in vivo functional studies and no in vitro binding studies of BSH-drug interactions are available. Data from two Japanese clinical phamacokinetic studies of BSH show an initial half-life for blood boron of 6-8 hours, but a much slower beta-phase half-life, low blood boron levels still being detectable 14 days after administration of BSH. Given the high affinity of the BSH-protein binding seen with in vitro binding studies, ISU researchers were surprised that $90 \%$ of blood boron was cleared from the human volunteers within 20 hours (BSH doses of $46-60 \mathrm{mg} / \mathrm{kg}$ ). This raises a question about the ability to extrapolate risk from in vitro binding assays.

Serendipitous functional studies of BSH-drug interactions in rats indicated that BSH rapidly and effectively reverses respiratory paralysis induced by neuromuscular junction blocking drugs; it also reverses the ability of propranolol (beta adrenergic antagonist) to block the vascular action of dobutamine (beta adrenergic agonist). Reversal probably reflects $\mathrm{BSH}$ binding to exogenous drug, reducing free drug concentrations to ineffectual levels. This ability to rapidly reverse the effect of muitiple drug classes is highly unusual and perhaps even unique and, in addition to the obvious drug interaction issues, leads to the question: "If BSH binds exogenous drug substances with high enough affinity to cause changes in physiological function, then might BSH not bind endogenous substances with equal affinity and consequence?" It may be that truly "free" BSH does not exist in the blood; rather, BSH may exist primarily as a complex with other small molecular weight substances present in blood. Thus, BSH toxicity and pharmacokinetics may be altered by preadministration of drugs, and treatment with other drugs or alterations in diet could result in unexpected effects on toxicity or efficacy. Formation of different complexes may explain the interspecies and intraspecies variability already observed for the pharmacokinetic and toxicity profiles of $\mathrm{BSH}$, since the physicochemical nature of the BSH-chemical complexes would likely determine their distribution and thus their propensity for eliciting adverse effects. Data from preliminary studies support this concept, although 
additional experimentation is required to determine if complex formation is actually an important determinant of $\mathrm{BSH}$ distribution and toxicity.

A second concern revolves around literature reports suggesting that $\mathrm{BSH}$ (and other boron compounds) may bind to blood cells. BSH binding to erythrocytes and platelets is of concern because of indirect evidence that suggests such binding may cause cellular agglutination and/or cell lysis. Cell lysis could elevate blood potassium concentrations, precipitating cardiac arrhythmias. Cardiac arrhythmias are the primary cause of death following high dose infusion of $\mathrm{BSH}$ and are temporally associated with high plasma potassium levels. BSH-mediated cell agglutination could block small capillaries, reduce blood flow to critical organs, and cause delayed tissue damage secondary to poor perfusion. Such an effect might explain observed damage to liver and kidney tissue. In addition. BSH-induced platelet activation would result in release of thromboxane $\mathrm{A} 2$. This potent vasoconstrictor might mediate the increase in total peripheral resistance associated with i.v. infusion of BSH.

\section{Acute Toxicity Profile of BSH}

Literature Reports of BSH Acute Toxicity: Other laboratories report that high doses of BSH cause hepatic and renal necrosis, induce erythrocyte aggregation, and cause skeletal muscle paralysis and respiratory arrest. Intravenous administration of $\mathrm{BSH}$ has been reported to kill rabbits at doses as low as $24 \mathrm{mg} / \mathrm{kg}$, but there are also reports that rabbits and other species tolerate i.v. infusions of large amounts of $\mathrm{BSH}$ (e.g., $600 \mathrm{mg} / \mathrm{kg}$ ). The $\mathrm{LD}_{50}$ for $\mathrm{BSH}$ in mice has been variously reported as $73,130,440$, or $>1,000 \mathrm{mg} / \mathrm{kg}$. Researchers at WSU report that dogs have died after i.v. infusion of approximately $200 \mathrm{mg} \mathrm{BSH} / \mathrm{kg}$ (B: $100 \mathrm{mg} / \mathrm{kg}$ ). English investigators recently reported that $\mathrm{BSH}$ doses above $200 \mathrm{mgB} / \mathrm{kg}$ killed their rats. ${ }^{45}$ These researchers suggest that a $\mathrm{BSH}$ dose of $100 \mathrm{mgB} / \mathrm{kg}$ is the maximum safely tolerated by rats.

\section{Acute Lethality of I.V. Administered BSH-Long-Evans and Sprague-Dawley} Rats: Lethality following acute i.v. administration of drug was influenced by dose-rate of administration. physiological state of the animal, and volume-rate of administration. Table 12 indicates that the volume-rate of administration affected the degree of BSH-induced lethality, with infusion of the same dose in larger volumes (i.e., greater dilution) being more lethal. Evaluated volume rates were 283,213 , and $142 \mathrm{uL} / \mathrm{min} / \mathrm{kg}$ (i.e., $17,12.8$, and $8.5 \mathrm{~mL} / \mathrm{hr} / \mathrm{kg}$ ), and rats were observed for 7 days.

Table 13 demonstrates that the rate of administration of $\mathrm{BSH}$, expressed as $\mathrm{mg} \mathrm{BSH}$ administered per minute per $\mathrm{kg}$, affected lethality. Rats were unconscious for the i.v. administration of drug, and instrumented only for recording of lead II EKG. Surviving animals were observed for 7 days. High and low BSH doses (625 and $200 \mathrm{mg} / \mathrm{kg}$ ) were not affected by dose rate of administration, but intermediate $\mathrm{BSH}$ doses ( 375 and $550 \mathrm{mg} / \mathrm{kg}$ ) were. The apparent insensitivity of high dose responses to rate of administration suggests that in acute overdose situations, blood levels may not predict toxicity.

The physiological state of the animal also seemed to affect BSH toxicity. Table 14 illustrates that (a) conscious rats seemed to tolerate BSH better than did anesthetized ones, and (b) anesthetized rats instrumented for measurement of cardiovascular and pulmonary function were much more sensitive to BSH's lethal effects than were anesthetized, noninstrumented ones. Drawing of blood samples also seems to accentuate BSH lethality. Instrumented animals were observed up to 6 hours post-BSH. Noninstrumented animals were observed up to 7 days, but only the results through 6 hours are presented. One possible explanation for these results is that instrumentation acts as a stressor and that stressed mammals are more susceptible to BSH toxicity than nonstressed manmals.

Whether BSH was dissolved in distilled water or $0.1 \mathrm{M}$ phosphate buffered saline had little influence on lethality, and BSH-induced changes in 
Table 12. Infusion of BSH $(550 \mathrm{mg} / \mathrm{kg})$ at different volume rates (dilutions).

\begin{tabular}{|c|c|}
\hline $\begin{array}{l}\text { Ratio of dead/ } \\
\text { injected animals }\end{array}$ & $\begin{array}{l}\text { Infusion rate } \\
(\mathrm{mL} / \mathrm{min} / \mathrm{kg})\end{array}$ \\
\hline \multicolumn{2}{|c|}{$\mathrm{BSH}-550 \mathrm{mg} / \mathrm{kg}$} \\
\hline $7 / 8$ & 17.0 \\
\hline $3 / 3$ & 12.8 \\
\hline $1 / 4$ & 8.5 \\
\hline \multicolumn{2}{|c|}{ Control } \\
\hline $0 / 5$ & 17.0 \\
\hline $0 / 6$ & 12.8 \\
\hline $0 / 4$ & 8.5 \\
\hline
\end{tabular}

Table 13. Effect of dose-rate of BSH administration on acute lethality.

\begin{tabular}{cc}
\hline $\begin{array}{c}\text { Rate of } \\
\text { administration of BSH }\end{array}$ & Ratio of injected/dead \\
\hline $200 \mathrm{mg} / \mathrm{min} / \mathrm{kg}$ (bolus) & Infusion time: $<2 \mathrm{~min}$ \\
\cline { 1 - 2 } BSH-625 mg/kg & Death assumed \\
BSH-550 mg/kg & $3 / 3$ \\
BSH-375 mg/kg & $6 / 4$ \\
BSH-200 mg/kg & $4 / 0$ \\
$28.3 \mathrm{mg} / \mathrm{min} / \mathrm{kg}$ & Infusion time: $<0.5 \mathrm{hr}$ \\
BSH-625 mg/kg & $5 / 5$ \\
BSH-550 mg/kg & $7 / 6$ \\
BSH-375 mg/kg & $3 / 11$ \\
BSH-200 mg/kg & $3 / 0$ \\
$7.1 \mathrm{mg} / \mathrm{min} / \mathrm{kg}$ & Infusion time: $1.5 \mathrm{hr}$ \\
BSH-625 mg/kg & $4 / 4$ \\
BSH-500 mg/kg & $4 / 3$ \\
BSH-375 mg/kg & $3 / 0$ \\
BSH-200 mg/kg & Assumed to be 0 \\
$1.8 \mathrm{mg} / \mathrm{min} / \mathrm{kg}$ & Infusion time: $6 \mathrm{hr}$ \\
BSH-625 mg/kg & $4 / 4$ \\
BSH-550 mg/kg & $3 / 0$ \\
BSH-375 mg/kg & $3 / 0$ \\
BSH-200 mg/kg & Assumed to be 0 \\
\hline
\end{tabular}

Table 14. Effect of physiological state on BSH lethality.

\begin{tabular}{cc}
\hline Ratio of dead/injected & $\begin{array}{c}\text { BSH dose } \\
(\mathrm{mg} / \mathrm{kg})\end{array}$ \\
\hline \multicolumn{2}{c}{ Conscious, noninstrumented rats } \\
\hline $3 / 3$ & 675 \\
$2 / 6$ & 550 \\
$1 / 3$ & 375 \\
Pentobarbital anesthetized, noninstrumented rats \\
\hline $3 / 3$ & 675 \\
$6 / 7$ & 550 \\
$3 / 11$ & 375 \\
$0 / 6$ & 200
\end{tabular}

Pentobarbital anesthetized, instrumented rats

$\begin{array}{ll}2 / 2 & 675-750 \\ 3 / 3 & 375\end{array}$

Urethane anesthetized. instrumented rats

$\begin{array}{ll}4 / 4 & 650-750 \\ 8 / 8 & 375-550 \\ 2 / 3 & 275 \\ 2 / 2 & 200 \\ 1 / 3 & 150\end{array}$

systemic osmolarity cannot explain the observed lethality. In fact, no deaths were observed in animals infused with equal volumes of osmotically equivalent vehicle.

BSH Contaminants-Lethality as a Function of Manufacturer. The odor of BSH differs from lot to lot and even within lots (BSH of the same lot is packaged in 1-gram vials, some of which smell worse than others). The odor difference raises the concern that there might be differences in the amount or nature of contaminants present, which might influence the observed safety profile. Specifications for BSH demand $95 \%$ purity, which is verified for each lot by Dr. W. Bauer, (National Center, INEL). The National Center supplies the BSH, which they obtain from Boron Biologicals. The European BNCT Consortium provided 2 grams of $\mathrm{BSH}$ from 
its English supplier, Centronics Corporation. It is understood that the synthetic routes used by Boron Biologicals and Centronics to produce their BSH differ, and that each manufacturer's BSH has quantitative and qualitative differences in the amount of BSH contamination present. One hypothesis is that ISU experiments are quantifying the toxicity of BSH contaminants rather than the toxicity of BSH. If this were the case, differences would be expected in lethality between lots of BSH with qualitative and quantitative differences in the contaminants present. Table 15 reports the direct comparison of Boron Biologicals and Centronics BSH in terms of their acute lethality. No gross differences in BSH lethality could be detected. Data displayed in Table 15 were collected from rats drawn from consecutive shipments from the same supplier, and volume and dose rates were kept constant. Blood samples from each animal (same number and volume) were drawn approximately hourly, and both sets of experiments were completed within 1 month of each other.

Centronics BSH had a strong odor and resulted in a clear, but slightly yellow-colored infusion solution. By contrast. Boron Biologicals BSH did not always have a distinguishing smell and, when prepared for injection, was a clear, colorless solution. Although comprehensive physiological monitoring was not undertaken in these experiments (to avoid any instrumentation-BSH interactions), the general impression was that the same physiological alterations resulted from administration of either batch of BSH. Although the number of animals evaluated was small, there seemed to be a tendency for the Centronics-treated animals to survive longer (i.e., Centronics $\mathrm{BSH}$ : death in 2-24 hours; Boron Biologicals BSH: death in 2-5 hours). Thus, the conclusion is that there currently is no reason to believe that acute toxicity evaluations of BSH are primarily measuring the toxicity of contaminants present within different lots of BSH.

\section{Subchronic and Chronic Studies}

The effect of repeat administration of BSH on physiological function has not been examined by ISU researchers. The older literature indicates that low dose, repeat administration of BSH does not elicit readily observable toxicities, but these studies are contradicted by the recent studies of Buchar et al., who reported that repeated, low-dose administration of BSH ( $25 \mathrm{mg} / \mathrm{kg} /$ day, 7 days) was associated with definite nephrotoxicity. ${ }^{46}$

\section{Administration, Distribution, Metabolism, and Elimination Pharmacokinetics}

Half-Life of Boron Following BSH Administration: Morris et al. ${ }^{45}$ reported that in rats, a BSH dose of $50 \mathrm{mg} / \mathrm{kg}$ has a half-life of about 4.5 hours. For the same drug. dose, and species, Clendenon et al.. reported a beta phase half-life of 6.2 hours. ${ }^{13}$ Morris et al. reported that higher doses of BSH resulted in slower boron clearance, so with a dose of $75 \mathrm{mg} / \mathrm{kg}$, the half-life increased to 6 hours and with a dose of $100 \mathrm{mg} / \mathrm{kg}$, the half-life increased to 18.5 hours. ${ }^{45}$ These investigators reported that a BSH dose of $200 \mathrm{mg} / \mathrm{kg}$ was lethal. Buchar et al. also reported data suggesting that the kinetic parameters for BSH change as a function of dose. ${ }^{46}$ Specifically, they reported that total body clearance was three times lower after a BSH dose

Table 15. Comparison of the lethality of Centronics BSH and Boron Biologicals BSH.

\begin{tabular}{cccc}
\hline & Centronics BSH & \multicolumn{2}{c}{ Boron Biologicals BSH } \\
\hline $\begin{array}{c}\text { Dose } \\
(\mathrm{mg} / \mathrm{kg})\end{array}$ & Ratio of dead/injected & $\begin{array}{c}\text { Dose } \\
(\mathrm{mg} / \mathrm{kg})\end{array}$ & Ratio of dead/injected \\
\hline 625 & $1 / 1$ & 625 & $1 / 1$ \\
500 & $2 / 2$ & 500 & $1 / 1$ \\
375 & $2 / 2$ & 375 & $2 / 2$ \\
200 & $1 / 2$ & 200 & $0 / 2$ \\
\hline
\end{tabular}


of $50 \mathrm{mg} / \mathrm{kg}$ as compared to a dose of $25 \mathrm{mg} / \mathrm{kg}$. Finkel et al., in a clinical study involving infusion of a BSH dose of about $25 \mathrm{mg} / \mathrm{kg}$ to a terminal patient, calculated a blood clearance half-life of about 7 hours and a total body clearance half-time of about 6 days. ${ }^{47}$ Based on their calculations, they suggested a BSH dose of about $240 \mathrm{mg} / \mathrm{kg}$ might be required for efficacious BNCT. Hatanaka, however, reports successful BNCT with $\mathrm{BSH}$ doses only half that much. ${ }^{48}$

Species Difference in Pharmacokinetics: Joel et al. reported "... a fundamental difference between rats and mice in the rates of metabolism, transport, and tissue exchange of the sulfhydryl boranes." 49 The issue of species differences in the pharmacokinetics of BSH has not been adequately addressed. However. pharmacokinetic parameters dramatically influence toxicity, and selection of animal species without regard to potential difference in pharmacokinetic issues raises the specter of animal toxicity data of no predictive value for humans.

Metabolism Studies: ISU researchers are unaware of any in vivo studies of BSH metabolism in either animals or humans. In vitro studies demonstrate that BSH can be oxidized to dimer of BSH (BSS) and oxidized dimer of BSH (BSSO). Little toxicity data are available for either oxidation product. although in 1966 , Hatanaka et al. reported that mouse $L D_{50}$ values were 62 and $53 \mathrm{mg} / \mathrm{kg}$ for BSS and BSSO, respectively. ${ }^{48}$ Studies by Joel et al. demonstrated that both the toxicity profile and the phamacokinetics of BSS differed from those of $\mathrm{BSH}, \mathrm{BSS}$ being retained longer in tumor. ${ }^{49}$

Current Research. Not surprisingly, there is a linear relationship between BSH dose infused and peak serum boron levels, at least over the dose range of $375-750 \mathrm{mg} / \mathrm{kg}$. Within 1 hour, serum boron levels drop to $50-70 \%$ of their peak values, but then plateau, with little change in serum levels over the next few hours. Preliminary data suggest that the plateau effect is not evident at a BSH dose of $200 \mathrm{mg} / \mathrm{kg}$. Additional studies of the clearance of BSH doses of 100 and $200 \mathrm{mg} / \mathrm{kg}$ are planned. The plateau observed in serum boron levels may reflect an impairment of renal excretion of boron/BSH. 


\section{TREATMENT PROTOCOL DEVELOPMENT}

\section{Dr. Carol Schwartz, Dr. Patrick Gavin, Pl, WSU, College of Veterinary Medicine}

For BNCT to be used successfully in human patients, efficacy and safety of the treatment must be determined. Research at the WSU College of Veterinary Medicine (CVM) employs large animal models to study these aspects of BNCT using BSH as the primary boron delivery agent. Canine subjects are used as the large animal model for several reasons. Their relatively large head and body size more closely approximates that of humans when compared to rats or mice and allows for restriction of the irradiation dose to the head, thus minimizing whole body doses. Use of an epithermal beam (as intended for human patients) requires this size differential to study the effect of irradiation of the head at tolerable total body doses. Another reason for using canine subjects is the spontaneous occurrence of tumors of similar type and at a similar rate as in humans. Research efforts during the past year at the WSU-CVM have concentrated heavily on safety of BNCT in this model.

Safety of BNCT is measured by the tolerance of normal brain tissue to the boron neutron capture reaction. These normal tissue tolerance studies are performed in canine subjects using varying peak physical doses. Response to the treatment is monitored through serial neurological exams, CT and MRI scans, and through postmortem histological exams. During the past year, WSU researchers have been able to define normal brain tissue tolerance endpoints for epithermal irradiation alone and for single and fractionated (two fractions) BNCT schedules for BSH (Table 16). For the fractionated studies, the radiation dose was divided into equal parts given on two consecutive days, with a boron infusion of $25 \mathrm{mg} / \mathrm{kg}$ preceding each irradiation. Studies were also performed in collaboration with Dr. Jeff Coderre at Brookhaven National Laboratories (BNL) in Upton, New York, to determine normal tissue tolerance to BNCT in a large animal model using BPA-fructose as the boron delivery agent.
A sublethal contrast-enhancing lesion in the cerebral cortex (Figure 25) was chosen as the endpoint for normal tissue tolerance studies. This contrast-enhancing lesion has been shown histologically to be consistent with radiationinduced cerebral necrosis. With $\mathrm{BSH}$. the boron is found inside vessels in normal tissue. In fact. almost all boron in normal brain can be accounted for by a $4 \%$ blood volume in the tissue (Figure 26). Given the BSH distribution in the normal brain, brain necrosis is logically due to endothelial damage, and this has been supported by histologic analysis of affected brains (Figure 27).

BNCT utilizing BSH in dogs with spontaneously occurring brain tumors started at the WSU-CVM in 1989 and continues to be an integral part of the research. These treatments provide information on both the efficacy of BNCT (how well BNCT affects tumor growth) and safety (how much BNCT affects normal brain tissue). Nine dogs were screened for presence of a mass in the brain during the past year. Three dogs showed evidence of a brain mass on CT and MRI. Of these, two were considered suitable for treatment consisting of surgical debulking of the tumor followed by BNCT. (The third received surgical debulking. but the mass was nonneoplastic so no irradiation was performed.) This brings the total number dogs treated on the project to 23 (Table 17). One dog remains alive and well 4 years following irradiation alone. A second dog,

Table 16. Normal brain tissue tolerance levels for BNCT.

\begin{tabular}{lc}
\hline \multicolumn{1}{c}{ Treatment } & $\begin{array}{c}\text { Peak physical } \\
\text { dose } \\
(\text { Gy) }\end{array}$ \\
\hline Epithermal neutrons only & 15 \\
Single dose-BSH (25 ppm) & 28.4 \\
Two fraction-BSH (25 ppm) & 27.6 \\
\hline
\end{tabular}




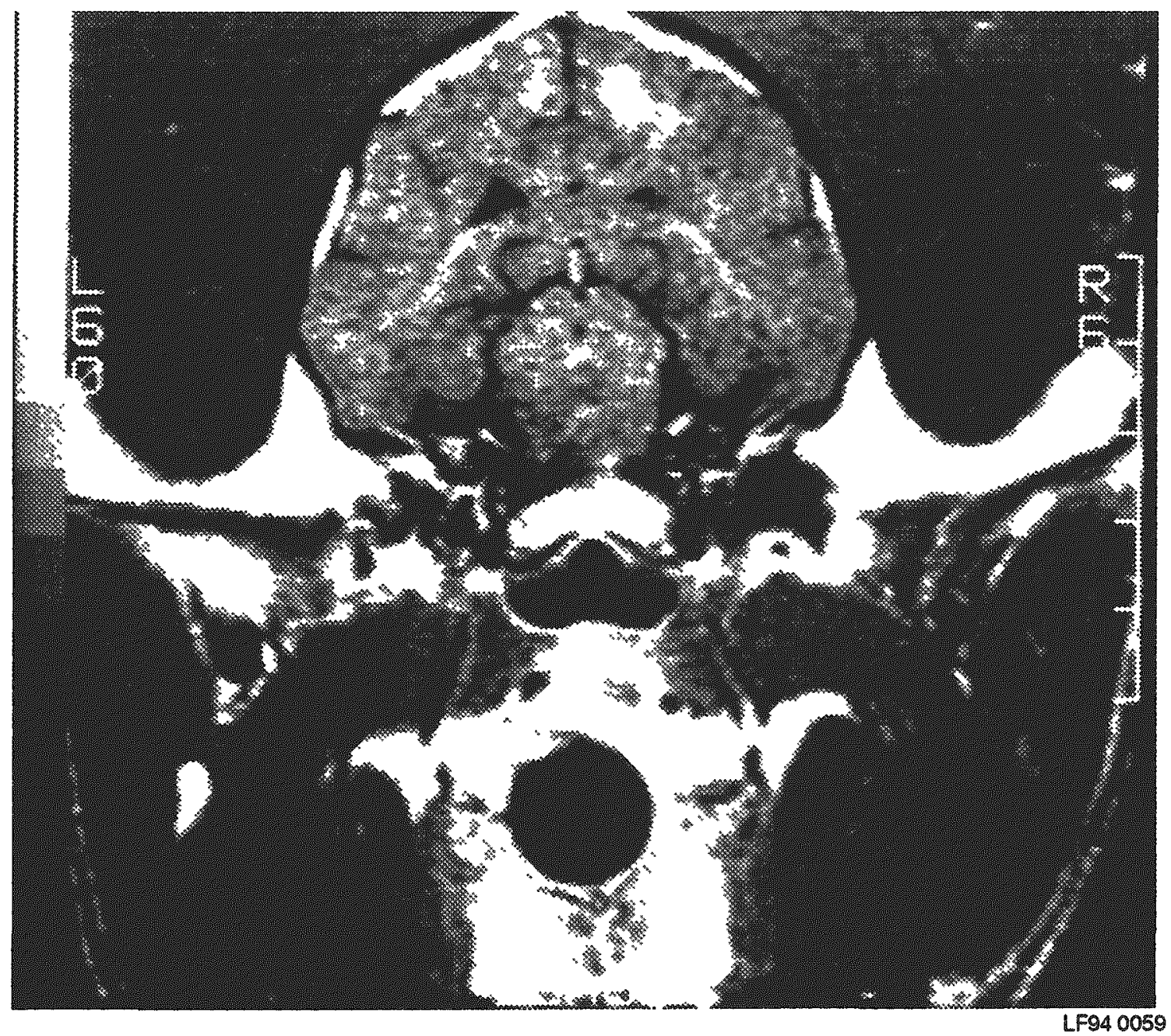

Figure 25. MRI showing radiation-induced, subclinical changes in the brain of a dog treated with BNCT.

which received $\mathrm{BNC}$ irradiation only, remained alive and symptom free for almost 3 years, dying recently of causes unrelated to the tumor. Although combination therapy consisting of surgical debulking followed by BNC irradiation should offer advantages over irradiation alone, low numbers and insufficient followup time to date do not allow definite conclusions.

Studies on dogs with spontaneously occurring brain tumors will continue. These studies will concentrate heavily on intraparenchymal tumors such as astrocytomas, as these more closely approximate the human glioblastoma.

Another aspect of the safety of BNCT that must be considered is the potential toxicity of the vari- ous boron delivery agents. This has been the focus of extensive study at other research institutions, particularly ISU. As an extension of the studies performed at ISU by Dr. Tom LaHann, evaluation of the potential toxicity of BSH is being performed in the large animal model at the WSU-CVM. One major finding in these studies at WSU is the apparent ability of BSH to dramatically affect blood coagulation. The significance of these findings is as yet unknown. Future studies are planned to attempt to further define these changes and their significance.

With the relative success of BNCT with BSH established in brain tumor patients, research at the WSU-CVM has branched into new areas of study. One such area is new boron compound 


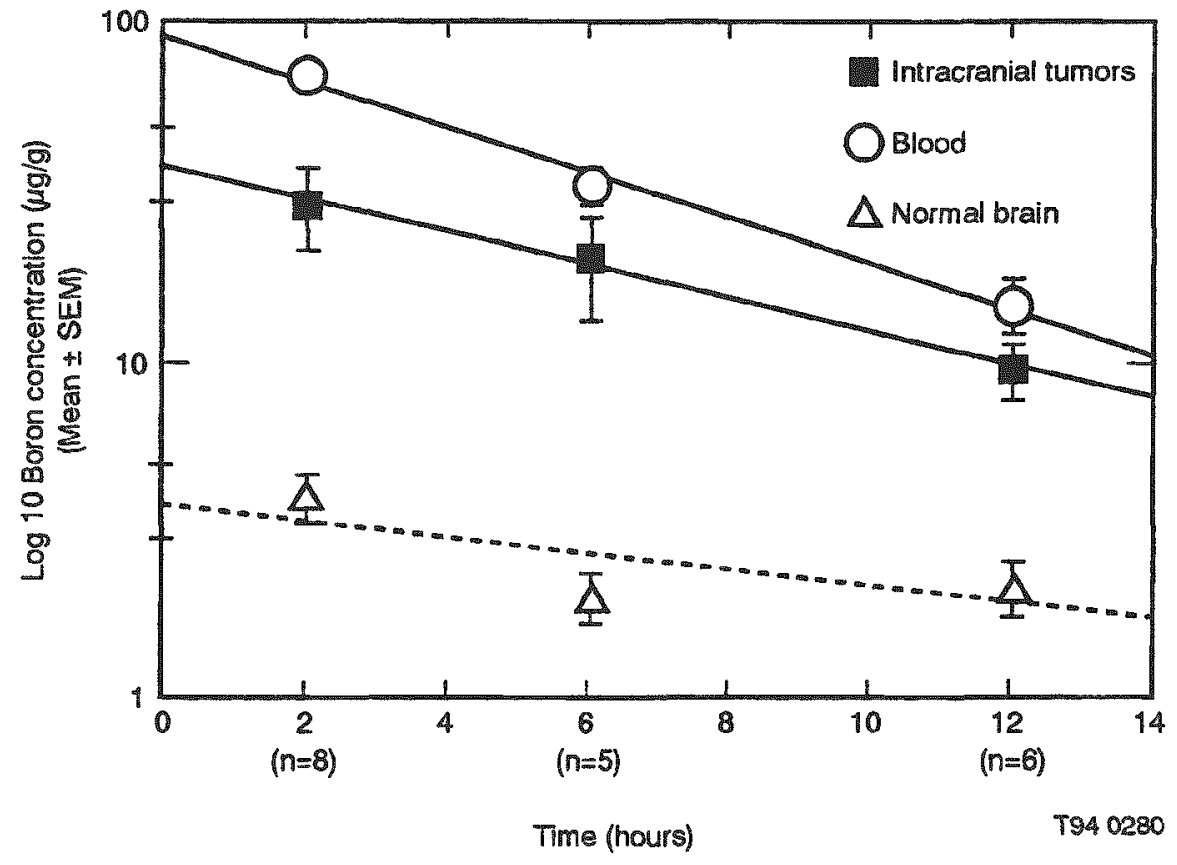

Figure 26. Changes in blood boron levels over time in intracranial tumors, blood, and normal brain. ( $\mathrm{n}=$ number of subjects sampled at 2,6 , and 12 hours).

development. Other research groups both at WSU and at different research institutions across the country have made significant progress in identifying potential delivery agents for boron to various types of tumors. Those that have shown promise thus far include boronated LDL and amino acids, and liposome-encapsulated boron compounds. In collaboration with researchers at UCLA, investigators at the WSU-CVM are studying uptake of liposome-encapsulated boron compounds in a small animal model. These biodistribution studies involve two avenues of investigation. Distribution of boron in tumor and other body tissue following administration of the liposome-encapsulated boron compound will be determined in rats with implanted intracranial brain tumors. Preliminary results show promising results for tumor retention of some agents yielding superior tumor-to-blood ratios compared to BSH or BPA. Studies of various formulations of the compound or vehicle are under way to refine and improve the studies. A second area of investigation involves ultrastructural studies in which stages of the uptake of the liposome-encapsulated boron compound into tumor cells grown in tissue culture will be demonstrated using electron microscopy.
In addition to the brain tumor studies. potential use of BNCT with BSH in dogs with spontaneously occurring lung tumors will be explored. For BNCT to be an effective treatment modality in a tumor system, several factors must be evaluated. The first is the ability to deliver sufficient quantities of boron to the tumor. As with brain tumors, the most easily accessible means of administering the boron will be intravenously. Therefore, a compound with relatively high tumor-to-blood and tumor-to-normal lung tissue ratios must be identified. Again, as in brain tumors, BSH would appear to meet these criteria. Second, the neutron beam must be able to penetrate to the site of the tumor. Unlike the abdominal cavity, which is "filled" with organs and fluid, the relative "emptiness" of the thorax afforded by the air-filled lungs makes beam penetration to relatively deep tumor sites possible. A third consideration is the presence of critical tissues in the path of the neutron beam, which, in these studies, would include the lung, heart, and spinal cord. With these considerations, evaluation of BNCT in lung tumors seems a logical extension of the studies performed with brain tumors. 


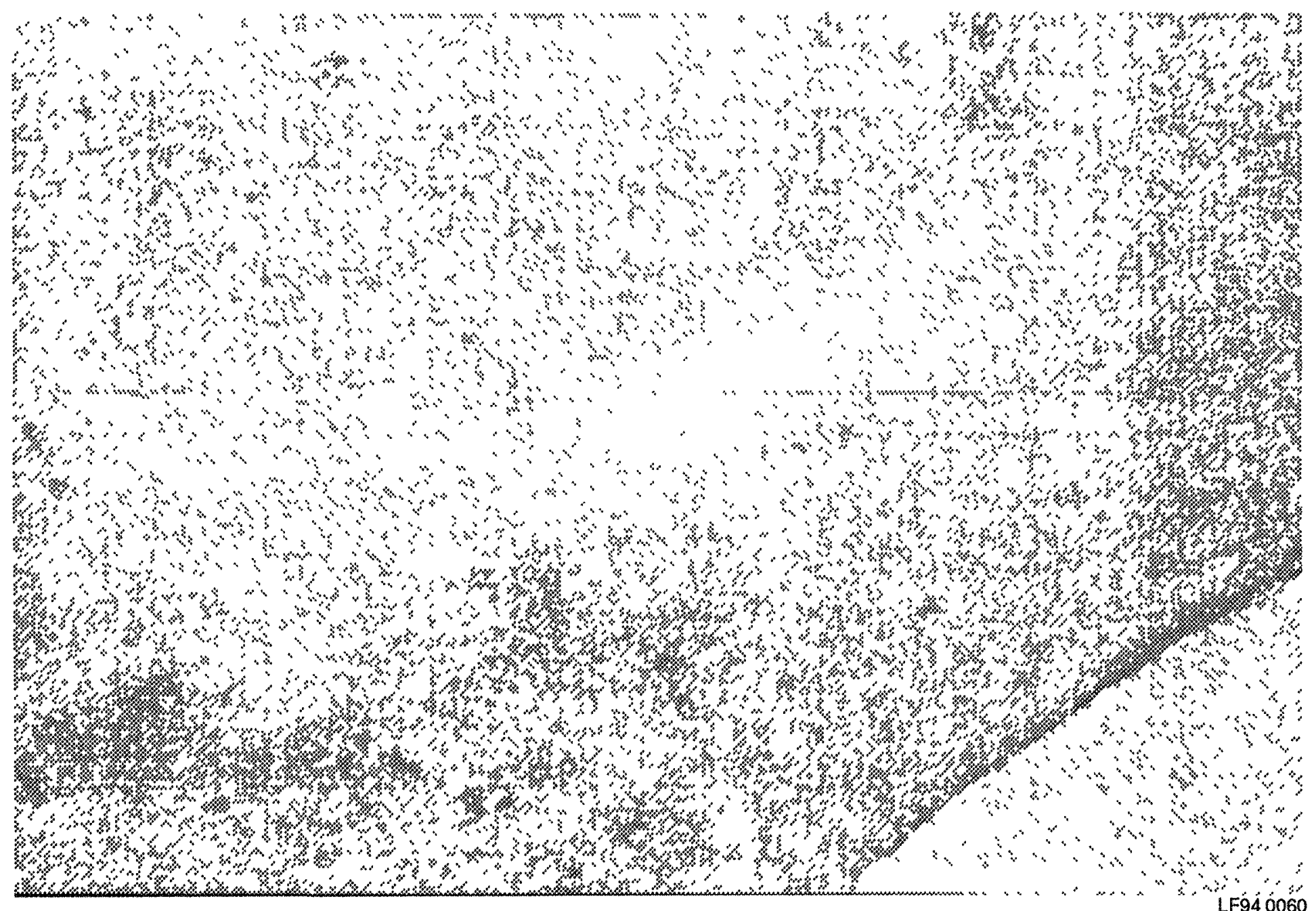

Figure 27. Histologic section of a dog brain showing radiation-induced changes following BNCT. Note the vessel proliferation in areas of necrosis. 
Table 17. INEL BNCT canine tumor treatment study $50 \mathrm{mg}{ }^{10} \mathrm{~B} / \mathrm{kg}$ body weight (BSH administered i.v.).

\begin{tabular}{|c|c|c|c|c|c|c|c|c|c|c|c|c|c|}
\hline \multirow[b]{2}{*}{ Dog 3} & \multirow[b]{2}{*}{$\begin{array}{l}\text { Sex/ } \\
\text { age }\end{array}$} & \multirow[b]{2}{*}{ Name of dog } & \multirow[b]{2}{*}{ Diagnosis } & \multicolumn{3}{|c|}{ Distribution } & \multicolumn{2}{|c|}{$\begin{array}{c}{ }^{10} \mathrm{~B} \text { average } \\
\text { (ppon) }\end{array}$} & \multicolumn{2}{|c|}{ Dose } & \multicolumn{3}{|c|}{ Euthanasia/death } \\
\hline & & & & Date & Time ${ }^{b}$ & Duration $^{\mathrm{c}}$ & Target & Meas. & Target & Calc. & Date & Days ${ }^{d}$ & Cause \\
\hline-79 & $\mathbb{1} / 7$ & "Pugee" Krebs & Oligodendroglioma ${ }^{e}$ & $07 / 07 / 89$ & 375 & 77.8 & 25 & 18.5 & 1900 & 1923 & $06 / 20 / 90$ & 348 & Died-urinary obstruction \\
\hline-80 & $\mathrm{M} / 4$ & "Mugsy" Marshall & Astrocytoma ${ }^{\mathrm{f}}$ & $08 / 07 / 89$ & 369 & 78.0 & 25 & 21.6 & 1900 & 1722 & $08 / 19 / 89$ & 12 & Died-anesthesia \\
\hline-83 & $\mathrm{M} / 11$ & "Rusty" Collins & Meningiomae & $08 / 25 / 89$ & 430 & 68.5 & 25 & 21.4 & 1900 & 1829 & $02 / 11 / 90$ & 170 & Died-focal encephatomalacia \\
\hline-87 & $\mathrm{M} / ?$ & "Benji" Williams & Meningioma $^{e}$ & $09 / 28 / 89$ & 420 & 80.3 & 25 & 20.6 & 1000 & 1653 & $02 / 14 / 90$ & 140 & Euthanasia-PND \\
\hline-93 & $\mathrm{~F} / 6$ & "Brandy" Grudzinski & Oligodendroglimoa ${ }^{f}$ & $10 / 30 / 89$ & 310 & 68.1 & 25 & 24.9 & 1900 & 1912 & $08 / 27 / 90$ & 300 & Died-PND \\
\hline-94 & $18 / 5$ & "Brandy" Hoff & Meningionaf & $10 / 25 / 89$ & 464 & 86.0 & 25 & 14.3 & 1900 & 1887 & - & - & - \\
\hline-95 & $\mathrm{M} / 6$ & ${ }^{\text {"Godfrey" Biers }}$ & Meningioma & $10 / 24 / 89$ & 388 & 63.3 & 25 & 24.5 & 1900 & 1743 & $10 / 25 / 89$ & 0.5 & $\begin{array}{l}\text { Died-PND following } \\
\text { irradiations }\end{array}$ \\
\hline-100 & $H 7$ & "Juno" Bagley & Meningiona & $11 / 30 / 89$ & 315 & 73.0 & 25 & 28.9 & 2300 & 2185 & $01 / 12 / 90$ & 43 & Euthanasia-PND \\
\hline-108 & $\mathrm{~F} / 4$ & "Irixie" Herklotz & Choroid plexus papillomaf & $02 / 16 / 90$ & 225 & 49.0 & 50 & 51.9 & 1900 & - & $06 / 7 ? / 90$ & $115^{h}$ & Unknown \\
\hline-118 & F/9 & "Scuzzy" Jenkins & Astrocytoma $^{e}$ & $10 / 19 / 90$ & 170 & 75.0 & 50 & 85.3 & 2300 & - & $03 / 26 / 91$ & 158 & Died-PND \\
\hline-129 & $\mathrm{~F} / 3$ & "Too Wide" Marshall & Choroid plexus papillomaf & $10 / 18 / 90$ & 210 & 116.0 & 50 & 56.9 & 2300 & 2141 & $11 / 08 / 91$ & 386 & Euthanasia-PND \\
\hline-132 & $\mathrm{M} / 13$ & "Sarge" Smith & Meningionae & $10 / 19 / 90$ & 198 & 164.0 & 50 & 34.5 & 2300 & - & $12 / 12 / 90$ & 54 & Died-GDV surgery \\
\hline-134 & $\mathrm{~F} / 8$ & $\begin{array}{l}\text { "Peggy" } \\
\text { Cunningham }\end{array}$ & Meningiona $^{e}$ & $10 / 29 / 90$ & 198 & 190.0 & 50 & $20.6^{\mathrm{i}}$ & 1900 & 1729 & $12 / 01 / 90$ & 33 & Died-PND \\
\hline-139 & M/11 & "Iloban" Felder & Meningiona $^{\mathrm{e}}$ & $01 / 22 / 91$ & 160 & 83.0 & 50 & 57.5 & 2300 & - & $02 / 04 / 91$ & 13 & Died-leg infection \\
\hline-140 & $1 / 3$ & "Muffy" Lower & Meningioma & $01 / 23 / 91$ & 149 & 152.0 & 50 & 40.3 & 2300 & - & $07 / 08 / 91$ & 166 & Euthanasia-PND \\
\hline-142 & $\mathrm{~F} / 6$ & "Sugar" Hllsworth & Meningiona $^{e}$ & $01 / 23 / 91$ & 168 & 105.0 & 50 & 44.5 & 2300 & - & $07 / 23 / 91$ & 181 & Futhanasia-PND \\
\hline-147 & M/9 & "Bomber" Buck & Malignant meningioma & $02 / 07 / 91$ & 206 & 132.0 & 50 & 37.1 & 2300 & - & $05 / 20 / 91$ & 102 & Euthanasia-PND \\
\hline-151 & $\mathrm{M} / 6$ & "Dudley" Fiset & $\begin{array}{l}\text { Unclassiffed enhancing } \\
\text { mass }^{\mathrm{f}}\end{array}$ & $02 / 28 / 91$ & 211 & 69.0 & 50 & 67.6 & 2300 & - & - & 一 & - \\
\hline-152 & $\mathrm{M} / 10$ & "Zar" Walter & Meningiona ${ }^{e}$ & $03 / 19 / 91$ & 204 & 78.4 & 50 & 60.8 & 2300 & - & $06 / 26 / 91$ & 99 & Euthanasia-nnrelated tumors \\
\hline-155 & $\mathbb{F} / 11$ & "Bessie" Blish & Meningioma $^{e}$ & $08 / 09 / 91$ & 202 & 24.0 & 100 & 101.6 & 2600 & - & $08 / 12 / 91$ & 3 & Died-unidentified \\
\hline$-161 \mathrm{u}$ & M/8 & "Pippin" O'Brien & Choroid plexus papilloma $^{\mathrm{e}}$ & $10 / 24 / 91$ & 178 & 27.2 & 100 & 102.2 & 2600 & - & $11 / 15 / 91$ & 22 & Euthanasia-PND \\
\hline
\end{tabular}


Table 17. (continued).

\begin{tabular}{|c|c|c|c|c|c|c|c|c|c|c|c|c|c|}
\hline \multirow[b]{2}{*}{ Dog ${ }^{\mathrm{a}}$} & \multirow[b]{2}{*}{$\begin{array}{l}\text { Sex/ } \\
\text { age }\end{array}$} & \multirow[b]{2}{*}{ Name of dog } & \multirow[b]{2}{*}{ Diagnosis } & \multicolumn{3}{|c|}{ Distribution } & \multicolumn{2}{|c|}{$\begin{array}{c}\text { 10 B average } \\
\text { (ppm) }\end{array}$} & \multicolumn{2}{|c|}{ Dose } & \multicolumn{3}{|c|}{ futhanasia/death } \\
\hline & & & & Date & $\operatorname{Time}^{\mathrm{b}}$ & Duration $^{\mathfrak{c}}$ & Target & Meas. & Target & Calc. & Date & Days $^{d}$ & Cause \\
\hline-164 & Fi9 & "Crystal" Ard & Meningioma & $03 / 22 / 93$ & 90 & 26.0 & 100 & 96.2 & 3200 & - & $12 / 31 / 93$ & 284 & Died-PND \\
\hline-177 & M/6 & "Ciocco" Peirsol & Meningioma & $12 / 05 / 93$ & 134 & 28.7 & $60-70$ & - & 2600 & - & - & - & - \\
\hline \multicolumn{14}{|c|}{ a. All tumor-treatment study dogs have a prefix number of 35447 . } \\
\hline \multicolumn{14}{|c|}{ b. Time (in minutes) from start of boron administration to start of irradiation. } \\
\hline \multicolumn{14}{|c|}{ c. Irradiation time (in minutes). } \\
\hline \multicolumn{14}{|c|}{ d. Number of posttreatment survival days. } \\
\hline \multicolumn{14}{|c|}{ e. Postmorten histopathology report. } \\
\hline \multicolumn{14}{|c|}{ f. Diagnosis from $\mathrm{CT}$ and/or MRI scans. } \\
\hline \multicolumn{14}{|c|}{ g. PND for several weeks prior to therapy. Dog recovered from anesthesia for 7 hours, followed by rapid deterioration in neurologic condition and death at 13 hours after irradiation. } \\
\hline \multicolumn{14}{|c|}{ h. Dog died sometime the week of June 11, 1990: was buried w/o necropsy. Owner did not retum messages or conmunicate with WSU. } \\
\hline \multicolumn{14}{|c|}{ i. Dog metabolized BSII much faster than predicted by historical pharmacokinetic data curves, resulting in low blood boron value. } \\
\hline \multicolumn{14}{|c|}{ j. These dogs received $100 \mathrm{mg} 10 \mathrm{~B} / \mathrm{kg}$ body weight (BSH administered IV). } \\
\hline \multicolumn{14}{|c|}{ GDV = gastric dilatation volvulus. } \\
\hline \multicolumn{14}{|c|}{ PND = progressive neurologic deterioration. } \\
\hline AND & $=$ act & neurologic deteri & & & & & & & & & & & \\
\hline
\end{tabular}


Preliminary studies in dogs with spontaneously occurring lung tumors will involve evaluating pharmacokinetics of BSH and/or BPA-fructose in lung tumors with further defining of tumorto-blood and tumor-to-nomal tissue ratios. Tissue tolerance and efficacy studies in dogs with spontaneously occurring lung tumors will also be initiated. It is hoped that these studies will be the first in an effort to study the usefulness of BNCT in tumors of other organ systems.

Other studies planned for the upcoming year include an extensive evaluation of alternative boron delivery agents in the large and small animal models developed here. These studies will consist mainly of obtaining biodistribution data for the various compounds in normal and neoplastic tissue. Treatment protocols for the more promising compounds may also be initiated. Collaborative efforts with Dr. Jeff Coderre (BNL) to evaluate efficacy of BNCT with BPA-fructose in dogs with spontaneously occurring brain tumors will also continue. Additional fractionation studies using BSH will also be performed. Although fractionation of the radiation dose in conventional radiation procedures is advantageous, theoretical evidence suggests that this is not the case with BNCT. Limited studies performed thus far tend to support this (Table 16). In these additional studies, the number of fractions will be increased from two to four to further characterize the effect of fractionated dose schedules for BNCT. 


\section{PHYSIOLOGICAL RESPONSE EVALUATION AND INTERDICTION}

\section{Dr. Phillp Rubin, Pl, University of Rochester ( $U$ of $R$ ), Department of Radiation Oncology}

\section{Introduction}

The key to effective BNCT is the selective delivery of a drug containing the stable, naturally occurring isotope boron- 10 to the tumor. The tumor region is then irradiated with low-energy neutrons; the products of the neutron capture reaction, ${ }^{10} \mathrm{~B}(\mathrm{n}, \alpha)^{7} \mathrm{Li}$, are very damaging to tissue, but of extremely short range ( 9 and $5 \mu \mathrm{m}$, respectively) so that the majority of ionizing energy released is confined to the microscopic vicinity of the boron-containing cells. Because the boron compounds are delivered systemically, there is concern that the brain microvasculature might be sensitive to $\mathrm{BNCT}$. Therefore, although BNCT should spare neurons and oligodendrocytes, the major thrust of this research study, carried out by Drs. Rubin, Hansen, and Gash at the U of $R$, in collaboration with Drs. Coderre and Joel at $\mathrm{BNL}$. is to establish direct measurement of the extent of vascular damage following BNCT, indicating the radiation dose range for the different boron salts, e.g.. BSH and BPA.

\section{Selective Radiation Effect of BNCT versus Photon Irradiation}

The 9L rat gliosarcoma is a widely used tumor model for human glioblastoma multiforme and has been used for investigating the effectiveness of single dose or fractionated photon irradiations. ${ }^{50,51}$ Investigators in this group have shown that single dose BNCT of intracerebral 9L gliosarcomas in rats yields up to $50-60 \%$ longterm survivors. ${ }^{52,53}$ Some long-term surviving rats were available from the BNCT-and $x$-irradiated groups and were examined to compare the effects of the respective treatments on brain parenchyma and vasculature.

\section{Experimental Procedure}

The 9L rat gliosarcoma cell line was originally derived from an $\mathrm{N}$-nitrosomethylurea-induced tumor in a Fischer 344 rat, and the cells were maintained in D-MEM supplemented with $10 \%$ fetal bovine calf serum (inactivated). The tumor cells ( $10^{4}$ cells) were implanted $5 \mathrm{~mm}$ beneath the surface of the skull. This technique resulted in a locally expanding tumor in all rats with no evidence of blood-borne metastasis. The experimental groups consisted of long-term (1-year) survivors of BPA-based BNCT and $\mathrm{X}$-irradiation, irradiated 14 days postimplantation, and age-matched controls.

The integrity of the $\mathrm{BBB}$ in the treated and control rats was assessed by determining the extent of horseradish peroxidase (HRP) leakage. Rats were anesthetized and an incision was made superior to the pectoralis muscle, exposing the external jugular vein. Blood was removed $(1.2 \mathrm{~mL})$ to prevent the animal from becoming hypervolemic and possibly compromising the $\mathrm{BBB}$. To prevent a histamine reaction to the HRP, $100 \mathrm{mg} / \mathrm{kg}$ diphenhydram ine hydrochloride (Benadryl) in $0.3 \mathrm{~mL}$ bacteriostatic saline was administered into the exposed jugular vein and allowed to circulate 5 minutes. HRP ( $200 \mathrm{mg} / \mathrm{kg}$ ) was then infused into the jugular vein in $0.7 \mathrm{~mL}$ bacteriostatic saline and allowed to circulate 10 minutes. The brain was then fixed using $3 \%$ glutaraldehyde and $2 \%$ paraformaldehyde in $100 \mathrm{mM}$ sodium cacodylate buffer ( $\mathrm{pH} 7.35$ ). The brains were subsequently frozen, sectioned altemately at 75 and $25 \mu \mathrm{m}$ thickness, and stored at $-20^{\circ} \mathrm{C}$ in cryoprotectant.

\section{Results and Discussion}

Figure 28a shows a coronal section of a normal brain in the area of tumor implantation. On the day of irradiation, 14 days postimplantation. the tumor was a large growing mass extending from the dorsum of the cortex to the midstriatum (Figure 28b). The principal pathologic changes evident in the BNCT-treated brains at 1 year postirradiation were enlarged ventricles and variable 


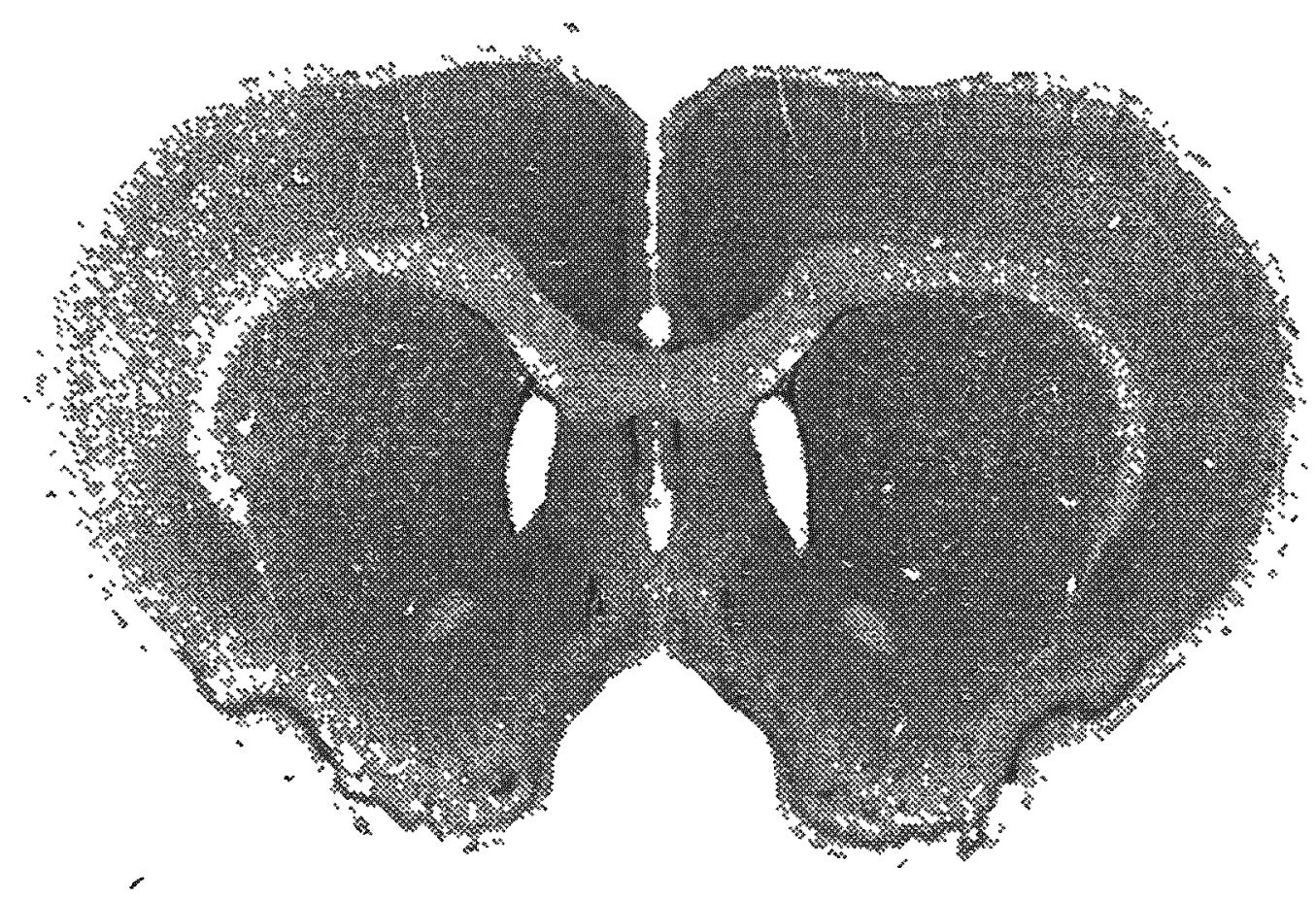

LFF40063

Figure 28a. Coronal section of a normal brain in the area of tumor implantation.

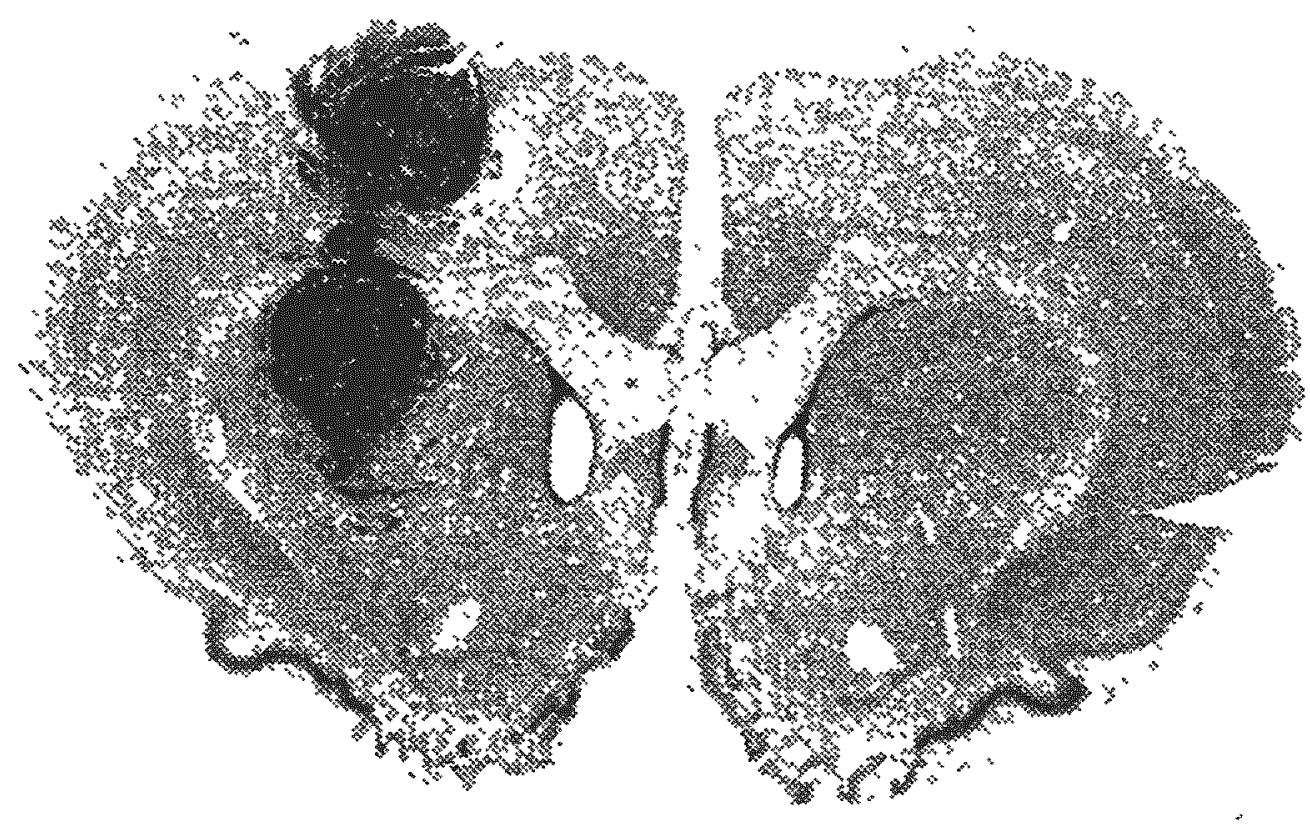

LF94 0062

Figure 28b. Coronal brain sections, 14 days postimplantation, showing tumor growth. 
atrophy of the corpus callosum (Figure 28c); the tumor had been replaced by a collagen-containing scar. In contrast, animals receiving $\mathrm{x}$-irradiation demonstrated severe damage, which was often bilateral (Figure 28d). The cortex and the striatum in the irradiated region were depleted in neurons, and the scar replacing the tumor was more cystic in nature. The corpus callosum was severely atrophied.

Whether the initial insult is to the vasculature or to the parenchyma, normal tissue damage produced during $\mathrm{BNCT}$ of brain tumors is of particular concern due to the presence of significant levels of boron in blood and in the surrounding normal brain during irradiation. The dose distribution in tissue during BNCT is critically dependent upon the location of the boron atoms relative to the nuclei of the target tumor cells and of the normal vascular endothelial cells. Boron analysis at subcellular resolution would be required for accurate estimation of the doses received by tumor cells. normal brain cells, and endothelium (both tumor and normal). Such resolution is not yet practicable in intact tissue sections. However, we have recently derived relative biological effectiveness (RBE) for the high-linear energy transfer (LET) dose components of BPA-based BNCT using the 9L gliosarcoma treated in vivo and assayed in vitro. ${ }^{54}$ Using our derived RBEs, we estimate that the photon-equivalent dose to the tumor is in the order of $51(\mathrm{~Gy}-\mathrm{Eq})$.

Accurate $\mathrm{RBE}$ values are not yet available for ${ }^{10} \mathrm{~B}(\mathrm{n}, \alpha)^{7} \mathrm{Li}$ radiations acting on brain parenchyma or endothelial cells. Based on geometrical factors, the physical dose to the capillary endothelium from the ${ }^{10} \mathrm{~B}(\mathrm{n}, \alpha)^{7} \mathrm{Li}$ $(6.2 \mathrm{~Gy})$ was calculated by adding $1 / 3$ of the dose to the blood and $2 / 3$ of the dose to the brain parenchyma. ${ }^{55.56}$ If the RBEs derived for BPA-based BNCT of the 9L tumor are used to calculate a photon-equivalent dose to the vascular endothelium, a value of $21(G y-E q)$ results. This is clearly an overestimate. Our data show that the damage to the normal brain in the BNCT-treated rats was substantially less than produced by 22.5 Gy x-rays.
Single dose $\mathrm{x}$-irradiations in the $20 \mathrm{~Gy}$ range have been reported to produce a $50 \%$ incidence of white matter necrosis at 1-year postirradiation, although dose curves shown by Calvo et al. ${ }^{57}$ showed a threshold of $17.5 \mathrm{~Gy}$ at which no effects were observed at 1 year. The histological observaLions of the BNCT-treated brains described above showed little or no damage at 1 year, which implies that the photon-equivalent dose to the vasculature and the parenchyma in our BNCT-treated rats was no greater than 17.5 (Gy - Eq). With an estimated tumor dose of 51 (Gy - Eq), our qualitative comparisons of damage to the normal brain parenchyma and to the $\mathrm{BBB}$ in the $\mathrm{BNCT}$ and the $x$-ray groups indicate a therapeutic gain (tumor dose/normal tissue dose) for BNCT of approximately three.

\section{Radiation Effects on Blood-Brain Barrier: Photons Versus BNCT}

This study was designed to examine the effects of irradiation on the $\mathrm{BBB}$ and determine the impact of the altered pathophysiology on the production of CNS late effects such as demyelination, gliosis, and necrosis. The first phase consists of producing $\mathrm{BBB}$ disruption with photons and developing a dose response curve. The second phase will involve producing $B N C T$ injury and correlating the resulting dose response with the photon damage.

\section{Experimental Procedure}

Rats, irradiated over a dose range of 15 to $60 \mathrm{~Gy}$, were serially sacrificed at $2,6,12$, and 24 weeks postirradiation. MRI analysis was obtained prior to sacrifice with selected animals from each group, and the remaining animals underwent HRP perfusion at the time of sacrifice, as described above.

\section{Results and Discussion}

Results discussed here deal mainly with those obtained from $60 \mathrm{~Gy}$ irradiation. HRP perfusion illustrated a progression of events, which was seen initially as a diffuse leakage, discemible at 2 weeks postirradiation following $60 \mathrm{~Gy}$. More 


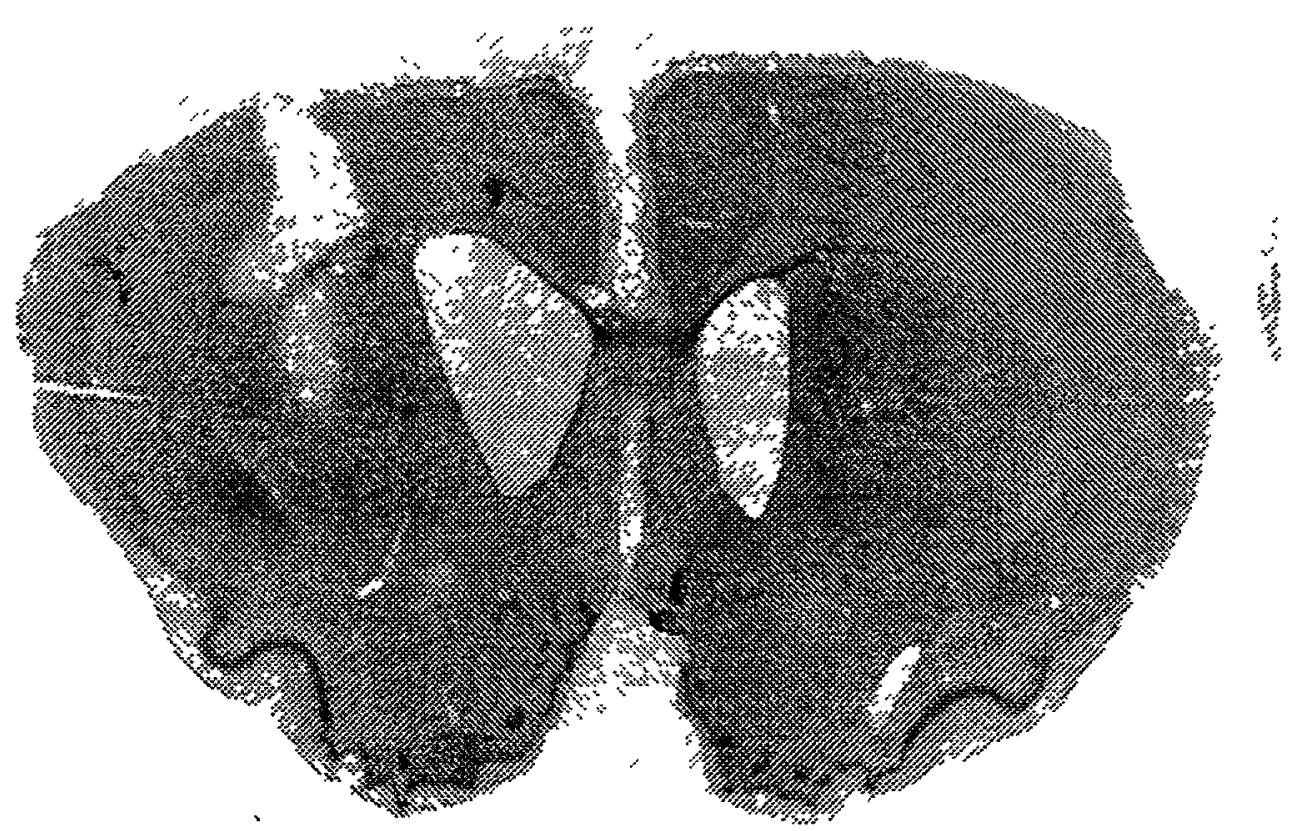

LF94 0061

Figure 28c. Coronal brain sections, 1 year post BNCT treatment.

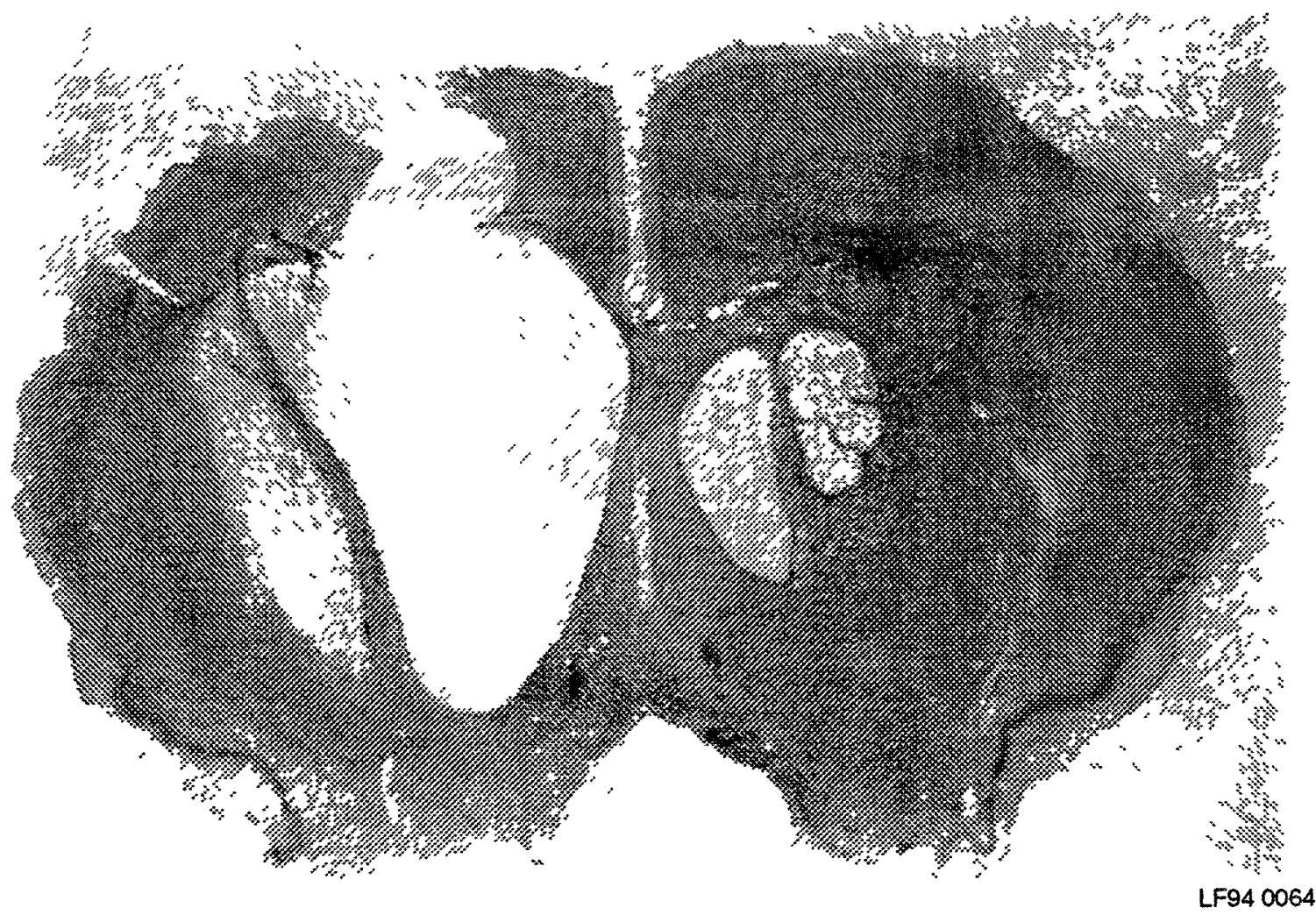

Figure 28d. Coronal brain sections, 1 year post $\mathrm{x}$-irradiation treatment. 
observable damage was visible by 12 weeks postirradiation when there was significant evidence of BBB leakage. The MRI study corroborated the events illustrated by the HRP: leakage of Gd-DTPA (the MRI contrast medium) was observed across the BBB at 2 weeks postirradiation; this was followed by recovery from 6 to 8 weeks, when a plateau, or even decrease, in damage was seen; finally, persistent leakage could be seen by the 24 -week point.

Quantification of $\mathrm{BBB}$ leakage by computer image analysis was performed using the Olympus Cue- 3 system, and involved measuring the leak area as compared with the total tissue area in the cortex, corpus callosum, and hippocampus, respectively (Figure 29). Earliest changes are noted at 6 weeks where BBB leakages show a small increase, particularly in the hippocampus, and are followed at 12 weeks by a small decrease in the BBB leaks in the cortex and hippocampus compared with the 6-week results. The dramatic increment in BBB leakage at 24 weeks is more generalized and is seen in all three areas of interest: the cortex, corpus callosum, and hippocampus. Relative vascular density. measured as the number of vessels per $\mathrm{mm}^{2}$ (Figure 30), showed little reduction from 2-12 weeks postirradiation followed by a more dramatic decrease particularly in the corpus callosum and hippocampus. Cerebral atrophy was estimated using an optical micrometer (Figure 31). Measurements were made in both hemispheres, extending radially every $2 \mathrm{~mm}$ and were carried out on all sections between 0 and $-4 \mathrm{~mm}$ bregma inclusive. These show a confirmatory pattem to the above sequence of events with no measurable loss between 2 and 12 weeks, although atrophy is evident at 24 weeks. These results have demonstrated the ability of the methodologies to identify and quantify early $\mathrm{BBB}$ disruption.

\section{Work in Progress in 1994}

The second phase of the research, involving the determination of the effect of $B N C T$ on $B B B$, has been initiated and is in progress. Physicists at $B N L$ have redesigned the collimator and rat holder, and the project has now entered an accelerated dose program. With the more exacting dosimetry, boron levels of 130 to $170 \mu \mathrm{g}$ $10_{\mathrm{B}} / \mathrm{g}$ and reactor exposures of 5,7 , and $9 \mathrm{MW}$ minutes give doses of up to 25 (Gy - Eq). These animals are being serially sacrificed at 6,12 , and 24 weeks postirradiation. Attempts to increase the BNCT effective dose further have resulted in acute CNS death, observed 24 to 48 hours posttreatment.

In addition, the photon irradiation dose response is being continued at time points from 1 day to 6 months posttreatment. It is anticipated that animals will develop BBB leakages and loss of vascularity as shown in HRP perfusions that will be scored as a function of radiation dose. Since BBB leakage occurs with doses between $20-60$ Gy, it is expected that 25 Gy BNCT will show some evidence of $\mathrm{BBB}$ disruption. Hopewell and coworkers ${ }^{58}$ in a recent study have shown that spinal cord necrosis occurs with BNCT and postulate a vascular mechanism. This study is directed at establishing tolerance of the brain microcirculation to $\mathrm{BNCT}$. 


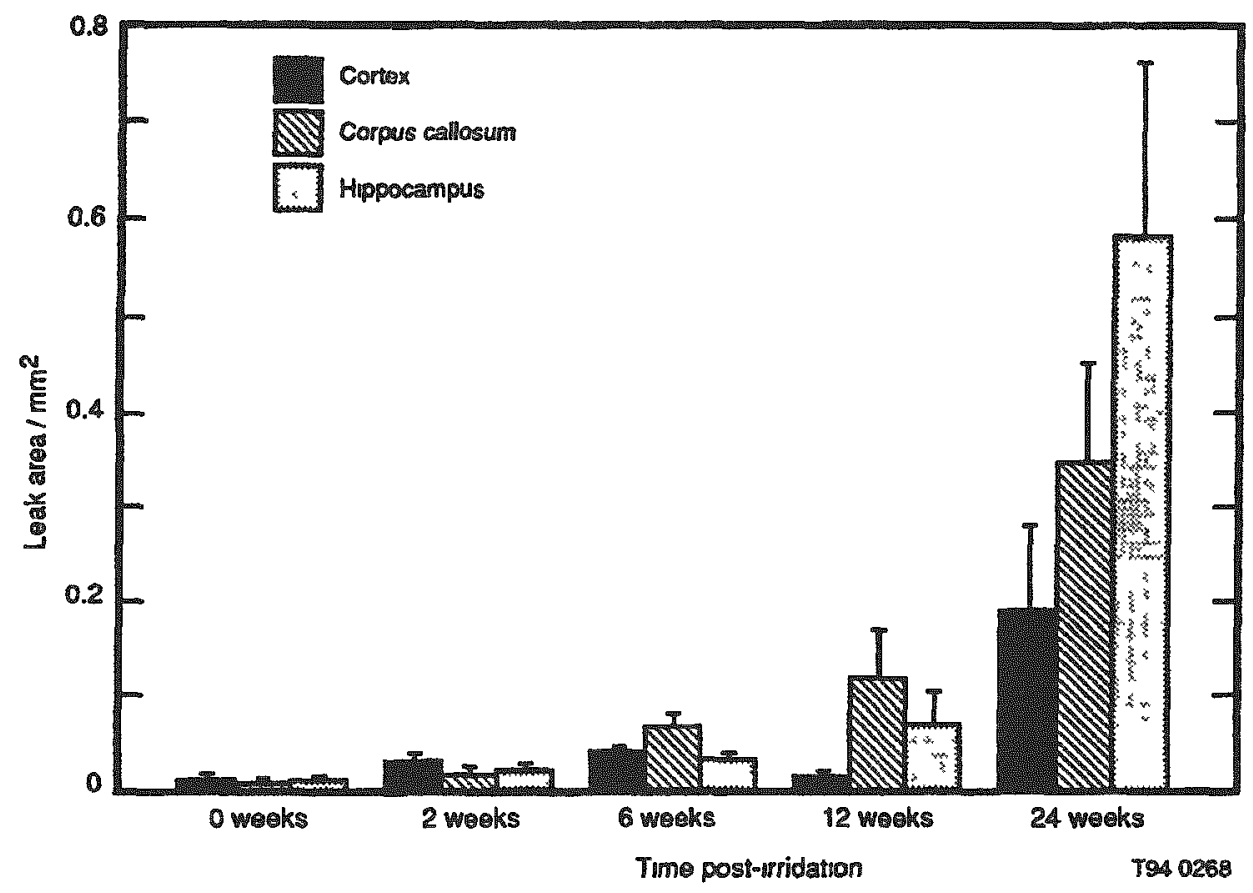

Figure 29. Quantification of blood brain barrier leakage.

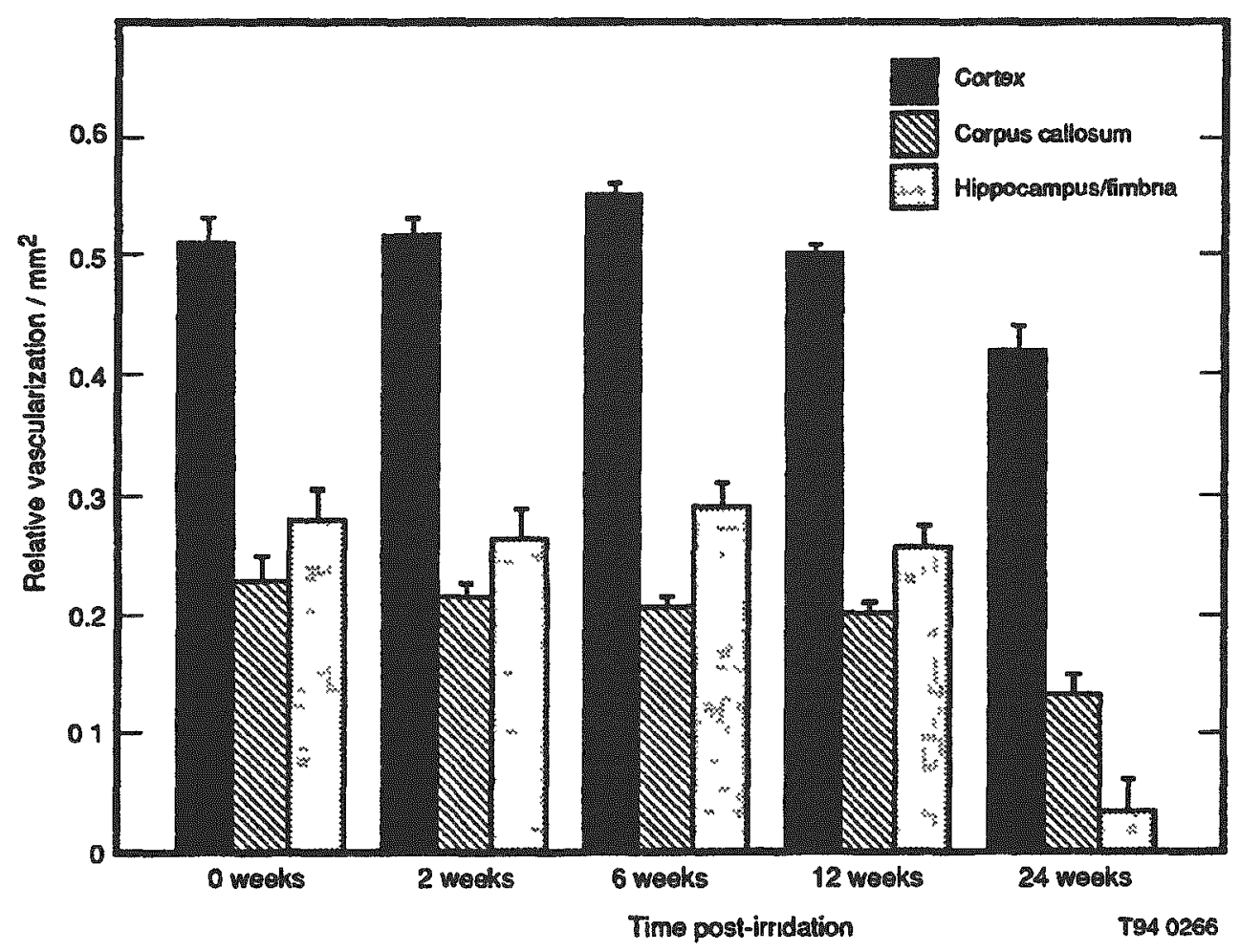

Figure 30. Relative vascular density postirradiation. 


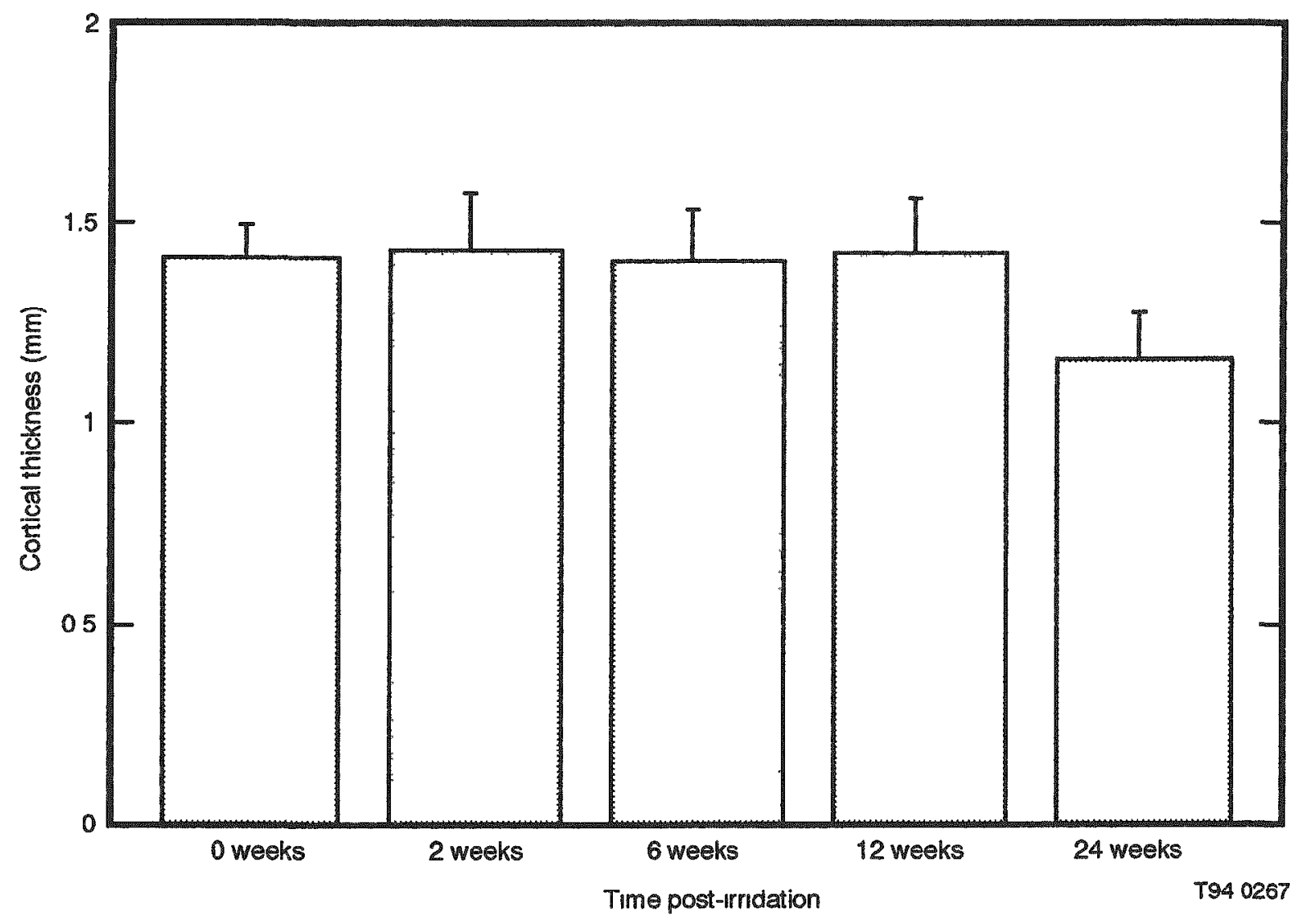

Figure 31. Cerebral atrophy, measured in both hemispheres. 


\section{METHODOLOGY FOR QUANTITATING BORONATED DRUG PHARMACOKINETICS VIA BORON-11 MAGNETIC RESONANCE IMAGING}

\section{Dr. Martin Schweizer, PI, Department of Medicinal Chemistry, University of Utah ( $U$ of $U)$}

\section{Semiquantitative Results on the Implementation of Boron-11 MRI in the Canine Model}

Since the inception of this project in late August 1991. the following population of breed characteristic black Labrador retrievers have been taken through conditioning programs in the Animal Resource Center to certify health and well-being. These dogs include five "normal" dogs and 13 dogs inoculated intracerebrally with canine gliosarcoma ${ }^{59}$ (two received bilateral implantations) of approximately $10^{6}$ cells. In these latter animals, 10 rapidly growing, ring-enhancing lesions developed in eight of them. Three animals were "nontakers" ( $23 \%$ rejection), and two died within 24 hours postinjection of complications. Of the eight tumor-bearing canines, one died prior to BSH infusion, and for one case, no boron- 11 image data were obtained due to machine failure. Thus. to date, boron image data exist for eight tumors in six dogs.

As noted in previous reports, boron-11 images of BSH in normal dog heads show the compound distributed to highest levels in well-vascularized tissue such as tongue, to lesser extent in extracranial muscle, and is not detectable in normal brain tissue. Exclusion from brain is consistent with the ionic properties of $\mathrm{BSH}$, and the higher content in vascular tissue results from the fact that serum albumin is a predominant delivery vehicle. Differential elimination from the different head tissues is readily followed noninvasively in vivo.

In the rapidly growing high-grade canine gliosarcoma. BSH is readily visualized within tumors in the boron- 11 images. An example is shown in Figure 32 for the female Lab, Isabel. On the left is an axial proton image showing a classical ring gadolinium-enhancing $9 \times 12 \mathrm{~mm}$ lesion in the left parietal lobe 10 days postimplantation. Other features include the bright boric acid reference on the top of the head and the evidence of inflamed left temporalis muscle just above the tumor region. On the right is an 8 -minute, $7.5-\mathrm{mm}$ voxel, boron-11 image, taken at the end of infusion of (as BSH) $100 \mathrm{mg}$ boron/ $\mathrm{kg}$. The arrow points to the intensity in tumor tissue. The boron-11 in the reference shows up at the top, and it is evident that BSH is also present in the inflamed muscle tissue. This latter fact somewhat confounds the ability to track BSH levels in the tumor during elimination, because the large voxels. necessary due to the low signal to noise, yields poor resolution between tumor and muscle.

Computer analysis of image intensities in a small region of interest (ROI) within Isabel's temporalis muscle, normalized to boric acid, showed that 40 minutes past the end of BSH infusion. the intensity loss was $40 \%$. The dog was then euthanized and reimaged 10 minutes later. In this postmortem period, the muscle lost an additional $10 \%$ intensity.

In tumor-bearing dogs, where lesions are deeper in the brain, muscle interference is lessened. For example. in Boo (Figure 33) (who developed two enhancing nodules in the left temporal lobe) the BSH washout from tumor(s) and other head tissues can be followed using image intensity changes. This can be seen visually in the two boron-11 images and more quantitatively by computer analysis of tissue intensities relative to the boric acid reference. Thus, at 1 hour past the end of BSH infusion, where the compound concentrations are always greatest, the retention of BSH by tumor was twice that of temporalis muscle.

Similar analyses in other tumor-bearing animals have shown that nondetectable amounts of BSH are present in tumor 3 hours postinfusion termination. Estimates from ICP-AES data are that this detection limit is around $10-200 \mathrm{ppm}$ boron. 




LF94 0068

Figure 32. Axial proton (left) and boron-11 (right) images for dog bearing ring-enhancing lesion in left parietal lobe. FOV-field of view.
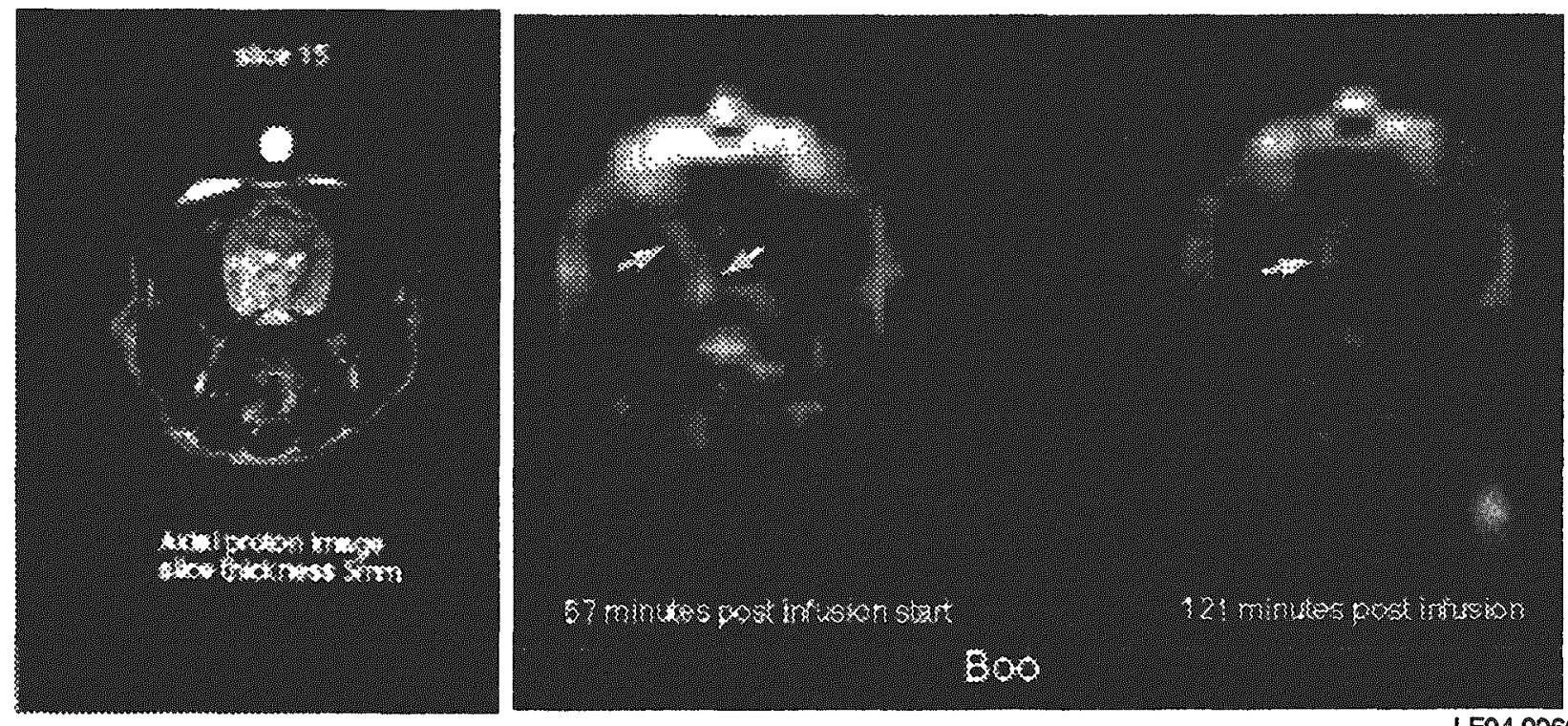

LF940066

Figure 33. Proton MRI (left) and two boron-11 images for Boo, bearing a 9-day gliosarcoma in left temporal lobe (arrow indicates tumor boron intensity). 
More precise quantitative measurements will be available when procedures discussed below are implemented. The current semiquantitative results have been submitted for publication. ${ }^{60}$

\section{Tumor Growth and Blood-Brain Barrier Breakdown}

In the attempt to probe the canine gliosarcomas as to accessibility of drugs, studies have begun of the entry of ionic gadolinium chelates (Magnevist: gadopentetate dimeglumine) as a fairly easily quantifiable substance. Entry of paramagnetic gadolinium into tumor accelerates tumor water proton relaxation. Via measurement of the longitudinal relaxation rate of tumor water with growth ${ }^{61}$, the degree of accessibility of other ionic substances, such as BSH as the tumor matures, can be estimated.

Generally, protocols involved using 2D "spoiled" GRASS and paired inversion recovery, spin echo sequences ${ }^{61}$ in axial slices encompassing the growing tumor and normal brain tissue. T1s were determined before and after injecting $0.1 \mathrm{mmol}$ Magnevist $/ \mathrm{kg}$ (generally $5 \mathrm{cc}$ of liquid) into the saphenous vein, chased with $5 \mathrm{cc}$ saline. These before and after determinations were usually conducted three to four times between innoculation of tumor cells and the terminal boron-11 MRI (a 48-hour interval is planned between the last gado injection and the BSH infusion due to potential competition for tumor binding and sites of the former for the latter).

Typical data are shown in Table 18 for Isabel, a $20 \mathrm{~kg}$ female black Lab who developed the usual gliosarcoma in the parietal parenchyma, which at 10 days postinnoculation was elliptical, $11 \times 14 \mathrm{~mm}$. Her pre- and postgadolinium T1s, and the ratio of post- to prevalues is shown in the table at the indicated days postinnoculation. Whereas these ratios progressively decrease in tumor tissue, denoting faster tumor water relaxation as a result of entry of the ionic chelate into tumor, very little change occurs in nearby normal tissue with an intact $\mathrm{BBB}$.

\section{Quantitative Boron-11 MRI and Spectroscopic Measurements of BSH Concentrations When Bound to Serum Albumin}

To establish quantitative relationships between boron-11 image intensities and $\mathrm{BSH}$ concentrations, investigations have focused upon phantoms containing BSH and serum albumins of known concentrations as well as boric acid standards.

Alterations in the effective magnetic field (B1) due to coil flaws and inductive loading changes from sample to sample are compensated using a dual boric acid reference scheme as outlined in Figure 34. Here, reference 1 is essentially on the coil surface, while reference 2 is near the collection of phantoms containing varying concentrations of $\mathrm{BSH}$ (75 to $250 \mathrm{ppm} \mathrm{B}$ as determined by ICP-AES) in $4 \%(\mathrm{w} / \mathrm{v})$ bovine serum albumin (BSA). For an in vivo experiment, this reference might be taped to the animal's head.

Relating the concentration, $\mathrm{C}_{\mathrm{S}}$, in any phantom (or tissue), with the image pixel intensity, $\mathbb{I}_{s}$ may be given by:

$$
\begin{aligned}
& I_{1}=C_{1} \Psi\left(\mathbf{r}_{1}\right)\left[1-e^{- \text {TR/Tlc }}\right] \\
& I_{2}=C_{2} \Psi\left(\mathbf{r}_{2}\right)\left[1-e^{-T R / T 1 c}\right] \\
& I_{S}=C_{S} \Psi\left(r_{S}\right)\left[1-e^{-T R / T 1 s}\right] B(T)
\end{aligned}
$$

Here, in addition to intensities and concentrations, $\psi(\mathrm{r})$ is the coil calibration factor at distance. $r$, from the coil center, TR is the time between repeat pulses, Tlc are longitudinal relaxation times for calibration references and subject, respectively, and $B(T)$ is an empirically determined binding parameter, temperature dependent, which adjusts for effects on image intensity as a result of binding between boronated drugs of interest and tissue and/or blood components. The concern here is with albumin binding; in vivo applications will need some tissue-specific information.

Simplification of the relationships above may be attained, for example, by eliminating the coil factor 
Table 18. T1 values for gliosarcoma and normal canine brain.

\begin{tabular}{|c|c|c|c|c|c|c|}
\hline & \multicolumn{3}{|c|}{ Tumor } & \multicolumn{3}{|c|}{ Brain } \\
\hline implantation & B Gd & P Gd & Ratio & B Gd & P Gd & Ratio \\
\hline 4 & 0.35 & 0.35 & 1.00 & 0.42 & 0.38 & 0.90 \\
\hline 6 & 0.51 & 0.34 & 0.67 & 0.41 & 0.38 & 0.92 \\
\hline 8 & 0.63 & 0.27 & 0.43 & 0.43 & 0.40 & 0.93 \\
\hline \multicolumn{7}{|c|}{ 2D Spoiled GRASS was used with TR $=5-\mathrm{ms}$} \\
\hline \multicolumn{7}{|c|}{$\mathrm{B}=$ Before gadolinium } \\
\hline \multicolumn{7}{|c|}{$\mathrm{P}=$ Postgadolinium } \\
\hline Ratio $=\mathrm{B} / \mathrm{P}$ & & & & & & \\
\hline
\end{tabular}

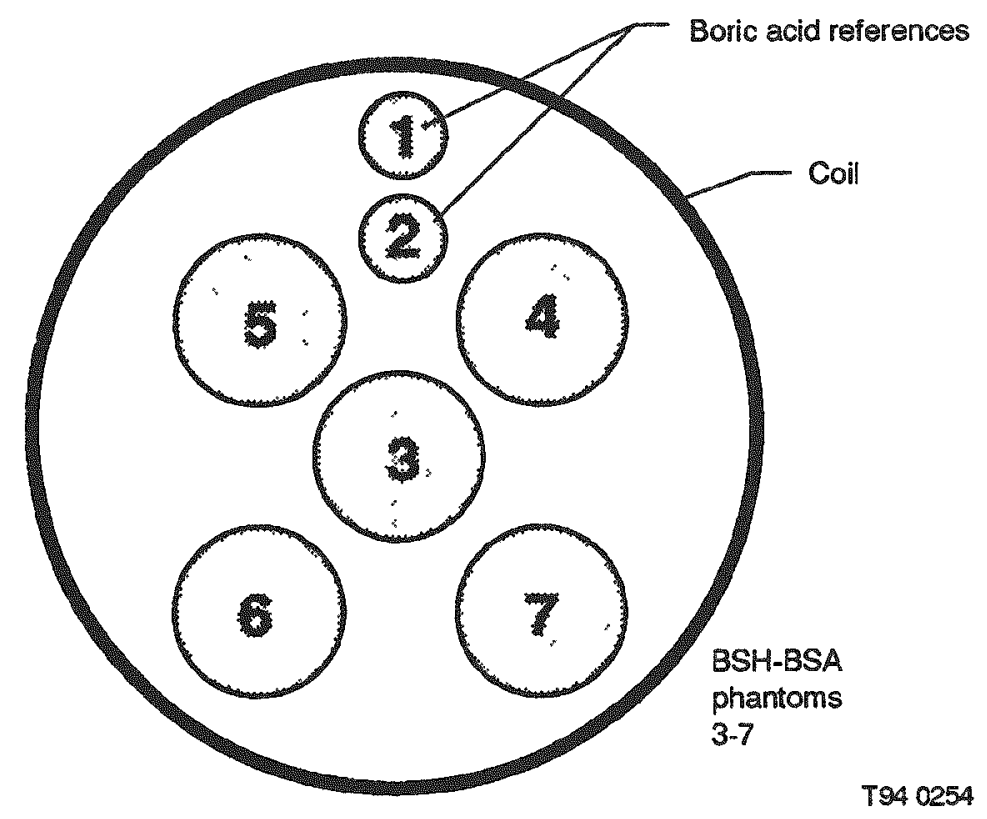

Figure 34. Placement of BSH-BSA phantoms and references within RF coil (axial view). 
if reference and object locations are similar; also, if in any experiment the temperature, reference concentration, and pulse rate remain constant (these constraints are easily met), then:

$$
\mathrm{C}_{S}=\mathrm{K} I_{S} / I_{C} B(T)
$$

Figure 35 contains boron- 11 image intensity versus temperature information for the five BSH/BSA solutions ( $50 \mathrm{~mL}$ plastic bottles and $200 \mathrm{ppm}$ boric acid reference in location \#2, Fig. 34). $T R=6 \mathrm{~ms}$, each $\mathbf{k}$-space (frequency space) projection averaged 64 times, total acquisition times 8.5 minutes. Glover et al. ${ }^{62}$ yielded images with axial views, from which intensities in RsOI were taken and plotted.

Also in Figure 35 it may be noted that the intensities are both temperature and BSH con- centration dependent. This behavior is consistent with a drug-protein interaction in fast exchange such that increase in temperature and/or concentration of drug results in a larger mole fraction of free BSH. Since the signal peak-height is much larger for free BSH compared with bound BSH, the peak-height increases. If the phantom BSH intensity, normalized to boric acid, is plotted as a function of concentration (determined by ICP-AES), for example at $22^{\circ} \mathrm{C}$, one obtains the graph presented in Figure 36 . This definite biphasic curve is thought to represent saturation of BSA binding sites for BSH. Roughly, the intersection of two straight lines drawn through the two lower and three upper points lies at a BSH concentration of $125 \mathrm{ppm}$ (boron). Above this value, BSH is unbound and peak-height is linearly related to concentration.

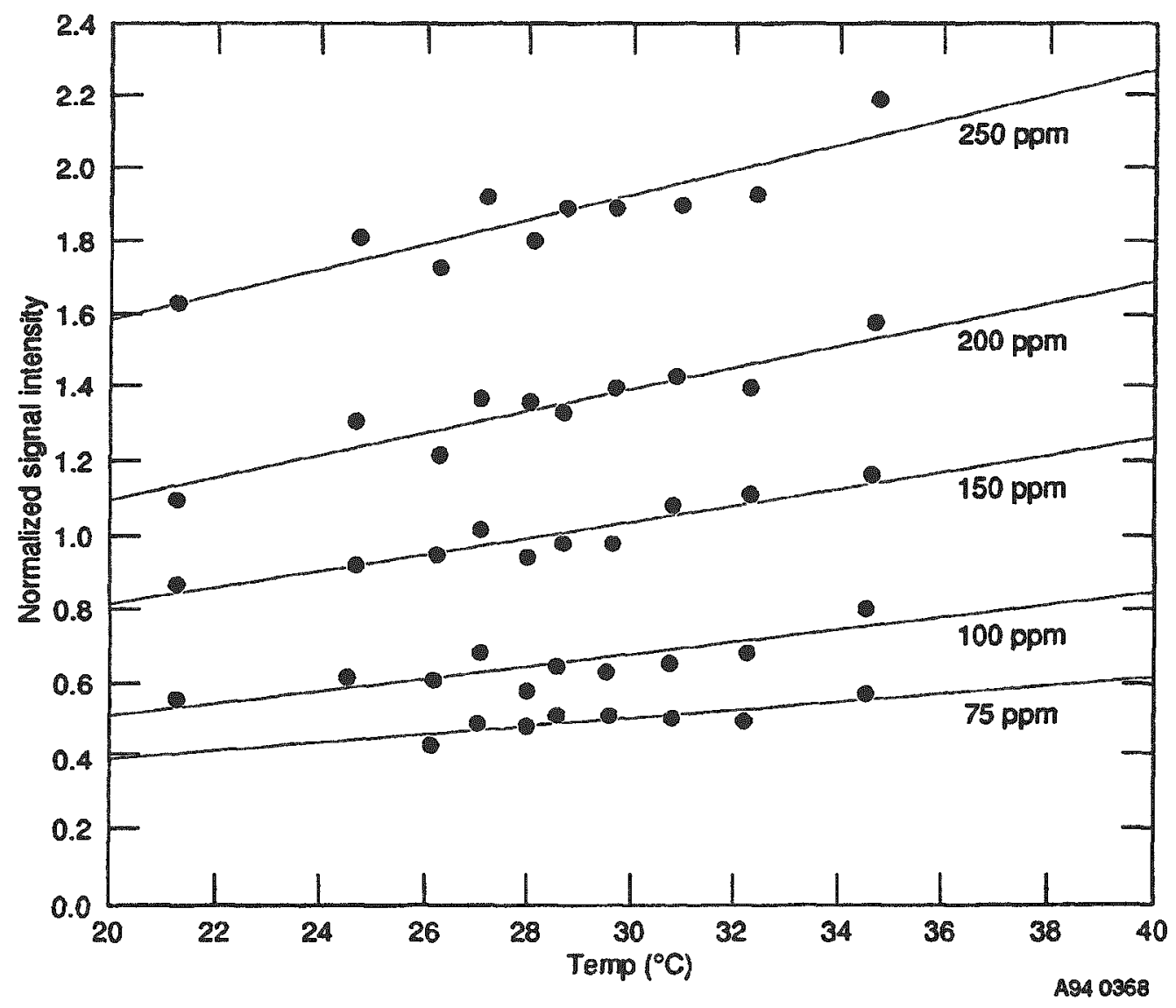

Figure 35. Comparison of BSH in $4 \%$ BSA for different temperatures. 


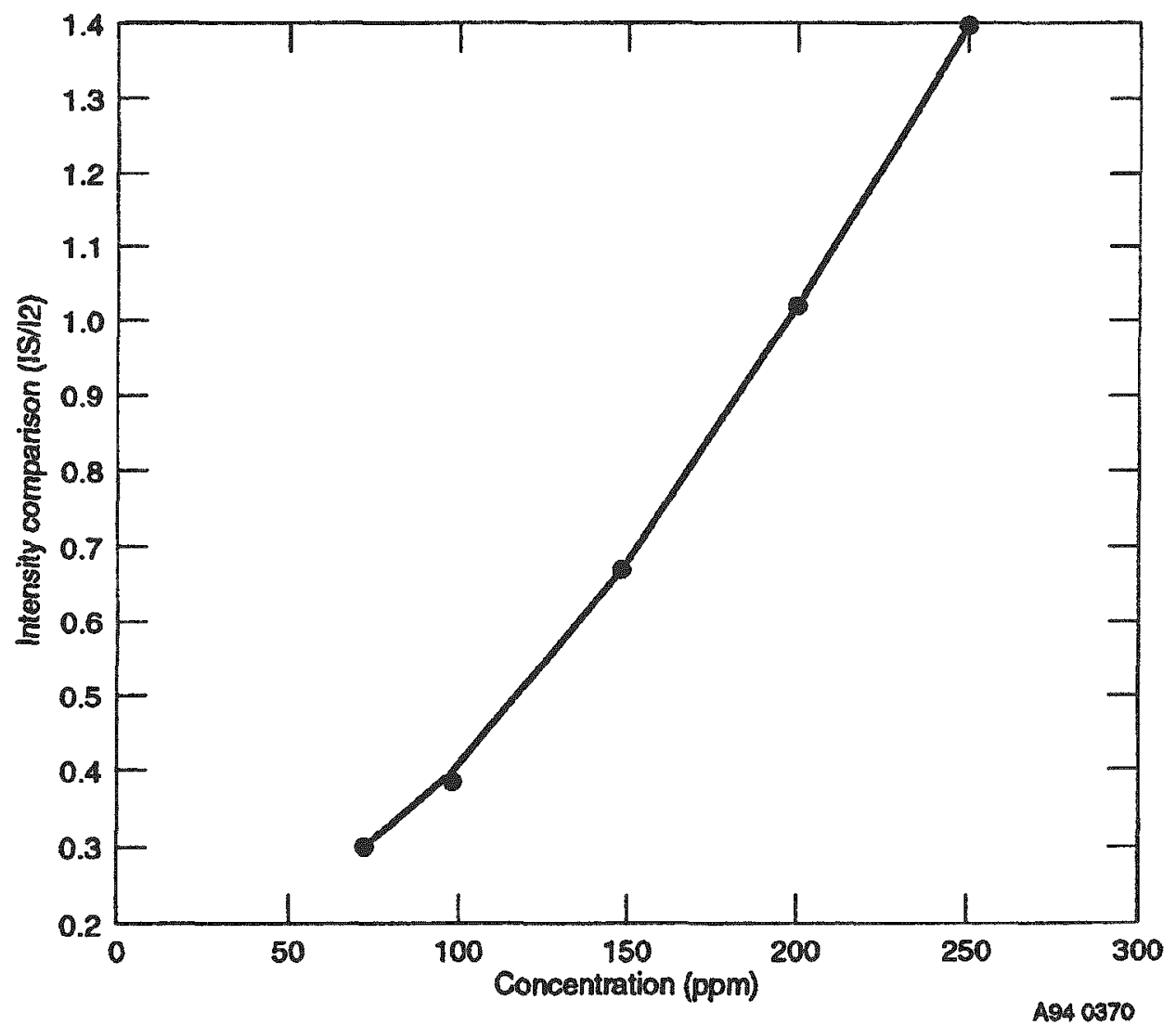

Figure 36. Intensity measurements compared with the actual boron concentrations determined by ICP-AES. Slopes of the higher and lower concentrations intersect at about $125 \mathrm{ppm}$, which is considered to be the saturation of binding sites on the albumin molecule.

These results coincide with the high-resolution data of Tang et al. ${ }^{63}$ who showed, by boron- 11 longitudinal relaxation rates $\left(R_{1}\right)$, that the saturating $\mathrm{BSH}$ concentration in $4 \%(\mathrm{w} / \mathrm{v}) \mathrm{BSA}$ was $150 \mathrm{ppm}$. In this study, these relaxation rates for the four kinds of boron nuclei in BSH (at a concentration of $200 \mathrm{ppm}$ in boron) were titrated with BSA. As shown in Figure 37, saturation is reached, and the relaxation promotion by the protein diminishes.

After improvements in hardware and software, now in process, the above quantitative analysis will be applied to the canine model. Some signalto-noise (SNR) improvements include a data system upgrade to a Sun platform that permits a decrease in the time between pulses from 6 to $3 \mathrm{~ms}$, allowing $2 x$ the number of scans in the same period. Lower system noise has been achieved via placement of preamps and quadrature splitter adjacent to the birdcage coil.

\section{Preliminary Results Involving a Rat Tumor Model}

Transfer of the boron-11 MRI technology to a small animal model such as the rat is desirable to noninvasively evaluate some of the promising new boronated preparations not yet available in sufficient quantities to be tested in the canine model. These preparations might include the liposome-encapsulated $B_{20}$ boron hydrides of Fred Hawthorne (UCLA) and the boronated porphyrins of Steve Kahl (UCSF). 

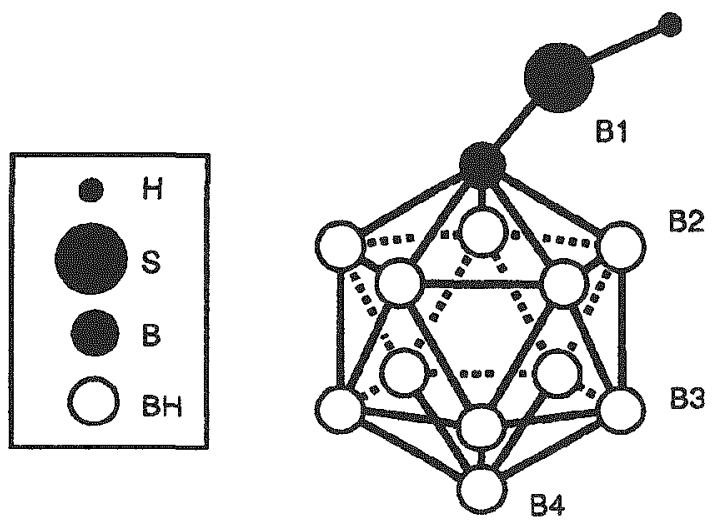

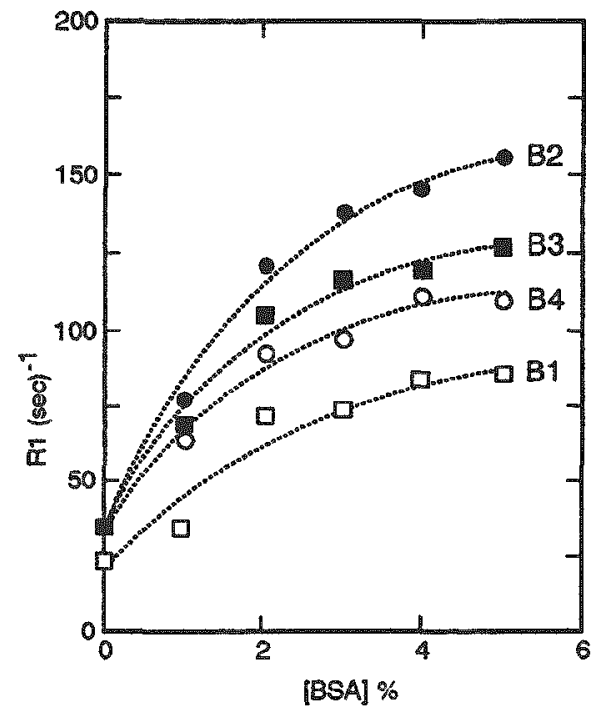

T94 0255

Figure 37. Boron-11 longitudinal relaxation rates $\left(\mathbb{R}_{1}\right)$ for $B S H$ ( 200 ppm boron) nuclei with increases in BSA concentration. Data taken at $160 \mathrm{MHz}$ on 11.75 Tesla Varian Unity 500.

The plan is to implement the methodology on a small bore $(31 \mathrm{~cm}) 2$ Tesla system with high gradient strengths (20 gauss/cm compared with 1 gauss/cm currently on the clinical GE Signa scanner). Upgrading this magnet system will be complete in 1994. Rat gliosarcoma 9L and glioma RG2 cell lines are being grown in tissue culture, and will be followed by intracranial innoculation into frontal cortex. (Frozen aliquots of 9L were obtained from Dr. John Hilton, Division of Oncology, Johns Hopkins University, and RG2 from Dr. Cathy Elstad, WSU.)

The two tumor lines have been successfully grown, harvested, and innoculated into several 200-300 g male, Fischer rats. all of which grew tumors typified by the proton MRI data in Figure 38.

The RG2 tumors were generally smaller and grew more slowly (4-5 mm diameter lesions were produced within 14-17 days with the 9L line. whereas the RG2 tumors at a similar time point postimplantation were $2-3 \mathrm{~mm}$ ).

Using a $6 \mathrm{~cm}$ diameter quadrature birdcage coil tuned to boron- 11 at $20.5 \mathrm{MHz}$ for the 1.5 Tesla magnet, whole body boron-11 images have been taken on nomal Fischer rats in the clinical scanner. These images will be used as a "starting point" with respect to rats.

Figure 39 contains coronal images at $24 \mathrm{~cm}$ field of view (FOV) with a proton scan on the left and corresponding boron-11 images obtained at 50 minutes (center) and 90 minutes (right) after infusion of $200 \mathrm{ppm}$ (boron) as BSH into the lateral tail vein. These 9-minute scans show high intensities in liver (top), bladder (middle), and tail (lower; some BSH was introduced into the tail before the vein was "found"). With higher gradient strengths on the small magnet, the FOV can be reduced and intensities in heads of tumor- bearing rats visualized and quantitated. 


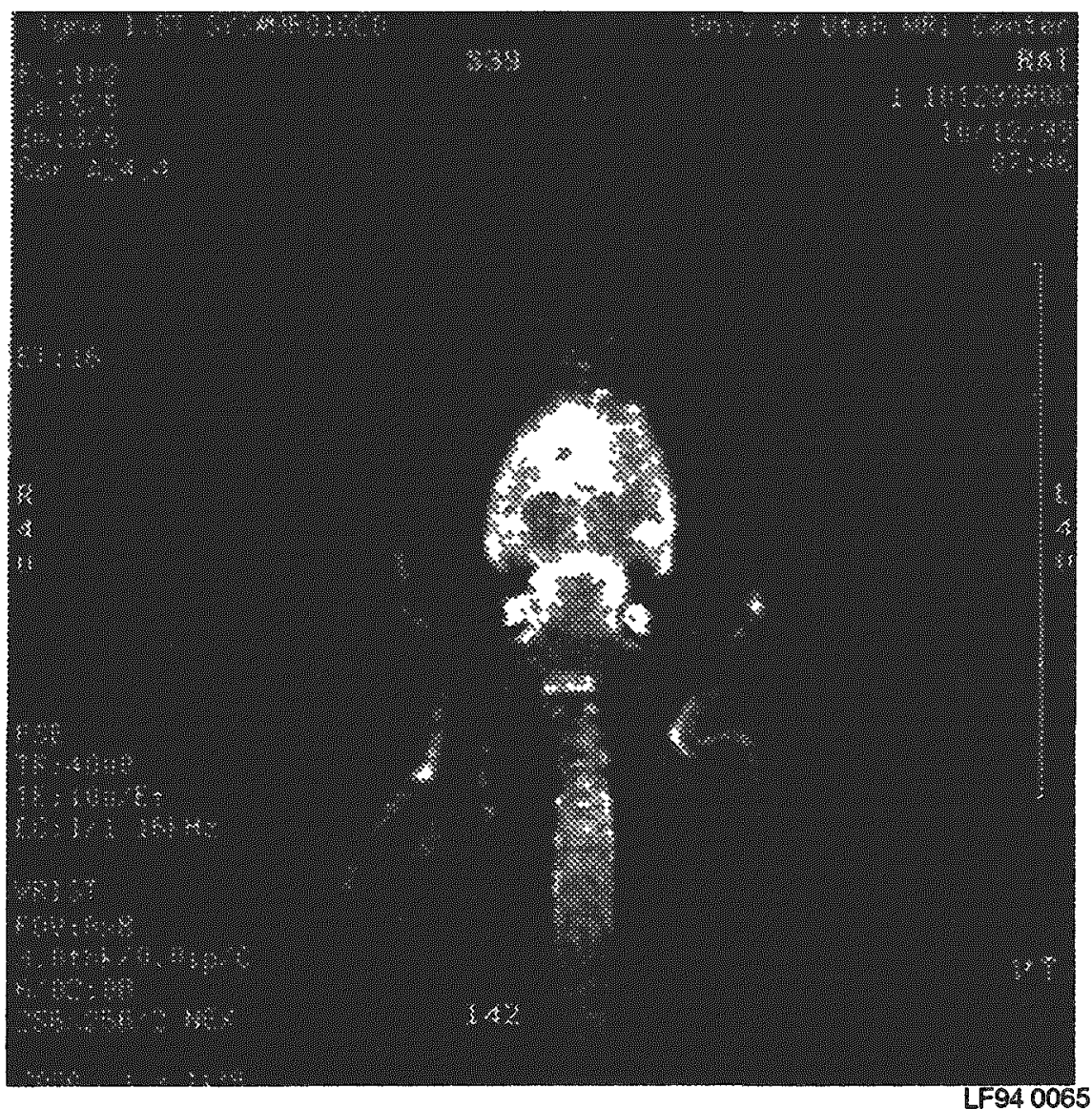

Figure 38. Coronal fast spin echo proton MR images of an 18-day 9L gliosarcoma in the frontal lobe of a Fischer 344 rat. 


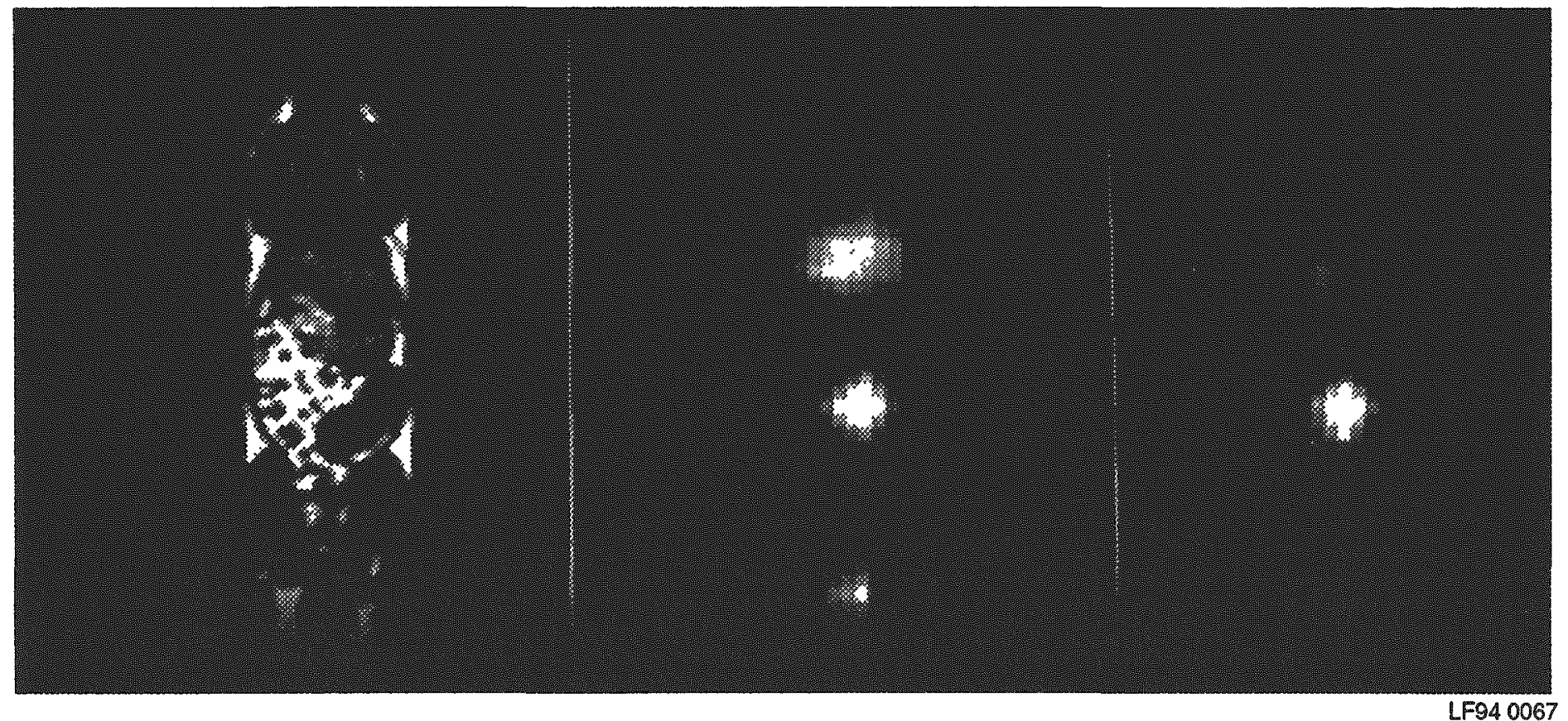

Figure 39. Coronal proton (right) and boron- 11 images of a Fischer 344 rat infused with $200 \mathrm{ppm}$ boron (as BSH). Center: 9-minute scan 50 minutes after end of infusion. Right: Boron-11 image 90 minutes posttermination of infusion. 


\section{RADIATION TRANSPORT IN TISSUE BY MONTE CARLO}

\section{Floyd Wheeler, Reactor and Radiation Physics, INEL}

\section{Patient-Treatment Planning Software Development}

Development of the Radiation Transport in Tissue by Monte Carlo (rtt_MC) software module continued. A new version (X02) is ready for beta testing by interested collaborators. This version contains several new features and is partially integrated with the bnct_edit reconstruction software. The radiation-transport software has been tested by comparison with analytic solutions, with results from other radiation transport software, and with measurements in the BMRR epithermal-neutron beam. Some of the new features are discussed below.

\section{Source Biasing for Fast Neutrons}

For BNCT Monte Carlo-based treatment planning, the fast-neutron dose is the most difficult component to converge to a good analytic solution. The reason is that the major fast-dose contributor is from the high-energy regions where the source density is necessarily low. In the unbiased Monte Carlo process, source selection would concentrate primarily in the epithermal region where source density is high. Thus, for the first 100 or so neutron-history simulations, there might be a relatively low estimate for fast dose based on epithermal source selection, then the source generator might select a high-energy neutron and the fast-dose estimate could increase several fold leading to large statistical error. This large statistical error, or variance, leads to a large demand on computer resource and long turnaround times for treatment planning.

Fast-dose solutions can be obtained in less time by selecting source energies based not on simple frequency data but on importance to dose, and then multiplying the neutron weight appropriately so as to remove the frequency bias. If the only quantity of interest were fast dose, the neutron history can be terminated once it scatters below some cutoff energy and thus avoid the computer time required for thermal scatter.

These fast-neutron tracking options were added to the rtt_MC code, and they are very easy to invoke. To run a standard neutron-only problem, an ' $\mathrm{N}$ ' run is specified. If the gamma dose is also desired, an 'NG' run is specified. The fast biasing option is invoked by specifying an ' $F$ ' run. The fast-dose component can be investigated only by specifying an ' $\mathrm{F}$ ' run, or a full neutron solution obtained by specifying an 'NF' run, or a complete neutron/gamma solution obtained by specifying an 'NFG' run. An example of speedup obtained by using the ' $F$ ' option is given in Table 19.

\section{Automatic Beam Locator}

Two new options were added to the software to aid in the treatment planning process. It is difficult to properly locate the beam in a three-dimensional model unless it is very simple, for example, directly above the head. Rotating the patient (or beam) geometry by hand requires many tedious, difficult-to-visualize operations which are highly error prone. To aid in the process, there are now three options available to automatically rotate and position the beam geometry: each requires specification of a target point, $T$, and a source center point, $S$.

1. Specify $\mathbf{Z}_{b}$, the distance from $\mathbf{T}$ to $S$ and two rotation angles.

2. Specify a new point $\mathbf{B}_{1}$, on the beam line between $\mathbf{T}$ and $\mathbf{S}$, and a separation distance, zsep, which spaces the source regions from the irradiated object. The code then automatically locates the source, with its associated geometry.

3. Specify zsep and the code will search over a $(4 \pi) / 2500$ staradian grid spacing and automatically locate the source geometry on the vector where the distance through the irradiated object is a minimum and the distance from the source to the irradiated object is set to equal zsep. This could be one reasonable guess at an optimum BNCT beam configuration. 
Table 19. Effect of ' $F$ ' Mode rt_MC peak dose calculation.

Lucite cylinder phantom; BMRR 3-in. diameter beam

\begin{tabular}{|c|c|c|c|c|}
\hline \multirow[b]{2}{*}{ Component } & \multirow[b]{2}{*}{$\mathrm{RBE} / \mathrm{CF}$} & \multirow{2}{*}{$\frac{\mathrm{RBE} * \text { dose rate }}{(\mathrm{cGy} / \mathrm{MW} \text {-min) }}$} & \multicolumn{2}{|c|}{$\begin{array}{l}\mathrm{SD} \\
(\%) \\
\end{array}$} \\
\hline & & & 'NG' & 'NFG' \\
\hline${ }^{10} \mathrm{~B}(25 \mathrm{ppm})$ & 0.33 & 2.00 & 1.32 & 1.32 \\
\hline${ }^{14} \mathrm{~N}(1.9 \mathrm{wt} \%)$ & 2.70 & 1.11 & 1.32 & 1.32 \\
\hline Gamma & 1.00 & 2.34 & 0.93 & 0.93 \\
\hline Fast & 4.00 & 1.66 & 12.02 & 2.82 \\
\hline Total & 0.8 & 7.11 & $3.69^{a}$ & $1.54^{\mathrm{a}}$ \\
\hline & CPU-time & $\left(\frac{3.69}{1.54}\right)^{2}\left(\frac{26 \mathrm{~min}}{31 \mathrm{~min}}\right)$ & $=4.8$ & \\
\hline
\end{tabular}

a. Assumes correlation coefficient $=1.0$.

b. CPU time on HP 750 .

These options have saved a lot of time when setting up an irradiation geometry where the beam must come in at an angle to the patient. The code also produces an axial, sagittal, and coronal view of the beam/patient geometry after the source is located, and this is very useful to verify the configuration.

\section{Validation Studies}

Several simulation runs were made to verify the results from the rt_MC software. Comparisons were made with analytic solutions, with results from other codes, and with measured results. In general, it is concluded that the physics, as implemented in the transport software, is adequate for treatment planning. Physics data are well verified for the isotopes and neutron energies of significance in BNCT. Primary errors will result from lack of knowledge of the spatial (macroscopic and microscopic) distributions in tissue and differences in the calculational model geometry and the actual geometry for the irradiation.
The analytic "searchlight" problems and comparisons with Monte Carlo Neutron and Photon Transport Code (MCNP) results for the water cylinder "Gedanken" experiments were repeated for this new version. These comparisons were reported earlier for the previous version, and results will not be reported here since the comparisons were essentially the same and in agreement with the analytic and MCNP solutions.

Also, measurements were made for the new BMRR epithermal beam by INEL researchers using a Lucite cylinder. Table 20 shows a comparison of measured and calculated thermal flux.

\section{Documentation}

A user's manual is being prepared for distribution to beta testers. This manual explains how to use the $\mathrm{rtt}$ MC transport modules as stand-alone tools or in conjunction with bnct_edit. Included in the documentation are sample problems and additional information on validation. 
Table 20. Calculated results for BMRR Lucite cylinder measurements.

\begin{tabular}{|c|c|c|c|}
\hline & & \multicolumn{2}{|c|}{$\begin{array}{l}\text { Peak thermal neutron flux } \\
\left(\mathrm{n} / \mathrm{cm}^{2} \mathrm{~s} \mathrm{MW}\right)\end{array}$} \\
\hline & & $\begin{array}{l}\text { April } 1991 \\
\text { measurements }\end{array}$ & $\begin{array}{c}\text { November } 1993 \\
\text { measurements }\end{array}$ \\
\hline \multicolumn{2}{|c|}{ Measurement } & $4.44 E+08$ & $5.66 \mathrm{E}+08$ \\
\hline \multicolumn{2}{|c|}{$\mathrm{rtt}$ MC calculation ( $10^{6}$ histories) } & $4.56 \mathrm{E}+08$ & $5.62 \mathrm{E}+08$ \\
\hline \multicolumn{4}{|c|}{ Notes: } \\
\hline 1. & \multicolumn{3}{|c|}{$6.35-\mathrm{cm}$ radius by $18.1-\mathrm{cm}$ high Lucite cylinder with 3 -in. beam delimiter. } \\
\hline 2. & \multicolumn{3}{|c|}{$\begin{array}{l}\text { Calculations use the least squares data fitting code (FERRET)-adjusted spectrum, which gives thermal flux } \\
\text { about } 7 \% \text { less than the unadjusted spectrum from the reactor model. }\end{array}$} \\
\hline 3. & \multicolumn{3}{|c|}{ The measured flux is about $30 \%$ higher for the later date due to fuel reconfiguration. } \\
\hline
\end{tabular}

\section{Calculated P-Factors for Petten HFR-HB11 Beam Measurements}

INEL researchers visited Petten this year to perform independent measurements for the HFR HB11 epithermal neutron beam. Similar measurements were performed in 1991. but improvements in the cryogenic system since that time have significantly affected beam characteristics, and new measurements were necessary.

Calculations were performed to provide measurement-foil cross sections used for converting measured reaction rate to flux in the process of deriving the complete neutron energy spectrum.
The 1991 calculations were based on a RAFFLE Monte Carlo model. Models used to compute these recent cross sections ( $\mathrm{P}$ factors) were converted to MCNP to be consistent with the Peter Watkins (Petten) model. The calculated absolute foil reaction rates, before adjustment, were from $25 \%$ low, to $29 \%$ high, compared to measurement. The largest differences appeared to be in the tungsten and manganese foils, where the MCNP representation appeared to overestimate resonance shielding. This was verified by comparing MCNP results with RAFFLE results. The RAFFLE code computes resonance cross sections explicitly at every neutron energy, and the MCNP code interpolates from precomputed tables. 


\section{BNCT RADIATION TREATMENT PLANNING ENVIRONMENT}

\author{
D. E. Wessol, F. J. Wheeler, Reactor and \\ Radiation Physics, INEL; R. S. Babcock, \\ Montana State University (MSU)
}

\section{Introduction}

Several new features have been developed for the BNCT radiation treatment planning environment (BNCT_Rtpe) during Fiscal Year 1993. The new acronym, BNCT_Rtpe, was adopted to more accurately reflect its purpose. The previous acronym, bnct_edit, is now obsolete.

These new features were developed at MSU and the INEL and are discussed in the following sections. The cognizant programmer for each new feature will be identified along with the status of that feature. In addition to the new features, there are some less visible changes that should make BNCT_Rtpe more reliable. Also, work in progress and work planned for Fiscal Year 1994 and beyond will be identified. The new BNCT_Rtpe user's manual is being written and should be available in 1994.

\section{Image Plane Dose Contours}

A dose contouring function (Xcontours) has been developed that displays the rtt_MC dose data computed for a specific plane onto the image corresponding to that plane. This function allows the user to quantify and spatially locate the dose delivered to the patient.

The Xcontours function utilizes the contouring utilities from the National Center of Atmospheric Research (NCAR) and requires a license from NCAR. Xcontours may be run either in stand-alone mode or from BNCT_Rtpe's image widget. The Xcontours function has a self-explanatory portable interface based on X11/Motif software standards.

Features include variable contour levels, smoothing, and label sizes, and options to manipulate the color map and contour colors. Xcontours is dynamically dimensioned and will work with either evenly or unevenly spaced gridded data.
Work is in progress that will allow automatic detection of the dose data's planar orientation and an option for the user to interactively specify $R B E$. A masking feature is also being developed that will remove contour lines generated outside the active image area.

Future options include the ability to handle a variety of image formats as well as useful image analysis tools. Xcontours was originally developed by Dan Wessol (INEL), Fred McClurg (INEL), and Gabor Kinces (MSU), with significant contributions from Floyd Wheeler (INEL).

\section{Voxel Editor}

The voxel editor is a tool designed to aid the user in creating fast and simple approximations of various objects within a volume data set of $C T$ or MRI images. Its application, as it pertains to the INEL BNCT Project, is to aid the user in creating voxel-based mesh elements for INEL radiation transport models, and volumetric calculations of tumor tissue and surrounding healthy material, as well as to have a quick visual means of determining relative positions of these bodies.

By means of a variably sized grid overlay, the user can construct a set of parallel-piped volumes for objects in each layer of the volume data set. Each object so constructed will have a unique material color associated with it, e.g., red for bone, blue for sinus regions. Resulting data can then be saved in a variety of formats: "raw." user-specified (for example, the INEL discrete ordinate particle transport models), FFOE (the free form object editor developed to support the creation of geometries in BNCT_Rtpe), and others. These supporting packages will allow the user to view or otherwise manipulate data.

The voxel editor was developed by Scott Stewart of MSU and currently operates in only stand-alone mode. There are no plans to integrate its operational features into BNCT_Rtpe, since its geometry basis is distinct from the $\mathbb{B}$-Spline basis employed in BNCT_Rtpe. 


\section{Automated Control Point Selection Algorithm}

Two adjunct utilities, REDA (Radial Edge Detection Algorithm) and EEDA (External Edge Detection Algorithm), allow for quick definition of control points surrounding objects in an image plane.

From a user-defined starting point within an object, REDA sends forth detection "rays" in a circular pattern, the length of which are bounded by user-defined upper and lower image intensity threshold values. Interactivity permits a refinement of the length of these rays. When finished, the end of each ray becomes a control point for use in spline curves and other geometries.

EEDA is a similar algorithm to REDA in that it uses "rays" for outlining the exterior boundary of an object. In this instance, the rays enter from the outside of the object. At the point of edge intersection, control points are automatically generated. When applied to several subsequent images from the same data set, a three-dimensional polygonal mesh is created with a minimum of difficulty.

Both REDA and EEDA were developed by Scott Stewart of MSU. Plans are under way to incorporate REDA and EEDA in BNCT_Rtpe during Fiscal Year 1994.

\section{QSH Image Format Implementation}

Maquire and Noz developed the QSH image format in the mid 1980s to help standardize imaging in the medical profession (QSH: A Minimal but Highly Portable Image Display and Handling Toolkit, Columbia University Technical Report CUCS-369-88, Maquire and Noz, 1988.) Each QSH-formatted file consists of an image file and a header file. While the image file contains all the pixel information for all the images in the file, the header file contains general information about the image file (i.e., the number and size of the slices, coarseness of the slices, the patient's name, the hospital name, date images were taken, etc.). Maquire and Noz have also provided a library of routines that perform all the basic operations on the image files. QSH files are being used at the University of Pennsylvania Medical School, New York University Hospital, Columbia University, as well as at the INEL.

As implemented in BNCT_Rtpe, when a user selects a QSH-formatted file for display, BNCT_Rtpe calls the appropriate QSH subroutines to read all of the file's header and pixel information. BNCT_Rtpe then converts the images so that they are suitable for display. After images are input to the BNCT_Rtpe data structure, BNCT_Rtpe builds a separate Motif-based window around each image and displays them. All standard image processing tools implemented in BNCT_Rtpe are available for use with the QSH images. Along with the images, the patient's identifier, scan type, field of view, and axial location are also displayed. The axial location is calculated from the user's initial input and from the thickness of each slice (read in from the header file). This implementation was developed by Phil Lee of MSU and is available in the current version of BNCT_Rtpe. During Fiscal Year 1994, plans are to develop a software toolkit that will convert various image formats, including raw images, into a QSH-formatted set. Using the geometric information from the QSH header file, work is in progress that will automatically convert the image space into modeling coordinates.

\section{B-Spline Surface Interference Checking Algorithm}

BNCT's radiation transport model, $r t$ _MC, requires that every three-dimensional object reconstructed by BNCT_Rtpe be unambiguous (i.e., not intersect with one another). Because of the way objects are defined, there always exists the possibility that two or more surfaces may intersect, especially if these objects are physically adjacent to one another. This method has been designed as a tool for moving the interfering bodies inside the three-dimensional representation of the reconstructed biological objects so as to enable the other tools in the same system to work correctly. 
Given two closed B-Spline surfaces, the algorithm finds a vector that should be added to a closed B-Spline surface so as to minimally separate it from another closed B-spline surface. The goal of the research has been to develop a system that lets the user choose any two bodies in the threedimensional representation of the brain. which are then checked for intersection, and one of the surfaces is moved so as to separate the two surfaces. All user interactions are through a Motif-based graphical user interface.

Points of intersection are found using a bounding box technique and stored in a linked list. Lines of intersection are then formed using these points of intersection. Then, the minimum vector by which one surface should be moved is found as follows:

Given any two closed B-Spline surfaces S1 and $S 2$, where $Q(a, b)$ and $P(1, m)$ are the sets of points defining $S 1$ and $S 2$, respectively, ' $a$ ' is the number of points in the ' $u$ ' parametric direction and ' $b$ ' is the number of points in the " $\mathrm{v}$ " parametric direction; ' 1 ' and ' $m$ ' are similarly defined for $\$ 2$. The aim is to find a vector

$$
\vec{M}=\hat{i} * m w_{x} M(x)+\hat{j} * m v_{y} M(y)+\hat{k} * m_{z} M(\xi)
$$

such that, when it is added to one of the surfaces, it gets isolated from the other surface. After having moved one of the surfaces, intersections are checked, and if the surfaces are still intersecting. follow the same procedure for isolation. This procedure is repeated until the surfaces are isolated. Once they are isolated, one of the surfaces can be moved back along the same vector such that the two surfaces are just separated.

The system, although currently being used on Closed B-Spline surfaces, is also applicable with some modifications to Open Uniform and Nonuniform B-Spline surfaces.

Modifications are being made that will truncate the two surfaces somewhere in the middle of the regions of intersection, so that an alternate solution to the problem of interfering splines will be available without moving the surfaces. The method was developed by Rajeev Chawla of MSU and works only in stand-alone mode. Plans are under way now to incorporate the method in BNCT_Rtpe during Fiscal Year 1994.

\section{General Cleanup}

There was a major change made to the "load bodies" portion of the reconstruction 3D viewing subsystem. Files were generated to store the color, material, and region names. These files will allow each site to tailor this interface to their particular needs. A more natural mechanism was generated by using lists of materials, regions, and colors from which the user chooses.

Previously, the "Unshow Points" selection was located on the main menu bar away from where the user would likely find it. To make the interface similar to the 'View Window,' a list widget was added so the user could interactively remove bodies from each slice. Also added was a selection to either 'show' or 'unshow' control points for each body.

The "render" option was added to the view window. When the user selects this option, the view matrix and bodies from the current 'View Window' are stored in a file named by the user. Next, the standard output and standard input are redirected from the operating system and assigned to the file previously defined by the user and the resulting output from rendering placed in the output file. Then the resulting file is displayed with the program getx11, which is available from the Utah Raster Toolkit (urt).

A simple MOCUP-like interface between BNCT_Rtpe and $\mathrm{rtt}$ MC was generated during this year.

All nonworking menu entries have been removed from BNCT_Rtpe. Redundant menu entries were also removed where they were deemed unnecessary or confusing.

The BNCT_Rtpe source code was reorganized into a new tree hierarchy in preparation for a beta release. Imakefiles were generated for all source directories. 


\section{Work in Progress}

A much-improved interface between $\mathrm{rtt}$ MC and BNCT_Rtpe is under development. Integration of the work described in this report section into BNCT_Rtpe is anticipated. Continued testing will enhance the robustness of the entire package. A more general "snapshot" mechanism needs to be defined.

There is still a persistent problem with colors when moving between platforms. Color now is consistent with a particular platform, but coordinating color changes between hardware platforms must await implementation of the X11 R5 "color screen characterization" feature.
The ability to read the medical image formats from various manufacturers continues to be a serious problem. The problem is further complicated by changes in vendor formats and media as they upgrade or revise their equipment. Image standards like ACR-NEMA are finally emerging. but this will not solve the problem for patients being scanned on older systems.

One solution under consideration is to promote a central facility that will deal with the nonstandard formats and media, and provide the images in QSH format as requested by the research or test sites.

Simultaneous display of other image data sets is planned. As other image file formats begin to be used, they will need to be integrated into the BNCT_Rtpe file input interface. 


\section{A COMPACT ACCELERATOR-BASED EPITHERMAL PHOTONEUTRON SOURCE FOR BORON NEUTRON CAPTURE THERAPY}

David W. Nigg, Woo Y. Yoon, Peactor and Radiation Physics, Vale D. Harker, Nuclear and Radiological Physics, NEL; James L. Jones, Westinghouse Idaho Nuclear Company

BNCT research in the U.S. and Europe has focused on the use of an epithermal $(0.5 \mathrm{eV}$ to $10 \mathrm{keV}$ ) neutron beam to generate the necessary thermal neutron field in deep-seated treatment volumes. Epithermal-neutron beams can be generated by nuclear reactors ${ }^{64-68}$ and by acceleratorbased neutron sources. ${ }^{69.70}$ So far, however, only reactors have actually been used to produce therapeutically useful epithermal-neutron beams for BNCT. Some low-intensity prototypes of accelerator-based sources generally featuring the use of proton beams and beryllium or lithium targets have been constructed. Scaling of these proton devices for therapeutic applications will require resolution of some rather difficult issues associated with target cooling. INEL researchers have developed a concept for an alternate approach to the realization of a clinically useful acceleratorbased source of epithermal neutrons for BNCT that reconciles the often conflicting objectives of target cooling, neutron beam intensity, and neutron beam spectral purity via a two-stage photoneutron production process.

A conceptual design for a device to produce epithermal photoneutrons is shown in Figure 40a. In this device, which was inspired by a related idea first described in Reference 71, electron beams impinge inward upon tungsten targets located at the outer radius of a small cylindrical tank of heavy water $\left(D_{2} O\right)$, which is centered upon the $Z$-axis of the system as shown in the figure. The $\mathrm{D}_{2} \mathrm{O}$ tank may include up to approximately $50 \%$ (by volume) of beryllium within the $\mathrm{D}_{2} \mathrm{O}$ region. A fraction of the energy of the electrons is converted in the tungsten targets into radially inward-directed bremsstrahlung radiation. Photoneutrons are subsequently generated in the deuterium (and beryllium) regions within the tank. The photoneutron yield per incident electron (about $10^{-4}$ at the incident electron energy of interest) from this arrangement is comparable to the neutron yield attainable ${ }^{69}$ with published accelerator-based epithermal-neutron sources for BNCT that use protons impinging on a lithium target. Photoneutrons produced in the central region enter a cylindrical moderating and filtering region composed of $90 \%$ aluminum fluoride $\left(\mathrm{AlF}_{3}\right)$ and $10 \%$ lithiated aluminum, by volume. Mixtures of $\mathrm{AlF}_{3}$ and $\mathrm{Al}$ have been shown ${ }^{68}$ to be extremely effective for producing epithermal neutrons in reactor-based systems. The filter/moderator region is followed by a bismuth-lead gamma shield and a lithiatedpolyethylene neutron beam delimiter. The device is symmetric about a plane perpendicular to the $\mathbf{Z}$-axis and passing through $\mathbf{Z}=0$ in the coordinate system shown in Figure 40a, providing for two opposed treatment beams.

Calculations to estimate performance of the proposed photoneutron device were performed using the ACCEPT $^{72}$ three-dimensional electronphoton coupled transport code to compute the bremsstrahlung flux throughout the device, and the DORT $^{73}$ neutron-photon transport code (with the BUGLE-80 ${ }^{74}$ cross section library) to compute the transport of photoneutrons (and neutron-capture gammas) to the irradiation position. These two codes were coupled using photoneutron production data developed and validated as described in Reference 75 . Confirmatory neutron and capturegamma transport calculations were performed using the MCNP ${ }^{76}$ Monte-Carlo neutron and photon transport code.

The DORT results for the calculated scalar neutron flux spectrum at the irradiation point for the concept illustrated in Figure 40a are presented in Figure $40 \mathrm{~b}$ for the case of an incident $5 \mathrm{MeV}, 1$ $\mathrm{mA}$ electron beam configuration. Similar results are obtained using MCNP. Scaling the electron beam current to $100 \mathrm{~mA}$ and integrating the computed neutron spectrum shown in Figure $40 \mathrm{~b}$ over the appropriate lethargy range yields a therapeutically useful total epithermal flux intensity at the irradiation point of $1.5 \times 10^{9} \mathrm{n} / \mathrm{cm}^{2} / \mathrm{s}$. The 


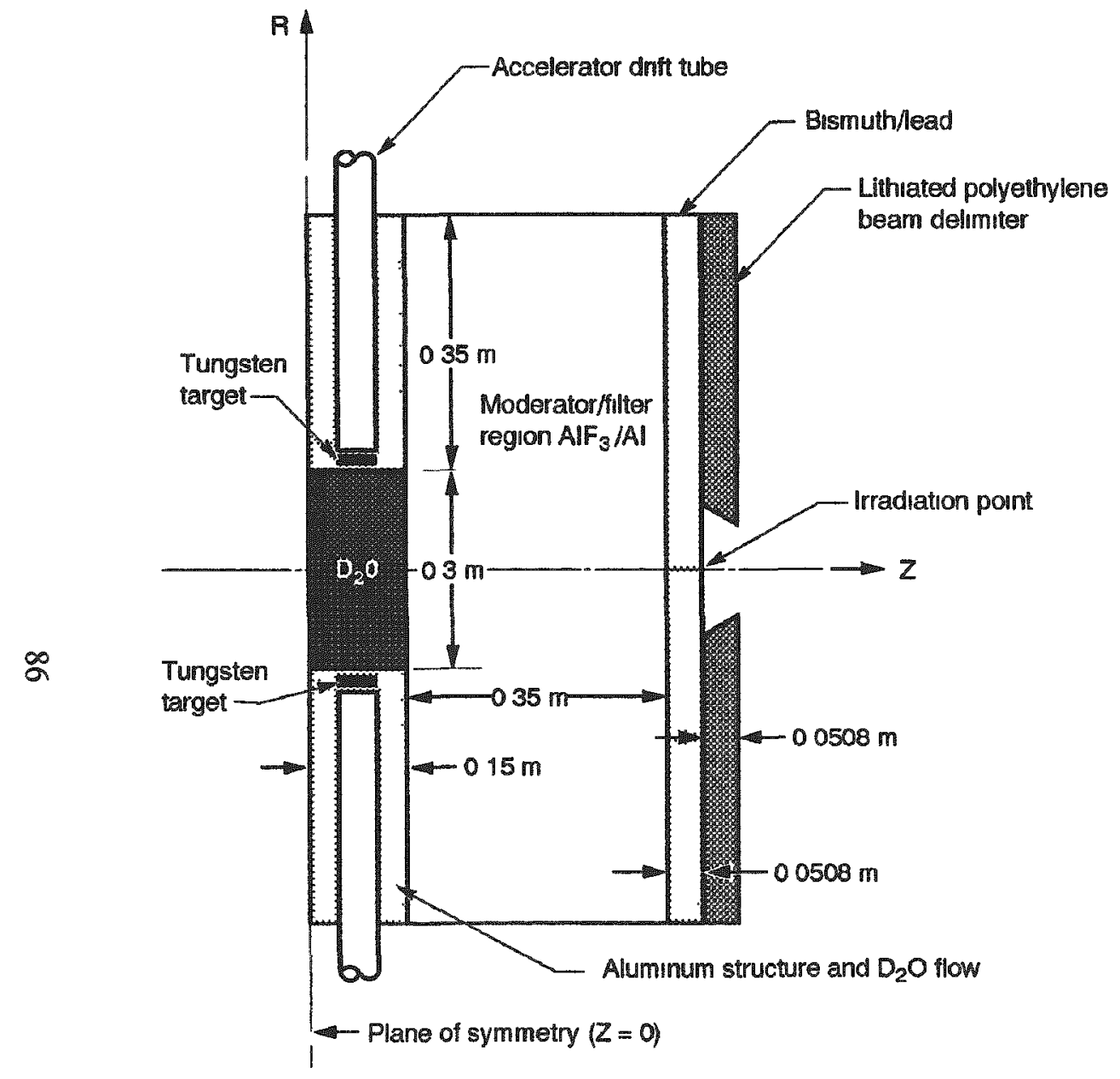

a Basic configuration (cylindrical geometry)

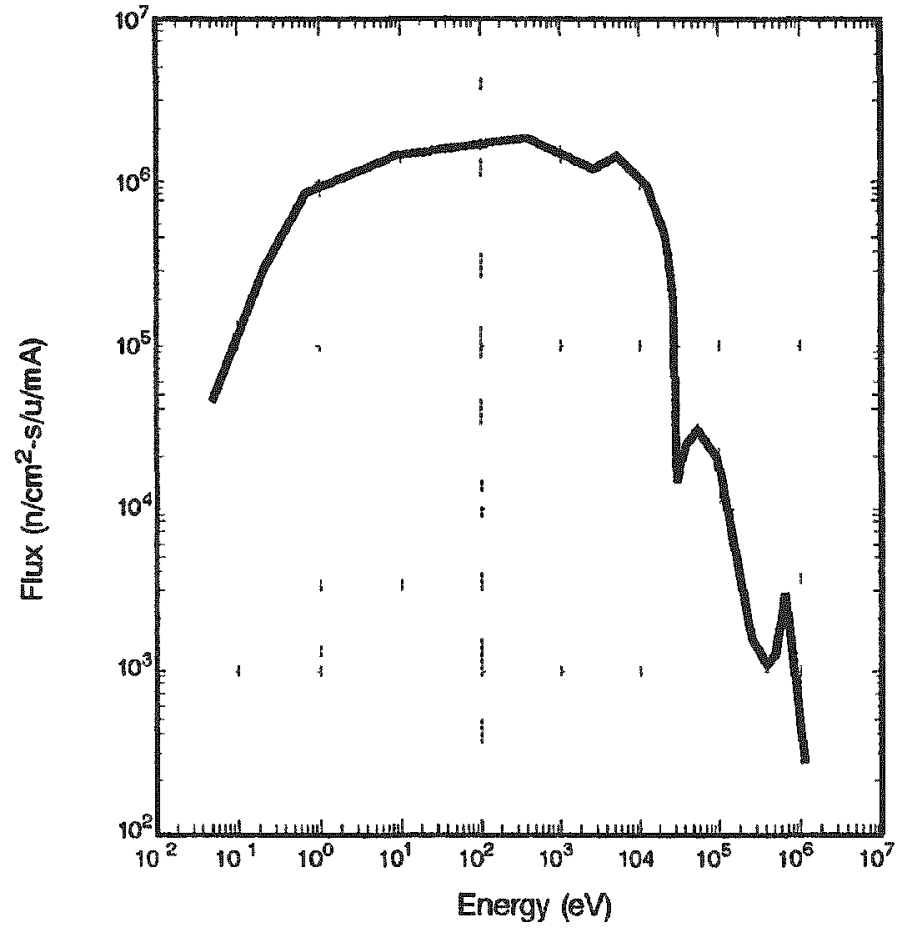

b Free-field tux spectrum at irradiation point

T940274

Figure 40. Conceptual accelerator-based epithermal photoneutron source for BNCT. 
calculated nonselective neutron-beam-induced proton recoil dose in hydrogeneous tissue per unit useful epithermal neutron flux at the irradiation point for this case is $1.7 \times 10^{-11} \mathrm{cGy} / \mathrm{n} / \mathrm{cm}^{2}$, comfortably below what is believed to be the radiobiologically allowable maximum. The incident gamma dose at the irradiation point due to neutron capture gammas originating in the device is $1.2 \times$ $10^{-11}$ in the same units. The incident gamma dose at the irradiation point due to direct source bremsstrahlung is controllable by appropriate shielding placed at various strategic locations within the device.

Computational results presented here indicate that the photoneutron concept offers a very promising alternative approach to the production of accelerator-based epithermal neutrons for BNCT. Clinically useful neutron source intensity and spectral purity levels can be obtained using existing electron accelerator technology. The accelerator target and photoneutron production components of the device can be designed in such a manner that waste heat can be easily removed. Experimental proof-of-principal testing for a low-current prototype of the device described is planned for late 1994 and beyond.

\section{Acknowledgment}

Extremely useful discussions with Iiro Auterinen (VTT-Finland) concerning the use of flourides as neutron filtering materials are gratefully acknowledged. 


\section{PURITY AND QUALITY DETERMINATIONS OF BOROCAPTATE SODIUM}

\author{
W. F. Bauer, A. K. Gianotto, and G. L. \\ Gresham, Analytical Chemistry, INEL
}

\section{Introduction}

The chemical purity and/or quality of any drug can influence its action in the body. Knowledge of the chemical purity of the boron delivery agent $\mathrm{BSH}\left(\mathrm{Na}_{2} \mathrm{~B}_{12} \mathrm{H}_{11} \mathrm{SH}\right)$ can have a direct effect upon its toxicity, ${ }^{77}$ biodistribution, ${ }^{78}$ and the proper interpretation of experimental data. ${ }^{79}$ The FDA requires that drugs seeking Orphan Drug or an investigational new drug status be chemically characterized. ${ }^{80}$ The purity of $\mathrm{BSH}$ is most often determined by procedures in HPLC. 77,80

"Purity" and "quality" are really different terms. "Purity" refers more to the presence or absence of contaminants looked for and is most often considered to be primarily a quantitative determination of the primary component, in this case BSH itself. "Quality" refers more to some of the qualitative aspects of purity such as the number, level, and kinds of impurities determined to be present in the sample. For example, if it was determined that $2 \mathrm{wt} \%$ of a particular lot of $\mathrm{BSH}$ consisted of $\mathrm{NaCl}$, the "purity" of the BSH would be assessed relatively low at $98 \%$. However, the quality of this lot of BSH would still be considered good, since $\mathrm{NaCl}$ would be considered a rather benign impurity given that it is usual to administer BSH in conjunction with a saline solution. On the other hand. if a lot of BSH contained $0.5 \mathrm{wt} \%$ of a highly toxic compound, the lot of BSH would be considered reasonably pure $(99.5 \%)$, but the quality could be considered relatively poor because of the nature and level of toxic impurity.

The determined purity and quality of any chemical compound is only as good as the techniques used to characterize it and as the number of potential impurities actively looked for in the sample. For these reasons, the somewhat more rigorous approach to purity and quality determinations for BSH described below has been adopted by the INEL Analytical Chemical Laboratory. The assumed purity and many aspects related to the quality of the BSH products are determined and/or verified to some degree using NMR; infrared (IR); carbon, hydrogen, nitrogen (CHN); HPLC; and ICP-AES analyses. The major problem related to most of these analyses is the question of what to use for quantitative and qualitative reference materials.

\section{Experimental}

HPLC is performed with $10-50 \mu \mathrm{L}$ injections onto a 300 or $250 \times 8 \times 4$ or $3 \mathrm{~mm}$ column packed with 5 or $10 \mu \mathrm{m}$ particles of Nucleosil (B) $\mathrm{C}_{18}$ (octadecylsilane) from Machery-Nagel. The mobile phase is approximately a $50: 50 \mathrm{CH}_{3} \mathrm{OH}: \mathrm{H}_{2} \mathrm{O}$ solution with $5 \mathrm{mM}$ tetrabutyl ammonium sulfate (TBAS) ion pairing reagent (Alltech Associates, Inc.) adjusted to $\mathrm{pH} 8.1$ and flowing at $1.0 \mathrm{~mL} / \mathrm{min}$ with the $4 \mathrm{~mm}$ inner diameter columns or at $0.4-0.6 \mathrm{~mL} / \mathrm{min}$ with the $3 \mathrm{~mm}$ inner diameter columns. Detection was performed from $200-300 \mathrm{~nm}$ with a Waters 991 Photodiode Array Detector.

Elemental determinations of boron, sulfur, and sodium are performed by ICP-AES. Aliquots $(150 \mu \mathrm{L})$ of samples and standards previously prepared for HPLC are either simply diluted or are digested with $3 \mathrm{~mL}$ of $\mathrm{HNO}_{3}$ prior to the final dilution to $10 \mathrm{~mL}$. Analyses of CHN are performed on a Model EA 1108, Carlo Erba CHNS Analyzer. BSH samples for the CHN analysis are weighed and placed in the combustion foils inside of nitrogen-filled glove bags to avoid additional contamination with water. Although the CHNS instrument is capable of sulfur analysis, results are extremely inconsistent, and the primary analysis of sulfur is via ICP-AES.

To ensure that BSH is the major boronated chemical component in the sample, ${ }^{10} \mathrm{~B}$ and ${ }^{11} \mathrm{~B}$ NMR spectra are obtained on a Bruker Model AC300 NMR. The sample is simply diluted with water and spiked with $\mathrm{D}_{2} \mathrm{O}$ to provide a lock signal. 
To qualitatively assess the water content and possible additional major contaminants, samples of BSH are also analyzed by Fourier transform infrared (FTIR) spectroscopy. Samples are prepared and handled for FTIR analysis entirely under nitrogen. A few $\mathrm{mg}$ of the BSH sample are mixed with potassium bromide ( $\mathrm{KBr}$ ) and then pressed into pellets. The actual sample mass in each pellet is not accurately determined. Consequently, the spectra are normalized to offset sample mass differences. All spectra are collected on a Digilab Model 65 FTIR.

\section{Discussion}

\section{Basic Purity/Quality Determinations}

Normally, HPLC is the primary method used to determine the "purity" of BSH salts. The primary analytes are usually the dimer (BSS) and oxidized dimer (BSSO). Typical chromatograms showing the separation of the oxidized species from the BSH parent peak are shown in Figure 41, and some actual BSS and BSSO concentrations are listed in Table 21. The BSS and BSSO concentrations in Table 21 were determined using BSS and BSSO salts acquired from a vendor. Purity and quality of these "reference" materials appear reasonable. However, the BSS salt contains varying levels of BSSO and other unknown components. The BSSO reference is similarly contaminated, to varying degrees, with other components.

A variety of problems with the chromatography and its use in determining contamination levels are also demonstrated in Figure 41. Sample AA has an obvious interference on the leading edge of the BSS peak, which can be expected to bias the results high. Sample AA also has significant levels of some contaminants that elute very late (>25 minutes) in the chromatogram. These lateeluting components have not yet been identified but show up consistently in this sample and in samples from many other BSH lots to varying degrees. Because these late-eluting components were consistently found in sample AA, this sample was selected as a reference sample used to identify and verify these unknown components in other $\mathrm{BSH}$ lots. Also, in the chromatograms in Figure 41 , there are several additional contaminants that elute in and around the BSS and BSSO peaks and some that possibly elute before the $\mathrm{BSH}$ parent peak. These components have not been positively identified but are believed to be byproducts of the reaction to produce BSH (see for example References 81 and 82) and/or additional oxidized forms of BSSO. With regard to any additional impurities in $\mathrm{BSH}$, it should be remembered that only compounds that absorb significant levels of ultraviolet light between $200-300 \mathrm{~nm}$ will be detected in the HPLC analysis.

Because of the possibility of serious contamination by other chemicals going undetected by HPLC, ICP-AES was used to determine elemental concentrations of $\mathrm{S}, \mathrm{B}$, and $\mathrm{Na}$ in the $\mathrm{BSH}$ samples. Table 22 gives some typical results from these determinations. The utility of this analysis is demonstrated by sample FF, which shows a noticeable problem with an excess of $\mathrm{Na}(\mathrm{Na} / \mathrm{S}=$ 2.47 and $\mathrm{B} / \mathrm{Na}=5.23$ ). The HPLC chromatograms and other analyses of FF were unremarkable. However, this sample obviously contains a nonboroncontaining sodium salt.

The $\mathrm{B} / \mathrm{S}$ ratios in Table 22 should be at or near 12. However, these ratios are typically between 12 and 13, possibly partially due to a slight bias $(1-2 \%)$ in the $B$ determinations or because of the presence of other boron-containing compounds. The $B / S$ and $N a / S$ ratios of sample $C C$ are excessively high, even though the $\mathrm{B} / \mathrm{Na}$ ratio is near normal. This is an obvious indication of a boron-containing sodium salt, most likely to be $\mathrm{Na}_{2} \mathrm{~B}_{12} \mathrm{H}_{12}$. A closer look at the HPLC chromatograms of sample $\mathrm{CC}$ indicated that the $\mathrm{B}_{12} \mathrm{H}_{12}{ }^{2-}$ anion may have been present and eluted just slightly before the BSH, but was not completely resolved from the BSH. Since the HPLC conditions used to determine BSS and BSSO were unable to completely separate $\mathrm{B}_{12} \mathrm{H}_{12}{ }^{2-}$ from $\mathrm{BSH}$, the conditions were adjusted and the chromatograms of $\mathrm{CC}$ in Figure 42 were obtained. The presence of $\mathrm{B}_{12} \mathrm{H}_{12}{ }^{2-}$ was confirmed and the concentration was estimated to be near $37 \mathrm{wt} \%$ (see 


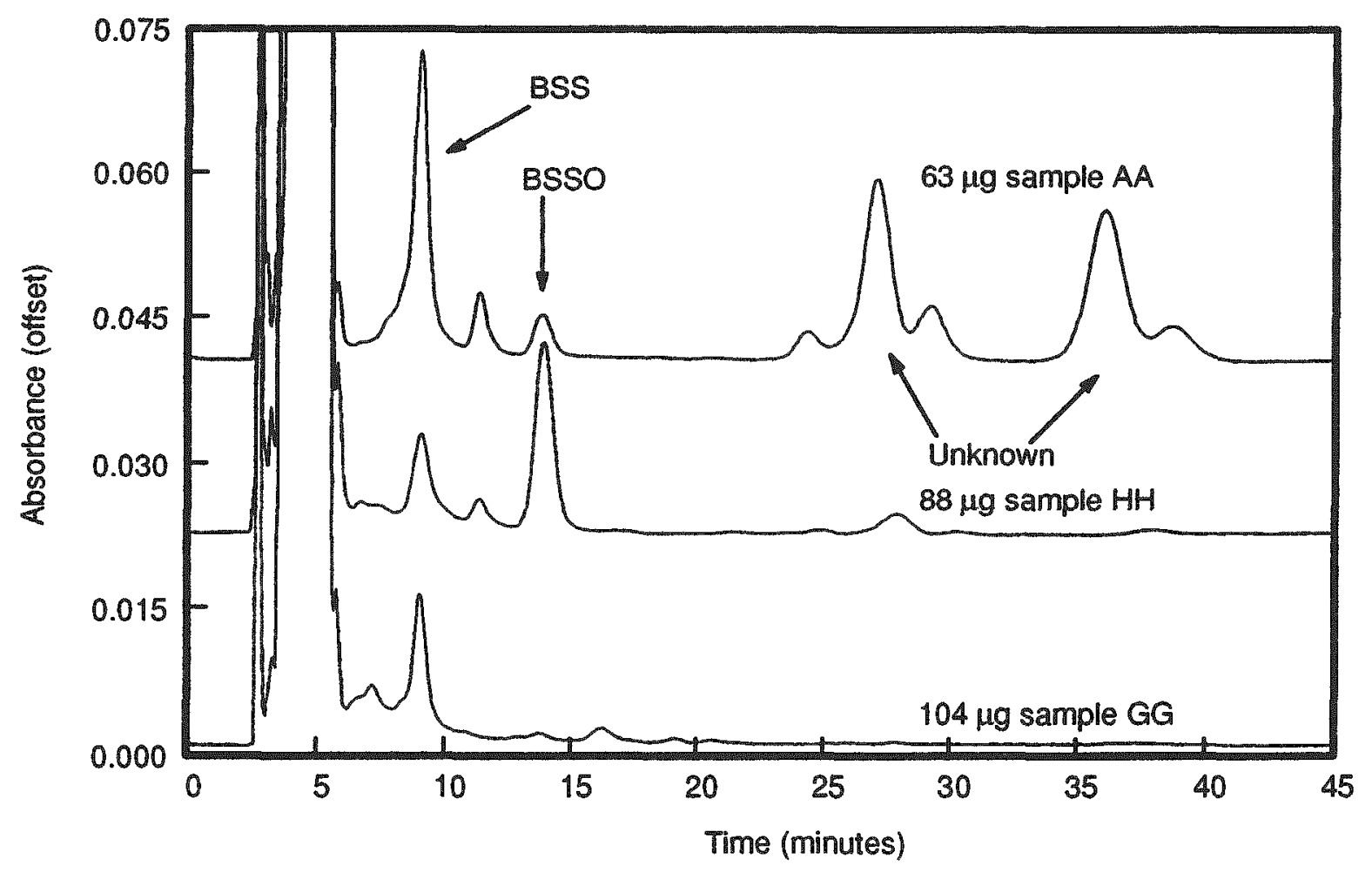

LF94 0044

Figure 41. Chromatograms of BSH samples. $20 \mu \mathrm{L}$ injection into $5 \mathrm{mM}$ TBAS in 50:50 $\mathrm{CH}_{3} \mathrm{OH}: \mathrm{H}_{2} \mathrm{O}$ flowing at $1 \mathrm{~mL} / \mathrm{min}$. Chromatogram plotted at $215 \mathrm{~nm}$.

Table 21. Typical results of HPLC analyses for BSS and BSSO contamination of BSH salts.

\begin{tabular}{llccc}
\hline Sample & Compound & $\begin{array}{c}\mathrm{BSS} \\
(\mathrm{wt} \%)\end{array}$ & $\begin{array}{c}\mathrm{BSSO}^{4-} \\
(\mathrm{wt} \%)\end{array}$ & $\begin{array}{c}\mathrm{B}_{12} \mathrm{H}_{12}{ }^{2-} \\
(\mathrm{wt} \%)^{\mathrm{b}}\end{array}$ \\
\hline $\mathrm{AA}$ & $\mathrm{Na}_{2} \mathrm{~B}_{12} \mathrm{H}_{11} \mathrm{SH}$ & $0.9 \pm 0.1$ & $0.097 \pm 0.004$ & $\mathrm{ND}$ \\
$\mathrm{BB}$ & $\mathrm{Na}_{2}{ }^{10} \mathrm{~B}_{12} \mathrm{H}_{11} \mathrm{SH}$ & $0.07 \pm 0.02$ & $0.277 \pm 0.009$ & $\mathrm{ND}$ \\
$\mathrm{CC}$ & $\mathrm{Na}_{2}{ }^{10} \mathrm{~B}_{12} \mathrm{H}_{11} \mathrm{SH}$ & $1.1 \pm 0.1$ & $0.34 \pm 0.01$ & $\sim 37$ \\
$\mathrm{DD}$ & $\mathrm{CS}_{2} \mathrm{~B}_{12} \mathrm{H}_{11} \mathrm{SH}$ & $0.35 \pm 0.05$ & $0.29 \pm 0.02$ & $\sim 3$ \\
$\mathrm{EE}$ & $\mathrm{Cs}_{2} \mathrm{~B}_{12} \mathrm{H}_{11} \mathrm{SH}$ & $0.40 \pm 0.06$ & $0.14 \pm 0.02$ & $<1$ \\
$\mathrm{FF}$ & $\mathrm{Na}_{2}{ }^{10} \mathrm{~B}_{12} \mathrm{H}_{11} \mathrm{SH}$ & $0.09 \pm 0.02$ & $\mathrm{ND}^{\mathrm{c}}$ & $\mathrm{ND}$ \\
$\mathrm{GG}$ & $\mathrm{Na}_{2}{ }^{10} \mathrm{~B}_{12} \mathrm{H}_{11} \mathrm{SH}$ & $0.23 \pm 0.05$ & $\mathrm{ND}^{\mathrm{c}}$ & $\mathrm{ND}$ \\
$\mathrm{HH}$ & $\mathrm{Na}_{2}{ }^{10} \mathrm{~B}_{12} \mathrm{H}_{11} \mathrm{SH}$ & $0.20 \pm 0.07$ & $0.35 \pm 0.02$ & \\
& & & & \\
$\mathrm{ND}=$ Not detected & & & \\
a. All concentrations have been corrected for isotopic abundance. & & \\
b. Single chromatograms with a single & & \\
c. Not detected at less than 0.05 weight percent. &
\end{tabular}


Table 22. Mole ratios determined from elemental analyses by ICP-AES.

\begin{tabular}{cllll}
\hline & & \multicolumn{3}{c}{ Mole ratios } \\
\cline { 3 - 5 } Sample & \multicolumn{1}{c}{ Compound } & \multicolumn{1}{c}{$\mathrm{B} / \mathrm{S}$} & \multicolumn{1}{c}{$\mathrm{B} / \mathrm{Na}$} & $\mathrm{Na} / \mathrm{S}$ \\
\hline $\mathrm{AA}$ & $\mathrm{Na}_{2} \mathrm{~B}_{12} \mathrm{H}_{11} \mathrm{SH}$ & 13.3 & 6.4 & 2.1 \\
$\mathrm{BB}$ & $\mathrm{Na}_{2}{ }^{10} \mathrm{~B}_{12} \mathrm{H}_{11} \mathrm{SH}$ & 12.7 & 6.5 & 2.0 \\
$\mathrm{CC}$ & $\mathrm{Na}_{2}{ }^{10} \mathrm{~B}_{12} \mathrm{H}_{11} \mathrm{SH}$ & 19.1 & 5.2 & 3.7 \\
$\mathrm{DD}$ & $\mathrm{Cs}_{2} \mathrm{~B}_{12} \mathrm{H}_{11} \mathrm{SH}$ & $13.2 \pm 0.2$ & & \\
$\mathrm{EE}$ & $\mathrm{Cs}_{2} \mathrm{~B}_{12} \mathrm{H}_{11} \mathrm{SH}$ & $12.6 \pm 0.3$ & & \\
$\mathrm{FF}$ & $\mathrm{Na}_{2}{ }^{10} \mathrm{~B}_{12} \mathrm{H}_{11} \mathrm{SH}$ & $12.83 \pm 0.06$ & $5.23 \pm 0.06$ & $2.47 \pm 0.06$ \\
$\mathrm{GG}$ & $\mathrm{Na}_{2}{ }^{10} \mathrm{~B}_{12} \mathrm{H}_{11} \mathrm{SH}$ & $12.8 \pm 0.6$ & $6.4 \pm 0.1$ & $2.0 \pm 0.1$ \\
$\mathrm{HH}$ & $\mathrm{Na}_{2}{ }^{10} \mathrm{~B}_{12} \mathrm{H}_{11} \mathrm{SH}$ & 13 & 6.5 & 2.0 \\
\hline
\end{tabular}

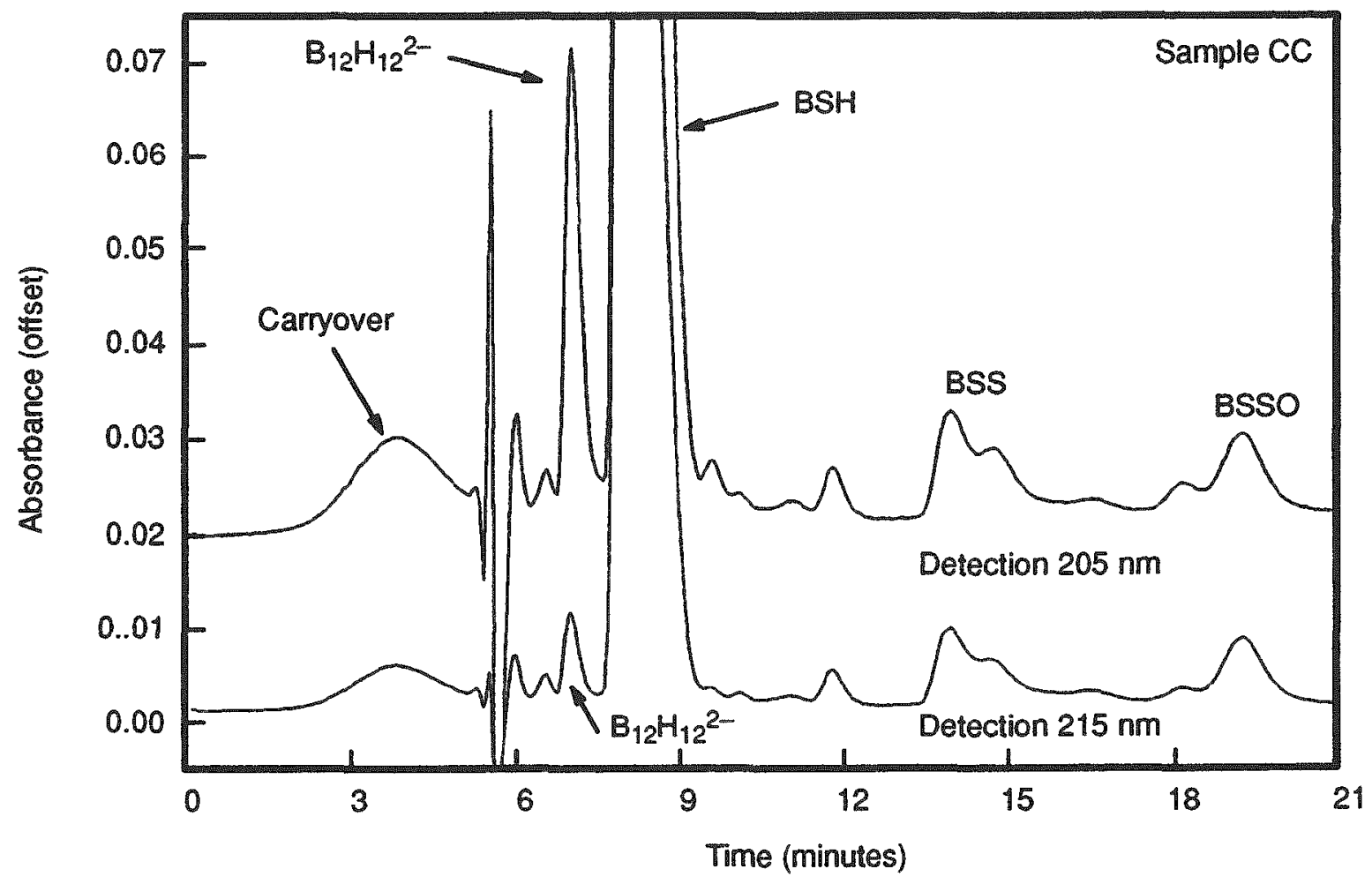

LF94 0046

Figure 42. HPLC showing major contamination of $\mathrm{CC}$ with $\mathrm{B}_{12} \mathrm{H}_{12}{ }^{2-}$. Conditions same as in Figure 41 but flowing at $0.5 \mathrm{~mL} / \mathrm{min}$. 
Table 21). The utility of photodiode array detection in these analyses is also demonstrated in Figure 42. Both chromatograms were from a single run, and the increased detectability of $\mathrm{B}_{12} \mathrm{H}_{12}{ }^{2-}$ at $205 \mathrm{~nm}$ could be exploited. Even at $205 \mathrm{~nm}, \mathrm{~B}_{12} \mathrm{H}_{12}{ }^{2-}$ does not have a large enough molar absorptivity coefficient to allow detection of this impurity at concentrations less than 1-2 wt\%.

The significant $\mathrm{B}_{12} \mathrm{H}_{12}{ }^{2-}$ contamination of sample CC is also clearly evident in NMR spectrum at $\sim \delta-15 \mathrm{ppm}$ (see Figure 43 ). Most NMR spectra of BSH show a slightly larger peak than expected peak at $\delta-15 \mathrm{ppm}$. It is possible that this peak-height enhancement could be due, in part, to non-BSH contaminants like $\mathrm{B}_{12} \mathrm{H}_{12}{ }^{2-}$. Typically, NMR should be capable of detecting boroncontaining contaminants, like $\mathrm{B}_{12} \mathrm{H}_{12}{ }^{2-}$, at levels less than $1 \mathrm{wt} \%$ if the solution was $2-3 \mathrm{mg}$ $\mathrm{BSH} / \mathrm{mL}$.

Many of the potential contaminants of BSH appear to be organic in nature. These BSH contaminants possibly include the reagents used in the synthesis and some intermediate products. Elemental CHN analysis should point to any

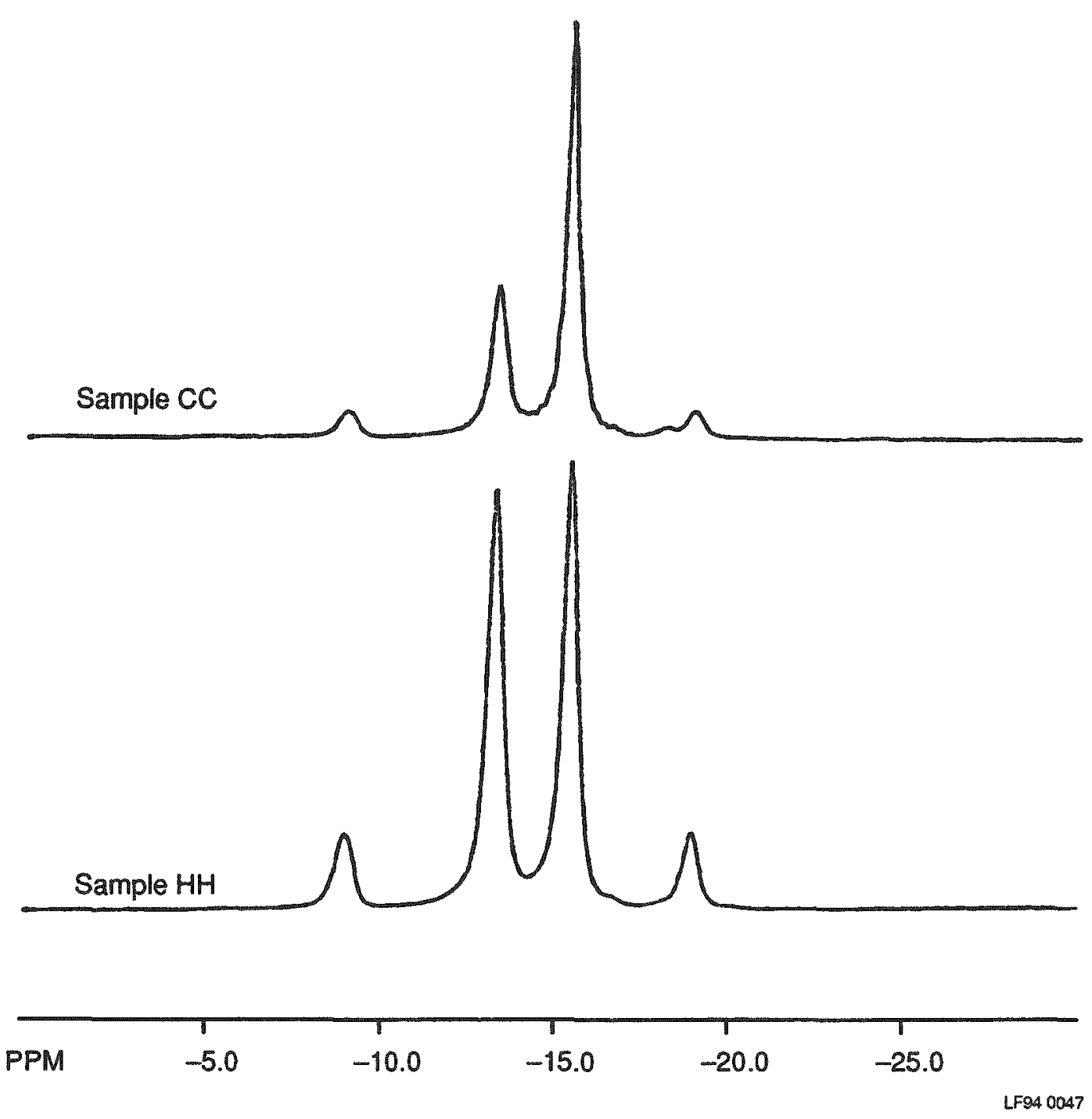

Figure 43. ${ }^{1} \mathrm{H}$ decoupled ${ }^{10} \mathrm{~B}$ NMR spectra for ${ }^{10} \mathrm{BSH}(\mathrm{HH})$ and ${ }^{10} \mathrm{BSH}$ with significant ${ }^{10} \mathrm{~B}_{12} \mathrm{H}_{12}{ }^{2-}$ (CC). 
significant contamination of $\mathrm{BSH}$ with these materials. The CHN analysis results indicated that sample FF had a relatively high level of $\mathrm{C}$ contamination $(\sim 1.7 \mathrm{wt} \% \mathrm{C})$. and sample EE had excessive contamination by an organic material $(-5.89$ wt\% C). Subsequent FTIR spectroscopy (Figure 44) confirmed the presence of an organic solvent, acetone, in sample EE that was not identified by HPLC and indicated that an unidentified hydrocarbon was present in FF. Also notable in the $\mathbb{R}$ spectra is the obvious presence of significant water in both samples FF and AA, while water is essentially totally absent in sample EE.

The need for and value of the multitechnique approach to the chemical characterization of BSH salts has clearly been demonstrated. Liquid chromatography may be used to quantitatively determine BSS and BSSO as well as to identify the presence of other unknown compounds. Elemental analysis may be used to confirm stoichiometry and can ultimately identify some impurities such as other salts containing B, S, or Na. Spectroscopic such as NMR and FTIR techniques cannot only identify the presence of major contaminants but also provide confirmation of the chemical nature of the contaminant. With the use of all the analytical techniques described here, some unidentified impurities have been discovered and these impurities are known to exist in much of the $\mathrm{Na}_{2} \mathrm{BSH}$ used for $\mathrm{BNCT}$ research.

\section{Most Recent Purity/Quality Determinations}

Two batches of new $\mathrm{Na}_{2}{ }^{10} \mathrm{BSH}$ were obtained during the latter part of 1993 from Boron Biologicals. Representative samples of each of these two batches were used for purity and quality verifications at the INEL. The first batch contained $241 \mathrm{~g}$ vials of $\mathrm{Na}_{2}{ }^{10} \mathrm{BSH}$ and the second contained $291 \mathrm{~g}$ vials of $\mathrm{Na}_{2}{ }^{10} \mathrm{BSH}$ and were designated by the lot numbers $\mathrm{KBI} 77$ and $\mathrm{KBI} 83$, respectively. All vials were labeled at the INEL for tracking purposes, and vials designated BNCT 620 and BNCT 646 were used as representative samples of the lots $\mathrm{KBI77}$ and $\mathrm{KBI83}$, respectively.
The HPLC analyses were performed using a new 250/1/4" $/ 3 \mathrm{~mm}$ column packed with type 120-5, $\mathrm{C}_{18}, 5 \mu \mathrm{m}$ particles of Nucleosil $®$. The mobile phase was approximately $48 \%$ methanol and $52 \%$ water solution, with $5 \mathrm{mM}$ TBAS ion pairing reagent flowing at $0.4 \mathrm{~mL} / \mathrm{min}$. These conditions were used to achieve resolution of both ${ }^{10} \mathrm{BSH}^{2-}$ and $\mathrm{B}_{12} \mathrm{H}_{12}{ }^{2-}$. Individual aliquots of $\mathrm{BNCT} 202$ were prepared as reference samples for each run. Samples BNCT 620 and BNCT 646 were prepared in triplicate. Duplicate chromatograms were acquired for all sample aliquots, reference sample aliquots, and standards prepared for $\mathrm{BSS}^{4-}$, $\mathrm{BSSO}^{4-}$ and $\mathrm{B}_{12} \mathrm{H}_{12}{ }^{2-}$. Because there were only minute quantities remaining of the $\mathrm{BSS}^{4-}$ and $\mathrm{BSSO}^{4-}$ materials used for standards, only qualitative standards for these anions could be prepared to determine retention times.

Figure 45 contains a representative chromatogram of BNCT 620 and a chromatogram of the reference sample BNCT 202. Figure 46 contains a representative chromatogram of BNCT 646 and chromatograms of the $\mathrm{BSS}^{4-}$ and $\mathrm{BSSO}^{4-}$ retention time standards. The only major contaminant in both batches appears to be the dimer, $\mathrm{BSS}^{4}$. Some dimer is always expected. The late-eluting components and other contaminants near the $\mathrm{BSS}^{4-}$ peak in the BNCT 202 chromatogram are not present in either the BNCT 620 or BNCT 646 chromatograms. BNCT 646 shows only one additional contaminant eluting at $\sim 8 \mathrm{~min}$. The identity of this peak is unknown. The $\mathrm{B}_{12} \mathrm{H}_{12}{ }^{2-}$ anion was not evident in the chromatograms of either BNCT 620 or BNCT 646.

Elemental analysis results for $\mathrm{Na}, \mathrm{S}$, and $\mathrm{B}$ in samples BNCT 620 and 646 are shown in Table 23, and the CHN results are shown in Table 24. Samples BNCT 202 and 313 have been used consistently as reference samples and have become increasingly wet with their use. This is reflected in the relatively poor recoveries of $\mathrm{Na}, \mathrm{S}$, and $\mathrm{B}$. Poor recoveries resulting from wet samples do not. however, affect mole ratios. It appears from the FTIR analyses shown in Figure 47 that both BNCT 620 and 646 are reasonably dry when compared to BNCT 313. However, BNCT 620 appears to be slightly wetter than BNCT 646 . The recovery of 




LF94 0048

Figure 44. Infrared spectra of BSH samples obtained from $\mathrm{KBr}$ pellets.

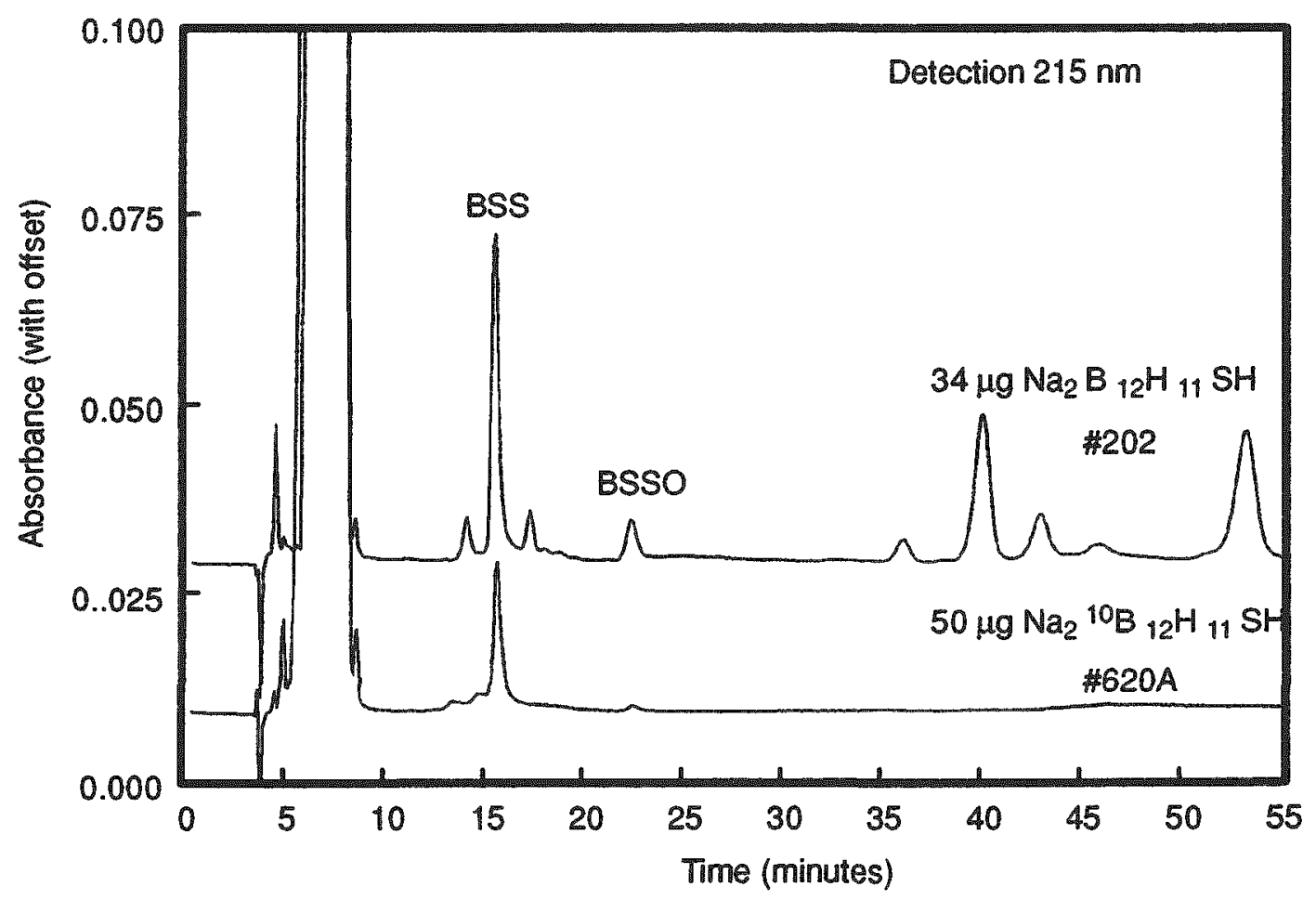

LF\$4 0049

Figure 45. Representative chromatograms of BNCT 202 and 620. See the text for the HPLC conditions. 


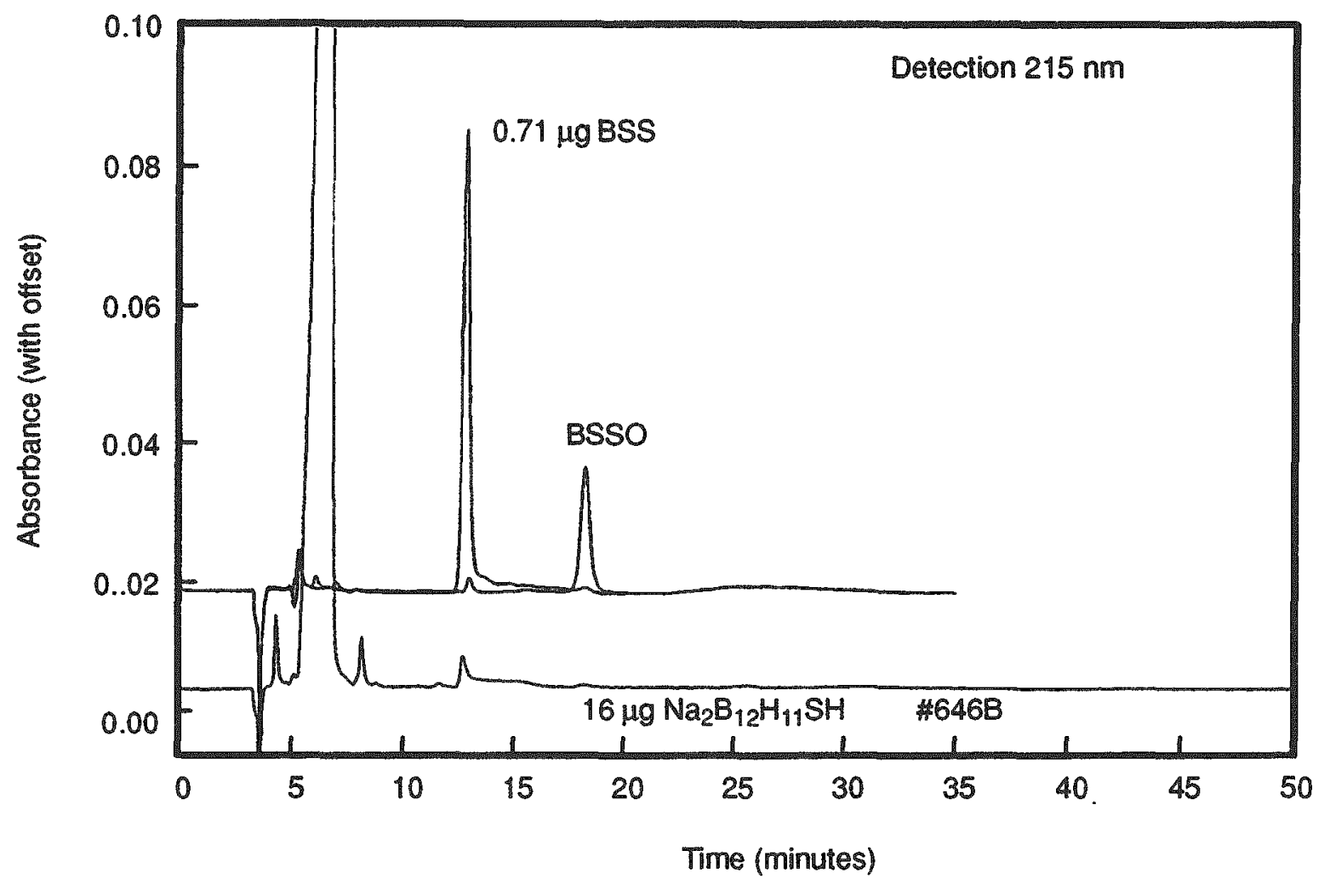

LF94 0050

Figure 46. Representative chromatograms of BNCT 646 and the $\mathrm{BSS}^{4-}$ and $\mathrm{BSSO}^{4-}$ retention time standards. See the text for the HPLC conditions.

Table 23. ICP-AES elemental analysis results for BNCT 620, BNCT 646, and representative reference compounds.

\begin{tabular}{|c|c|c|c|c|c|c|c|}
\hline \multirow{2}{*}{$\begin{array}{r}\text { BNCT } \\
\text { number }\end{array}$} & \multirow[b]{2}{*}{ Compound } & \multicolumn{3}{|c|}{$\begin{array}{c}\text { Concentrations } \\
(\mathrm{w} \%)^{\mathrm{a}}\end{array}$} & \multicolumn{3}{|c|}{ Mole ratios } \\
\hline & & $\mathrm{Na}$ & $\mathbf{s}$ & B & $\mathrm{Na} / \mathrm{S}$ & $\mathrm{B} / \mathrm{Na}$ & $B / S$ \\
\hline \multicolumn{8}{|c|}{ Analysis of $8 / 31 / 93$} \\
\hline 202 & $\mathrm{Na}_{2} \mathrm{~B}_{12} \mathrm{H}_{11} \mathrm{SH}$ & $16.5(2.9)$ & 10.0 & $46.2(1.2)$ & $2.30(2.9)$ & $5.94(1.8)$ & $13.7(2.9)$ \\
\hline 576 & $\mathrm{Na}_{4}{ }^{10} \mathrm{~B}_{24} \mathrm{H}_{22} \mathrm{~S}_{2}$ & $4.18(0.01)$ & 11.5 & $45.9(0.01)$ & $2.02(1.0)$ & $6.3(0.9)$ & $12.7(0.1)$ \\
\hline 620 & $\mathrm{Na}_{2}{ }^{10} \mathrm{~B}_{12} \mathrm{H}_{11} \mathrm{SH}$ & $20.3 \pm 0.7$ & 13.3 & $53.1 \pm 0.9$ & $2.2 \pm 0.2$ & $5.6 \pm 0.1$ & $12.1 \pm 1.0$ \\
\hline \multicolumn{8}{|c|}{ Analysis of $11 / 23 / 93$} \\
\hline 313 & $\mathrm{Na}_{2}{ }^{1{ }^{-}} \mathrm{B}_{12} \mathrm{H}_{11} \mathrm{SH}$ & 19.8 & 12.8 & 50.3 & 2.15 & 5.81 & 12.5 \\
\hline 426 & $\mathrm{Na}^{10}{ }^{10} \mathrm{~B}_{12} \mathrm{H}_{11} \mathrm{SH}$ & $18.8(3.8)$ & $11.5(2.6)$ & $47.2(1.8)$ & $2.27(1.2)$ & $5.74(2.0)$ & $13.0(0.8)$ \\
\hline 576 & $\mathrm{Na}_{4}{ }^{10} \mathrm{~B}_{24} \mathrm{H}_{22} \mathrm{~S}_{2}$ & 15.8 & 10.4 & 41.8 & 2.13 & 6.04 & 12.9 \\
\hline 646 & $\mathrm{Na}_{2}{ }^{10} \mathrm{~B}_{12} \mathrm{H}_{11} \mathrm{SH}$ & $23.3 \pm 0.9$ & $13.9 \pm 0.3$ & $55 \pm 1$ & $2.3 \pm 0.1$ & $5.39 \pm 0.08$ & $12.6 \pm 0.5$ \\
\hline
\end{tabular}


Table 24. CHN analysis of BSH samples BNCT 620,646 , and 313.

\begin{tabular}{ccccc} 
& & \multicolumn{3}{c}{$\begin{array}{c}\text { Concentrations } \\
(\text { wt } \%)^{\mathrm{a}}\end{array}$} \\
\cline { 3 - 5 } BNCT number & Compound & Carbon & Nitrogen & Hydrogen \\
\hline 620 & $\mathrm{Na}_{2}{ }^{10} \mathrm{~B}_{12} \mathrm{H}_{11} \mathrm{SH}$ & $0.02 \pm 0.02$ & 0.0 & $6.08 \pm 0.13$ \\
313 & $\mathrm{Na}_{2}{ }^{10} \mathrm{~B}_{12} \mathrm{H}_{11} \mathrm{SH}$ & $0.37 \pm 0.04$ & 0.0 & $7.21 \pm 0.08$ \\
646 & $\mathrm{Na}_{2}{ }^{10} \mathrm{~B}_{12} \mathrm{H}_{11} \mathrm{SH}$ & $0.31 \pm 0.02$ & $0.01 \pm 0.01$ & $6.13 \pm 0.02$ \\
\hline & & & & \\
\hline
\end{tabular}

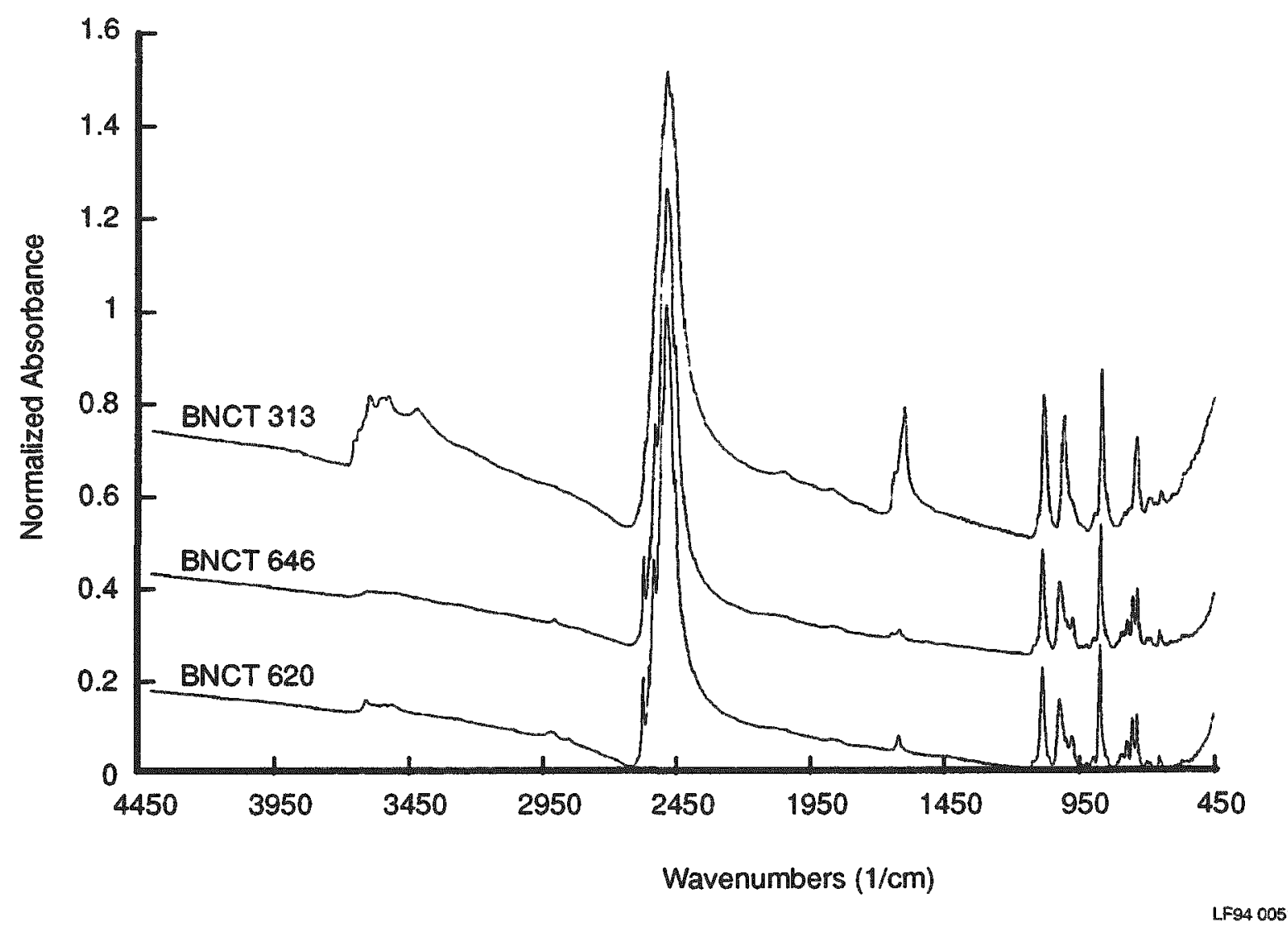

Figure 47. Infrared spectra of BNCT 620,646 , and 313 in $\mathrm{KBr}$ pellets. 
BNCT 620 calculated from the ICP-AES results appears to be consistently somewhat low ( $-90 \%)$. While the B/S ratios for both BNCT 620 and 646 appear not to be significantly different from 12 , the $\mathrm{B} / \mathrm{Na}$ ratios appear to be consistently low and the $\mathrm{Na} / \mathrm{S}$ ratios appear to be somewhat high indicating the possible presence of a nonboron-containing $\mathrm{Na}$ salt.

Also in Table 23 are results for BNCT 576, which is the newest batch of BSS that INEL researchers hope to use as a standard. Results for the preparations made nearly 3 months apart are very similar and lead to the conclusion that this material is either very wet or contains a significant unknown impurity. No significant contaminants have been noted for BNCT 576 in any of the HIPLC experiments. A sample HPLC chromatogram of the material can be seen in Figure 46.

The ${ }^{10} \mathrm{~B}$ and ${ }^{11_{B}}$ NMR spectra for both $\mathrm{BNCT}$ 620 and 646 (Figure 48) were relatively unremarkable and simply indicate that $10_{\mathrm{BSH}}$ is the primary boron-containing component in the samples. The ${ }^{1} \mathrm{H}$ NMR did not indicate the presence of any additional contaminants having ${ }^{1} \mathrm{H}$ resonances that were resolved from the ${ }^{1} \mathrm{H}$ envelope of $\mathrm{BSH}$.
Overall, the quality of the newer ${ }^{10} \mathrm{BSH}$ lots appears to be acceptable with respect to the analyses performed at this point in time. The levels of ${ }^{10} \mathrm{BSS}$ detected were quite low and may have been partially due to oxidation in the solution. Essentially no ${ }^{10} \mathrm{BSSO}$ was detected in either sample and no unknown late-eluting components were noted. There may be some slight contamination by a nonboron-containing Na salt. The sample of the new BSS that researchers had hoped to use as a standard appears to have a significant contaminant that was not detected by the methods used.

\section{Additional Purity/Quality Problems and Analyses}

While the methods described and used above may adequately identify the majority of the BSH purity and quality problems, one additional significant problem with BSH remains. There appears to be some toxicity associated with the use of BSH at relatively high concentrations $>\sim 75 \mathrm{mg}$ $\mathrm{B} / \mathrm{kg}$ ). It is not clearly evident that this toxicity is consistent from batch to batch, from vial to vial within a batch, or that it is necessarily associated

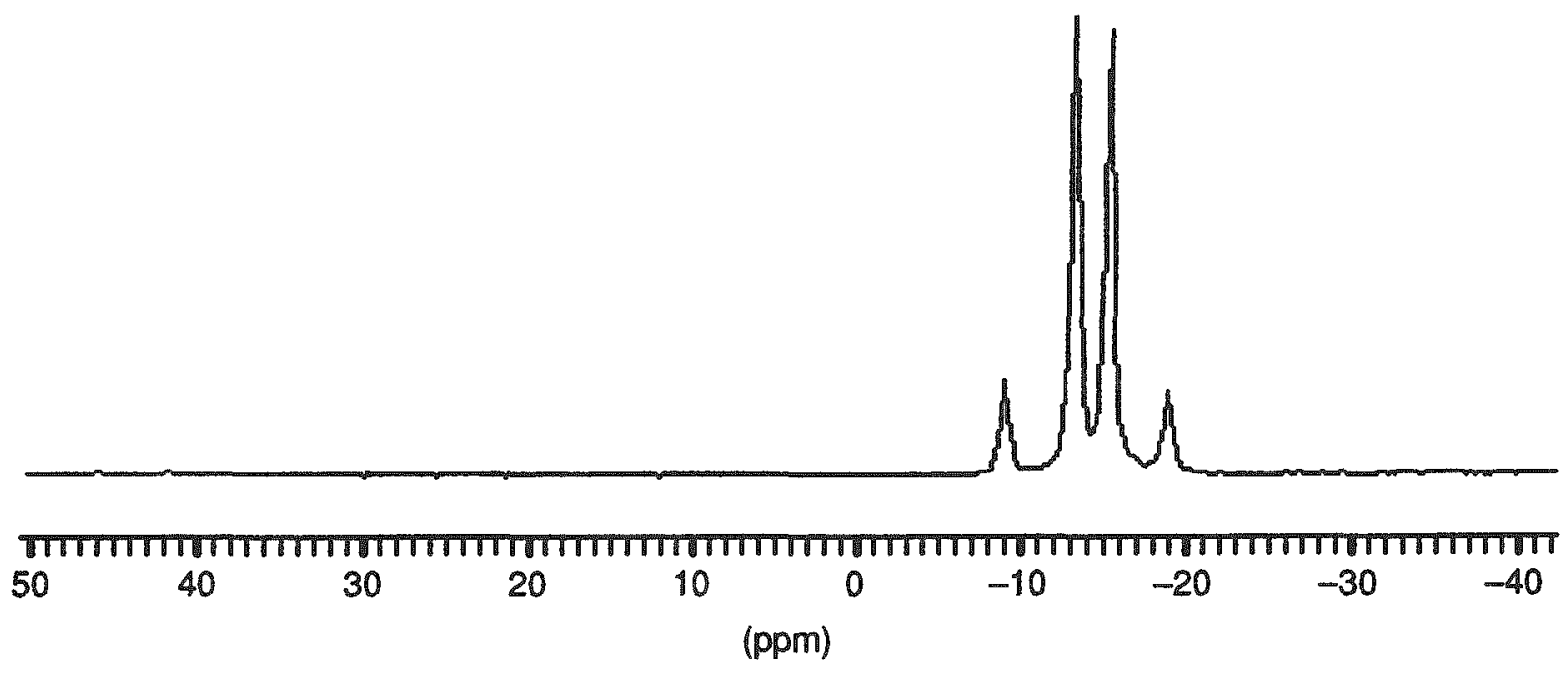

Figure 48. ${ }^{1} \mathrm{H}$ decoupled ${ }^{10} \mathrm{~B}$ NMR spectrum of BNCT 646. 
with BSH itself and, in fact, is more likely to be related to a contaminant. Since BSH does not appear to significantly or irreversibly bind to or interact with anything biologically, the most likely candidate contaminants to be toxic are the dimer and oxidized dimer (BSS and BSSO) which have been shown to be somewhat more toxic than BSH. $49,77,83,84$ The toxicity of the BSS and BSSO appears to be related to the very strong binding of these anions to blood proteins, which is likely to cause hemato- and hepato-toxicity. This strong binding of the dimer to proteins has previously been demonstrated. $49,83,85$

An indication of some potential contaminants that may be related to the toxicity of BSH is that it generally smells terrible. The odor is most reminiscent of sulfur-containing compounds like hydrogen sulfides or mercaptans, compounds that can certainly be associated with some toxicity. Qualitative (i.e., via the nose) experience indicates that the "odor intensity" varies from batch to batch and, possibly, even within a particular batch. There is also the possibility that age may play a role in odor "intensity." Other BNCT researchers have indicated that they are also quite aware of the smell.
The initial investigation of the nature of the gases began with the injections of a few headspace samples $(0.5-1.0 \mathrm{~mL})$ from the vials that $\mathrm{BSH}$ is delivered in onto a $30 \mathrm{~m} \times 0.25 \mathrm{~mm}$ i.d. XTI-5 capillary column installed on a Varian Satum gas chromatograph/ion trap mass spectrometer (GC/ITMS). The chromatographic column is far from optimal for the separation of the low molecular weight gases likely associated with the smell, but the low flows required for this column work well with the very sensitive ITMS. A temperature program beginning at $-20^{\circ} \mathrm{C}$ was required to achieve any degree of separation. The presence of $\mathrm{H}_{2} \mathrm{~S}$ could not be confirmed as it appeared to coelute with the components of air. However, there were indications that compounds such as methanethiol, dimethyl sulfide, and methyl ethyl disulfide may have been present.

Based upon the initial study and the desire to clearly separate $\mathrm{H}_{2} \mathrm{~S}$ from the components of air for detection by GC/MS, a POROPLOT Q column was purchased for use with the Hewlett Packard GC/MS system. The GC/MS instrument parameters are listed in Table 25. These conditions were used for all subsequent analyses.

Table 25. Instrumentation and experimental parameters used for determining volatile compounds over BSH.

GC conditions

GC/MS system

5890 Series II Gas Chromatograph

5989A Quadrapole Mass Spectrometer

MS detector conditions

Mass range $(\mathrm{m} / \mathrm{z})$

Source temperature

Quadrapole temperature
Column

Column inner distance

Column length

Film thickness

$10-650$

$250^{\circ} \mathrm{C}$

$100^{\circ} \mathrm{C}$
Injector temperature

Transfer line temperature

Column head pressure

Initial oven temperature

Initial time

Ramp rate

Final temperature

Final time

Injection volume
Poroplot Q

$0.32 \mathrm{~mm}$

$27.5 \mathrm{~m}$

$10 \mu \mathrm{m}$

$175^{\circ} \mathrm{C}$

$280^{\circ} \mathrm{C}$

$8 \mathrm{psi}$

$20^{\circ} \mathrm{C}$

$1 \mathrm{~min}$

$12^{\circ} \mathrm{C} / \mathrm{min}$

$250^{\circ} \mathrm{C}$

$2 \mathrm{~min}$

$0.5-1.0 \mathrm{~mL}$ 
Initially, samples were injected from the headspace over dry BNCT 456 . BNCT 456 was received on $9 / 15 / 92$ and is $10_{\mathrm{B}}$ enriched $\mathrm{BSH}$ representing lot \# 082792 from Boron Biologicals (note: this compound was packaged in the same pink-capped vials as used by Centronics, Ltd). Carbon disulfide was identified. However, no other "sulfide" compounds were noted.

In an attempt to force more of the suspected compounds into solutions, the $\sim 0.75 \mathrm{~g}$ of $\mathrm{BNCT}$ 456 were dissolved in $1 \mathrm{~mL}$ of water to make a highly ionic solution that would force volatile compounds out of solution into the headspace. It was also postulated that some of the sulfide compounds may have had an affinity for the surfaces of the metal needle on the gas-tight syringe. Therefore, the metal needle was replaced with a length of $0.25 \mathrm{~mm}$ i.d. fused silica tubing. The sample was heated to $50^{\circ} \mathrm{C}$ to increase the vapor pressure of the volatile components in the vial headspace. Figure 49 is the total ion current (TIC) chromatogram of the $50^{\circ} \mathrm{C}$ headspace over the solubilized BNCT 456. The only notable compounds found in this sample were carbonyl sulfide and carbon disulfide. However, the carbon disulfide had a much higher signal-to-noise ratio. Both of the compounds found in this sample are known to be quite poisonous. Selected ion chromatograms for characteristic ions of these two compounds are shown in Figure 50 and confirm the presence of these two compounds.

TIC of bnct $456 a . d$

bnct 456: Run at 01:48 PM MST on Fri Dec. 03, 1993

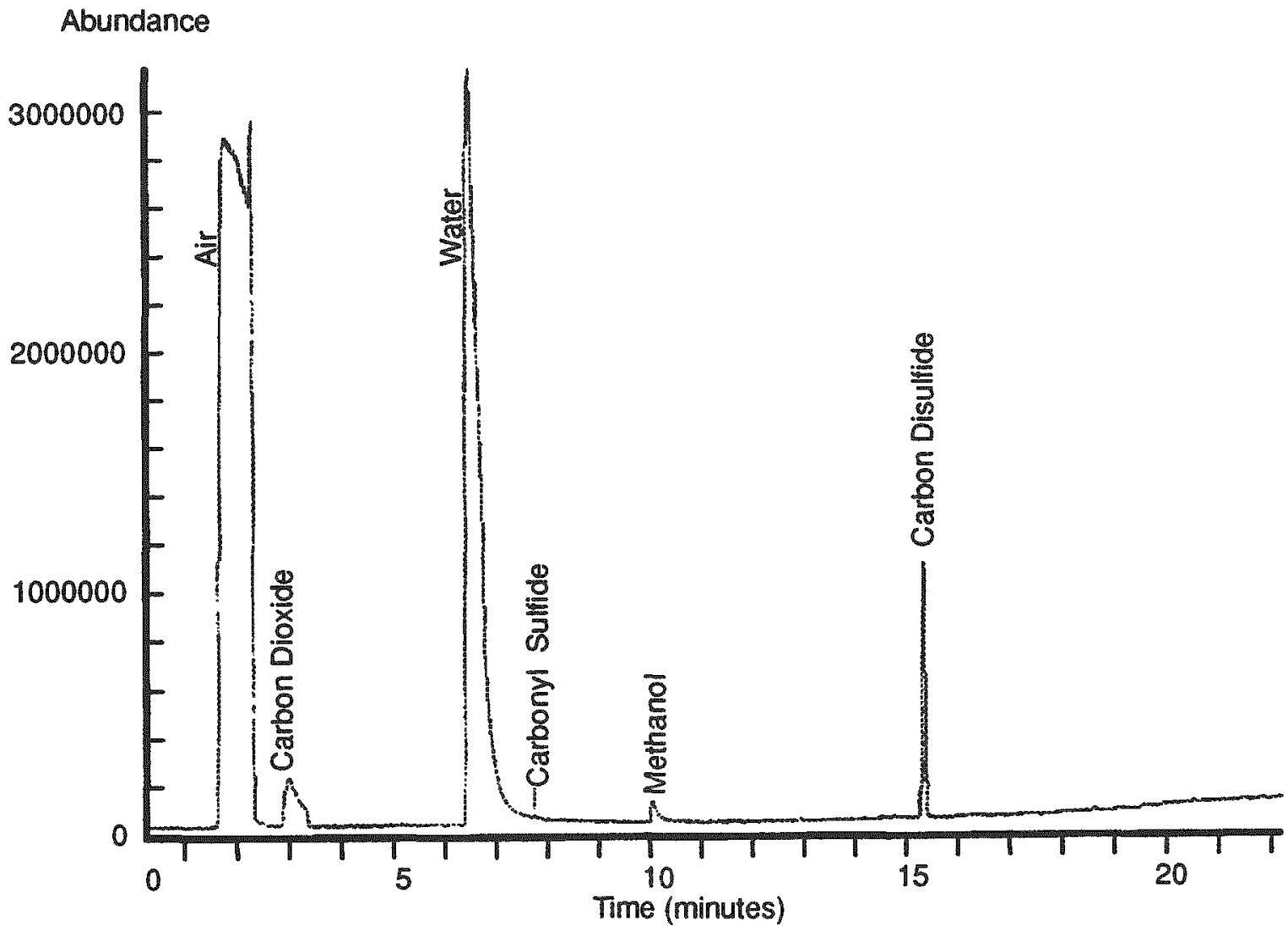

LF94 0070

Figure 49. TIC of $50^{\circ} \mathrm{C}$ headspace over solubilized BNCT 456. 
Ion 76,00 amu from bnct456a.d

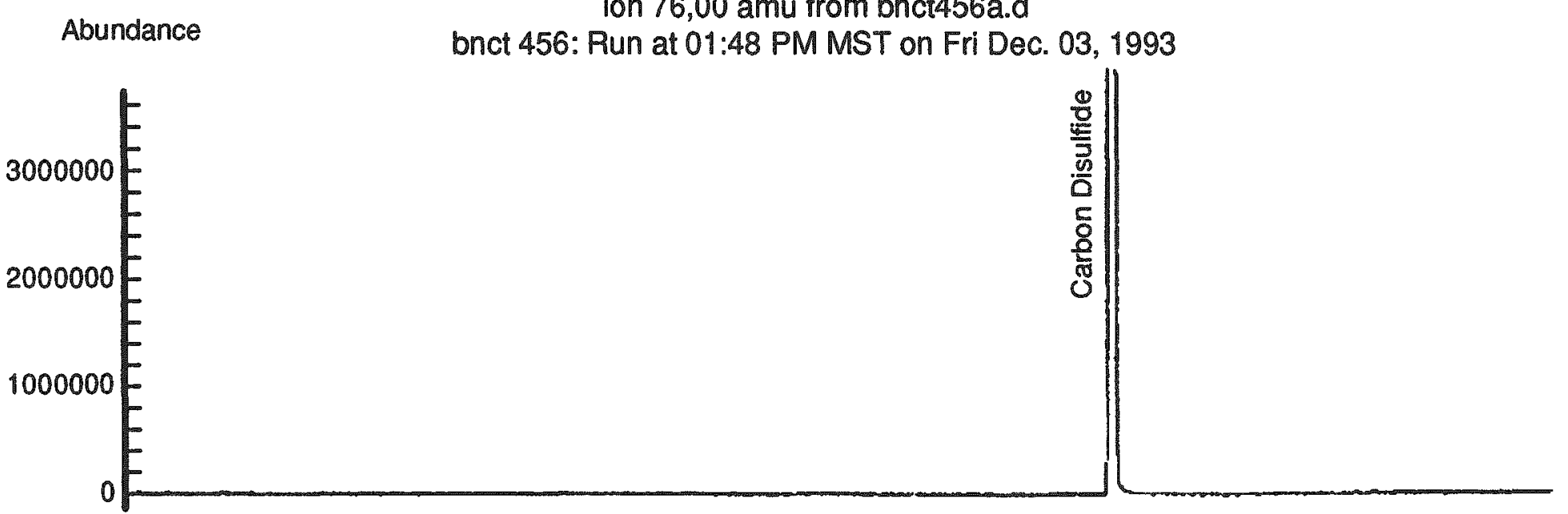

Ion 60,00 armu fron bact $456 a, d$

Abundance

8

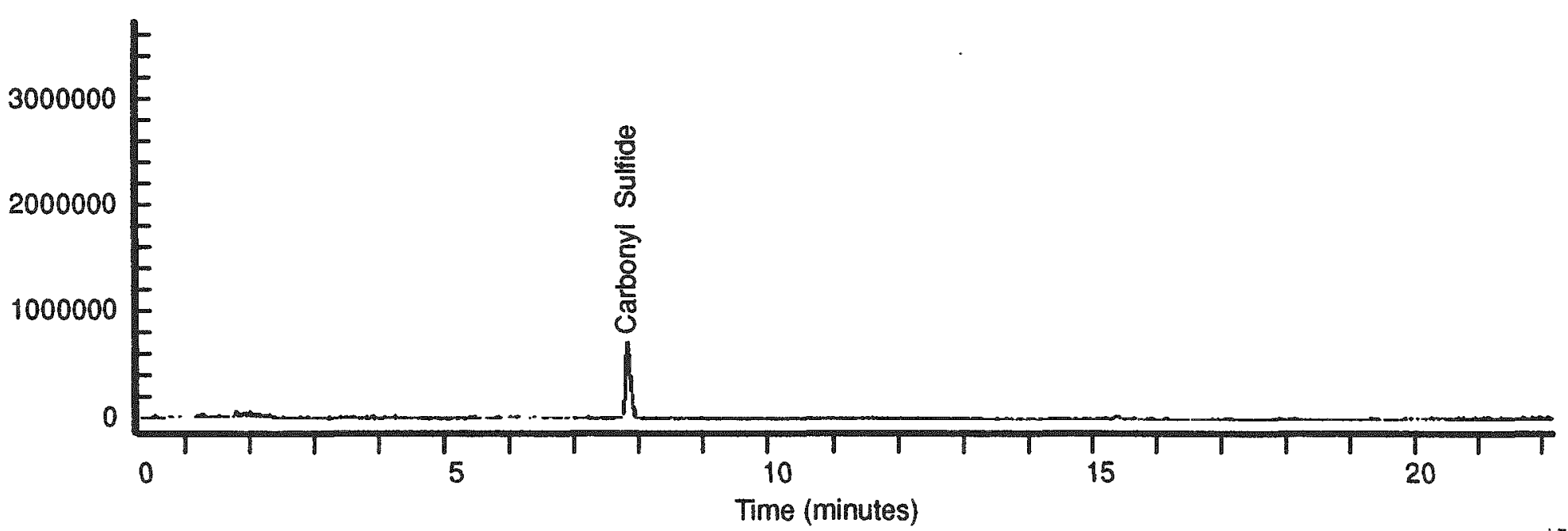

Figure 50. Selected ion chromatograms of the $50^{\circ} \mathrm{C}$ headspace over solubilized BNCT 456 at $\mathrm{m} / \mathrm{z} 60$ (bottom) and $\mathrm{m} / \mathrm{z} 76$ (top). 
The headspace over a second sample of dry BSH powder was also examined on the GC/MS with the Poroplot Q column. BNCT 170 was selected as the second sample because of its relative age and the fact that we would probably no longer need to retain this $\sim 0.8 \mathrm{~g}$ of compound. BNCT 170 is $\mathrm{BSH}$ with natural abundance boron received from Callery Chemical Company on 12/12/89 and has been stored in a freezer ever since. The screw cap on the vial was replaced with a septum topped cap in the open laboratory air and the sample was heated to $50^{\circ} \mathrm{C}$ prior to sampling for the $\mathrm{GC} / \mathrm{MS}$ run. The odor emanating from this compound could be detected by the nose when the septum top was pierced with a needle to prepare an entry slot for the fused silica syringe needle. Figure 51 is the TIC chromatogram of the headspace over BNCT 170. Significant levels of $\mathrm{H}_{2} \mathrm{~S}$ were identified, and $\mathrm{C}_{1}-\mathrm{C}_{4}$ thiols were also clearly identified. This sample also appeared to be contaminated with a variety of solvents, many of which are not commonly used in INEL laboratories. Only methanol was identified in a blank injection of air and in the previous injection of the BNCT 456 headspace. One could infer from this sample that this batch of compound was made and handled in a relatively "solvent-contaminated" environment prior to packaging. The $\mathrm{H}_{2} \mathrm{~S}$ and the simple thiols are most likely responsible for the odor associated with this compound and probably result from degradation of the pyrolidone or the pyrolidone-BSH intermediate compounds. The selected ion chromatograms shown in Figure 52 indicate that traces of carbonyl sulfide and carbon disulfide may also have been present in the BNCT 170 headspace.

The GC/MS work has been limited in its scope. However, it has allowed us to clearly identify several compounds associated with the smell connected with BSH. It is likely that these compounds may also be associated with some of the toxic effects associated with $\mathrm{BSH}$. Work will continue to develop appropriate method(s) by which these gases can be identified and quantified on a routine basis. Solvent extraction with octane or nonane may be appropriate for the thiol compounds, but it is not likely to work well for $\mathrm{H}_{2} \mathrm{~S}$. Simple headspace analysis will work well for qualitative analysis but will be quantitatively difficult. since known quantities of the BSH salt would need to be weighed and some loss of analyte is likely to occur. However, one could assume that each new vial contains exactly one gram of BSH. It is not known what the "partitioning ratio" of these compounds is between the headspace and the BSH solid.

This work raises several interesting questions and problems that warrant further investigation:

- Are any of these compounds responsible for the spurious peaks noted in the high-pressure liquid chromatography (HPLC) experiments? In particular, are any of these compounds responsible for the "late-eluting peaks" noted in much of the HPLC of the BSH in previous years?

- Is there a relationship between the presence of gaseous sulfur compounds and the way in which the compounds were made or isolated?

- Is there a relationship between the age of the BSH sample and the presence or quantity of the volatile contaminants (i.e., shelf life)?

- Is there a relationship between the storage conditions and the presence of gaseous sulfur-containing contaminants?

- Can the presence of these compounds be positively related to the toxic (or, in some cases, the lack of toxic) effects noted for BSH? 
TIC of bnct456b.d

bnct 170 dry: Run at 03:03 PM MST on Fri Dec. 03, 1993

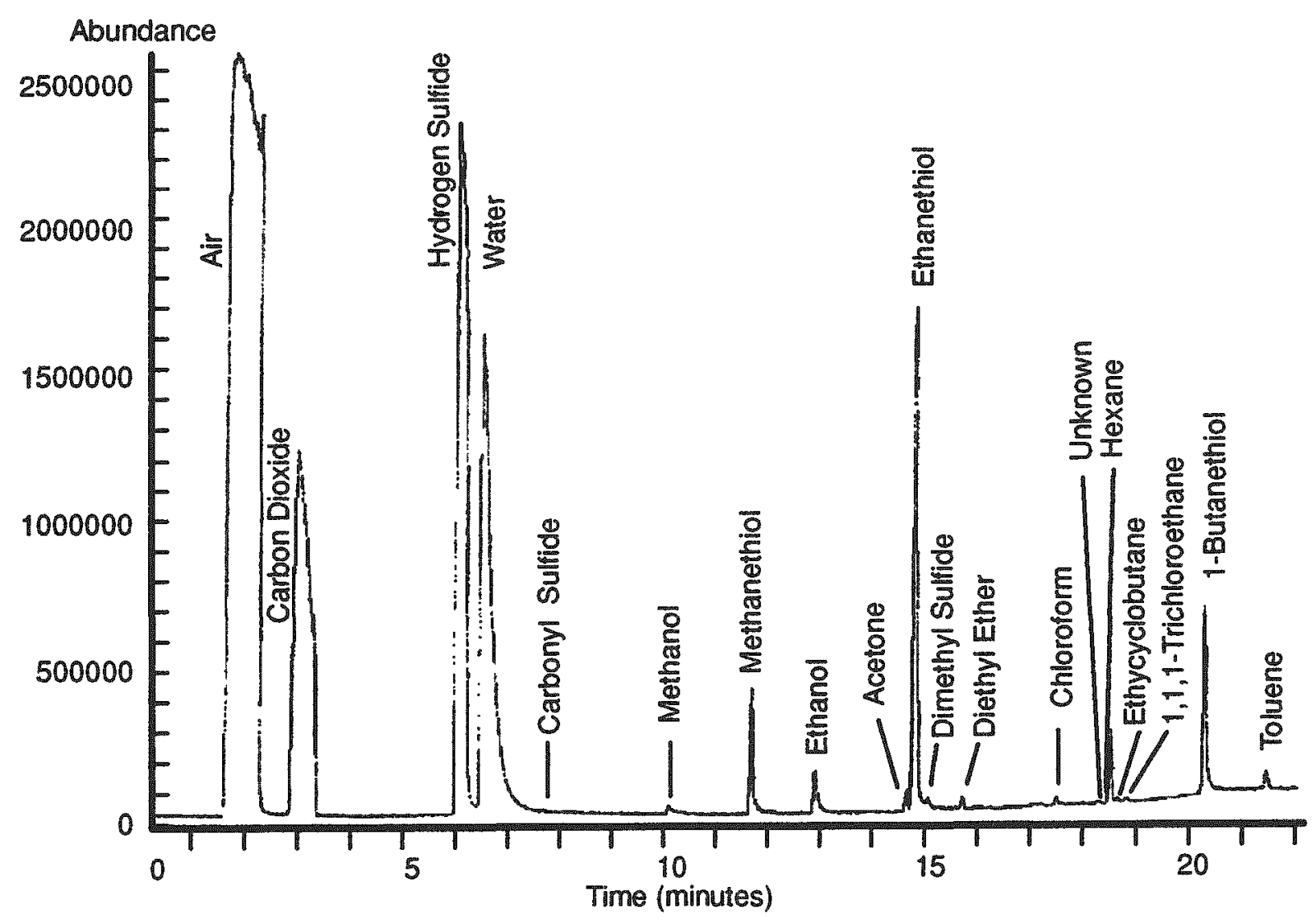

LF94 0073

Figure 51. TIC of $50^{\circ} \mathrm{C}$ headspace over BSH powder from BNCT 170 . 

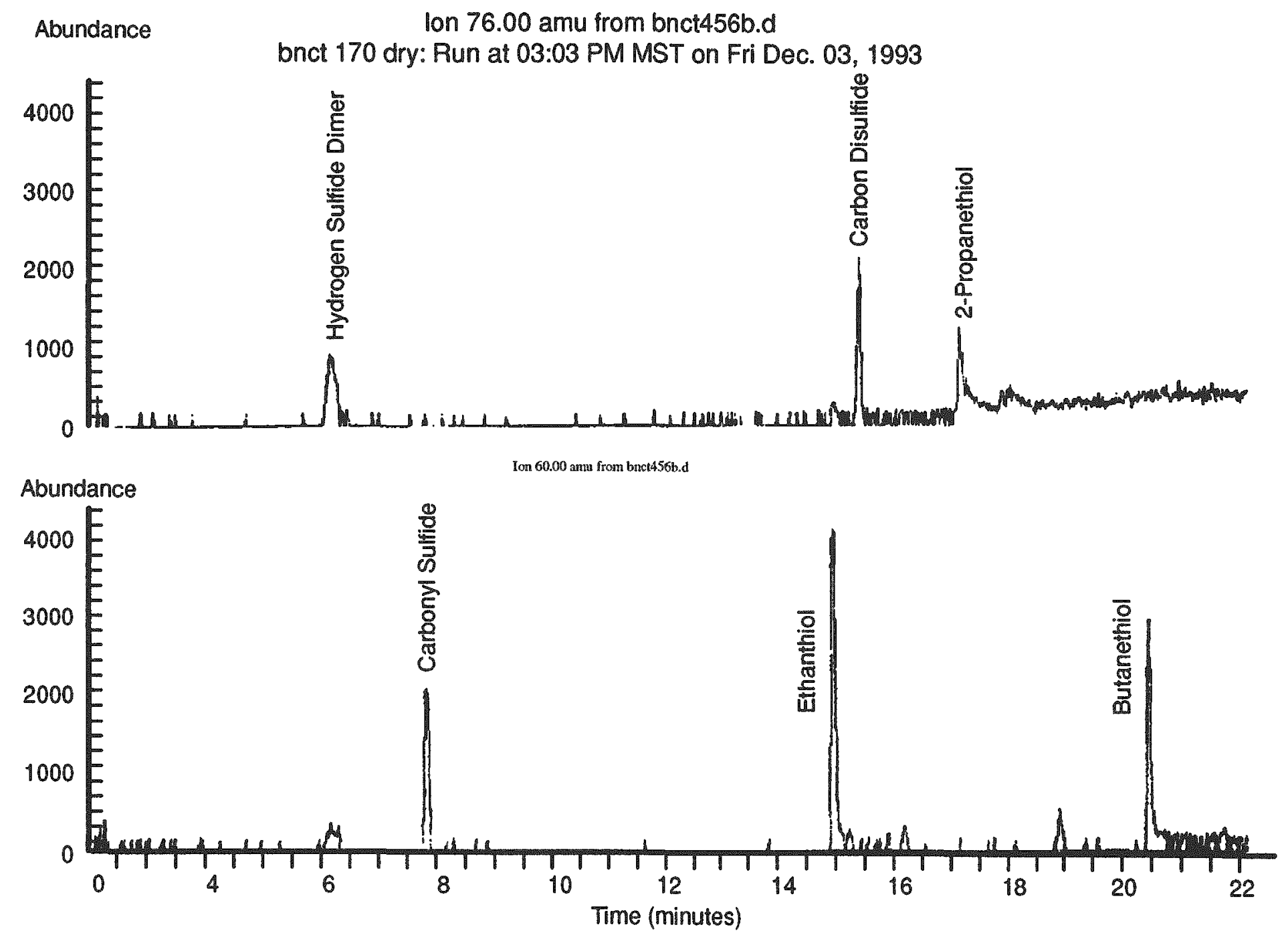

LF94 0072

Figure 52. Selected ion chromatograms of the $50^{\circ} \mathrm{C}$ headspace over dry $\mathrm{BNCT} 170$ at $\mathrm{m} / \mathrm{z} 60$ (bottom) and $\mathrm{m} / \mathrm{z} 76$ (top). 


\section{MEASUREMENT DOSIMETRY}

Y. D. Marker, C. R. Amaro, Nuclear and Radiological Physics, INEL; P. $D$. Randolph, Radiation Measurements and Development, INEL

\section{Real-Time Neutron Monitor}

The operation of two small fission chambers was tested at BMRR to determine how well they would function as real-time flux monitors. Two chambers were obtained from TGM Detectors, Inc., of Waltham MA. They are $44.5 \mathrm{~mm}$ long by $6.3 \mathrm{~mm}$ in diameter and are integrally attached to a $5 \mathrm{~m}$ length of coaxial signal/high-voltage cable. The active length is $25 \mathrm{~mm}$. One chamber had a cathode of $1,000 \mathrm{micrograms} / \mathrm{cm}^{2}$ of ${ }^{235} \mathrm{U}_{3} \mathrm{O}_{8}$, and the other had the same amount of depleted $\mathrm{U}_{3} \mathrm{O}_{8}$ for its cathode. These chambers were tested at reactor power levels from 0.1 to $3.0 \mathrm{MW}$ at the filtered epithermal port of the BMRR. It was found that the bare ${ }^{235} \mathrm{U}$ chamber gave too high count rates $\left(>6 \times 10^{4} \mathrm{cps}\right.$ at $\left.0.5 \mathrm{MW}\right)$ and was swamped (i.e., $100 \%$ dead) at $3 \mathrm{MW}$, whereas the bare ${ }^{238} \mathrm{U}$ chamber gave count rates of $60 \mathrm{cps}$ at $0.5 \mathrm{MeV}$. Tests with and without a cadmium cover over the ${ }^{238} \mathrm{U}$ chamber showed that its response was primarily from thermal neutrons due to the remnant ${ }^{235} \mathrm{U}$ in depleted $\mathrm{U}$. With the small amount of ${ }^{235} \mathrm{U}$ in this chamber, it would be able to serve as an adequate real-time neutron monitor.

\section{Accelerator Measurements}

Preliminary tests of proton target/moderator configurations for an accelerator-based BNCT neutron source were begun using the radio frequency quadrupole ( $R F Q$ ) proton linear accelerator at ISU. The proton energy produced by this accelerator is $2 \mathrm{MeV}$ and the beam current is limited to $150 \mu \mathrm{A}$ average. Most accelerator source studies for BNCT focus on using $2.5 \mathrm{MeV}$ protons on a lithium target and predict that beam currents of the order of $100 \mathrm{ma}$ will be required for therapeutic purposes. As can be seen, the ISU RFQ does not have the beam current to be capable of therapeutic testing but it is adequate to perform neutron filter physics and dosimetry studies. At this point the work has focused on characterizing the neutron source from the RFQ using target assemblies similar to the assemblies that will be required in more intense therapeutic sources. The reaction being studied in this work is the ${ }^{7} \mathrm{Li}(\mathrm{p}, \mathrm{n})^{7} \mathrm{Be}$ reaction, which has a threshold at a proton energy of approximately $1.8 \mathrm{MeV}$.

It is known from physics of the ${ }^{7} \mathrm{Li}(\mathrm{p}, \mathrm{n})^{7} \mathrm{Be}$ reaction that the neutrons coming from the lithium target will be forward-directed along the direction of the original proton beam with an angular distribution. which will be a maximum at $0^{\circ}$ and a minimum at $180^{\circ}$. The neutron energy will also change with angle with the maximum energy of $\approx 230 \mathrm{keV}$ (for $2 \mathrm{MeV}$ protons) at $0^{\circ}$ and the minimum energy of $\approx 15 \mathrm{keV}$ at $180^{\circ}$. Most work reported on angular and energy distributions for the proton on lithium reaction have been done on thin targets with little structural assembly interference. In this work the neutron energy and angular distributions are being extended to thick targets similar to those needed for the therapeutic neutron sources and target assemblies that can handle the physical and thermal requirements. Preliminary data have been obtained on the angular distribution of the neutrons from a thick lithium target (Figure 53), and neutron spectra for two angles have been obtained from a thin lithium target (Figure 54). The intensity versus angle data for the thick target indicate a significant alteration of the neutron flux versus angle due to the water cooling on the target and the target support structure around the periphery of the target. The thin target neutron spectra are being used to provide an energy calibration for the neutron spectrometers being used. Once the spectrometers are calibrated, they will be used to measure the neutron spectra versus angle for a variety of target assemblies ranging from the thin targets with little structure and cooling to thick targets with full structure and cooling. 


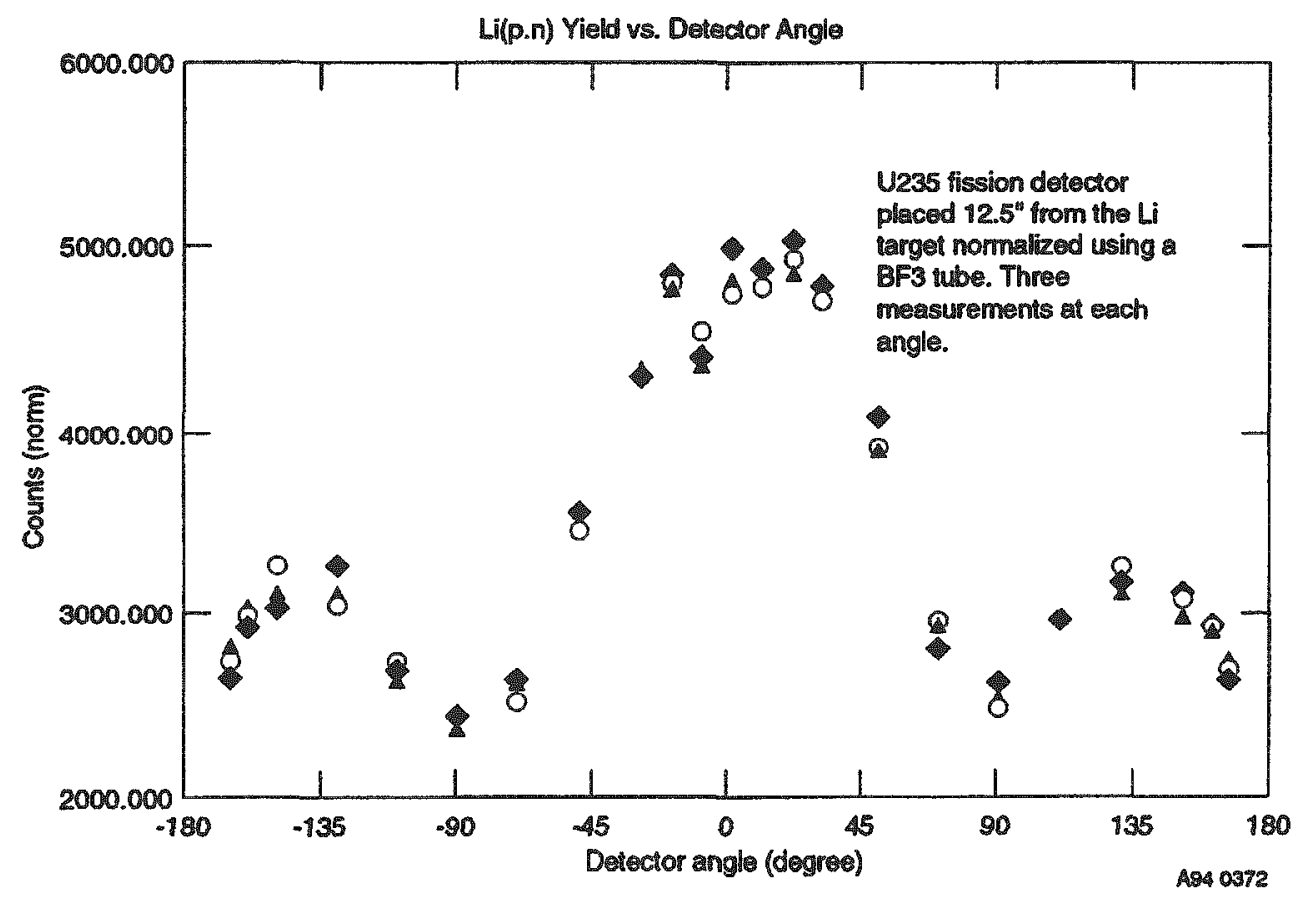

Figure 53. Neutron angular distribution from a thick lithium target.

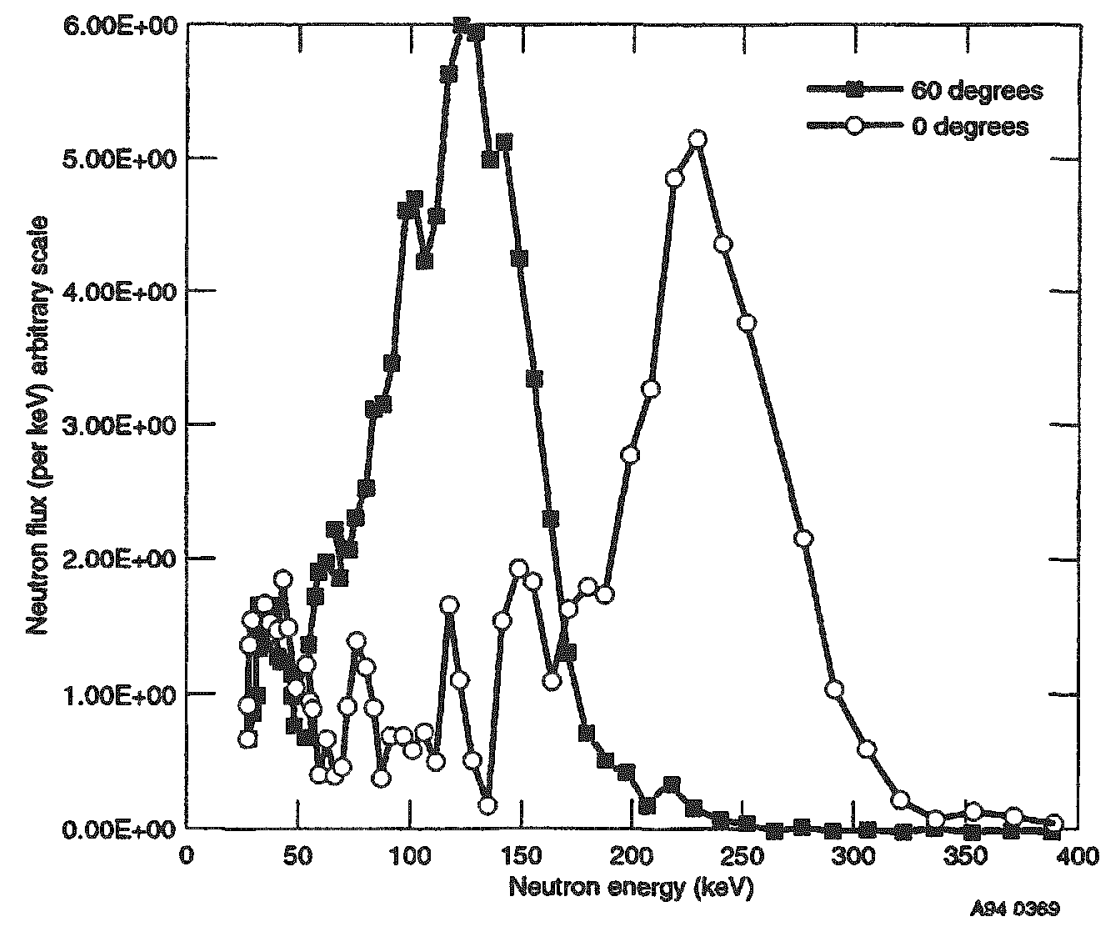

Figure 54. Neutron spectra from a thin lithium target for neutron angles of 0 and 60 degrees relative to the proton beam. 


\section{Neutron Spectrum Measurement and Confirming Dosimetry}

During the summer of 1992 , the BMRR core was rearranged by BMRR staff, and new fuel elements were added to increase the neutron flux at the epithermal filtered beam. It was therefore both necessary and desirable to repeat the free beam neutron spectrum and phantom measurements made in 1991. These measurements were taken at the beginning of Fiscal Year 1993 (November 1992).

Similar measurements had been made in 1991 at the HB-11 collimated beam port of the High Flux Reactor (HFR) reactor at Petten, Holland. Since those measurements were taken, the heat exchanger for the liquid argon neutron/gamma filter has been upgraded, thereby reducing liquid argon boiling in the filter. With this change in the filter it was necessary to take new measurements to determine the effects of improving the HFR liquid argon filter on the intensity and energy spectrum of the free neutron beam and the effective neutron dose delivered inside a phantom. The new measurements were taken in April 1993.

During this year, dosimetry was provided for 21 Labrador-cross dogs that were irradiated at BMRR for dose tolerance studies. Dosimetry was provided for two client dogs that were treated at the BMRR. Dosimetry was also provided for 12 beagles infused with BPA that were irradiated as part of a Brookhaven study.

\section{Neutron Field Characterization at BMRR and HFR}

Free-field measurements of neutron flux, after the core fuel rearrangement, were made at the filtered beam port of the $3 \mathrm{MW}$ BMRR using resonance activation foils. The foils were $\mathrm{In}, \mathrm{Au}$, $\mathrm{W}, \mathrm{Co}$, and $\mathrm{Cu}$. Fast neutron flux was measured using the threshold activation reaction, ${ }^{115} \operatorname{In}\left(n, n^{\prime}\right)^{115 m}$ In.

Epithermal and thermal neutron flux measurement in a Lucite phantom were made using
$98.5 \% \mathrm{Cu} / 1.5 \% \mathrm{Au}$ alloy wires. The phantom is a Lucite cylinder $12.7 \mathrm{~cm}$ in diameter by $17.8 \mathrm{~cm}$ in length.

These same foil materials and phantom were also measured during April 1993 at the HB-11 collimated beam of the 45 MW High Flux Reactor (HFR) in Petten, the Netherlands. The HB-11 irradiation location at HFR is much more collimated, and is much farther from the core than that of the BMRR filtered beam facility. At BMRR, the free beam measurements were made at $1 \mathrm{~cm}$ from the bismuth face of the beam port with no aperture-defining mask, while the phantom measurements were $5 \mathrm{~cm}$ from the bismuth with the phantom at the exit face of a $5 \mathrm{~cm}$ thick lithiated polyethylene mask having a $7.6 \mathrm{~cm}$ diameter aperture. The free beam measurements at the HFR were done at $2 \mathrm{~cm}$ from the borated polyethylene exit aperture, and the phantom measurements were were made with the front face phantom flush with the beam aperture at the borated polyethylene exit. For both the free field and phantom measurements at HFR, the beam-defining aperture was $8 \mathrm{~cm}$ in diameter.

All measurements at BMRR have been normalized to its maximum power of $3 \mathrm{MW}$. All measurements at HFR were done at its standard operating power level of $45 \mathrm{MW}$.

Table 26 shows a comparison of the 1991 and 1993 free beam total and epithermal flux results at the HFR and BMRR. The filter modifications at HFR reduced the total and epithermal flux to $88 \%$ of the 1991 values, and fast neutron flux to 91\%. At BMRR, the fuel movement, which pushed the effective center of the core toward the filteredbeam side of the reactor, resulted in a 30 to $50 \%$ increase in fluxes and a $20 \%$ increase in fast dose. Table 27 displays the net result of the changes as a comparison of fast dose per unit of epithermal neutron fluence. For the free field, the HFR liquid argon filter modifications resulted in an increased relative fast dose, whereas at BMRR the fuel rearrangement reduced the relative fast dose component. 
Table 26. HFR/BMRR comparison: free beam.

\begin{tabular}{|c|c|c|c|}
\hline & 1991 & 1993 & $93 / 91$ \\
\hline \multicolumn{4}{|c|}{ Total neutron flux $\left(\mathrm{n} / \mathrm{cm}^{2} \mathrm{sec}\right)$} \\
\hline HFR & $4.3 \times 10^{8}$ & $3.8 \times 10^{8}$ & 0.88 \\
\hline BMRR & $2.0 \times 10^{9}$ & $2.9 \times 10^{9}$ & 1.5 \\
\hline HFR/BMRR & 0.22 & 0.13 & \\
\hline \multicolumn{4}{|c|}{ Epithermal neutron flux $[0.5 \mathrm{eV}<\mathrm{E}<10 \mathrm{keV}]\left(\mathrm{n} / \mathrm{cm}^{2}-\mathrm{sec}\right)$} \\
\hline HFR & $3.8 \times 10^{8}$ & $3.3 \times 10^{8}$ & 0.87 \\
\hline BMRR & $1.9 \times 10^{9}$ & $2.8 \times 10^{9}$ & 1.5 \\
\hline HFR/BMRR & 0.20 & 0.12 & \\
\hline \multicolumn{4}{|c|}{ Fast neutron flux $[E>10 \mathrm{keV}]\left(\mathrm{n} / \mathrm{cm}^{2} \mathrm{sec}\right)$} \\
\hline HFR & $5.4 \times 10^{7}$ & $4.9 \times 10^{7}$ & 0.91 \\
\hline BMRR & $1.0 \times 10^{8}$ & $1.3 \times 10^{8}$ & 1.3 \\
\hline HFR/BMRR & 0.54 & 0.38 & \\
\hline \multicolumn{4}{|c|}{ Fast neutron dose rate $(\mathrm{cGy} / \mathrm{sec})$} \\
\hline HFR & 0.031 & 0.029 & 0.94 \\
\hline BMRR & 0.084 & 0.10 & 1.2 \\
\hline HFR/BMRR & 0.37 & 0.29 & \\
\hline
\end{tabular}

Table 27. HFR/BMRR comparison: free beam fast dose per unit epithemal fluence.

\begin{tabular}{clll}
\hline & \multicolumn{1}{c}{1991} & 1993 & $93 / 91$ \\
\hline Units: $\left(\mathrm{cGy}-\mathrm{cm}^{2}\right)$ & & & \\
HFR & $8.2 \times 10^{-11}$ & $8.8 \times 10^{-11}$ & 1.1 \\
BMRR & $4.5 \times 10^{-11}$ & $3.6 \times 10^{-11}$ & 0.80 \\
HFR/BMRR & 1.8 & 2.4 & \\
\hline
\end{tabular}


Table 28 displays the results of the Lucite cylindrical phantom measurements. showing the peak thermal flux, which occurs $2-3 \mathrm{~cm}$ inside the phantom. and the fast dose per thermal neutron fluence. The HFR peak thermal flux was reduced by $22 \%$, while at BMRR, it increased by $30 \%$. The fast dose per unit thermal neutron fluence was increased by $20 \%$ at HFR, but there was a $10 \%$ reduction at $B M R R$.

\section{Animal Dosimetry}

During Fiscal Year 1993, 21 Labrador-cross dogs were irradiated at BMRR as part of an ongoing dose tolerance study. Each irradiation was right hemispherical using a $5 \times 10 \mathrm{~cm}$ aperture in the $5 \mathrm{~cm}$ thick LiOH-polyethylene mask in the beam port. Seventeen dogs were infused with BSH at various levels, and four had no boron. Table 29 gives a summary of the desired doses, and the range of irradiation times and boron concentrations used.

The dosimeters each consisted of a $1.3 \times 2.5 \mathrm{~cm}$ black polyethylene envelope containing 3 TLD-400 rods $(6 \times 1 \times 1 \mathrm{~mm})$ for gamma dose, and a flat-rolled or folded length of $1.5 \% \mathrm{Au}-\mathrm{Cu}$ wire (1 $\mathrm{mm}$ diameter, weighing approximately $70 \mathrm{mg} / \mathrm{cm}$ ) used to measure thermal and epithermal neutron flux by neutron activation. The dosimeter locations are beam center at the top of the skull, over the left eye, over the right eye, at the rear of skull, on the spine at the shoulder, on the throat at the thyroid, on the chest at the heart, and on the testicles. An additional dosimeter packet is placed inside the throat at the trachea. For each irradiation, a neutron flux monitor of the same $\mathrm{Au} / \mathrm{Cu}$ wire is placed in front of the beam limiting aperture next to the bismuth face of the beam port and approximately $3 \mathrm{~cm}$ to the side of the aperture opening. To reduce neutron albedo effects from the lithiated polyethylene, the bean monitor packet has a $2.5 \mathrm{~cm}$ diameter $\times 0.05 \mathrm{~cm}$ thick cadmium backing placed between the dosimeter packet and the lithiated polyethylene. The whole assembly is sandwiched between the bismuth port face and the $\mathrm{LiOH}$-polethylene beam mask.

The four dogs that had no boron were irradiated with the right side of the scalp reflected prior to irradiation in order to determine the effects when the neutron moderation caused by the scalp and muscle are removed. For these dogs, neutron flux measurements were made within the right hemisphere reflected area. The neutron dosimeters were $1 \mathrm{~cm}$ lengths of $1.5 \% \mathrm{Au} / \mathrm{Cu}$ wires stacked alternately with $4 \mathrm{~mm}$ plastic separators into plastic shrink tubing (Kynar) and the ends sealed. The assembled tubes were packaged and sterilized prior to shipment to BNL. Two such tubes were used for each dog. They were placed on the exposed skull of the right hemisphere lengthwise parallel to the sagittal plane, at $1 \mathrm{~cm}$ above and $1 \mathrm{~cm}$ below the beam center. The tubes were kept in place by sutures at each end.

Eight of the boron-infused dogs were given two fractional irradiations at a $25 \mathrm{ppm}$ level of boron. Each dog was infused with $\mathrm{BSH}$, then irradiated to half the desired total dose. The process of infusion-irradiation was repeated 24 hours later. 
Table 28. HFR/BMRR comparison cylindrical Lucite phantom.

\begin{tabular}{cclc}
\hline & 1991 & \multicolumn{1}{c}{1993} & $93 / 91$ \\
\hline Peak thermal neutron flux $\left(\mathrm{n} / \mathrm{cm}^{2} \mathrm{sec}\right)$ & & & \\
\hline HFR & $7.2 \times 10^{8}$ & $5.6 \times 10^{8}$ & 0.78 \\
BMRR & $1.3 \times 10^{9}$ & $1.7 \times 10^{9}$ & 1.3 \\
HFR/BMRR & 0.55 & 0.33 & \\
Fast dose per thermal neutron fluence $\left(\mathrm{cGy}^{\left.-\mathrm{cm}^{2}\right)}\right.$ & & \\
HFR & $4.3 \times 10^{-11}$ & $5.2 \times 10^{-11}$ & 1.2 \\
BMRR & $2.0 \times 10^{-11}$ & $1.8 \times 10^{-11}$ & 0.90 \\
HFR/BMRR & 2.2 & 2.9 & \\
\hline
\end{tabular}

Table 29. Summary of dose tolerance Labrador dog irradiations Fiscal Year 1993.

\begin{tabular}{cllll}
\hline $\begin{array}{c}\text { Number } \\
\text { of dogs }\end{array}$ & $\begin{array}{c}\text { Total } \\
\text { dose cGy }\end{array}$ & $\begin{array}{c}\text { Irradiation } \\
\text { time hrs }\end{array}$ & $\begin{array}{c}\text { Desired B } \\
\text { conc. ppm }\end{array}$ & \\
\hline 5 & $3,200-3,400$ & $1.0-1.65$ & $50-70$ & \\
4 & $3,500-4,200$ & $1.0-1.2$ & $80-100$ & \\
4 & 2.700 & $0.8-0.9$ & 25 & 2 irrads. 1,350 cGy each \\
4 & 3.000 & $0.8-0.9$ & 25 & 2 irrads. 1,500 cGy each \\
4 & 1.325 & $2.2-2.6$ & 0 & Reflected scalp \\
\hline
\end{tabular}




\section{REFERENCES}

1. Leitha, T., A. Staudenherz, B. Gmeiner, M. Hermann, M. Hüttiner, and R. Dudczak, ${ }^{99 m}$ Tc Labeled LDL as a Tracer for Quantitative LDL Scintigraphy. II. Invivo Validation, LDL Receptor-Dependent and Upspecific Hepatic Uptake and Scintigraphic Results, Eur. J. Nucl. Med, 20, 674, (1993).

2. Huang, L. R., et al., Boronated Metalophorphins: A Novel Approach to Diagnosis and Treatment of Cancer Using Contrast Enhanced MRI and Neutron Capture Therapy, J. Magn. Resonan. Imaging, 3, 351, (1993).

3. Shelly, Kenneth, Debra A. Feakes, M. Frederick Hawthorne, et al.。 "Model Studies Directed Toward the Boron Neutron Capture Therapy of Cancer: Boron Delivery to Murine Tumors with Liposomes," Proc. Natl. Acad. Sci. U.S.A., 89, 9043, (1992).

4. Pilling, Richard L., M. Frederick Hawthome, and Eugene A. Pier, "The Boron-11 Nuclear Magnetic Resonance Spectrum of $\mathrm{B}_{20} \mathrm{H}_{18}{ }^{2-}$ at $60 \mathrm{Mc} . / \mathrm{sec} ., " J$. Am. Chem. Soc., 86, 3568, (1964).

5. Hawthome, M. Frederick, Richard L. Pilling, and Phillip M. Garrett, "A Study of the Reaction of Hydroxide Ion with $\mathrm{B}_{20} \mathrm{H}_{18^{2-, "}}$, J. Am. Chem. Soc., 87, 4740, (1965).

6. Nemoto, Hisao, J. Gerald Wilson, Hiroyuki Nakamura, et al., "Polyols of a Cascade Type as a Water-Solubilizing Element of Carborane Derivatives for Boron Neutron Capture Therapy," J. Org. Chem., 57, 435, (1992).

7. Macaulay, Suzanne R., "Isomerization of Internal Triple Bonds of Alkyn-1-ols with Sodium Hydride in 1,3-Diaminopropane." J. Org. Chem., 45, 734, (1980).

8. Thapar, K., K. Kovacs, E. R. Laws, el al., Pituitary Adenomas: Current Concepts in Classifications, Histopathology, and Molecular Biology, The Endocrinologist, 3(1): 39-57, (1993).

9. Vance, N. L., and N. O. Thomer, Prolactinomas, In: Pituitary Tumors: Diagnosis and Management, Endocrinology and Metabolism Clinics 13(3): 731-753, (1987).

10. Barth, R. F., A. H. Soloway, R. G. Fairchild, et al., Boron Neutron Capture Therapy for Cancer: Realities and Prospects, Cancer 70: 2995-3007, (1992).

11. Sweet. W. H., and M. Javid, The Possible Use of Neutron-Capturing Isotopes Such as ${ }^{10}$ Boron in the Treatment of Neoplasias. I. Intercranial Tumors, I Neurosurgery 9: 200-209, (1952).

12. Soloway, A. H., H. Hatanaka, and N. A. Davis, Penetration of Brain and Brain Tumor. VII. Tumor Binding Sulfhydryl Boron Compounds, J Med Chem 10: 714 717, (1967).

13. Clendenon, N. R., R. F. Barth, W. D. Gordon, et al., Boron Neutron Capture Therapy of a Rat Glioma, Neurosurgery 26: 47-55, (1990).

14. Hatanaka, H., and K. A. Sano, A Revised Boron Neutron Capture Therapy for Malignant Brain Tumors. 1. Experience on Terminally III Patients after Cobalt-60 Radiotherapy, Z Neurol 204: 309-332, (1973).

15. Lundstrum, M., Medical Miracles, Woman's World 11, 41, 36-37, (1990). 
16. Hawthome, M. F., Personnel Communication from Zakharkin L. I., Chapovskii Y. A., Brattsev V. A., and Stanko V. I., Zh Obshch Khim 36: 878, (1966).

17. Morels, J. L., and Brown. J. H., Solid Phase Synthesis of Ovine Corticotropin Releasing Factor, J. Pepride and Protein Res 26: 49-54. (1985).

18. Furth, J., E. L. Gadsen, and A. C. Upton, ACTH Secreting Transplantable Pituitary Tumors, Proc Soc Exptl Biol Med 84: 355-361, (1953).

19. Tashjian, A. H., Y. Yasumura, L. Levine, et al., Establishment of Clonal Strains of Rat Pituitary Tumor Cells that Secrete Growth Hormone, Endocrinology 82: 342-352, (1968).

20. Tashjian, A. H., F. C. Bancroft, and L. Levine, Production of Both Prolactin and Growth Hormone by Clonal Strains of Rat Pituitary Tumor Cells, J Cell Biol 47: 61-70, (1970).

21. Grosch, D. S., and L. E. Hopwell, Biological Effects of Radiation, 2nd Edition, Academic Press, NY, 94-97, (1979).

22. Aguilera, G., M. A. Millan, R. L. Hauger, et al., Corticotropin Releasing Factor Receptors: Distribution and Regulation in Brain, Pituitary, and Peripheral Tissues, In: The Hypothalamic-Pituitary-Adrenal Axis Revisited, a Symposium in Honor of Dorothy Krieger and Edward Herbert, Anals NY Acad Sci, 512, 48, (1987).

23. Gabriel, S. M., C. M. Milbury, S. M. Alexander, et al., Iso-Stimulation of Growth Hormone and Cyclic AMP: Comparison of $\beta$-Adrenergic to Growth Hormone Releasing Factor-Stimulated Growth Hormone Release and Cyclic AMP Accumulation in Monolayer Cultures of Anterior Pituitary Cells In Vitro, Neuroendocrinol 50: 170-176, (1989).

24. Albertson, B. D. M. A. Millan. S. E. Binney, et al., Use of Boron Neutron Capture Therapy, Proceedings of the 5th International Symposium on Neutron Capture, Columbus, OH, 1992 (Soloway A. H., Barth R. F., and Carpenter D. E., eds.). Plenum Publishing Corp., New York. NY, 623-628, (1993).

25. Gregoire, D. C., Determination of Boron in Fresh and Saline Waters by Inductively Coupled Plasma Mass Spectroscopy, J Anal Atom Spectr 5: 623-626, (1990).

26. Smith, F. G., D. R. Wiederin, R. S. Houk, et al., Measurement of Boron Concentration and Isotope Ratios in Biological Samples by Inductively Coupled Plasma Mass Spectrometry with Direct Injection Nebulization, Anal Chimica Acta 248:229-234, (1991).

27. Durrant, S. F., Inductively Coupled Plasma-Mass Spectrometry for Biological Analysis, Trends in Analvical Chemistry 11(2): 68-73, (1993).

28. Orth, D. N., Corticotrophin-Releasing Hormone in Humans, Endocrine Reviews 13(2): 164-191, (1992).

29. Ahmad, I., and T. M. Allen, Antibody-Mediated Specific Binding and Cytotoxicity of Liposome-Entrapped Doxorubicin to Lung Cancer Cells, In Vitro, Cancer Research 52: 4817-4820, (1992).

30. Ahmad, I., M. Longenecker. J. Samuel, et al., Antibody-Targeted Delivery of Doxorubicin Entrapped in Sterically Stabilized Liposomes can Eradicate Lung Cancer in Mice, Cancer Research 53: 1484-1488, (1993). 
31. Allen, T. M., C. Hansen, F. Martin, et al., Liposomes Containing Synthetic Lipid Derivatives of Poly(ethylene glycol) Show Prolonged Circulation Half-Lives, In Vivo, Biochimica et Biophysica Acta 1066: 29-36, (1991).

32. Forssen, E. A., D. M. Coulter, and R. T. Proffitt, Selective In Vivo Localization of Daunorubicin Small Unilamellar Vesicles in Solid Tumors, Cancer Research 52: 3255-3261, (1992).

33. Gabizon, A., and D. Papahadjopoulos, Liposome Formulations with Prolonged Circulation Time in Blood and Enhanced Uptake by Tumors, Proc. Natl. Acad. Sci. USA 85: 6949-6953, (1988).

34. Gregoriadis, G. (ed.), Liposomes as Drug Carriers: Recent Trends and Progress, John Wiley \& Sons, New York, (1988).

35. Huang, S. K., K-D Lee, K. Hong, et al., Microscopic Localization of Sterically Stabilized Liposomes in Colon Carcinoma-Bearing Mice. Cancer Research 52: 5135-5143, (1992).

36. Huang, S. K. E. Mayhew, S. Gilani, et al., Phamacokinetics and Therapeutics of Sterically Stabilized Liposomes in Mice Bearing C-26 Colon Carcinoma, Cancer Research 52: 6774-6781, (1992).

37. Lestavel-Delattre, S. F. Martin-Nizard, V. Clavey, et al., Low-Density Lipoprotein for Delivery of an Acrylophenone Antineoplastic Molecule into Malignant Cells, Cancer Research 52: 3629-3635, (1992).

38. Laster, B. H., S. B. Kahl, E. A. Popenoe, et al., Biological Efficacy of Boronated Low-Density Lipoprotein for Boron Neutron Capture Therapy as Measured in Cell Culture, Cancer Research 51: 4588-4593, (1991).

39. Liu. D. A. Mori, and L. Huang, Role of Liposome Size and RES Blockade in Controlling Biodistribution and Tumor Uptake of $\mathrm{GM}_{1}$-Containing Liposomes, Biochimica et, Vol. P, (1992).

40. Potter, D. A., C. M. Gorschboth, and P. D. Schneider, Liposome Uptake by Melanoma: In Vitro Comparison with Hepatocytes, Joumal of Surgical Research 39: 157-163, (1985).

41. Vitols, S., C. Peterson, O. Larsson, et al., Elevated Uptake of Low-Density Lipoproteins by Human Lung Cancer Tissue, In Vivo, Cancer Research 52: 6244-6247, (1992).

42. Elstad, C. A., B. A. Mathison, L. M. Recknagle, et al., Enhanced In Vivo Uptake of Boronophenylalanine into B16-BL6 Melanoma Mediated by Phenylalanine Ammonia-Lyase, Proc. Amer. Assoc. Cancer Res. 34: 91, (1993).

43. Fontenelle, L., G. Gamer, B. Graham, R. Goettsch, and B. Soltani, In Vivo and In Vitro Studies of the Effects of Mercaptoundecahydrododecaborate (BSH) on Hepatic Cytochrome P-450 MonoOxygenase Enzyme Activity and on Hexobarbital (HXB)-Induced Sleep in Mice, Strahlentherapie Und Onkologie 165: 172-173, (1989).

44. Hayashi, Y., H. Furukawa, Y. Kawano, M. Matsuura, A. Harihara, S. Araki, Y. Muraoka, Y. Maeda, T. Yamashita, and M. Muto, "Toxicity of Sodium Monomercaptoundecahydro-closo-dodecaborate by Single I.V. Injection," Technical Report, Shionozi Research Laboratories, Fukushima-ku, Osaka, Japan.

45. Morris, G. M., G. Constantine, G. Ross, T. K. Yeung, and J. W. Hopewell, Boron Neutron Capture Therapy: Long-Term Effects on the Skin and Spinal Cord of the Rat, Radiation Research 135: 380-386, (1993). 
46. Buchar, E., S. Bednarova, B. Gruner. P. Walder, O. Strouf, and I. Janku, Dose-Dependent Disposition Kinetics and Tissue Accumulation of Boron after Intravenous Injections of Sodium Mercaptoundecahydrododecaborate in Rabbits, Cancer Chemotherapy \& Pharmacology 29: 450-454. (1992).

47. Finkel, G. C., C. E. Poletti, R. G. Fairchild, D. N. Slatkin, and W. H. Sweet, Distribution of 10 B after Infusion of Na210B12H11SH into a Patient with Malignant Astrocytoma: Implications for Boron Neutron Capture Therapy, Neurosurgery 24: 6-11, (1989).

48. Hatanaka, H. (ed.), Boron-Neutron Capture Therapy for Tumors, Nishimura Co.. Ltd., pp. 97 and 349-379, (1986).

49. Joel, D. D., D. N. Slatkin, P. L. Micca, M. M. Nawrocky, T. Dubois, and C. Velez, Uptake of Boron into Human Gliomas of Athymic Mice and into Syngeneic Cerebral Gliomas of Rats after Intracarotid Infusion of Sulfhydryl Boranes, Basic Life Sciences 50: 325-332, (1989).

50. Barker, M., D. F. Deen, and D. G. Baker, BCNU and X-Ray Therapy of Intracerebral 9L Rat Tumors, Int.J.Radiat.Oncol.Biol.Phys. 5:1581-1583, (1979).

51. Henderson, S. D., B. F. Kimler, R. A. Morantz, Radiation Therapy of 9L Rat Brain Tumors, Int.J.Radiat.Oncol.Biol.Phys. 7:497-502. (1981).

52. Coderre, J. A., D. D. Joel, P. L. Micca, et al. Control of Intracerebral Gliosarcomas in Rats by Boron Neutron Capture Therapy with p-boronophenylalanine. Radiat.Res. 129:290-296, (1992).

53. Joel, D. D., R. G. Fairchild, J. A. Laissue, et al., Boron Neutron Capture Therapy of Intracerebral Rat Gliosarcomas, Proc.Natl.Acad.Sci., USA 87:9808-9812, (1990).

54. Coderre, J. A., M. S. Makar, P. L. Micca, et al., Derivations of RBEs for the High-LET Radiations Produced During Boron Neutron Capture Irradiations of the Rat $9 \mathrm{~L}$ Gliosarcoma In Vitro and In Vivo, Int.J.Radiat.Oncol. Biol.Phys. 28:7, (1994).

55. Rydin, R. A., O. L. Deutsch, and B. W. Murray, The Effect of Geometry on Capillary Wall Dose for Boron Neutron Capture Therapy. Phys.Med.Biol. 21:134-138, (1976).

56. Slatkin, D. N., R. D. Stoner, K. M. Rosander, et al., Central Nervous System Radiation Syndrome in Mice from Preferential ${ }^{10} \mathrm{~B}(\mathrm{n}, \alpha)^{7} \mathrm{Li}$ Irradiation of Brain Vasculature, Proc.Natl. Acad.Sci., USA $85: 4020-4024,(1988)$.

57. Calvo, W., J. W. Hopewell, H. S. Reinhold, et al., Time- and Dose-Related Changes in the White Matter of the Rat Brain After Single Doses of X-Rays. Brit.J.Radiol. 61: 1043-1052, (1988).

58. Morris, G. M., J. A. Coderre, E. M. Whitehouse, et al., Boron Neutron Capture Therapy: A Guide to the Understanding of the Pathogenesis of Late Radiation Damage to the Rat Spinal Cord, Int.J.Radiat.Oncol. Biol.Phys. 28:5, (1994).

59. Salcman, M., E. W. Scott, R. S. Schepp, et al., Transplantable Canine Glioma Model for Use in Experimental Neuro-Oncology, Neurosurgery 11: 372-381, (1982).

60. Bradshaw, K. M., J. R. Hadley, R. H. Tippets, et al., Boron-11 MRI of Borocaptate Sodium Pharmacokinetics in Canine Head, Manuscript to be Submitted to Journal of Magnetic Resonance Imaging. 
61. Larsson, H. B., W. M. Stubgaard, J. L. Frederiksen, et al., Quantitation of Blood-Brain Barrier Defect by Magnetic Resonance Imaging and Gadolinium-DTPA in Patients with Multiple Sclerosis and Brain Tumors, Magnetic Resonance in Medicine 16: 117-131. (1990).

62. Glover, G. H., J. M. Pauly, and K. M. Bradshaw, Boron-11 Imaging with a Three-Dimensional Reconstruction Method, Journal of Magnetic Resonance Imaging 2: 47-52, (1992).

63. Tang, P., M. P. Schweizer, K. M. Bradshaw, et al., Boron-11 Longitudinal Relaxation Rate Studies to Determine the Binding of BNCT Agents to Serum Albumins, Manuscript to be Submitted to Biochemical Pharmacology.

64. Wheeler, F. J., et al., "Epithermal Neutron Beam Design for Neutron Capture Therapy at the PBF and BMRR Reactor Facilities," Nuclear Technology, 92:106-117, (1990).

65. Harling, O. K.. et al., "Boron Neutron Capture Therapy and Radiation Synovectomy Research at the Massachussetts Institute of Technology Research Reactor," Nuclear Science and Engineering. $110: 330,(1992)$.

66. Nigg, D. W., and F. J. Wheeler, "Conceptual Physics Design for an Epithermal-Neutron Beam at the Georgia Institute of Technology Research Reactor," Transactions of the ANS, 65:146, (1992).

67. Moss, R. L., "Progress Toward Boron Neutron Capture Therapy at the High-Flux Reactor Petten," Neutron Beam Design, Development, and Performance for Neutron Capture Therapy, O. K. Harling, et al., Editors, Plenum Press, New York, 1990.

68. Auterinen, I., and P. Hiismaki, "Epithermal BNCT Neutron Beam Design for a TRIGA II Reactor," Advances in Neutron Capture Therapy: R. Barth and A. Soloway, Editors, Plenum Press, New York. 81-84, (1993).

69. Wang. C. K., et al., "A Neutronic Study of an Accelerator-Based Neutron Irradiation Facility for Boron Neutron Capture Therapy." Nuclear Technology, 84:93, (1989).

70. Yanch, J. C., et al., "Accelerator-Based Epithermal Neutron Beams for Neutron Capture Therapy," Advances in Neutron Capture Therapy; R. Barth and A. Soloway, Editors, Plenum Press, New York, 95-98. (1993).

71. Jones, J. L., and W. Y. Yoon, "Feasibility Study of the Application of a Linear Electron Accelerator to BNCT," Proceedings of the 12th International Conference on the Application of Accelerators in Research and Industry, University of North Texas, Denton TX, November 1992.

72. Hablieb, J. A., and T. A. Mehlhorn. "ITS_-The Integrated TIGER Series of Coupled Electron/Photon Monte Carlo Transport Codes," SAND84-05873, Sandia National Laboratory, November 1984.

73. Rhoades, W. A., and R. L. Childs, "An Updated Version of the DOT-4 One- and Two-Dimensional Neutron/Photon Transport Code, ORNL-5851, Oak Ridge National Laboratory, (1982).

74. Roussin, R. W., "BUGLE-80 Coupled 47-Neutron, 20 Gamma-Ray $P_{3}$ Cross Section for LWR Shielding Calculations," DLC-75, Radiation Shielding Information Center, Oak Ridge National Laboratory, (1980).

75. Jones, J. L., et al., "Material Identification Technology (MIT)-Concept Feasibility Study," WINCO-1147, Idaho National Engineering Laboratory, (1993). 
76. Briesmeister, J. F., editor, "MCNP-A General Monte Carlo Code for Neutron and Photon Transport, LA-7396 (Rev. 2), Los Alamos National Laboratory, September 1986.

77. Yoshizaki, T., I. Ikechi, and K. Nagasawa, "Quality Control of $\mathrm{Na}_{2}{ }^{10} \mathrm{~B}_{12} \mathrm{H}_{11} \mathrm{SH}$ for Neutron Capture Therapy," in Neutron Capture Therapy, ed. H. Hatanaka (Nishimura Co., Ltd., Niigata, Japan also MTP Press, Morwell, MA), 394-400, (1986).

78. Slatkin, D., P. Micca, A. Forman, et al., "Boron Uptake in Melanoma, Cerebrum, and Blood from $\mathrm{Na}_{2} \mathrm{~B}_{12} \mathrm{H}_{11} \mathrm{SH}$ and $\mathrm{Na}_{4} \mathrm{~B}_{24} \mathrm{H}_{22} \mathrm{~S}_{2}$ Administered to Mice," Biochemical Pharmacology 35, 1771-1776, (1986).

79. Soloway, A. H., F. Alam, and R. F. Barth, Future Boronated Molecules for Neutron Capture Therapy, Workshop on Neutron Capture Therapy, eds. R. G. Fairchild and B. P. Bond, (Brookhaven National Laboratory, Upton), BNL-51994, 162-172, (1986).

80. Shremmer, J. M., D. J. Noonan, J. L. Russell, Jr., et al., "Advances in Analytical Techniques for Neutron Capture Therapy." in Neutron Caprure Therapy, ed. H. Hatanaka (Nishimura Co., Ltd., Niigata, Japan also MTP Press, Morwell, MA), 388-393, (1986).

81. Tolpin, E. I., G. R. Wellum, and S. A. Berley, "Synthesis and Chemistry of MercaptoundecahydroCloso-Dodecaborate(2-)," Inorg. Chem. 17, 2867-2873, (1978).

82. Grüner, B., Z. Plzák, and I. Vin, "Chromatographic Behaviour of the Closo- $\left[\mathrm{B}_{12} \mathrm{H}_{12}\right]^{2-}$ Derivatives on Hydroxyethylmethacrylate Gels," J. Chrom. 588, 201-210, (1991).

83. Slatkin, D., D. Joel, R. Fairchild, et al., "Distributions of Sulfhydryl Borane Monomer and Dimer in Rodents and Monomer in Humans: Boron Neutron Capture Therapy of Melanoma and Glioma in Boronated Rodents," Clinical Aspects of Neutron Capture Therapy, R. Fairchild, V. Bond, and A. Woodhead, eds. (Plenum Press, NY), 180-192. (1989).

84. Marshall, P., M. Miller, S. Grand, et al., "Toxicities of $\mathrm{Na}_{2} \mathrm{~B}_{12} \mathrm{H}_{11} \mathrm{SH}$ and $\mathrm{Na}_{4} \mathrm{~B}_{24} \mathrm{H}_{22} \mathrm{~S}_{2}$ in Mice," Clinical Aspects of Neutron Capture Therapy, R. Fairchild, V. Bond, and A. Woodhead, eds. (Plenum Press, NY), 325-332, (1989).

85. Hotz, N. J., and W. F. Bauer, "Determination of Strongly Protein-Bound Borocaptate Species by HighPerformance Liquid Chromatography with Online Inductively Coupled Plasma Atomic Emission Spectroscopy Detection of Boron," Advances in Neutron Capture Therapy, A. Soloway, R. Barth, and D. Carpenter, eds. (Plenum Press, NY), 439-444, (1993). 

EG\&G Idaho

P.O. Box 1625

Idaho Falls, Idaho

83415 